\author{
Universidade de São Paulo \\ Instituto de Física
}

\title{
Estudo dos mecanismos responsáveis pela passivação de metais: Cobre
}

\author{
Márcia Regina Pereira Attie \\ Orientador: Prof. Dr. Manfredo Harri Tabacniks
}

Tese de doutorado apresentada ao Instituto de Física da Universidade de São Paulo para a obtenção do título de Doutor em Ciências

Comissão Examinadora:

Prof. Manfredo Harri Tabacniks (IFUSP)

Profa. Helena Maria Petrilli (IFUSP)

Prof. José Fernando Diniz Chubaci (IFUSP)

Prof. Marcelo Nelson Paez Carreño (EPUSP)

Profa. Elidiane Cipriano Rangel (UNESP/Sorocaba)

São Paulo 
Aos meus grandes amores, Sosinho, Biel e Bia, pelos momentos ausentes, paciência, compreensão e amor.

À minha mãe, pelo amor, presença e segurança transmitida durante todos esses anos.

Eu dedico este trabalho. 


\section{Agradecimentos}

Ao Prof. Manfredo Tabacniks, pela orientação, dedicação, paciência e conhecimento transmitido. Mesmo nos difíceis momentos deste trabalho sempre esteve presente.

Ao Manfredo, pelo carinho e amizade.

Aos grandes amigos Jorge e Wanda, pela ajuda, carinho e dedicação.

À Lu pela dedicação e cuidados dispensados aos meus filhos.

Aos colegas de Laboratório, Carol, Marcel, Marquinhos e Vinícius, pelo profissionalismo e, principalmente, por tornarem os momentos de trabalho mais agradáveis.

À Profa. Márcia Fantini, pela gentileza em disponibilizar o seu laboratório para análises XRD e pela valiosa ajuda na interpretação dos espectros; ao Antônio Carlos por trabalhar até tarde tão bem humorado.

Ao Prof. Paulo de Tarso Cavalcante, do Departamento de Física da UFC, pelas análises e discussão dos resultados de Espectroscopia Raman.

Aos sempre grandes amigos Cris, Kukinha, Nilza, André e Lucien, pela enorme amizade, carinho, hospedagem, receptividade e disposição para ouvir.

Aos professores e funcionários da Poli, pela grande acolhida. À Lia, pelo carinho e atenção.

À Universidade Estadual de Santa Cruz, pela liberação e incentivo para a realização deste trabalho.

Enfim, a todos aqueles que contribuíram de alguma maneira para a realização deste trabalho. 
Faça o que for necessário para ser feliz. Mas não se esqueça de que a felicidade é um sentimento simples. Você pode encontrá-la e deixá-la ir embora por não perceber a sua simplicidade. (Mário Quintana) 


\section{Resumo}

É estudada a cinética de oxidação filmes finos de cobre e os mecanismos envolvidos em sua passivação através de: implantação iônica, formação de ligas e utilização de uma camada protetora. Filmes finos, obtidos por bombardeamento eletrônico, foram implantados com $\mathrm{Pd}^{+}, B^{+}$e $A r^{+}$. As doses variaram de $10^{13}$ a $10^{17}$ íns $/ \mathrm{cm}^{2}$ e as energias de 10 a $100 \mathrm{keV}$. O estudo da passivação através de formação de ligas foi realizado a partir da estrutura $\mathrm{Cu} / \mathrm{Al} / \mathrm{Si}$ e a passivação por camada protetora foi estudada com a estrutura $\mathrm{C} / \mathrm{Cu} / \mathrm{C}$. Os ensaios de oxidação foram feitos em atmosfera ambiente, com temperaturas variando entre $100^{\circ} \mathrm{C}$ e $350^{\circ} \mathrm{C}$. Os filmes de cobre puro e os submetidos aos tratamentos para o estudo da passivação foram caracterizados através de perfilometria para medida de espessura, RBS, PIXE, para composição elementar e difração de Raios-X e espectroscopia Raman para composição química. A resistividade foi medida pelo método de quatro pontas. Os resultados obtidos permitem afirmar que na oxidação de filmes finos de cobre puro, há uma dependência da energia de ativação com a concentração de defeitos do filme, tornando-se necessário um rigoroso controle da espessura do filme para a correta determinação da cinética de oxidação, que também é dependente do intervalo de temperatura de oxidação. Esses fatores podem justificar a grande discrepância entre os dados encontrados na Literatura. Para oxidação em $180^{\circ} \mathrm{C}$, foi comprovada a existência do óxido $\mathrm{Cu}_{3} \mathrm{O}_{2}$ e, além disso, observou-se que após 90 minutos de oxidação, há uma total conversão desse óxido para $\mathrm{CuO}$. Poucos trabalhos relatam o aparecimento desse óxido, considerado um defeito metaestável do $\mathrm{Cu}_{2} \mathrm{O}$. No estudo da passivação dos filmes, resultados sugerem semelhanças entre a implantação iônica em baixas energias e a utilização de ligas. Em implantação de $B^{+}$, o mecanismo responsável pela passivação é o mesmo que a adição de impurezas: a redução da mobilidade, através do preenchimento das vacâncias. Na passivação através da formação de ligas, houve variação da eficiência da proteção superficial, que se mostrou dependente da temperatura e do tempo utilizado no tratamento térmico, mostrando que essa proteção está relacionada à distribuição do Al no filme de cobre, de maneira semelhante à variação da dose e da energia na implantação iônica. Na passivação por camada protetora conclui-se que uma proteção inicial é conseguida, mas para tempos mais longos de oxidação, o filme de carbono permite a difusão do cobre até a superfície, e, consequentemente sua oxidação. 


\begin{abstract}
Oxidation kinetics and its mechanisms has been studied for thin Copper films deposited by PVD on glossy carbon (UDAC) and Si wafers. Copper oxidation rate after Ion implantation with $\mathrm{Pd}^{+}, \mathrm{B}^{+}$and $A r^{+}$, alloying with $\mathrm{Al}$ and protective layers of Carbon have been tested. Oxidation was done in air, with temperatures ranging from $100^{\circ} \mathrm{C}$ and $350^{\circ} \mathrm{C}$. Thickness of the Copper films were measured by profilometry, Particle Induced X-ray emission, PIXE and Rutherford Backscattering Spectrometry, RBS were used to measure the elementary film composition and to detect possible contaminants, X-ray difraction and Raman spectroscopy were used for chemical characterization and resistivity was measured as usual by four contact probes. Results showed that in the oxidation of pure Copper films, the activation energy depends on the concentration of defects in the film, demanding a rigorous control on film thickness, for the precise determination of the oxidation kinetics which is also dependent on the temperature interval used in the experiment. This may explain the large disagreement of data in literature. Oxidation at $180^{\circ} \mathrm{C}$ showed the initial formation of $\mathrm{Cu}_{3} \mathrm{O}_{2}$ which was totally converted to $\mathrm{CuO}$ after 90 minutes of oxidation. Direct observation of $\mathrm{Cu}_{3} \mathrm{O}_{2}$ is rare. This oxide use to be considered a metastable defect $\mathrm{Cu}_{2} \mathrm{O}$. There are many similarities between ion implantation at low energies and alloying. The mechanism for the passivation by $B^{+}$implants in Copper is similar to the addition of impurities, e.g. the reduction of the mobility of the Copper ions due to the filling of vacancies. In the passivation through alloying with aluminum, the protection of the Copper surface depends on the annealing time, showing that this protection may be related to the distribution of $\mathrm{Al}$ in the film, like the dependence on dose and range for ion implantation. The addition of a protective layer, only delays the oxidation process. The thin carbon film just reduced the oxidation rate but still allowed the difusion of the Copper to the surface, and consequently its oxidation.
\end{abstract}




\section{Sumário}

1 Introdução $\quad 9$

2 Estado da arte $\quad 12$

2.1 Oxidação de metais . . . . . . . . . . . . . . . . . . . . . . 12

2.2 Passivação de superfícies metálicas . . . . . . . . . . . . . . 17

2.2.1 Passivação do cobre através da formação de ligas . . . . . . . . . . 17

2.2.2 Passivação por camada protetora . . . . . . . . . . . . . . 20

2.2.3 Passivação através da implantação iônica . . . . . . . . . . . . . . . 21

3 Fenômenos físico-químicos $\quad 26$

3.1 Oxidação de metais . . . . . . . . . . . . . . . . . . 26

3.1 .1 Cinética de oxidação . . . . . . . . . . . . . . . . . . 30

3.2 Implantação Iônica . . . . . . . . . . . . . . . . . . . . . . . . 32

3.2 .1 Perda de energia $\ldots \ldots \ldots \ldots . \ldots \ldots \ldots$

4 Materiais e Métodos $\quad 37$

4.1 Preparação das amostras . . . . . . . . . . . . . . . . . . . . . 37

4.1 Limpeza dos substratos . . . . . . . . . . . . . . . 38

4.1.2 Bombardeamento eletrônico . . . . . . . . . . . . . . . . . . 40

4.1 .3 Implantação Iônica . . . . . . . . . . . . . . . . . . . . . . . . . . . 42

4.1.4 Sistema de oxidação das amostras . . . . . . . . . . . . . . . 43

4.2 Técnicas de caracterização das amostras . . . . . . . . . . . . . . 43

4.2.1 Análise por Retro-espalhamento Rutherford . . . . . . . . . . . . . 44

4.2 .2 O Método PIXE . . . . . . . . . . . . . . . . . . . . . 48

4.2 .3 Perfilometria . . . . . . . . . . . . . . . . 50

4.2.4 O Método de quatro pontas . . . . . . . . . . . . . 51 
4.2.5 Difração de raios-X . . . . . . . . . . . . . . . . . 52

4.2.6 Espectroscopia Raman . . . . . . . . . . . . . . . . . 55

4.2.7 Microscopia de força atômica . . . . . . . . . . . . . . . . . 55

$\begin{array}{lll}5 & \text { Resultados e discussão } & 58\end{array}$

5.1 Caracterização dos filmes de cobre puro . . . . . . . . . . . . . . 58

5.1 .1 Análise de contaminantes . . . . . . . . . . . . 58

5.1 .2 Aderência dos filmes . . . . . . . . . . . . . . . . . 59

5.1 .3 Determinação da densidade . . . . . . . . . . . . . . . 60

5.1.4 Medidas da resistividade elétrica . . . . . . . . . . . . . 61

5.1.5 Textura de filmes de cobre puro . . . . . . . . . . . . . . . 62

5.1.6 Cinética de oxidação de filmes de cobre puro . . . . . . . . . . . . 63

5.2 Passivação superficial de filmes de $\mathrm{Cu} / \mathrm{Al} / \mathrm{Si} \ldots \ldots$. . . . . . . . . . 90

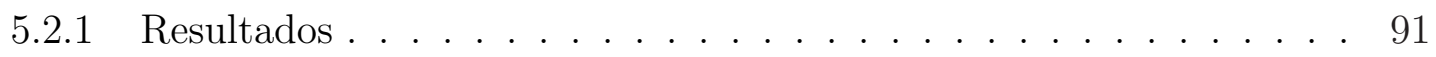

5.2 .2 Passivação superficial . . . . . . . . . . . . . . . . . . . . . . . . 92

5.3 Passivação de filmes de cobre através de cobertura de carbono . . . . . . . 97

5.4 Estudo da passivação de filmes de cobre dopados com cloro . . . . . . . . . 100

5.5 Passivação de filmes de cobre através de implantação iônica . . . . . . . . 103

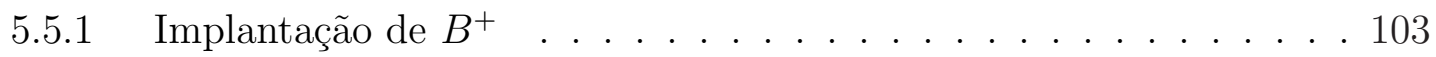

5.5.2 Implantação de $P d^{+} \ldots$. . . . . . . . . . . . . . . . . 108

5.5.3 Implantação de $A r^{+} \ldots$. . . . . . . . . . . . . . . . . 110 


\section{Capítulo 1}

\section{Introdução}

Tem-se realizado um considerável esforço, em nível mundial, visando ao desenvolvimento de um processo que concretize a desejável substituição do alumínio pelo cobre no processamento de dispositivos em microeletrônica. Potencialmente, vislumbra-se o cobre como o material ideal para interconexões em circuitos integrados [1],[2].

As grandes vantagens na utilização desse material são a maior resistência à eletromigração ( $\mathrm{Cu}$ policristalino comparado ao $\mathrm{Al}$ policristalino) [3] e a baixa resistividade elétrica $(1.68 \mu \Omega . c m$ comparada a $2.70 \mu \Omega . c m$ para o $\mathrm{Al})$. Este último fator é responsável pelo tempo de atraso dos dispositivos eletrônicos [4].

Apesar da utilização do alumínio em grande escala pela indústria, sua resistência à eletromigração é menor do que se deseja. Além disso, a redução das dimensões dos circuitos integrados faz com que os metais conduzam altas densidades de correntes, o que torna o problema causado pela eletromigração ainda mais significativo [5]. A eletromigração tem sido considerada um dos principais fatores limitantes no desempenho dos dispositivos eletrônicos [6], pois o aquecimento do material produz a degradação das características elétricas dos dispositivos.

Apesar das vantagens em relação ao alumínio, a utilização de cobre não é um processo livre de problemas. É bem conhecido que esse metal oxida-se rapidamente, possui baixa aderência ao óxido de silício, é um rápido difusor em sílicio e em óxido de silício [7] e cria centros de recombinação no silício, reduzindo o tempo de vida dos portadores minoritários e afetando o desempenho dos dispositivos [8]. Quanto à difusão, trabalhos apontam para a utilização de filmes de TiSiN [9] ou Ta/TaN [10] para contornar o problema. A utilização 
de ligas de cobre-manganês também resolve o problema da difusão e, além disso, apresenta melhoras no desempenho em relação ao problema da aderência [11], [12] e [13].

Ainda assim, para o cobre tornar-se o material mais apropriado para o processamento de dispositivos, é necessário também reduzir a sua taxa de oxidação. Diferentemente do alumínio, o cobre apresenta uma grande degradação ambiental. Ele oxida-se rapidamente em baixas temperaturas e nenhuma camada de óxido protetora é formada para evitar posterior oxidação [14].

Não existe convergência entre as várias teorias usadas para explicar o fenômeno da oxidação do cobre em função do tempo, da temperatura e da pressão parcial de oxigênio, mas os resultados de um grande número de estudos indicam que o comportamento da cinética de oxidação do cobre varia do logarítimico ao parabólico; passando pelo linear e cúbico, dependendo das condições de oxidação.

Outro fato interessante na oxidação de cobre é a forma de crescimento do óxido. Inicialmente, há a formação de núcleos de óxido na superfície do filme e posteriormente, a coalescência destes. Dessa maneira, a oxidação acontece através do crescimento de núcleos de óxido como ilhas na superfície e não como uma camada uniforme.

Os fenômenos envolvidos na oxidação do cobre são muito complexos. Alguns trabalhos têm mostrado a existência de um terceiro tipo de óxido, $\mathrm{Cu}_{3} \mathrm{O}_{2}$, em determinadas condições de oxidação, dependendo do histórico da amostra. Esse óxido tem sido modelado como um defeito estrutural do $\mathrm{Cu}_{2} \mathrm{O}$ [15] e [16].

O estudo do processo de oxidação do cobre é de grande importância para o entendimento dos mecanismos responsáveis pela passivação da superfície do metal contra oxidação e para isto têm sido utilizadas técnicas complementares de análise como RBS[17], XPS[18], Espectroscopia Raman[19], AFM, SIMS, Método de quatro pontas [20], FTIR [21], possibilitando a caracterização estrutural, elétrica e morfológica da superfície do filme e dos produtos resultantes da oxidação em variados ambientes e temperaturas.

Com o objetivo de reduzir a taxa de oxidação do cobre e manter a alta condutividade elétrica, vários trabalhos têm sido realizados e divulgados, alguns resultando inclusive em patentes [22] e [23]. Dentre os vários textos publicados, é importante destacar os textos que envolvem a utilização de implantação iônica [24] e [25], os que discorrem sobre a composição de estruturas [26], artigos que tratam da deposição de uma camada superficial 
de outro material [27] e os que abordam a adição de elementos formando ligas [2] e [28]. Alguns dos tópicos mencionados aparecem combinados no mesmo artigo [29].

Em se tratando de filmes superficiais e estruturas compostas, o mecanismo de proteção já foi elucidado. No caso de implantação iônica, os pesquisadores têm tentado relacionar a proteção às espécies iônicas, à dose e à energia, mas os mecanismos responsáveis pela redução da taxa de oxidação do metal ainda não foram suficientemente compreendidos.

Os métodos experimentais, em geral, procuram determinar ou a resistividade do filme fino, ou a formação de compostos tais como $\mathrm{CuO}$ e $\mathrm{Cu}_{2} \mathrm{O}$ através de $\mathrm{XRD}$, ou finalmente a introdução do oxigênio devido à oxidação.

Para determinar a incorporação de oxigênio, usam-se métodos espectrométricos tais como RBS, SIMS, etc., especialmente quando as amostras são depositadas sobre o substrato de carbono amorfo ultra denso(UDAC). A utilização deste substrato, que foi adotada no presente trabalho, permite inequivocamente quantificar o oxigênio com excelentes limites de detecção, o que não é possível quando o substrato de silício é usado, como na maioria dos trabalhos na literatura específica.

No esforço de contribuir para a investigação e compreensão do fenômeno, iniciou-se um trabalho que visasse o entendimento dos mecanismos responsáveis pela passivação superficial dos metais contra a oxidação. Para isso, foi realizado um estudo sobre o processo de oxidação de cobre, determinando a cinética de oxidação e as fases existentes em cada alcance de temperatura de interesse tecnológico para o processamento dos dispositivos. A partir desses resultados foram discutidos métodos de passivação e o mecanismos associados, tendo como parâmetros a dose e a energia da espécie implantada, além da própria espécie. 


\section{Capítulo 2}

\section{Estado da arte}

O fenômeno da oxidação pode alterar profundamente as propriedades superficiais dos metais. Em alguns casos, até inviabiliza a utilização tecnológica desses metais, pois há grande alteração de suas propriedades físicas. A resistência à corrosão de alguns metais é atingida através da formação de um óxido passivador. No caso da superfície do cobre, a camada passivadora não é formada, e o óxido inicialmente formado permite a difusão do cobre e, com isso, possibilita que a oxidação continue. Vários mecanismos são empregados para proteger a superfície de cobre da oxidação, mas os fenômenos envolvidos em tais processamentos ainda não são muito bem compreendidos e nem modelados.

Neste capítulo será feita uma revisão bibliográfica do estado da arte no estudo da oxidação de cobre e passivação de superfícies metálicas, além de uma revisão dos fenômenos físico-químicos envolvidos na oxidação de metais.

\subsection{Oxidação de metais}

O interesse no estudo da oxidação do cobre tem aumentado devido ao seu uso em interconexões eletrônicas, nos quais os processamentos são feitos em temperaturas abaixo de $200{ }^{\circ}$ C. Os óxidos que se formam sobre o cobre nessas temperaturas podem ser química e mecanicamente instáveis, podendo resultar em perda de aderência [18].

As análises por RBS [30] e [31], Espectroscopia Raman [19] e [32], XPS[18] e [33] e elipsometria [34] e [17] têm sido usadas para estudar o fenômeno de oxidação do cobre, mas questões como o tipo de óxido formado e a cinética de oxidação ainda permanecem sem respostas. 
Como já foi afirmado na introdução deste trabalho, não existe uma total convergência entre as várias teorias utilizadas para para explicar o fenômeno da oxidação do cobre em função do tempo, temperatura e pressão parcial de oxigênio, mas os resultados de um grande número de estudos indicam que o comportamento varia do logarítimico ao parabólico, passando pelo linear e cúbico, dependendo das condições de oxidação.

A teoria de Cabrera e Mott [35] descreve muito bem a formação de filme de óxido em baixas temperaturas, mas no caso do cobre estudos mostram divergência em relação aos resultados obtidos por esses pesquisadores.

Cabrera e Mott explicaram o processo de oxidação inicial do filme através do crescimento de uma camada uniforme de óxido. Essa camada é controlada pelo transporte iônico, que por sua vez é governado pelo campo elétrico. Com isso, o crescimento inicial é totalmente dependente da espessura do óxido formado. Trabalho realizado por Yang e colaboradores utilizando TEM mostrou que o mecanismo central na formação de ilhas de $\mathrm{Cu}_{2} \mathrm{O}$ no estágio inicial de oxidação é a difusão de oxigênio, que, junto com sua dissociação e absorção facilita a nucleação em $\mathrm{Cu}_{2} \mathrm{O}$ sobre a superfície reconstruída [36].

Vários estudos desenvolvidos em condições experimentais bem controladas e em altas capacidades em resolução e limpeza têm mostrado que o estágio inicial de oxidação envolve nucleação e posterior crescimento de ilhas de óxido metálico [37] [38],[39],[40] e [41]. Em trabalho elaborado por Guangwen Zhou e Judith Yang [42], foi verificada a formação de núcleos e o crescimento destes como ilhas de óxido e não como uma camada uniforme, mesmo em pressões atmosféricas. Foram identificados vários estágios durante a progressiva exposição da superfície do cobre ao oxigênio. No estágio inicial ocorreu a dissociação e a absorção do oxigênio sobre a superfície do cobre. Com a contínua exposição ao oxigênio, os núcleos das ilhas do óxido aparecem sobre a superfície reconstruída depois de um período de incubação. Em seguida, inicia-se o crescimento e, posteriormente, a coalescência dessas ilhas com a contínua exposição ao oxigênio. Nesta fase, o processo é dominado pela difusão superficial e interfacial do oxigênio. Uma vez encerrada a coalescência, há uma redução na taxa de crescimento do óxido.

Os dados levantados sobre a cinética de oxidação de cobre são bastante divergentes em relação aos tipos de óxido formados e ao comportamento da taxa de oxidação com a temperatura. Vários trabalhos mostram a formação do óxido $\mathrm{Cu}_{3} \mathrm{O}_{2}$ em determinadas condições experimentais. Weider e Czanderna [43] elaboraram um trabalho delineando 
cinco regiões de oxidação em temperaturas que alcançaram desde a temperatura ambiente até $330{ }^{\circ} \mathrm{C}$. Os resultados estão sintetizados na figura 2.1. As regiões estudadas foram: (1) abaixo de $70{ }^{\circ} \mathrm{C}$, (2) $70{ }^{\circ} \mathrm{C}-110{ }^{\circ} \mathrm{C}$, (3) $110{ }^{\circ} \mathrm{C}-200{ }^{\circ} \mathrm{C}$, (4) $200{ }^{\circ} \mathrm{C}-270{ }^{\circ} \mathrm{C}$, (5) 270 ${ }^{\circ} C-330{ }^{\circ} C$. Na região (1) há crescimento de um óxido amorfo. Nas regiões (2) e (4)

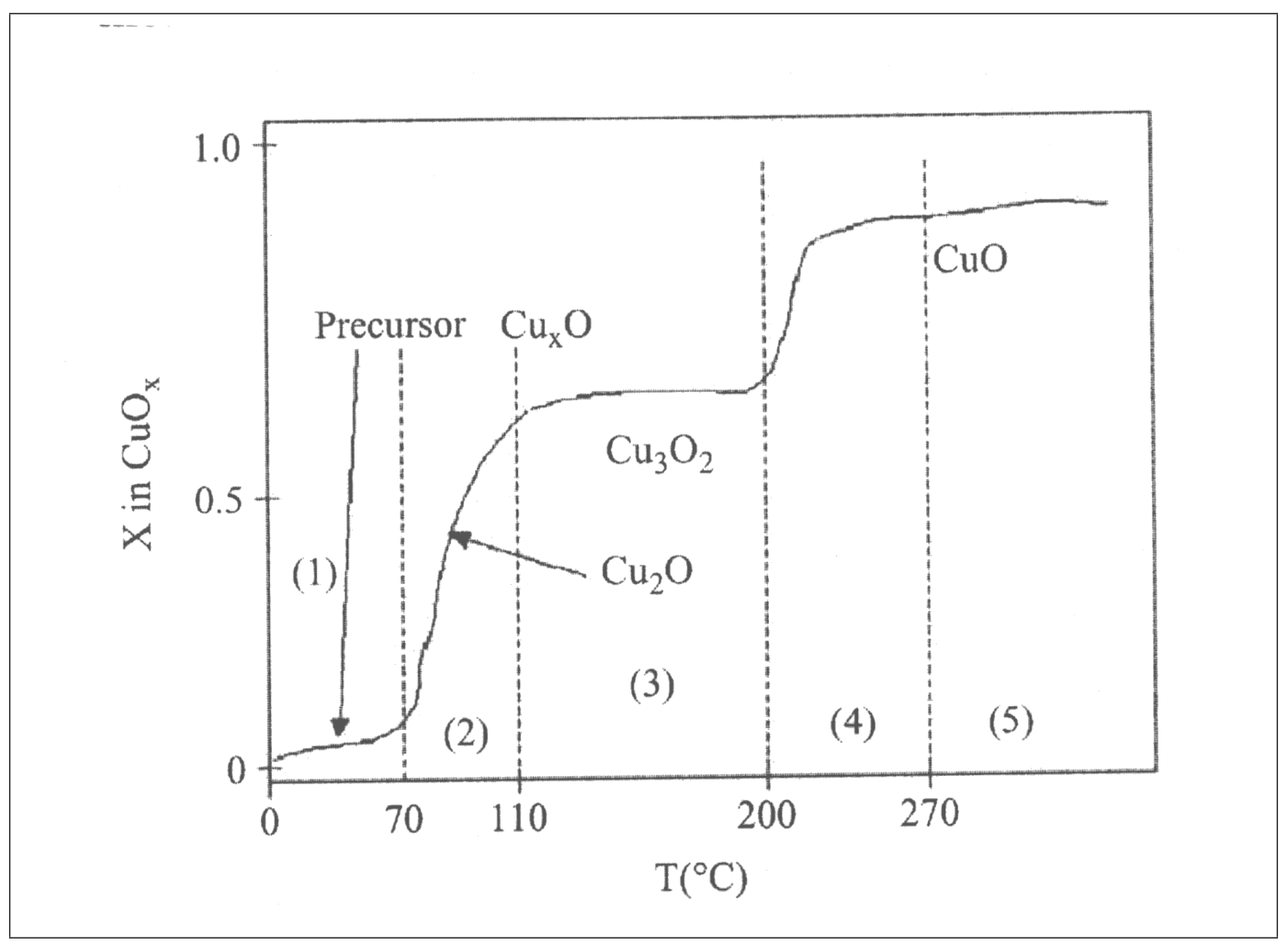

Figura 2.1: Formação de diferentes óxidos de cobre em função da temperatura $[43]$

há mudanças na composição da camada do filme. Na região (5) ocorre o crescimento do óxido cúprico, $\mathrm{CuO}$. Diferentemente do que se espera, a região (03) mostra um óxido cuja composição é $\mathrm{CuO} \mathrm{O}_{0.67}\left(\mathrm{Cu}_{3} \mathrm{O}_{2}\right)$, quando o esperado era $\mathrm{Cu}_{2} \mathrm{O}$. Mais tarde, os mesmo autores confirmaram esta estrutura através de medidas ópticas.

Neumeister e Jaenicke [44] estudaram a influência dos defeitos no tipo de óxido formado e encontraram significativas diferenças no crescimento do óxido dependendo do histórico da amostra. Um modelo cujo mecanismo de oxidação do cobre depende fortemente da quantidade de defeitos no $\mathrm{Cu}_{2} \mathrm{O}$ foi proposto, sendo $\mathrm{Cu}_{3} \mathrm{O}_{2}$ considerado um defeito estrutural do $\mathrm{Cu}_{2} \mathrm{O}$. Aparentemente, um aumento no número de defeitos no $\mathrm{Cu}_{2} \mathrm{O}$ facilitaria a formação de $\mathrm{Cu}_{3} \mathrm{O}_{2}$.

Para interpretação deste modelo, consideram-se oito reações na oxidação do cobre: 


$$
\begin{aligned}
& \mathrm{Cu}_{2} \mathrm{O}+1 / 2 \mathrm{O}_{2} \rightarrow 2 \mathrm{CuO} \\
& 3 \mathrm{Cu}_{2} \mathrm{O}+1 / 2 \mathrm{O}_{2} \rightarrow 2 \mathrm{Cu}_{3} \mathrm{O}_{2} \\
& \mathrm{Cu}_{3} \mathrm{O}_{2}+1 / 2 \mathrm{O}_{2} \rightarrow 3 \mathrm{CuO} \\
& \mathrm{Cu}_{3} \mathrm{O}_{2} \rightarrow \mathrm{CuO}+\mathrm{Cu}_{2} \mathrm{O} \\
& 2 \mathrm{Cu}+1 / 2 \mathrm{O}_{2} \rightarrow \mathrm{Cu}_{2} \mathrm{O} \\
& \mathrm{Cu}+1 / 2 \mathrm{O}_{2} \rightarrow \mathrm{CuO} \\
& 3 \mathrm{Cu}+\mathrm{O}_{2} \rightarrow \mathrm{Cu}_{3} \mathrm{O}_{2} \\
& \mathrm{Cu}+\mathrm{CuO} \rightarrow \mathrm{Cu}_{2} \mathrm{O}
\end{aligned}
$$

Para oxidação de cobre em $200^{\circ} \mathrm{C}$ e 50 Torr de pressão parcial de $\mathrm{O}_{2}$ foi observada somente a formação de $\mathrm{Cu}_{2} \mathrm{O}$. Depois da oxidação de $85 \%$ do cobre, verifica-se a mudança quase completamente para $\mathrm{Cu}_{3} \mathrm{O}_{2}$, conforme as reações 2.2 e 2.7, sem a formação de $\mathrm{CuO}$. Assim, a oxidação de $\mathrm{Cu}_{3} \mathrm{O}_{2}$ para $\mathrm{CuO}$ inicia-se na sua superfície externa, reação 5.2, mas ao mesmo tempo ele se decompõe em $\mathrm{CuO}$ e $\mathrm{Cu}_{2} \mathrm{O}$ na interface cobre-óxido, reação 2.4. Depois que o $\mathrm{Cu}_{3} \mathrm{O}_{2}$ se esgota, o processo de oxidação continua lentamente, através da oxidação do $\mathrm{Cu}_{2} \mathrm{O}$ e $\mathrm{Cu}$ para $\mathrm{CuO}$, reações 2.1 e 2.6. Assim, os pesquisadores assumem que as oito reações constituem o mecanismo de oxidação do cobre.

Estudo realizado por Lenglet e colaboradores [45] mostrou que em temperatura ambiente e pressão atmosférica, forma-se um óxido que tem característica de $\mathrm{Cu}_{2} \mathrm{O}$, mas contém cobre metálico. Entre 100 e $200^{\circ} \mathrm{C}$, formam-se $\mathrm{Cu}_{3} \mathrm{O}_{2}$ e $\mathrm{Cu}_{2} \mathrm{O}$, com $\mathrm{Cu}_{3} \mathrm{O}_{2}$ sendo mais prevalente quando o tempo de oxidação aumenta e, finalmente, acima de $200{ }^{\circ} \mathrm{C}$, $\mathrm{CuO}$ começa a se formar e há evidências de que ele cresça internamente na fase $\mathrm{Cu}_{3} \mathrm{O}_{2}$. Esse processo é descrito pelas seguintes reações:

oxidação em temperatura ambiente:

$$
2 \mathrm{Cu}+1 / 2 \mathrm{O}_{2} \rightarrow C u_{x} \mathrm{O}(\text { precursor })
$$

oxidação de cobre em $\mathrm{Cu}_{2} \mathrm{O}$ :

$$
2 \mathrm{Cu}+1 / 2 \mathrm{O}_{2} \rightarrow \mathrm{Cu}_{2} \mathrm{O}
$$


oxidação de $\mathrm{Cu}_{2} \mathrm{O}$ em $\mathrm{Cu}_{3} \mathrm{O}_{2}$

$$
3 \mathrm{Cu}_{2} \mathrm{O}+1 / 2 \mathrm{O}_{2} \rightarrow \mathrm{Cu}_{3} \mathrm{O}_{2}
$$

oxidação de $\mathrm{Cu}_{3} \mathrm{O}_{2}$ em $\mathrm{CuO}$

$$
\mathrm{Cu}_{3} \mathrm{O}_{2}+1 / 2 \mathrm{O}_{2} \rightarrow 3 \mathrm{CuO}
$$

Em trabalho desenvolvido com temperaturas de oxidação entre 150 e $250{ }^{\circ} \mathrm{C}$, foi constatada uma rápida conversão de cobre em $\mathrm{Cu}_{3} \mathrm{O}_{2}$ e uma lenta formação de $\mathrm{CuO}$ por agregação de vacâncias internas em $\mathrm{Cu}_{3} \mathrm{O}_{2}$, resultando formação de uma estrutura multicamada $\left(\mathrm{CuO} / \mathrm{Cu}_{3} \mathrm{O}_{2} / \mathrm{Cu}_{2} \mathrm{O} / \mathrm{Cu}\right)$ [15].

Outros estudos têm mostrado que a oxidação de cobre pode ser ainda mais complexa e que para oxidação entre a temperatura ambiente e $70^{\circ} C$, o óxido precursor $C u_{x} O$ já é uma estrutura pelo menos bicamada [45] e [46].

Ainda não há consenso entre o tipo de óxido formado e o comportamento da taxa de oxidação. Entretanto é sabido que a oxidação de cobre para $C u_{2} \mathrm{O}$ ocorre com forte dependência da temperatura e da pressão parcial de oxigênio e que se torna independente da pressão parcial de oxigênio quando $\mathrm{Cu}_{2} \mathrm{O}$ oxida-se para $\mathrm{CuO}$ [47].

Utilizando a teoria de Cabrera e Mott e técnicas como RBS e SEM, Yao Hu e colaboradores [17] estudaram oxidação de cobre em ambientes secos e úmidos, com temperaturas variando entre $100{ }^{\circ} \mathrm{C}$ e $600^{\circ} \mathrm{C}$. Para as temperaturas de $300^{\circ} \mathrm{C}$ e $400^{\circ} \mathrm{C}$, a espessura do óxido apresentou um comportamento parabólico em relação ao tempo de oxidação. Esse mesmo comportamento foi verificado com temperaturas entre $350{ }^{\circ} \mathrm{C}$ e $1050{ }^{\circ} \mathrm{C}$ [48], do mesmo modo para temperaturas variando entre $600^{\circ} \mathrm{C}$ e $1050{ }^{\circ} \mathrm{C}$ [49]. Em temperaturas mais baixas, $200{ }^{\circ} \mathrm{C}$ a $300{ }^{\circ} \mathrm{C}$, Ang e colaboradores encontraram um comportamento linear para a cinética de oxidação do cobre [50]. Trabalho realizado por W.Gao [51] permitiu determinar uma temperatura crítica que separa a cinética linear da parabólica. Para filmes de cobre depositados por sputtering e oxidados em temperaturas abaixo de $250{ }^{\circ} \mathrm{C}$ a cinética é linear. Recentemente, um estudo feito sobre oxidação de filmes de cobre de $1000 \AA$, em temperaturas entre $180{ }^{\circ} \mathrm{C}$ e $260{ }^{\circ} \mathrm{C}$ [20], determinou uma cinética de crescimento do óxido com comportamento parabólico e energia de ativação de $0.57 \mathrm{eV}$.

Sintetizando, alguns trabalhos apontam para a formação de um terceiro óxido, $\mathrm{Cu}_{3} \mathrm{O}_{2}$, enquanto em outros é verificada somente a formação de $\mathrm{CuO}$ e $\mathrm{Cu}_{2} \mathrm{O}$. Resultados de 
estudos mostram que a cinética de oxidação pode ser linear ou parabólica, mas o comportamento é divergente em relação à faixa correspondente de temperatura e à energia de ativação.

Nos trabalhos realizados, em geral, nenhuma referência em relação à espessura dos filmes de cobre estudados é feita. Será visto mais adiante neste trabalho, que essa grandeza é de fundamental importância na caracterização do processo de oxidação do cobre.

\subsection{Passivação de superfícies metálicas}

Vários métodos são utilizados na passivação de superfícies metálicas contra oxidação. Do ponto de vista tecnológico, os trabalhos mais relevantes consistem na adição de impurezas para formação de ligas, na utilização de camadas de material protetor e na implantação iônica. O grande desafio é descobrir um método que reduza a taxa de oxidação de cobre e, ao mesmo tempo, mantenha inalteradas características como alta condutividade e a alta resistência à eletromigração.

\subsubsection{Passivação do cobre através da formação de ligas}

O estudo do comportamento da adição de elementos a um metal na taxa de oxidação tem sido realizado através da incorporação de alguns metais. Diversos elementos têm sido utilizados separadamente, sendo os mais freqüentes $\mathrm{Al}, \mathrm{Cr}$ e $\mathrm{Mg}$ [28], [47], [52], [53], [54] e [55]. Para o cobre, a formação de ligas aumenta a aderência ao $\mathrm{SiO}_{2}$, aspecto muito importante na tecnologia de circuitos integrados. Dependendo da quantidade de material adicionada e da temperatura de oxidação, a passivação superficial tem ocorrido. Também tem sido mostrado que a adição de $\mathrm{Bi}_{2} \mathrm{O}_{3}$ ao cobre aumenta dramaticamente a sua taxa de oxidação [56].

Mayer e colaboradores [47] compararam o comportamento de filmes finos de cobre e de ligas com Ti, $\mathrm{Pd}, \mathrm{Cr}$ e $\mathrm{Al}$ quanto à oxidação e verificaram que a adição desse materiais ao cobre reduz a taxa de oxidação. A resistividade, entretanto, é aumentada, o que é uma limitação da técnica. Os pesquisadores fundamentaram a explicação para a redução da taxa de oxidação na redução da mobilidade do cobre quando a liga é formada, no caso do Ti, Pd e Al. Verificaram também que a liga amorfa CuTi é mais resistente à oxidação, 
comparada à fase cristalina. Quando é formada um liga de cobre com cromo, a formação do óxido de cromo é responsável pela pela proteção superficial.

Pesquisadores como Lanford e Ding estudaram a influência da introdução de pequenas concentrações de alumínio na resistência à corrosão, na resistividade, na adesão ao silício e na estabilidade sobre $\mathrm{SiO}_{2}$ e deram grandes contribuições através de uma série de trabalhos discutidos a seguir.

No primeiro trabalho [53], os pesquisadores partiram de amostras de cobre com várias concentrações de alumínio, obtidas por sputtering simultâneo de alvos de cobre e alumínio em um plasma de argônio. Utilizando técnicas como método de quatro pontas e análises RBS, foram determinadas a resistividade elétrica e a relação $\mathrm{Al} / \mathrm{Cu}$. Como resultado, verificaram que a taxa de oxidação era menor que a do cobre puro e a aderência ao $\mathrm{SiO}_{2}$ foi aumentada. Além disso, os filmes dopados não apresentaram nenhuma difusão em $\mathrm{SiO}_{2}$, mesmo em temperaturas acima de $700{ }^{\circ} \mathrm{C}$.

Em outro trabalho deste grupo, foi estudada a possibilidade de se utilizar uma camada de alumínio por sputtering, formando amostras $\mathrm{Cu}(\mathrm{Al}) / \mathrm{SiO}_{2} / \mathrm{Si}$ como forma de melhorar a adesão ao $\mathrm{SiO}_{2}$ e evitar a oxidação dos filmes de cobre [26]. Utilizando os métodos de quatro pontas e RBS para medir respectivamente a resistividade elétrica e as espessuras do filme, os autores concluíram que os filmes crescidos apresentavam redução substancial na taxa de oxidação e melhoraram a estabilidade morfológica e a adesão ao $\mathrm{SiO}_{2}$, ocorrendo, entretanto, a redução da condutividade do filme, para tratamento térmico em temperaturas maiores que $350{ }^{\circ} \mathrm{C}$.

Ainda investigando as mudanças das propriedades de filmes de cobre por adição de elementos, o mesmo grupo estudou o comportamento de filmes de cobre dopados com várias concentrações de magnésio [57]. Filmes de cobre e magnésio foram depositados por sputtering, por exposição simultânea a alvos de cobre e magnésio. A relação $\mathrm{Cu} / \mathrm{Mg}$ foi determinada por RBS e a resistividade elétrica foi obtida pelo método de quatro pontas. Após tratamento térmico, foi verificado que os filmes $\mathrm{Cu}-\mathrm{Mg}$ apresentavam uma taxa de oxidação muito menor que os filmes de cobre puro e, quando tratados termicamente em argônio, a $400^{\circ} \mathrm{C}$, uma camada de óxido de magnésio formava-se sobre a superfície e interrompia completamente a oxidação. Além disso, o tratamento térmico reduzia a resistividade elétrica dos filmes para valores iguais aos dos filmes de cobre puro. 
Um trabalho bastante relevante do grupo citado foi a tentativa do controle da espessura da camada inicial do alumínio na estrutura $\mathrm{Cu} / \mathrm{Al} / \mathrm{SiO}_{2} / \mathrm{Si}$. Através da observação do diagrama de fase da estrutura $\mathrm{Cu}-\mathrm{Al}$ e das energias livres de Gibbs para formação dos óxidos correspondentes, concluíram ser possível o controle da espessura da camada inicial do alumínio e das condições de tratamento térmico para formar uma estrutura consistindo de cobre puro entre óxido de alumínio superficial e o complexo $\mathrm{Si}-\mathrm{Al}-\mathrm{O}$ na interface metal $/ \mathrm{SiO}_{2}: \mathrm{Al}_{2} \mathrm{O}_{3} / \mathrm{Cu} / \mathrm{Si}-\mathrm{Al}-\mathrm{O} / \mathrm{SiO}_{2} / \mathrm{Si}$. O grau de passivação dos filmes foi determinado através do aquecimento das amostras em atmosfera ambiente. A análise pelo método de quatro pontas e RBS foram utilizados para determinar a resistividade elétrica e a espessura do óxido crescido. Os autores verificaram que os filmes oxidavam muito mais lentamente que os filmes de cobre puro e que a espessura do óxido crescido era proporcional à raiz quadrada do tempo de oxidação. Foi constatada também a reduzida alteração da resistividade.

$\mathrm{Na}$ tentativa de determinar qual a melhor escolha de um elemento para formar liga com cobre e resolver problemas como difusão e adesão ao $\mathrm{SiO}_{2}$ e resistência à corrosão, mantendo baixa a resistividade elétrica, Ding e colaboradores estudaram detalhadamente o comportamento de filmes de cobre após adição de alumínio e magnésio. Fizeram comparações entre duas ligas de cobre: $\mathrm{Cu}(\mathrm{Al})$ e $\mathrm{Cu}(\mathrm{Mg})$ [58]. Análises RBS e XRD permitiram identificar o tipo de óxido e sua espessura. Os autores verificaram que embora as duas ligas apresentassem resultados relativamente parecidos, o sistema $C u(M g)$ apresentou melhor desempenho em relação à manutenção da baixa resistividade elétrica.

O estudo dos mecanismos envolvidos na redução da taxa de oxidação do cobre também teve contribuição de Kaatz e colaboradores [55], que descreveram um procedimento para fazer $\mathrm{Cu}_{80} \mathrm{Co}_{20}$ nanocristalino e apresentaram dados comprovando que a precipitação do cobalto na superfície do nanocristal reduzia a taxa de oxidação do cobre.

Pesquisadores como Moore e Hryn [59] estudaram o comportamento de algumas ligas quanto à oxidação para selecionar um óxido passivador sobre a liga, através do controle de sua composição e das condições de tratamento térmico e desenvolveram um método de crescimento de óxidos passivadores, em alta temperatura, sobre ligas metálicas, em condições de alto vácuo, monitorando com XPS a oxidação em tempo real.

Ogbuji e Humprhrey [60] monitoraram a oxidação de cobre em $\mathrm{Cu}_{2} \mathrm{O}$ e $\mathrm{CuO}$ e determinaram a cinética de oxidação de três ligas de cobre. Eles verificaram que, em temperaturas 
entre $550^{\circ} \mathrm{C}$ e $750{ }^{\circ} \mathrm{C}$, a taxa de oxidação era linear ou parabólica, dependendo da pressão parcial de oxigênio.

Na tentativa de determinar a influência de impurezas na oxidação de cobre em altas temperaturas, Zhu e colaboradores [61] compararam a cinética de oxidação de amostras obtidas com cobre $2 \mathrm{~N}$ e $6 \mathrm{~N}$ em oxigênio $2 \mathrm{~N}$. Dentre outros aspectos, eles verificaram que a taxa de oxidação de $\mathrm{Cu}(2 \mathrm{~N})$ é menor do que a do $\mathrm{Cu}(6 \mathrm{~N})$ em $600{ }^{\circ} \mathrm{C}$, mas é maior entre $800{ }^{\circ} \mathrm{C}$ e $1000{ }^{\circ} \mathrm{C}$. Entre $600{ }^{\circ} \mathrm{C}$ e $1000{ }^{\circ} \mathrm{C}$ havia formação de um óxido $\mathrm{CuO}$ poroso e, conseqüentemente, não protetor em amostras feitas a partir de $\mathrm{Cu} 2 \mathrm{~N}$, diferentemente das outras, que apresentaram um óxido $\mathrm{CuO}$ compacto.

Plascencia e colaboradores [62] estudaram a oxidação em altas temperaturas de ligas de $\mathrm{Cu}(\mathrm{Al})$ e propuseram um modelo para explicar o comportamento quanto à oxidação e determinar a quantidade de oxigênio dissolvido na liga, inter-relacionando estes dois aspectos. Foi verificado que a taxa de oxidação das ligas de $\mathrm{Cu}(\mathrm{Al})$ variava com a composição e a temperatura e que, quanto mais alta a temperatura, maior quantidade de alumínio era necessária para passivar a superfície. Outro trabalho desse grupo [63] investiga o comportamento de ligas de $\mathrm{Cu}(\mathrm{Al})$ em temperaturas acima de $1000{ }^{\circ} \mathrm{C}$, constatando que amostras submetidas a tratamento térmico antes da oxidação apresentam maior resistência à oxidação.

Resumidamente, pode-se dizer que, em se tratando de ligas de cobre e outro metal, o principal objetivo tecnológico hoje é determinar qual a quantidade mínima de metal, necessária para passivar a superfície e determinar como essa concentração varia com a temperatura de oxidação, verificando também a dependência da resistência à oxidação dessas ligas com o tratamento térmico, tendo em mente a manutenção da alta condutividade elétrica do cobre.

No presente trabalho, ligas de $C u A l$ foram estudadas para auxiliar no entendimento do mecanismo de proteção oferecido pela formação de liga através da adição de material ao cobre.

\subsubsection{Passivação por camada protetora}

A deposição de um filme fino tem sido utilizada como técnica de passivação superficial. Filmes finos de Cr, TiN, Ta [64], TaN [65], Al [66] e Ti [67] são usados como camadas 
passivadoras sobre o cobre, funcionando como uma barreira contra a difusão, impedindo assim, a oxidação do metal.

Utilizando técnicas analíticas como XPS e Spectroscopia Auger, Mayumi e colaboradores [27] verificaram a proteção oferecida por um filme fino da liga $\mathrm{Al}(\mathrm{W})$ contra oxidação do cobre. Os resultados alcançados indicam que os filmes de $50 \mathrm{~nm}$ de $\mathrm{Al}(\mathrm{W})$ protegem a superfície de cobre da oxidação mesmo com temperaturas alcançando $500{ }^{\circ} \mathrm{C}$ durante uma hora em atmosfera.

Chuang e Chen verificaram que um filme de tântalo ou nitreto de tântalo, depositado sobre cobre, formando a estrutura $\mathrm{Ta}(\mathrm{N}) / \mathrm{Cu} / \mathrm{SiO}_{2} / \mathrm{Si}$ fornecem uma proteção efetiva contra oxidação. Nenhuma camada de óxido foi encontrada após os filmes serem tratados termicamente em atmosfera de $\mathrm{O}_{2}$ a $400{ }^{\circ} \mathrm{C}$ por 50 minutos [68] e [65].

A deposição de uma fina camada de $\operatorname{Ti}(3,7 \mathrm{~nm})$ mostrou ser efetiva na passivação de filmes de cobre, evitando a oxidação [67]. Da mesma forma, a utilização de níquel [69] e ouro [70] serviram como camadas protetoras do cobre.

No presente trabalho, a tentativa de passivar a superfície de filmes de cobre através de camada protetora foi feita utilizando-se uma camada de carbono, depositada por bombardeamento eletrônico sobre a superfície do filme de cobre, resultando em uma estrutura $\mathrm{C} / \mathrm{Cu} / \mathrm{C}$.

\subsubsection{Passivação através da implantação iônica}

Implantação iônica é uma técnica que emprega aceleradores de íons para direcionar feixes de íons energéticos sobre materiais. Além do controle preciso do número total de íons implantados, a implantação iônica tem como vantagens a possibilidade de se atingir concentrações superiores às concentrações de equilíbrio e também a possibilidade de serem utilizadas muitas combinações de íons e alvos. A energia empregada no processo de bombardeamento iônico encontra-se entre algumas dezenas de $\mathrm{keV}$ até alguns $\mathrm{MeV}$, com concentrações variando de $10^{11}$ a $10^{17}$ íons $/ \mathrm{cm}^{2}$. Em microeletrônica, as dose de íons são relativamente baixas e é importante restaurar a cristalinidade do semicondutor através de tratamento térmico [71] e [72]. Em se tratando de metais ou polímeros, isso nem sempre é necessário.

Essa técnica tem sido usada por muitos anos para dopar semicondutores, visando a produção de dispositivos de estado sólido [73],[74], [75],[76] e [77]. 
Nas últimas décadas, várias pesquisas têm sido feitas com o objetivo de utilizar a implantação iônica na formação de ligas nas superfícies de metais e na alteração da microestrutura das camadas superficiais dos metais, alterando dessa forma várias propriedades [78] [79]. Dentre elas, pode-se citar a resistência à corrosão [80] e [81], o coeficiente de fricção [82], a aderência [83], a dureza [84], mudanças na faixa de absorção de energia [85] e [86].

Em relação à passivação superficial, vários estudos têm sido realizados. Alguns atribuem a passivação superficial à formação de um óxido que bloqueia o transporte da espécie oxidante[87], outros ao efeito halogênio [88] ou ao bloqueio da difusão das espécies oxidantes pelo próprio íon implantado [89], mas ainda não há um modelo que relacione todos os mecanismos responsáveis pela passivação de superfícies metálicas. Assim, este trabalho pretende dar uma contribuição à elucidação desses mecanismos.

O mecanismo responsável pela passivação de cobre em uma estrutura multicamada de $\mathrm{SiO}_{2} / \mathrm{Mg} / \mathrm{Cu} / \mathrm{SiO}_{2} / \mathrm{Si}$ foi estudado por Zhen-Cheng Wu [29]. Neste trabalho, a implantação de $A r^{+}$foi utilizada para deslocar átomos de $\mathrm{Mg}$ até a superfície de cobre. Dependendo da dose e da energia dos íons implantados, esses processos inibiram ou reduziram a taxa de oxidação do cobre. A passivação superficial foi atribuída à formação de $\mathrm{MgO}$, que serviu de barreira contra a difusão das espécies oxidantes.

Em 1976, Naguib e colaboradores estudaram o efeito da implantação de várias espécies iônicas na taxa de oxidação do cobre [90]. Analisando as conseqüências dessas implantações, foram observados efeitos diversos a cada espécie implantada. Utilizando-se o boro ou neônio como espécie implantada, ocorria uma redução da taxa de oxidação, que se mostrava independente da dose e da energia da espécie implantada. Quando foi empregado o carbono como espécie implantada, observou-se que a taxa de oxidação aumentava para o conjunto de todas as doses e energias medidas. Para o nitrogênio, contudo, a taxa de oxidação apresentou um resultado totalmente dependente da dose; para doses baixas, a taxa aumentava, para doses altas, a taxa se reduzia. De posse de tais dados, foi concluído que a taxa de oxidação pode ser diminuída ou majorada de acordo com a espécie a ser implantada. Tais inferências puderam ser feitas a partir dos efeitos químicos e dos danos causados à rede pela espécie implantada.

Com o objetivo de determinar quais espécies implantadas deveriam ser estudadas mais detalhadamente para passivar a superfície de cobre, Ratcliffe e Collins publicaram, em 
1983, um trabalho fruto do estudo do efeito da implantação de trinta e um íons em cobre policristalino e nove íons em cobre monocristalino, cuja orientação era (110) [91]. Tentando esclarecer os resultados encontrados, os autores basearam-se em um modelo no qual o efeito da implantação dependeria da localização da impureza. Ao mesmo tempo, consideraram que as discrepâncias em relação a esse modelo ocorreriam devido ao efeito do stress produzido por algumas espécies implantadas no filme. Também concluíram que, para amostras policristalinas, havia uma correlação entre a massa da espécie implantada e o grau de oxidação. Para alguns íons, os efeitos foram relacionados à dose implantada.

Com o objetivo de elucidar os mecanismos envolvidos na passivação do cobre, cinco anos mais tarde, os mesmos pesquisadores selecionaram 22 dentre as 31 espécies estudadas [92]. Buscava-se com isso a comprovação do modelo de junção pn proposto por Morris [93]. Tal modelo baseia-se no fato de que a implantação iônica leva à formação de uma região tipo n no óxido predominantemente tipo p, dificultando a difusão durante o crescimento do óxido. A conclusão a que os autores chegaram foi que o modelo de Morris consegue explicar o comportamento de alguns íons implantados em cobre. Entretanto, é um modelo muito simplista para ser usado isoladamente. Além disso, concluíram que na análise do comportamento, para uma espécie em particular, devem ser considerados os seguintes fatores: a concentração e a distribuição com a profundidade, os danos e o stress provocados pela implantação e ainda a natureza química da espécie implantada.

Em 1994, Lanford e colaboradores, investigaram o mecanismo responsável pela resistência à corrosão causada pela implantação iônica de boro [94]. Eles observaram que a implantação iônica reduzia a taxa de oxidação. Concluíram também que a passivação causada pela implantação do boro permanece até mesmo quando as amostras são tratadas termicamente. O mecanismo responsável pela proteção superficial foi a autopassivação: o boro, no óxido, reduz o transporte do íon $C u^{+}$. Dessa forma, a difusão do oxigênio no $\mathrm{Cu}_{2} \mathrm{O}$ ficaria significativa, resultando na formação de um filme $\mathrm{CuO}$. Esse óxido por ser muito denso, reduziria o transporte de íons $\mathrm{Cu}^{+}$para a superfície, dificultando a oxidação.

A redução do transporte de íons $C u^{+}$também foi proposta em outro trabalho [89]. Neste estudo, a implantação de $B F^{+2}$ bloqueiaria a difusão, impedindo a oxidação do cobre.

Na tentativa de modelar os fenômenos responsáveis pela passivação de cobre por implantação iônica, foi realizado um estudo envolvendo a implantação iônica de $\mathrm{He}^{+}$em 
UHV foi por Kellock e colaboradores [95]. Eles partiram da hipótese de que havia três mecanismos possíveis para explicar o fato de que a irradiação de uma superfície metálica protegia essa superfície de oxidação: 1) a quebra dos átomos de carbono residentes ou continuamente adsorvidos sob a superfície do metal, produzindo uma camada de carbono suficientemente espessa para inibir a difusão de oxigênio; 2) a indução da quebra de ligações das moléculas adsorvidas sob o metal, produzindo uma superfície passivada que não pode adsorver facilmente o oxigênio; e 3) a possível mudança estrutural do metal. Nesse artigo, os autores estudam o efeito da implantação iônica na ausência do carbono, depositando o metal e fazendo a implantação em uma câmara UHV, livre de carbono. Permanecendo a passivação, esta seria atribuída a efeitos estruturais. Caso contrário, a passivação poderia ser modelada como uma modificação associada ao carbono resultante da implantação iônica. Os autores concluíram que a irradiação de uma superfície de cobre livre de carbono não inibe a oxidação. Concluíram também que a exposição da superfície de cobre à contaminação atmosférica leva à formação de uma monocamada residual de $C_{x} O_{y}$ e que é a irradiação dessa monocamada o processo responsável pela redução da oxidação.

Em 2001, o grupo de Zhao estudou os efeitos de implantação de alumínio, cromo e magnésio bem próxima à superfície de cobre, com variadas doses[24]. Monitoração dos filmes através do método de quatro pontas, RBS e microscopia eletrônica de varredura permitiram concluir que a implantação iônica nas doses utilizadas melhora efetivamente a resistência à oxidação e não tem nenhuma influência em sua condutividade elétrica. Por outro lado, a implantação iônica altera a evolução e estrutura de filmes de óxido de cobre formados sobre a superfície de filmes de cobre.

Os efeitos da implantação de alumínio em cobre foram investigados utilizando-se RBS, AFM e elipsometria espectroscópica por Poperenko e colaboradores [25]. Nesse trabalho, os autores concluiram que a implantação iônica não muda a rugosidade superficial, mas aumenta a resistência do cobre à oxidação em temperatura ambiente.

Muitos trabalhos têm sido realizados com o objetivo de estudar o comportamento de filmes de cobre com a implantação iônica. Têm sido investigados tanto a resistência à oxidação, como as mudanças topográficas, a condutividade elétrica, a aderência ao silício, etc. Pode-se concluir que poucos trabalhos tentam modelar o fenômeno da passivação ou 
mesmo entendê-lo. Este trabalho tem como objetivo colaborar no estudo dos mecanismos responsáveis pela passivação de cobre. 


\section{Capítulo 3}

\section{Fenômenos físico-químicos}

Como já dissemos, o fenômeno da oxidação pode alterar profundamente as propriedades superficiais dos metais. Em alguns casos, até inviabiliza a utilização dos metais, pois as propriedades físicas das superfícies oxidadas são completamente diferentes das não oxidadas. Um importante exemplo é o cobre. Quando oxidado, ele se transforma em um semicondutor tipo p, deixando de ter as características do cobre metálico.

Existem metais, como o $\mathrm{Al}$, em que a resistência à corrosão é atingida através da formação de um óxido passivador. No caso da superfície do cobre esta camada passivadora não é formada, e o óxido inicialmente formado permite a difusão do cobre em direção à superfície e com isto, sua oxidação. Vários mecanismos são utilizados para proteger a superfície do cobre da oxidação, mas muitos fenômenos envolvidos em tais processamentos ainda não são muito bem entendidos e modelados.

Como foi descrito no capítulo anterior, técnicas como implantação iônica, utilização de uma camada protetora e formação de ligas são utilizadas na passivação de superfícies metálicas.

Buscando entender os fenômenos envolvidos na oxidação e passivação do cobre, neste capítulo será feito um estudo dos fenômenos físico-químicos envolvidos na oxidação de metais e na implantação iônica.

\subsection{Oxidação de metais}

Na corrosão em meio gasoso, a reação mais comum é entre o metal e o oxigênio, envolvendo os fenômenos de dissociação, ionização, adsorção e absorção de moléculas de 
oxigênio, com subseqüente incorporação de íons para formar a camada de óxido [96]. A tendência de um metal reagir com o oxigênio é indicada pela variação da energia livre que acompanha a formação do óxido. A oxidação será possível do ponto de vista termodinâmico se houver redução da energia livre.

A maioria dos metais apresentam uma energia livre de formação de seus óxidos negativa. A energia de formação dos óxidos metálicos de interesse industrial ocorre com variação negativa da energia livre padrão em temperaturas variando entre a temperatura ambiente e o ponto de fusão dos metais. Esse fenômeno tem sua cinética determinada pela energia livre de Gibbs, $\Delta G$, da reação:

$$
a A+b B \Leftrightarrow c C+d D
$$

onde $A$ e $B$ são os reagentes e $C$ e $D$, os produtos. A variação da energia livre de Gibbs para uma reação dada pela equação 3.1 é definida por:

$$
\Delta G=\Delta G^{0}+R T \ln \frac{[C]^{c}[D]^{d}}{[A]^{a}[B]^{b}}
$$

onde $\Delta G^{0}$ é a variação da energia livre de Gibbs padrão e $T$ é a temperatura absoluta.

Baseado nos valores de $\Delta G$, há três possibilidades:

1. $\Delta G=0$, indicando um sistema em equilíbrio;

2. $\Delta G<0$, indicando o favorecimento de formação dos produtos $C$ e $D$;

3. $\Delta G>0$, indicando que a reação não ocorrerá espontaneamente.

Alguns metais de interesse tecnológico possuem $\Delta G<0$ para a formação de seu óxido, o que significa um grande obstáculo para a sua aplicação. O alumínio possui a energia livre de formação do óxido $\Delta G=-120,7 k c a l$ e cobre $\Delta G=-31,5 k c a l$ por átomo de oxigênio. Mas, diferentemente do comportamento de oxidação do alumínio, a taxa de oxidação do cobre é alta e nenhuma camada passivadora é formada para evitar posterior oxidação [97].

A descrição mais geral da oxidação que ocorre entre um metal e o oxigênio é dada pela reação:

$$
n M+m O_{2} \rightarrow M_{n} O_{2 m}
$$

onde $M$ é a espécie metálica e $M_{n} O_{2 m}$ é o óxido produto. A formação do óxido iniciase com a oxidação do metal. Posteriormente, ocorre o processo de redução do oxigênio próximo à interface óxido-gás, quando há absorção dos elétrons em excesso. 
O crescimento do filme de óxido próximo à interface metal-óxido indica uma difusão aniônica, caracterizada pela lenta difusão do íon metálico e dominado pela rápida difusão dos íons $O^{2-}$ para dentro do óxido. Por outro lado, difusão catiônica é dominada pela difusão para fora dos íons metálicos, devido à lenta difusão dos íons de oxigênio, produzindo um novo óxido próximo à interface óxido-gás. Em se tratando de cobre, um estudo feito utilizando traçador radioativo mostrou que no seu processo de oxidação são os íons desse metal que difundem através do filme de óxido [98].

A determinação da interface onde se dá o crescimento do filme de óxido está relacionada à porosidade do óxido. Se o filme inicialmente formado é poroso, o oxigênio pode passar através dos poros e reagir na interface metal-óxido.

Se o película de óxido é não porosa podem acontecer os seguintes mecanismos:

1. A oxidação pode ocorrer na interface óxido-gás. Neste caso, os íons metálicos se difundem desde a interface metal-óxido até a interface óxido-gás;

2. A oxidação pode ocorrer na interface metal-óxido. Os íons oxigênio se difundem através da película para reagir na interface metal-óxido;

3. Outro mecanismo é uma combinação dos dois casos anteriores em que os íons oxigênio se difundem até o interior e os íons metálicos, junto com os elétrons, até o exterior. Nesse caso, o lugar da reação pode ser qualquer sítio dentro da película de óxido.

Baseando-se na porosidade dos filmes de óxido formado, Pilling e Bedworth estabeleceram critérios para a potencialidade de proteção contra uma posterior oxidação, classificando os filmes de óxidos metálicos como protetores e não protetores. A relação de PillingBedworth $(\mathrm{PB})^{1}$, relaciona a porosidade de um óxido metálico à sua densidade específica e é definida como a razão entre o volume do óxido, que é produzido pela reação entre o metal e o oxigênio e o volume do metal consumido. Para a reação dada por 3.3, PB será dado por:

$$
P B \equiv \frac{\frac{M_{o x}}{n N_{a} \rho_{o x}}}{\frac{M_{m}}{N_{a} \rho_{m}}}
$$

onde $M_{o x}, M_{m}$ e $\rho_{o x}, \rho_{M}$ são as massas moleculares $(M)$ e as $\operatorname{densidades}(\rho)$ do óxido e do metal, respectivamente e $N_{a}$, o número de Avogadro.

\footnotetext{
1 Não foi encontrado o artigo referente a esse trabalho. Os autores são Bruce Chalmers e Gordon McKay.
} 
A tabela 3.1 mostra valores da razão PB para vários metais que formam óxidos protetores e não protetores.

Tabela 3.1: Razões P-B para alguns metais

\begin{tabular}{c|c}
\hline óxidos protetores & óxidos não protetores \\
\hline $\mathrm{Al} 1.28$ & $\mathrm{~K} 0.45$ \\
$\mathrm{~Pb} 1.40$ & $\mathrm{Cd} 1.21$ \\
$\mathrm{Ni} 1.52$ & $\mathrm{Ag} 1.59$ \\
$\mathrm{Be} 1.59$ & $\mathrm{Ta} 2.33$ \\
$\mathrm{Pd} 1.60$ & $\mathrm{Sb} 2.35$ \\
$\mathrm{Cu} 1.68$ & $\mathrm{Hf} 2.61$ \\
$\mathrm{Mn} 1.79$ & $\mathrm{~V} 3.18$ \\
$\mathrm{Co} 1.99$ & Mo 3.40 \\
$\mathrm{Cr} 1.99$ & W 3.40
\end{tabular}

Uma relação $P B$ menor que 1 significa que o óxido formado possui volume menor que o metal, tendendo a ser poroso, não cobrindo totalmente a superfície do metal e, com isto, não o protegendo [99]. Um exemplo deste comportamento é observado para o magnésio. Estudo recente mostra que quando esse elemento é adicionado ao cobre para passivar a sua superfície ocorre exfoliação e falta de aderência superficial do óxido de magnésio ao filme de cobre. Isto pode ser atribuído à baixa relação $\mathrm{P}-\mathrm{B}$ do $\mathrm{MgO}$ [2].

Resultados mais recentes mostram que, para $P B>2$, o volume do óxido é maior que o do metal e, inicialmente, é formado um filme protetor. À medida em que aumenta a espessura do óxido, este fica sob a ação de stress altamente compressivo, podendo desprender-se da superfície, expondo o metal, que continua o processo de oxidação. Este é um comportamento típico do ferro, quando oxidado em determinados valores de temperatura. Quando a relação se aproxima da unidade, forma-se uma película não porosa e aderente, que cobre toda a superfície do metal, permitindo classificar o filme de óxido como potencial protetor, mas não garantindo a proteção do metal.

Apesar do cobre possuir relação PB entre 1 e 2, o óxido formado não o protege de posterior oxidação. Assim, conclui-se que a tabela 3.1 mostra a potencialidade que determinados elementos têm em formar óxidos protetores, mas além de possuir a relação PB 
entre 1 e 2,condição necessária, o sistema óxido + metal deverá satisfazer às seguintes condições:

i) Volatilidade: os protetores devem ser não voláteis;

ii) Resistividade elétrica: as películas de maior resistividade elétrica oferecem maior dificuldade à difusão iônica, sendo mais protetoras por imporem maior restrição à passagem desses íons;

iii) Impermeabilidade da rede cristalina: quanto mais compacta a rede cristalina maior será a dificuldade para a difusão e, portanto, mais protetor será o óxido;

iv) Aderência: as películas mais finas são, de modo geral, mais aderentes. Quando a rede cristalina do produto de corrosão é semelhante à do metal tem-se normalmente maior aderência da película. Películas mais aderentes são mais protetoras;

v) Refratariedade: as películas para serem protetoras não devem fundir a baixas temperaturas;

vi) Elasticidade: as películas muito duras fraturam com facilidade, tendendo a ser menos protetoras;

vii) Porosidade: está intimamente ligada à impermeabilidade da rede cristalina. Quanto menos porosa, mais protetora será a película;

viii) Coeficiente de expansão térmica para o metal e o óxido devem ter valores próximos.

\subsubsection{Cinética de oxidação}

Em oxidação de metais, a cinética é totalmente dependente da espessura do filme e da temperatura, com a espessura apresentando um comportamento logarítmico, linear, parabólico, cúbico ou ainda a composição destes, dependendo das condições de crescimento do filme de óxido.

Em baixas temperaturas e para filmes finos de óxido é observado o comportamento logarítmico ou inverso logarítmico.

Cabrera e Mott propuseram uma teoria explicando a oxidação de metais [35]. Segundo este modelo, em baixas temperaturas, metais mostram inicialmente um crescimento muito 
rápido da camada de óxido. Quando a espessura atinge valores em torno de $100 \AA$ A , há uma grande redução da velocidade de oxidação. Em baixas temperaturas, o modelo proposto sugere que o crescimento do filme de óxido não é uma reação ativada termicamente, mas é determinado pelo forte campo elétrico existente devido à diferença de potencial de contato entre o metal e o oxigênio adsorvido. Assim, o transporte iônico (íons de oxigênio ou de metal) devido ao campo elétrico acelera a oxidação inicial, mas é reduzido rapidamente à medida que cresce a espessura da camada de óxido. Isto resulta em uma cinética determinada pela seguinte equação:

$$
\frac{1}{x}=b-k_{l} \log (t)
$$

onde $k_{l}$ é a constante da taxa logarítmica, $b$ é uma constante e $t$ é o tempo.

Quando o óxido atinge uma espessura de cerca de $100 \AA$ A, o campo elétrico não é suficientemente forte para induzir a migração dos íons. Após a formação de uma capa de óxido aderente, o metal fica separado do oxigênio e a oxidação se dará por difusão de uma das espécies através da película de óxido. Devido ao equilíbrio termodinâmico nas interfaces metal-óxido e óxido-oxigênio, as concentrações de metal (ou oxigênio) nas duas faces serão diferentes. Assim, o metal ou oxigênio difundirá devido ao gradiente de concentração, que é proporcional a $1 / x, \operatorname{com} x$ igual à espessura do óxido formado. A taxa de oxidação estará governada pela velocidade com que a espécie reativa (metal ou oxigênio) for transportada através do óxido, resultando em:

$$
\frac{d x}{d t}=k_{p} \frac{1}{x}
$$

A solução desta equação descreve uma cinética de crescimento parabólica dada por:

$$
x^{2}=\frac{1}{2} k_{p} t
$$

onde $k_{p}$ é a constante da taxa parabólica, que é dependente da temperatura $\mathrm{T}$ de acordo com a seguinte equação:

$$
k_{p}=A e^{\frac{-E_{a}}{R T}}
$$

onde $A$ é uma constante e $E_{a}$ e $T$ são a energia de ativação e a temperatura, respectivamente.

Quando a temperatura é alta suficiente para os íons difundirem sem a ajuda do campo elétrico, mas a espessura não é suficientemente grande para a cinética parabólica, o pro- 
cesso pode seguir uma lei cúbica ou linear [100], ou uma composição de vários comportamentos. O comportamento linear é obtido quando a taxa de oxidação é constante e controlada pela velocidade de reação, conforme a equação abaixo:

$$
\frac{d x}{d t}=k_{l i}
$$

resultando em:

$$
x=k_{l i} t
$$

onde $k_{l i}$ é a constante da relação linear.

\subsection{Implantação Iônica}

Implantação iônica tem sido largamente utilizada em indústrias e em diversas pesquisas nas áreas de materiais e fundamentos de estrutura da matéria.

Esta técnica emprega aceleradores de íons para direcionar feixes de íons energéticos sobre materiais. Além do controle preciso do número total de íons implantados, a implantação iônica tem como vantagens a possibilidade de serem atingidas concentrações superiores às concentrações de equilíbrio, possibilitando a introdução de uma grande quantidade de espécies atômicas diferentes, independentes de fatores termodinâmicos.

A energia empregada no processo de bombardeamento iônico encontra-se entre algumas dezenas de $\mathrm{keV}$ até alguns $\mathrm{MeV}$, com concentrações variando de $10^{11}$ a $10^{17}$ íons $/ \mathrm{cm}^{2}$. Para corrigir a produção de defeitos na estrutura do sólido durante a implantação iônica, usam-se processos térmicos para restaurar a ordem do material [71] e [72].

Neste trabalho foram implantados íons em metais com o objetivo de estudar como isso afeta o processo de oxidação de filmes de cobre.

\subsubsection{Perda de energia}

As alterações mais profundas nas propriedades de sólidos bombardeados com partículas carregadas são conseqüência da transferência de energia entre íons e alvo. Quando um feixe de íons energéticos incide sobre um alvo sólido ocorre uma grande variedade de processos, tais como ejeção de íons e elétrons para fora da superfície, cascatas de colisões e deslocamentos de átomos no interior do material, emissão de raios-X devido às excitações eletrônicas, etc. À medida que o íon vai penetrando no alvo há perda de energia, com 
consequënte geração de danos no material. De forma geral, a interação e a perda de energia de íons em movimento num meio material, pode ser classificada em 5 processos [101].

1. Freamento eletrônico. É uma interação de natureza inelástica, resultante das interações entre os íons incidentes e os elétrons do alvo, produzindo excitação eletrônica, transferência de carga, fônons, etc. Para íons com altas velocidades $v, \operatorname{com} v>>v o(v o$ = velocidade de Bohr dos elétrons atômicos) é o principal processo de perda de energia.

2. Interação entre os campos elétricos parcialmente blindados dos núcleos do projétil e do alvo. Ocorre em baixas velocidades quando o íon está parcialmente neutralizado. É denominado freamento nuclear. Neste processo, o íon transfere energia cinética para os átomos do alvo, sendo responsável pela produção de danos(deslocamentos de átomos da rede). Pode ocorrer a emissão de um quantum de radiação de freamento.

3. Interação direta entre as cargas nucleares do projétil e do alvo. Denominado espalhamento Rutherford, tem pouca importância no contexto do freamento iônico devido à baixa seção de choque.

4. Interação entre forças nucleares do projétil e do alvo. É um fenômeno raro e de alta energia. O íon precisa penetrar a eletrosfera e vencer o campo coulombiano nuclear. Tem pouca importância no contexto do freamento iônico.

5. Emissão de radiação de freamento. Acompanha todos os processos de freamento, tanto do íon quanto dos elétrons secundários.

Assim, para valores de energias utilizadas para implantação iônica visando a modificação de propriedades dos materiais, a perda de energia se dá através de colisões eletrônicas, resultando na excitação e na ejeção de elétrons e colisões nucleares, nas quais a energia é transferida como um movimento translacional para o átomo alvo.

Definindo $x$ como a distância a partir da superfície do material, a perda de energia de um íon em movimento num material(S, s ou $\varepsilon$ ) pode ser expressa de várias formas diferentes:

$$
S=-\frac{d E}{d x}
$$




$$
\begin{gathered}
s=-\frac{1}{\rho} \frac{d E}{d x} \\
\varepsilon=-\frac{1}{N} \frac{d E}{d x}
\end{gathered}
$$

onde $\rho$ é a densidade de massa e $\mathrm{N}$ é a densidade atômica do meio. O sinal negativo nas definições acima, gera um valor positivo para o poder de freamento uma vez que a energia diminui à medida que o íon penetra no material.

A perda total de energia será o resultado da soma das perdas eletrônica e nuclear de energia:

$$
\left(\frac{d E}{d x}\right)=\left(\frac{d E}{d x}\right)_{e}+\left(\frac{d E}{d x}\right)_{n}
$$

onde os índices e e $n$ representam a contribuição do freamento eletrônico e nuclear, respectivamente.

O tratamento teórico do poder de freamento acompanha os vários regimes de velocidade: Quando a velocidade do íon $v<<v_{0}$, sendo $v_{0}$ a velocidade de Bohr dos elétrons atômicos, predomina o freamento nuclear com o íon parcialmente neutralizado e o freamento é dominado pelas interações íon-alvo. À medida que a velocidade aumenta $\left(0,1 v_{0}<v<Z^{\frac{2}{3}} v_{0}\right)$, o freamento nuclear diminui $\left(S_{n} \propto 1 / \mathrm{E}\right)$ sendo rapidamente suplantado pelo freamento eletrônico crescente $\left(S_{e} \propto E^{\frac{1}{2}}\right)$. Em velocidades altas, quando $v>>Z^{2} v_{0}$ e a carga efetiva do íon alcança seu valor máximo (com o íon totalmente ionizado), a perda de energia pode ser adequadamente calculada pelo modelo de BetheBloch em que $S \propto Z_{1}^{2} Z_{2} M_{1} / E_{1} \cdot \ln \left(E_{1} / M_{1} Z_{2}\right)$. Acima de $10 \mathrm{MeV} / u$ é necessário considerar efeitos relativísticos. Na região de velocidades intermediárias, em que $v \sim v_{0}$, não existe um tratamento teórico adequado. Em geral, usam-se tabelas ajustadas em dados experimentais[102].

As curvas do poder de freamento em função da energia e da distribuição de íons de argônio em cobre são mostradas na Figuras 3.1 e 3.2. Em destaque é mostrado o comportamento para energias entre 1 e $10 \mathrm{keV}$.

Pela figura 3.1 podemos concluir que, inicialmente, ambas as componentes aumentam com o aumento da velocidade do íon. Nota-se também que o freamento nuclear é mais importante na desaceleração de íons com energias mais baixas, enquanto o freamento eletrônico predomina para íons com energias mais altas. 


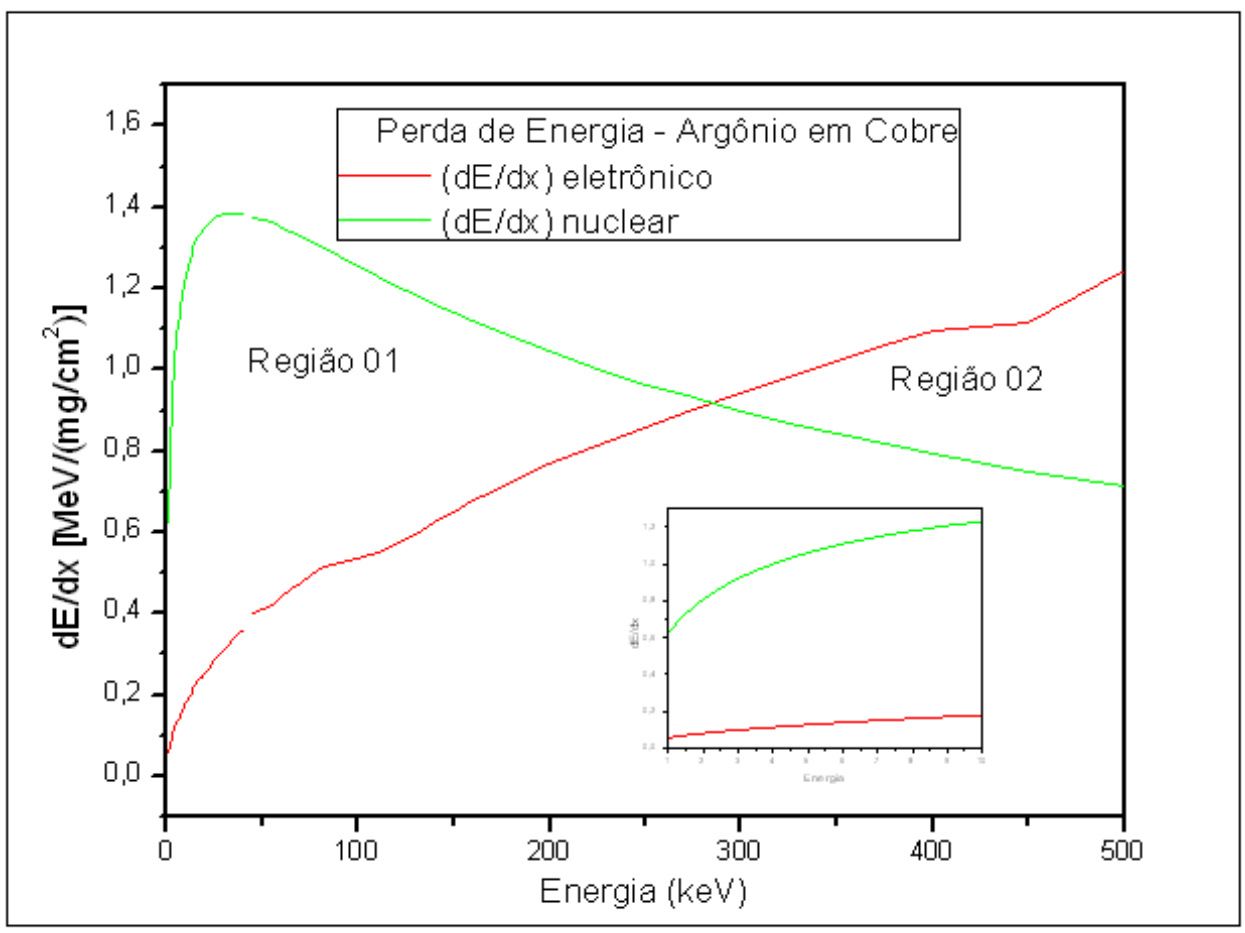

Figura 3.1: Poder de freamento eletrônico e nuclear para implantação de argônio em cobre

Desta forma, o íon percorre o sólido e é continuamente desacelerado por colisões com elétrons. Quando a energia do projétil é diminuída para algumas dezenas de keV, a seção de choque nuclear aumenta e o freamento nuclear torna-se-se o mecanismo mais importante, sendo responsável também pela dispersão angular do feixe de íons.

A figura 3.2 mostra a distribuição dos íons de argônio implantados em cobre, obtida através de simulação com o programa SRIM(The Stopping and Range of Ions in Matter) [103]. Pode ser observado que quando íons de argônio são implantados em cobre, a maior parte da energia desse íon é perdida entre a superfície e $100 \AA$ de profundidade.

A contribuição de cada um dos mecanismos em um processo de irradiação iônica é definida pelas características do alvo e pelos parâmetros utilizados no bombardeamento. Apesar de ser um fenômeno quântico e discreto, o grande número de eventos que ocorrem no freamento de um íon, permitem o tratamento macroscópico como se fossem eventos contínuos e a determinação de um valor médio para o poder de freamento. 


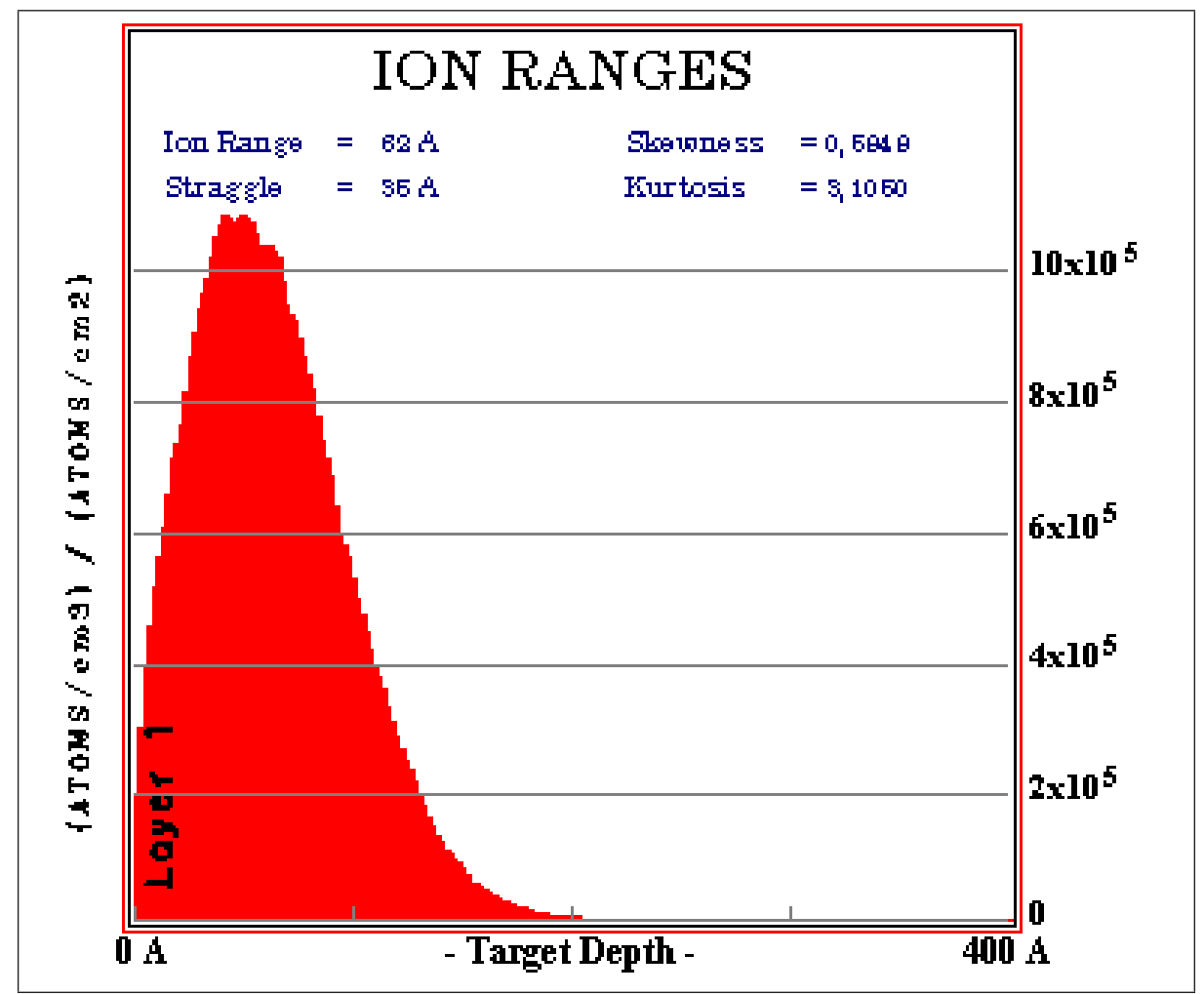

Figura 3.2: Distribuição dos íons de argônio implantados em cobre, com energia igual a $10 \mathrm{keV}$. 


\section{Capítulo 4}

\section{Materiais e Métodos}

Este capítulo apresenta-se uma breve descrição do processo de obtenção das amostras e dos métodos utilizados para a caracterização dos filmes. São discutidos também os princípios físicos envolvidos no funcionamento dos equipamentos utilizados.

Inicialmente será descrita a técnica de deposição, bombardeamento eletrônico, e a implantação iônica, realçando os aspectos físicos inerentes ao processo, que poderão explicar determinadas propriedades apresentadas pelos filmes.

A segunda parte deste capítulo foi reservada à descrição das várias técnicas utilizadas na caracterização dos filmes de cobre.

\subsection{Preparação das amostras}

Os filmes utilizados nos experimentos foram depositados sobre substrato de carbono e silício. A utilização de dois tipos de substratos foi necessária devida às especificidades dos métodos analíticos escolhidos. A escolha do carbono se deve ao fato de que é fundamental neste trabalho determinar a espessura do óxido crescido através da quantidade de oxigênio incorporada ao filme. Para que isso seja feito com precisão através de análises RBS é desejável que o pico correspondente a este átomo seja facilmente identificado e não esteja sobreposto a nenhum outro. Isso pode ser claramente observado nas Figuras 4.1 e 4.2 . Já o silício monocristalino foi utilizado na determinação da resistividade e verificação da aderência a este substrato, que constitui no material mais utilizado na fabricação de circuitos eletrônicos. Na escolha do método de deposição foi considerado o grau de 
contaminação dos filmes obtidos por variados métodos. Em função disto, escolheu-se a deposição por bombardeamento eletrônico.

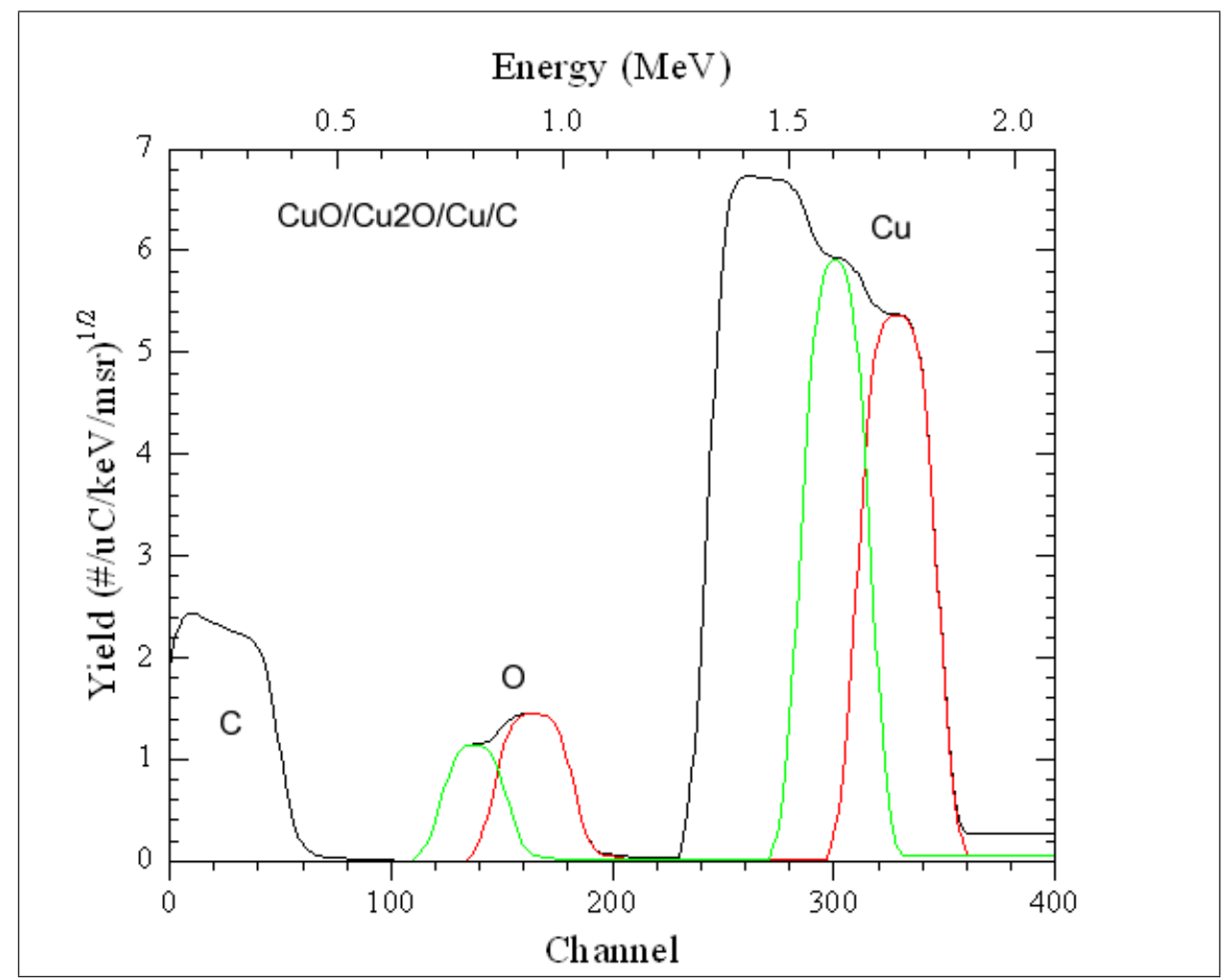

Figura 4.1: Simulação do espectro RBS da estrutura $\mathrm{CuO} / \mathrm{Cu} u_{2} \mathrm{O} / \mathrm{Cu}$ feita sobre substrato de carbono. As linhas vermelha e verde referem-se aos elementos $\mathrm{Cu}$ e $\mathrm{O}$ presentes nas camadas $\mathrm{CuO}$ e $\mathrm{Cu}_{2} \mathrm{O}$, respectivamente.

\subsubsection{Limpeza dos substratos}

Para a deposição dos filmes de cobre foram utilizados UDAC e silício (111) e (100). As lâminas de silício foram clivadas em formato quase retangular com dimensões de aproximadamente $1,5 \mathrm{~cm}$ por $1 \mathrm{~cm}$. Já as de carbono tiveram formatos e tamanhos variados. Antes de cada deposição os substratos foram limpos de acordo com a seguinte seqüência:

1. Imersão em água com detergente neutro, durante 20 minutos em ultra-som;

2. Enxague com água destilada;

3. Banho em ultra-som de álcool isopropílico por 10 minutos,

4. Lavagem rápida em água deionizada; 


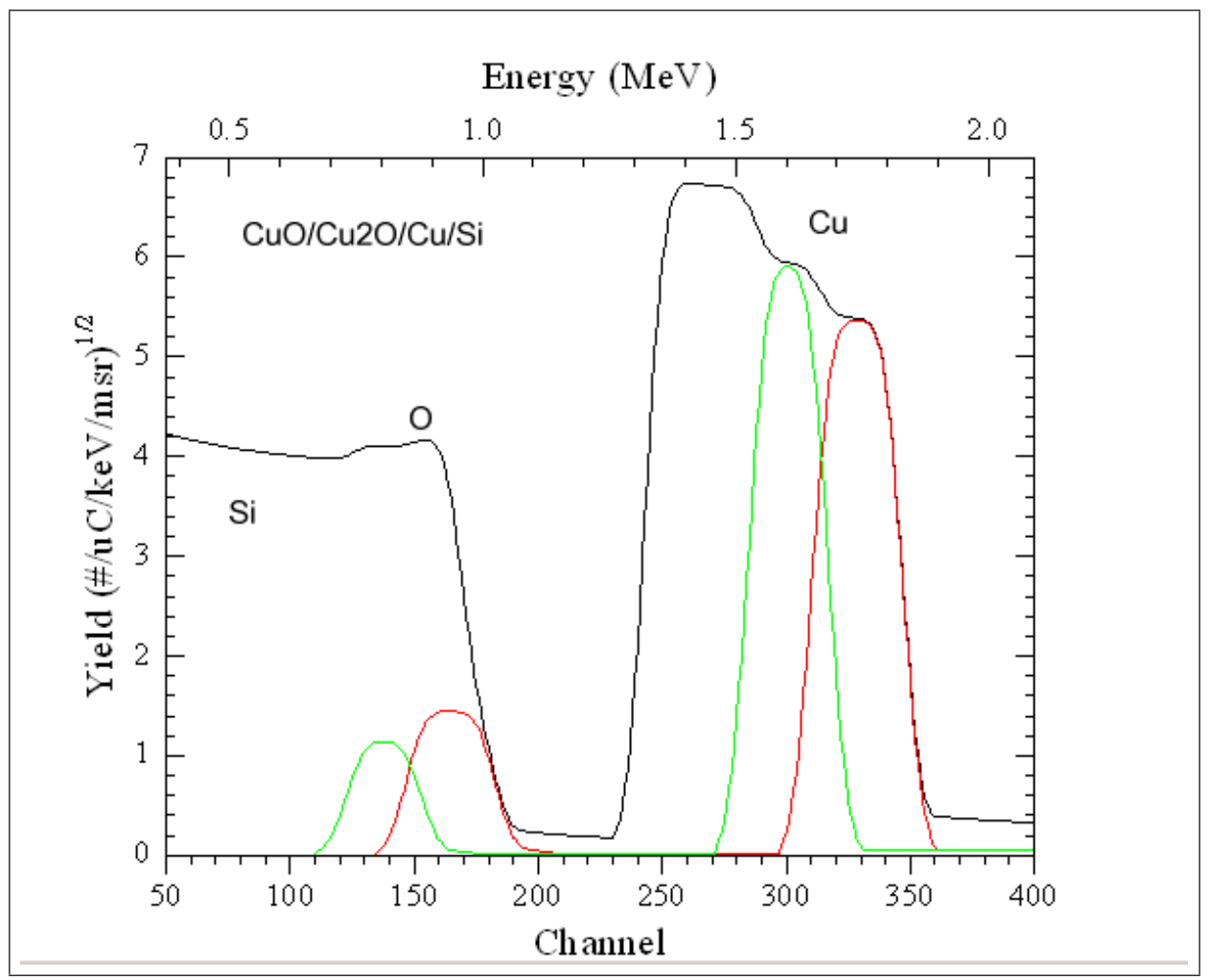

Figura 4.2: Simulação do espectro RBS de óxidos de cobre feitos sobre substrato de silício. As linhas vermelha e verde referem-se aos elementos $\mathrm{Cu}$ e $\mathrm{O}$ presentes nas camadas $\mathrm{CuO}$ e $\mathrm{Cu}_{2} \mathrm{O}$, respectivamente.

5. Secagem com jatos de nitrogênio seco. Em seguida, os substratos foram presos ao porta-substratos e colocados na câmara para evaporação.

O cobre 99.9\% utilizado na deposição tinha como contaminantes os seguintes elementos: $\operatorname{Ag}(0.02 \%), \operatorname{As}(0.002 \%), \mathrm{Fe}(0.005 \%), \operatorname{Mn}(0.001 \%), \operatorname{Pb}(0.001 \%), \operatorname{Sb}(0.001 \%)$, $\operatorname{Sn}(0.0001 \%)$ e $\mathrm{P}(0.001 \%)$. Para limpeza e remoção do óxido de cobre as lâminas passavam pelos seguintes processos:

1. Imersão em solução de tricloroacético por 5 minutos,

2. Enxague com água destilada,

3. Fricção com detergente neutro,

4. Enxague com água destilada,

5. Enxague com álcool isopropílico,

6. Lavagem em água deionizada e 
7. Secagem com jatos de nitrogênio seco. Após a limpeza, as lâminas foram dobradas com uma pinça e levadas ao cadinho.

\subsubsection{Bombardeamento eletrônico}

O bombardeamento eletrônico faz parte dos processos de deposição por fase vapor (PVD) e consiste basicamente de quatro etapas:

1. Aquecimento do material a ser depositado e conseqüente transformação do estado sólido para o estado gasoso;

2. Transporte do material até o substrato;

3. Condensação no substrato;

4. Processos de superfície ativados termicamente.

O aquecimento do material a ser depositado é feito através do bombardeamento de elétrons, gerados a partir do aquecimento de um filamento. A redução da temperatura de evaporação do material é obtida através da utilização de baixa pressão no ambiente, em geral $10^{-6}$ Torr. Com esta pressão, garante-se um livre caminho médio no interior da câmara de deposição suficientemente alto, bem superior à distância do cadinho ao porta substratos. O livre caminho médio pode ser expresso pela seguinte equação [104].

$$
x(\mathrm{~cm})=\frac{5 \cdot 10^{-3}}{\text { pressão }(\text { Torr })}
$$

Para uma molécula deixar a superfície do material, é necessário que a componente da força perpendicular à superfície seja maior que as forças intermoleculares. As moléculas que são desprendidas da superfície do material viajam no espaço em uma linha reta até encontrar uma outra molécula ou a superfície do substrato. Quando as moléculas encontram a superfície do substrato, que permanece em temperatura ambiente, há condensação, formando um filme. Para garantir que um número reduzido de colisões ocorra entre a fonte e o substrato, a concentração de moléculas que constituem a atmosfera residual deve ser baixa (alto vácuo). A quantidade de moléculas espalhadas, $N_{e}$, antes de atingir o substrato por colisões com moléculas da atmosfera residual depende do livre caminho médio e é obtida através da equação abaixo [104]: 


$$
\frac{N_{e}}{N_{0}}=1-\exp \left(\frac{-h}{x}\right)
$$

onde h é a distância do cadinho aos substratos e $N_{0}$ é o número de moléculas que são ejetadas da fonte.

Várias deposições de cobre foram feitas, com pressão base na câmara entre $2,0 \times 10^{-7}$ e $5 \times 10^{-6}$ Torr. Nestas condições, o livre caminho médio obtido através da equação 4.1 será de no mínimo 10 m. Substituindo este valor na equação 4.2, e, considerando que no arranjo experimental utilizado a distância cadinho-substrato é de $20 \mathrm{~cm}$, obtém-se $N_{e} / N_{0}$ $=2,0 \%$. Assim, de cada 100 moléculas que são ejetadas da superfície do material, no máximo duas colidem com outras moléculas do ambiente, nas condições trabalhadas.

\section{Descrição do sistema de deposição}

Três sistemas de bombardeamento eletrônico foram utilizados na confecção das amostras; uma Evaporadora Edwards E306 e um UNIVEX 450 da Leybold, instalados no Laboratório de Alvos do IFUSP e uma evaporadora Edwards, de mesmo modelo, instalada no Laboratório de Materiais Magnéticos. Somente o sistema da Leybold, mostrado na Figura 4.3 será descrito. Os outros sistemas funcionam de modo semelhante.

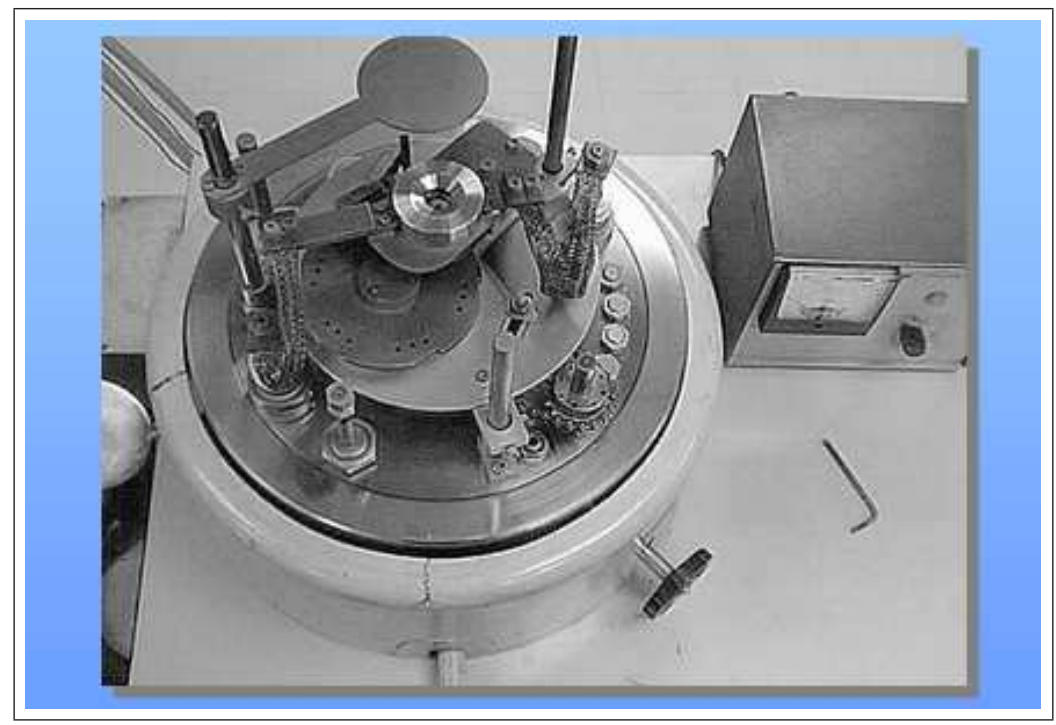

Figura 4.3: Interior da Evaporadora Leybold Univex 450.

Este sistema é composto de uma campânula no interior da qual há um suporte para substrato, um obturador, um suporte para os cadinhos e, diferentemente dos outros utilizados neste trabalho, há um cristal oscilador, que permite medir a taxa de deposição. No 
sistema existem dois medidores de pressão: um para alto vácuo, penning e um para baixo vácuo, pirani. Uma bomba mecânica e uma criogênica são utilizadas para evacuação do sistema, o que permite atingir uma pressão de $2 \times 10^{-7}$ Torr.

A pressão base foi no máximo $3 \times 10^{-6}$ Torr e foram feitas deposições de filmes de cobre. A distância entre os cadinhos e os substratos foi mantida fixa em $20 \mathrm{~cm}$ e a taxa de deposição ficou em torno de $110 \mu \mathrm{g} / \mathrm{s}$. Todos os filmes finos foram depositados sem aquecimento do substrato. Os cadinhos utilizados foram de carbono, escolhidos após a verificação de que tanto tântalo quanto tungstênio apresentaram alta reação com o cobre durante a deposição.

No segundo sistema de deposição, Edwards E 306 foram feitas as amostras multicamadas de $\mathrm{Cu} / \mathrm{Al} / \mathrm{C}$ e $\mathrm{Cu} / \mathrm{Al} / \mathrm{Si}$. O alumínio e o cobre foram evaporados subseqüentemente, sem quebra de vácuo. Nessa evaporadora, a ausência de um medidor de espessura dificultou o controle da quantidade de material depositado, que foi feito através do conhecimento da massa do material. Um controle aproximado foi utilizado a partir da equação que relaciona a espessura t com a massa $\mathrm{M}$ do material a ser evaporado.

$$
M=4 \pi h^{2} t \rho
$$

onde h é a distância entre o cadinho e os substratos e $\rho$ a densidade do material a ser depositado. Esse método não apresentou reprodutibilidade, havendo grande variação nas espessuras dos filmes obtidos.

Após a evaporação, o aumento da pressão na câmara para possibilitar sua abertura e retirada das amostras foi conseguido utilizando nitrogênio. Todo este cuidado tinha como objetivo reduzir possível oxidação dos filmes de cobre, uma vez que havia grande aquecimento durante as deposições prolongadas para obter as espessuras desejadas dos filmes.

\subsubsection{Implantação Iônica}

Neste trabalho, foram utilizados 4 implantadores iônicos para o estudo da passivação dos filmes de cobre por implantação iônica.

Um implantador iônico é constituído por uma fonte de íons, um sistema de aceleração e focalização do feixe, um sistema de varredura, responsável pela distribuição uniforme da implantação no alvo, uma fonte de alta tensão e um sistema de vácuo. Os íons são 
gerados em plasmas de catodo quente a partir de compostos na fase gasosa ou líquida que contenham a espécie química a ser implantada. A alimentação, necessária para o estabelecimento e a manutenção da descarga e da extração das diversas espécies iônicas formadas no plasma, é fornecida por uma fonte de alta tensão. Os íons são colimados e selecionados por sua curvatura em campo magnético. Isto permite a seleção dos íons com uma determinada razão carga-massa do feixe, tornando dispensável a utilização de materiais com alto grau de pureza.

O feixe é acelerado por um campo elétrico e focalizado sobre a amostra com o auxílio de lentes eletrostáticas. Na câmara de bombardeamento, a introdução e retirada das amostras é efetuada sem que haja quebra do vácuo. As irradiações são realizadas com o auxílio de um sistema de varredura eletrostática do feixe constituído por placas verticais e horizontais alimentadas por rampas de tensão triangulares. Isso garante alto grau de uniformidade e reprodutibilidade.

Inicialmente, as implantações foram realizadas em um implantador iônico Eaton GA4204, instalado no Centro de Componentes Semicondutores, CCS, da Faculdade de Engenharia Elétrica e de Computação, FEEC, da UNICAMP, no Laboratório de Microeletrônica da Escola Politécnica da USP e no Instituto de Física da UFRS. Na etapa final, as irradiações foram realizadas no LAMFI.

\subsubsection{Sistema de oxidação das amostras}

O sistema utilizado na oxidação das amostras consiste de uma placa aquecedora, marca Fisatom, modelo 501, que fornece até 250 W. À superfície desta placa foi colocado uma capela de alumínio, que permitiu maior estabilidade térmica. O controle automático de temperatura foi desativado e substituído por um Variac, um multímetro e um termômetro. Para a medição da temperatura foi utilizado um termômetro digital da Minipa, que permite medir temperaturas entre 50 e $1300{ }^{\circ} \mathrm{C}$, com resolução e precisão mostradas na tabela 4.1.

\subsection{Técnicas de caracterização das amostras}

Várias técnicas analíticas foram utilizadas na caracterização das amostras. Nesta seção será feita uma breve descrição das técnicas e das suas limitações e sensibilidade. 
Tabela 4.1: Características do sistema de medição da temperatura

\begin{tabular}{c|c|c}
\hline $\mathrm{T}\left({ }^{\circ} C\right)$ & Precisão $\left({ }^{\circ} C\right)$ & Resolução $\left({ }^{\circ} C\right)$ \\
\hline-50 a 199 & $\pm(0,2 \% L+1)$ & 0,1 \\
200 a 1000 & $\pm(0,4 \% L+2)$ & 1,0 \\
1000 a 1300 & $\pm(0,6 \% L+2)$ & 1,0
\end{tabular}

\subsubsection{Análise por Retro-espalhamento Rutherford}

A espectrometria por retro-espalhamento Rutherford é um método não destrutivo de análise de materiais que emprega íons com energias entre 0,5 e $3 \mathrm{MeV} / u$ para determinação da composição atômica de materiais. É possível a detecção de concentrações tão baixas quanto $10^{15}$ átomos $/ \mathrm{cm}^{2}$, dependendo da composição e do perfil de distribuição dos elementos na amostra.

\section{Fundamentos da técnica}

A técnica de análise por RBS consiste em medir a energia de partículas retro-espalhadas, provenientes de um feixe monoenergético, que sofreram colisões com os átomos do alvo. Durante a colisão, os íons incidentes perderão energia por colisões com os átomos do material. Como foi dito, essa perda de energia da partícula espalhada depende da razão das massas da partícula incidente e do átomo alvo. A determinação da energia da partícula retroespalhada permite identificar a massa dos átomos do alvo e, portanto, qual o elemento químico correspondente. Identificado o átomo alvo, a sua espessura em átomos $/ \mathrm{cm}^{2}$ pode ser determinada pela probabilidade de colisão entre as partículas incidentes e os átomos do alvo, medindo-se o número total de partículas detectadas, A, para um certo número Q de partículas incidentes, que é medido pela corrente do feixe. A relação entre A e Q é dada pela seção de choque de espalhamento. Além disto, uma vez que o íon perde energia continuamente ao longo de seu percurso no interior da amostra, a distância à superfície do local onde ocorreu a colisão também pode ser determinada. Dessa forma a espectroscopia RBS pode ser usada para determinar a composição atômica e seu perfil em profundidade numa amostra. Essa técnica é muito adequada para medir a concentração de oxigênio incorporado em filmes; especialmente quando os filmes são depositados em substratos de carbono, conforme foram vistos nas figuras 4.1 e 4.2 . 
No arranjo experimental típico esquematizado na Figura 4.4, um feixe monoenergético, colimado por um conjunto de fendas é dirigido sobre uma amostra a ser analisada. As partículas do feixe espalhadas pela amostra são detectadas em ângulo traseiro, $\theta$. A análise da energia da partícula retro-espalhada fornece informações sobre o alvo e sobre a localização deste alvo ao longo da espessura da camada analisada.

Além do ângulo de espalhamento $(\theta)$, os principais parâmetros experimentais são: a intensidade e a energia das partículas no feixe, a inclinação da amostra e o ângulo sólido de detecção $\Omega$.

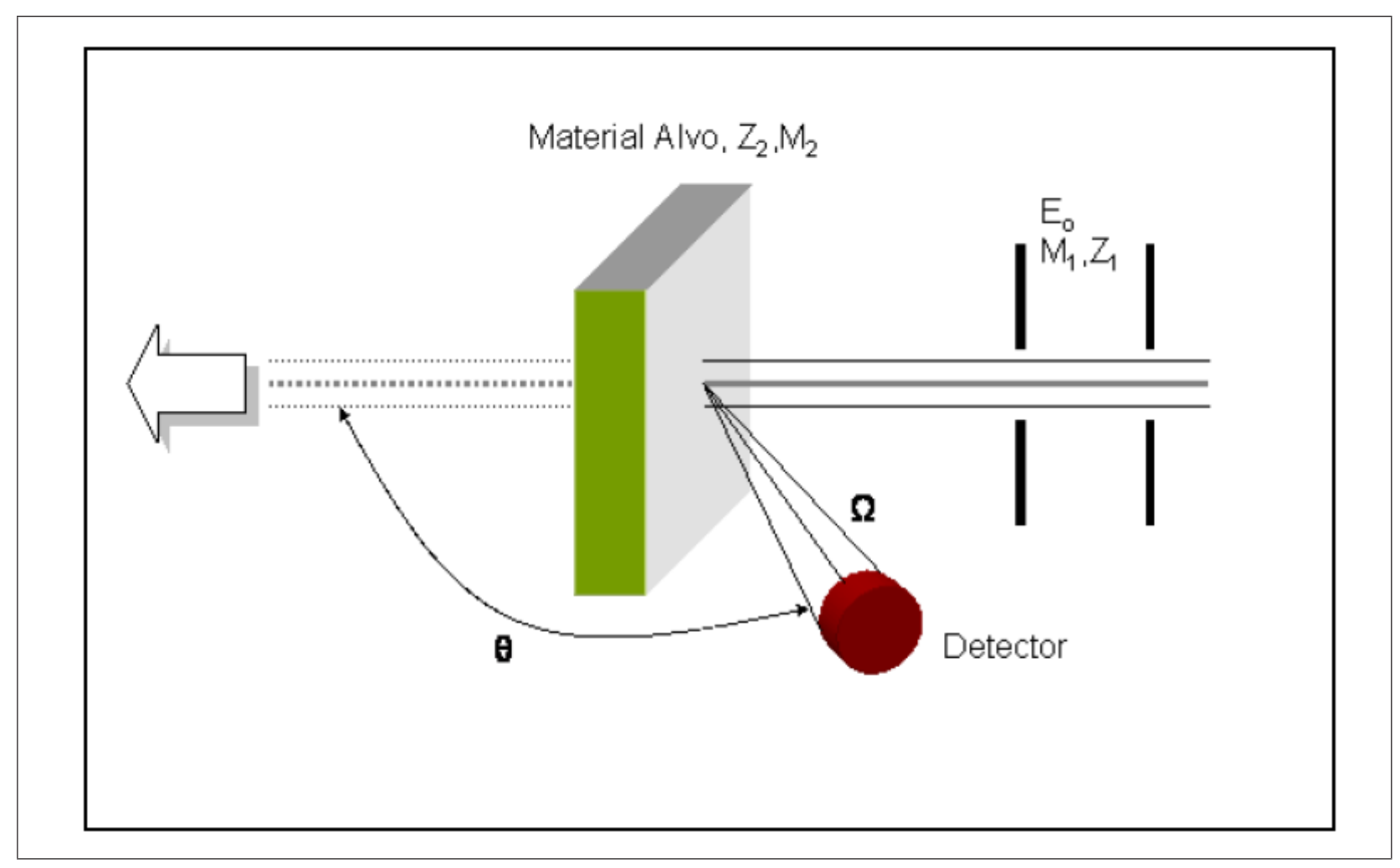

Figura 4.4: Retro-espalhamento de um feixe colimado de íons, com massa $M_{1}$, incidindo numa amostra com átomos de massa $M_{2}>M_{1}[102]$

Nas condições das análises por RBS, a colisão entre partículas do feixe e átomos do alvo pode ser descrita como um espalhamento clássico em um campo de forças central entre duas massas puntiformes com carga positiva. A cinemática da colisão é independente de ligações eletrônicas e, portanto, insensível ao estado químico da amostra. Numa colisão elástica, a conservação da energia e do momento linear permitem calcular a razão entre a 
energia da partícula espalhada, $E_{1}$ e sua energia inicial, $E_{0}$ denominada fator cinemático $K_{1}$, conforme a equação 4.4 .

$$
K_{1} \equiv \frac{E_{1}}{E_{0}}=\left[\frac{\left.\left[1-\left(M_{1} / M_{2}\right)^{2} \cdot \sin ^{2} \theta\right)\right]^{1 / 2}+\left(M_{1} / M_{2}\right) \cdot \cos \theta}{1+\left(M_{1} / M_{2}\right)}\right]^{2}
$$

Para $\theta=180^{\circ}$, obtém-se:

$$
K_{1}^{180}=\frac{M_{2}-M_{1}}{M_{2}+M_{1}}
$$

Nas análises das amostras deste trabalho foi utilizado feixe de $\mathrm{He}^{+}$e detectou-se o espalhamento a $170^{\circ}$ e a $120^{\circ}$, em relação ao feixe incidente, devido às características físicas do feixe e do detector, pois a máxima transferência de energia (colisão frontal) ocorre quando $\theta=180^{\circ}$ e é dada pela equação 4.6.

$$
E_{2}^{180}=E_{0}-E_{1}^{180}=E_{0} \frac{4 M_{1} M_{2}}{\left(M_{1}+M_{2}\right)^{2}}
$$

Considerando uma amostra de cobre e oxigênio, obtém-se uma diferença relativa entre o resultado dado pela equação 4.5 e nossas condições experimentais $\left(\theta=170^{\circ}\right)$ de no máximo $0,7 \%$.

A colisão frontal é a condição de máximo da derivada $\delta K_{1} / \delta M_{2}$ onde ocorre o máximo de $\delta E / \delta M_{2}$ e, portanto, o maior poder de discriminação de massas atômicas.

Considerando-se que a camada espalhadora possui uma espessura x, um evento de espalhamento na superfície frontal do filme será detectado com uma energia $K E_{0}$, enquanto o mesmo evento de espalhamento ocorrido na interface final do filme é detectado com uma energia menor. Eventos que ocorrem em uma região intermediária entre a superfície frontal e final são registrados com energias intermediárias. É com base neste comportamento que o perfil de distribuição das espécies químicas presentes no alvo é determinado por RBS.

O conhecimento do fator cinemático e da perda de energia permite determinar qualitativamente a composição da amostra. A análise quantitativa depende da probabilidade do projétil sofrer uma colisão nuclear elástica com um átomo do alvo, ser retro-espalhado e detectado em um ângulo sólido, isto é, depende da seção de choque.

O número de partículas detectadas, A, está relacionado à seção de choque $(\sigma)$ por:

$$
A(\theta)=\sigma \Omega Q \cdot \rho . t
$$

onde Q é o número total de partículas incidentes, $\Omega$ o ângulo sólido e $\rho . t$ o número de átomos de uma espécie por unidade de área na amostra. 


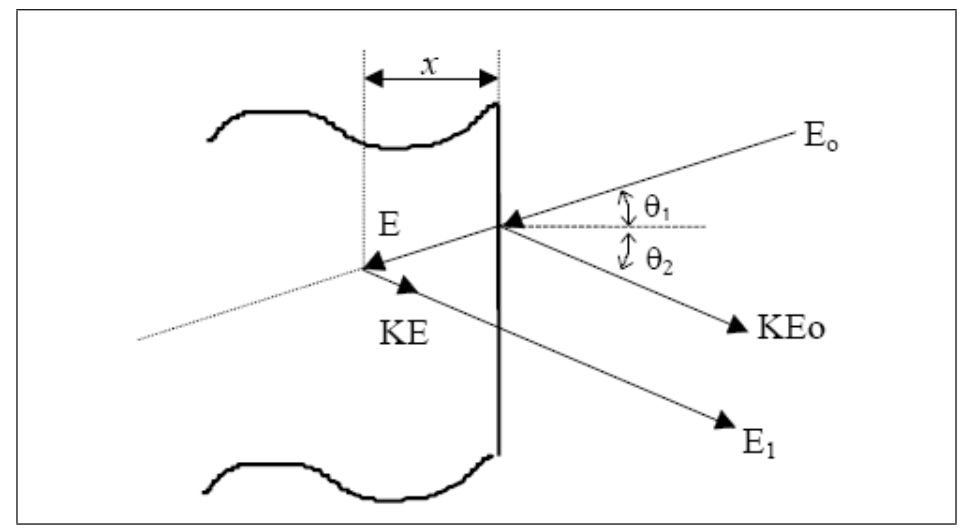

Figura 4.5: Diagrama esquemático mostrando o fator cinemático

A secção de choque correspondente é a do espalhamento em campo central coulombiano, dada, no centro de massa, pela equação[105]:

$$
\frac{d \sigma}{d \Omega}\left(E_{c}, \theta_{c}\right)=\left(\frac{1}{4 \pi \epsilon_{0}}\right)^{2}\left(\frac{Z_{1} Z_{2} e^{2}}{4 E_{c}}\right)^{2} \frac{1}{\sin ^{4}\left(\frac{\theta_{c}}{2}\right)}
$$

A principal fonte de incertezas na equação da determinação da espessura da amostra é a carga integrada, geralmente medida com $3 \%$ de erro. Na ausência de um fundo contínuo significativo, basta ter mais de 5000 contagens, para que a espessura elementar possa ser obtida de forma absoluta com precisão da ordem de 3\%. Isso não ocorre em casos como o mostrado na Figura 4.2, onde o sinal do oxigênio está sobreposto ao intenso fundo contínuo do substrato de silício $\left(M_{S i}>M_{O}\right)$. Para medir elementos leves, tais como oxigênio e nitrogênio é recomendável depositar o filme sobre um substrato leve, de carbono, como mostrado na Figura 4.1. Quando possível, foi adotado esse procedimento.

As medidas RBS foram realizadas no Laboratório de Análises de Materiais por Feixes Iônicos(LAMFI), com o acelerador tipo Pelletron-Tandem de 3 MV. Foi utilizado um feixe de $H e^{+}$de 2.2 a $2.4 \mathrm{MeV}$, incidindo a $90^{\circ}$ em relação à superfície do filme. As partículas retroespalhadas foram detectadas em dois detectores de barreira de superfície de Si posicionados a $120^{\circ}$ e $170^{\circ}$ em relação à direção ao feixe incidente. A resolução em energia dos detectores é de $22 \mathrm{keV}\left(170^{\circ}\right)$ e de $27 \mathrm{keV}\left(120^{\circ}\right)$. Estes detectores são conectados à eletrônica de amplificação e a um multicanal que permitem determinar a energia das partículas retro-espalhadas. A calibração da carga integrada é feita utilizando um copo de Faraday posicionado no fundo da câmara. A medida de carga integrada é feita comparando a medida da carga total que chegou ao copo de Faraday com o número de íons retroespalhados e detectada pelo detector. 
Os resultados experimentais foram analisados utilizando o programa RUMP (Rutherford Universal Manipulation Package, www.genplot.com), para obter os valores da espessura e a composição dos filmes. Este programa contém os conceitos físicos necessários a uma análise de RBS. É introduzido um modelo de composição que deve aproximar dos valores experimentais através de várias iterações que têm como objetivo aproximar o ajuste teórico aos valores experimentais. Esse ajuste teórico contém entre outros fatores, os elementos que compõem a amostra, as quantidades em que eles estão presentes, a sua distribuição em profundidade na amostra e a não uniformidade na espessura. O erro máximo na determinação da composição varia entre 5 e 10\% devido a incerteza existente no poder de freamento. A resolução em profundidade é de $100 \AA$ A. Esta técnica mede espessuras em unidades de átomos $/ \mathrm{cm}^{2}$, convertidos em espessuras de filme através da densidade deste.

Antes das medidas foi feita a calibração em energia do multicanal para os parâmetros usados nas medidas, utilizando-se padrões de referência de uma amostra composta por $T i+$ $A l+T a$. Na análise dos filmes empregou-se esta técnica para quantificar a concentração atômica de cada elemento das amostras.

RBS é uma poderosa técnica de análise, mas como toda técnica de análise tem suas limitações. Quantificar elementos leves cujo sinal está sobreposto ao mais pesado(O e Si, figura 4.2) torna a análise complexa e diminui o grau de precisão; discriminar dois elementos vizinhos na tabela periódica é tarefa quase impossível; determinar contaminação desconhecendo o histórico da utilização do sistema de deposição também não é simples. Como forma de aumentar a confiabilidade do método dois procedimentos foram adotados: utilização de substrato de carbono, quando possível, e a combinação com o método PIXE para determinar possível contaminação resultante dos processamentos. Desta maneira, aliou-se a sensibilidade e o perfil em profundidade da análise RBS com o melhor poder de discriminação do método PIXE.

\subsubsection{O Método PIXE}

O método PIXE é um poderoso método não destrutivo de análise elementar. Neste método induz-se a emissão de raios-X característicos de uma amostra(em vácuo ou não), irradiando-a com um feixe de íons, geralmente prótons ou partículas alfa com energia entre 1 e $2 \mathrm{MeV} / \mathrm{u}$ de energia. Para a detecção dos raios-X usa-se um detetor de estado 
sólido tipo $\mathrm{Si}(\mathrm{Li})$, com um absorvedor de raios-X entre a amostra e o detetor. O sinal é armazenado em um analisador multicanal. O método PIXE é capaz de identificar e quantificar elementos com $Z>10$, com limite de detecção de $1.0 \mu \mathrm{g} / \mathrm{g}(\mathrm{ppm})$, ou $10^{14}$ átomos $/ \mathrm{cm}^{2}$ no caso de filmes finos, e precisão absoluta de 5 a $30 \%$. Existem detectores sem janela ou com janela ultra fina, que permitem reduzir ainda mais o limite inferior elementar acessível.

O arranjo PIXE do LAMFI utiliza detectores $\mathrm{Si}(\mathrm{Li})$, com janela de Be.

\section{Fundamentos da técnica}

No método PIXE, a ionização de orbitais atômicos é realizada com um feixe de íons com energia entre 1 e $2 \mathrm{MeV} / \mathrm{u}$. Fótons característicos com energia entre 0,1 a $60 \mathrm{keV}$ podem ser emitidos quando vacâncias em camadas K, L ou M são preenchidas espontaneamente com elétrons mais periféricos. A energia das linhas emitidas segue a lei de Moseley, que estabelece uma relação unívoca e monótona entre o número atômico elementar e a energia da radiação característica. As transições radioativas observadas são, em sua maioria, transições de dipolo cujas regras de seleção são dadas por:

$$
\Delta l \neq 0, \quad \Delta j=0, \pm 1 \quad \text { com } j=l \pm|s|
$$

onde $l$ é o momento angular orbital, s é o momento angular de spin, e j é o momento angular total.

No método PIXE, as transições eletrônicas de interesse são determinadas pela região útil do detector $\mathrm{Si}(\mathrm{Li})$, entre 1,2 e $30 \mathrm{keV}$. Assim, são medidas as linhas K para elementos com $10<Z<40$ e as linhas L para elementos com $Z>30$.

$\mathrm{Na}$ análise PIXE de um filme fino, o número de raios-X detectados, $N_{x}$, é proporcional à quantidade $t_{z}$ em átomos $/ \mathrm{cm}^{2}$ da espécie química com número atômico $\mathrm{Z}$ presente na amostra e à carga coletada Q, conforme pode ser visto pela equação 4.10.

$$
N_{x}(z)=\frac{\Omega}{4 \pi} \sigma_{x} T t_{z} \frac{Q}{q e}
$$

onde $\Omega$ é o ângulo sólido do detector, $\sigma_{x}$ a seção de choque de produção de raios-X característicos, $\xi$ a eficiência do detector, T é a transmitância para raios-X dos absorvedores colocados entre a amostra e o detector, q é o estado de carga da partícula incidente e é a carga do elétron. 
Definindo-se o rendimento efetivo para raios-X, $Y_{\text {ef }}$, como:

$$
Y_{e f}=\frac{\Omega}{4 \pi} \sigma_{x} \xi T \frac{1}{q e}
$$

a equação 4.10 pode ser reescrita como:

$$
t_{z}=\frac{1}{Y_{e} f}\left(\frac{N_{x}}{Q}\right)
$$

Conforme podemos concluir pela equação 4.11, o rendimento efetivo depende apenas de parâmetros do arranjo experimental e de grandezas físicas fundamentais. Na prática, esta grandeza é determinada por meio de calibração com amostras de espessura $t_{z}$ conhecida, a partir da equação 4.12 .

O sistema PIXE do LAMFI é composto por um acelerador eletrostático tipo PelletronTandem, modelo 5SDH, fornecido pela NEC, Nacional Electrostatic Corporation, que alcança até 1.7 MV de tensão no terminal, uma fonte de íons SNICS( Source of Negative Ions sputtering by Cesium), uma câmara de análise de alto vácuo e dois detectores $\mathrm{Si}(\mathrm{Li})$. O atual arranjo PIXE do LAMFI permite a obtenção dos espectros PIXE e RBS concomitantemente. Assim, as condições experimentais adotadas nas análises PIXE foram as que possibilitaram melhores resultados nas análises RBS. Foi utilizado um feixe de $\mathrm{He}^{+}$ de 2.2 a $2.4 \mathrm{MeV}$, incidindo a $90^{\circ}$ em relação à superfície do filme.

Maior detalhamento sobre esta técnica pode ser encontrado nas referências [106] e [107].

\subsubsection{Perfilometria}

Um perfilômetro é um equipamento que determina e mede o perfil da superfície do filme mediante o contato e deslizamento de uma ponta de diamante sobre essa superfície. Um desenho do equipamento usado neste trabalho é mostrado na Figura 4.6. Este equipamento é acoplado a um computador para controle, aquisição e processamento de dados.

A medida é feita eletromecanicamente pelo movimento da agulha com a ponta de diamante sobre a amostra e as variações na topografia são apresentadas na tela de um computador. A agulha é conectada mecanicamente a um núcleo de ferro situado no centro de um transformador diferencial variável linear (LVDT), conectado a um suporte com controle de movimento de alta precisão, que move o LTDV e conseqüentemente a agulha sobre a amostra, numa velocidade e extensão pré-estabelecidas pelo usuário. A amplitude 


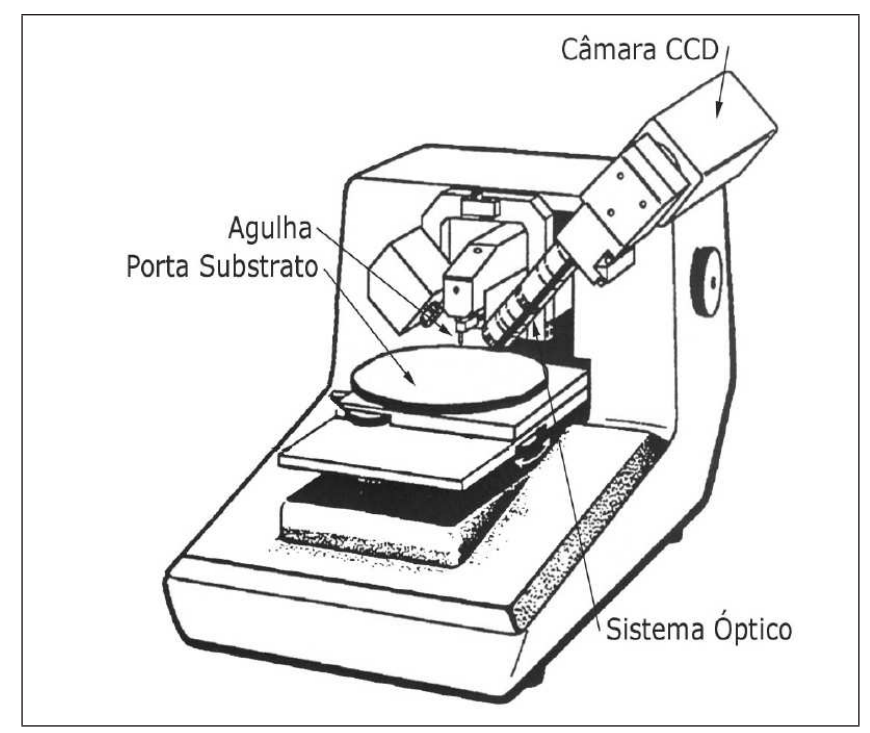

Figura 4.6: Desenho do perfilômetro

da tensão alternada de saída de um LTDV é proporcional ao deslocamento relativo do núcleo de ferro. Com o movimento da agulha, as variações no perfil da superfície causam um deslocamento vertical e conseqüentemente um sinal do LTDV proporcional a esse deslocamento. O sinal analógico do LVDT é transformado em um sinal digital por um conversor analógico-digital de alta precisão, e transferido para um computador. Através do computador, que roda os programas de controle dos parâmetros de varredura, análise e manipulação dos dados obtidos, é fornecido ao usuário um gráfico do deslocamento vertical da agulha em função da distância percorrida na amostra (perfil da superfície).

Para as medidas por perfilometria, foram utilizadas amostras cuja a existência de uma zona descoberta sem filme depositado, resultado de um efeito de máscara durante a deposição, possibilitou traçar o perfil em forma de degrau da zona do filme para o substrato. As análises foram feitas com um perfilômetro marca Veeco Instruments Inc, modelo Dektak 3, com alcance vertical de 0,01 a 65,5 $\mu \mathrm{m}$, resolução vertical 1,0 nm, alcance horizontal: 50 a $30000 \mu m$ e agulha com ponta de diamante, cujo raio é $5 \mu m$.

\subsubsection{O Método de quatro pontas}

O método de quatro pontas é uma técnica de análise que permite medir a resistividade folha de uma amostra através da passagem de corrente entre as pontas externas e a medida da diferença de potencial entre as duas pontas internas.

Considerando que a resistência de um material é dada por: 


$$
R=\rho \frac{d x}{A}
$$

Em um filme fino cuja espessura é muito menor que o espaçamento entre as pontas $(t<<a)$, conforme a figura 4.7 teremos:

$$
R=\int_{x_{1}}^{x_{2}} \rho \frac{d x}{2 \pi t x}=\int_{a}^{2 a} \rho \frac{d x}{2 \pi t x}=\frac{\rho}{2 \pi t} \ln 2
$$

Assim, a resistividade da amostra será:

$$
\rho=\frac{\pi t}{\ln 2}\left(\frac{V}{I}\right)
$$

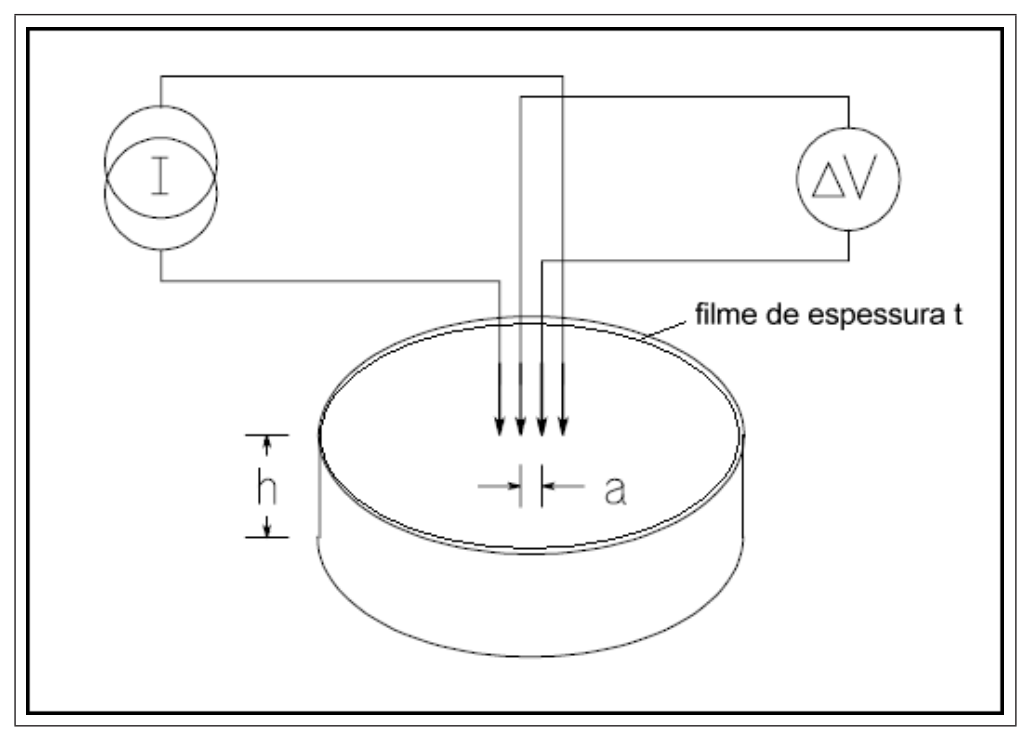

Figura 4.7: Esboço de um arranjo para medida da resistência folha, ilustrando a técnica.

As medidas de resistência folha foram realizadas no Laboratório de Microeletrônica e no de Sistemas Integráveis da Escola Politécnica da USP, em equipamento Four Point Probe FPP 5000 da Veeco Instruments Inc. Este equipamento é constituído de quatro pontas de tungstênio, espaçadas a $0,5 \mathrm{~mm}$ acoplado a uma fonte de corrente e um voltímetro.

\subsubsection{Difração de raios-X}

Difração de raios-X é uma eficiente técnica analítica que tem sido amplamente usada para identificar e caracterizar materiais cristalinos. É uma técnica não destrutiva, dispensa métodos complexos de preparação das amostras e possibilita análises de materiais constituídos de uma mistura de fases. 
Filmes finos preparados por bombardeamento eletrônico podem ser policristalinos ou amorfos, dependendo do material depositado e das condições de preparação. Nos filmes policristalinos cada um dos grãos pode apresentar uma orientação cristalográfica diferente da do seu vizinho, mas observando os grãos como um todo, estes podem estar distribuídos aleatoriamente em relação a um determinado plano de referência ou podem apresentar-se segundo uma ou várias orientações particulares. Neste último caso, o filme apresenta uma orientação cristalográfica preferencial ou textura.

Feixes de raios-X monocromáticos são usados para determinar os espaçamentos interplanares dos filmes a serem analisados. Quando as condições de Bragg, equação 4.16, para interferência construtiva são obtidas, um máximo de intensidade é produzido.

$$
n \lambda=2 d_{h k l} \cdot \operatorname{sen} \theta_{h k l}
$$

onde:

$\mathrm{n}=$ ordem de difração

$\lambda=$ comprimento de onda dos raios-X incidentes

$d_{h k l}=$ distância interplanar

$\theta_{h k l}=$ é o semi-ângulo de difração, medido em relação à direção dos raios-X incidentes.

Nos espectros obtidos pela técnica de XRD, as posições e intensidades dos picos fornecem informações importantes sobre o material analisado, permitindo a obtenção de dados sobre as estruturas cristalinas, tais como, grupos espaciais, coordenadas atômicas, porcentagem de ocupação e de substituição de sítios, parâmetros de rede, além da quantificação das fases presentes, incluindo as amorfas. Já a largura dos picos permite a determinação do tamanho dos cristalitos e das distorções na rede cristalina.

O esquema de um espectrômetro de difração de raios-X é representado na Figura 4.8.

Em uma análise de difração de raios-X podem ser variados dois parâmetros: $\lambda$ e $\theta$. O difratômetro utilizado neste trabalho mantém fixo o comprimento de onda $\lambda$ (feixe de radiação monocromática de $C u K_{\alpha}$ ) enquanto o ângulo $\theta$ é variado. No modo $\theta-2 \theta$, o ângulo de incidência $\alpha$ é posicionado sucessivamente em valores de $\theta$ e para cada um destes, o detector é posicionado sincronizadamente na direção de difração $2 \theta$, registrando

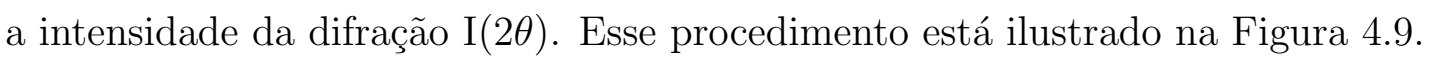




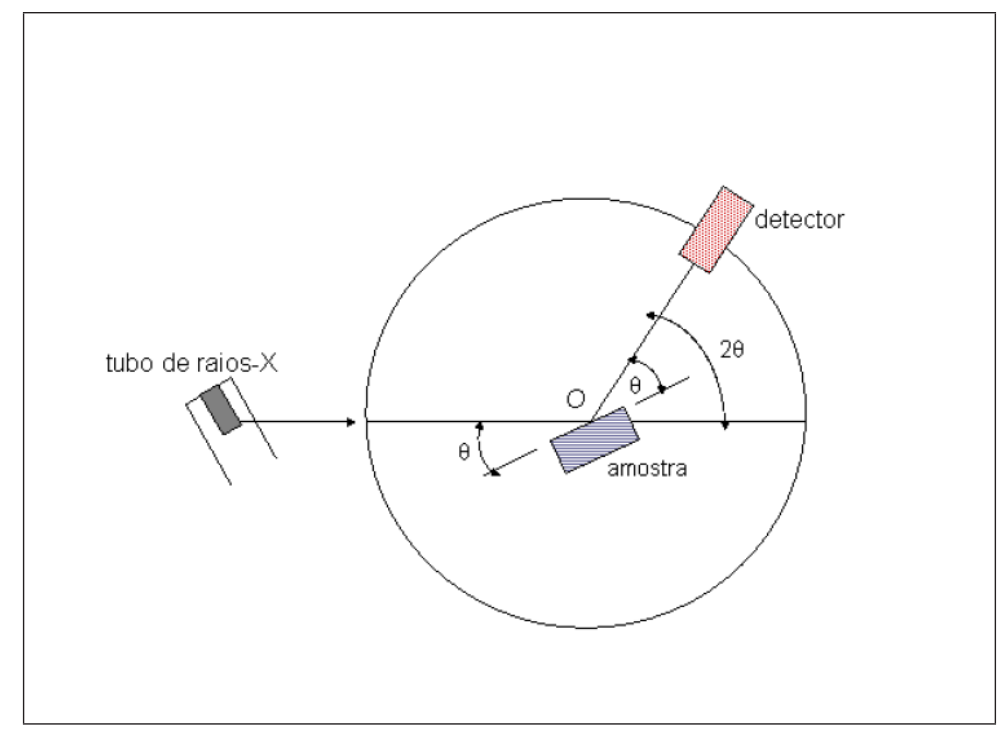

Figura 4.8: Esquema de um espectrômetro de difração por raios-X

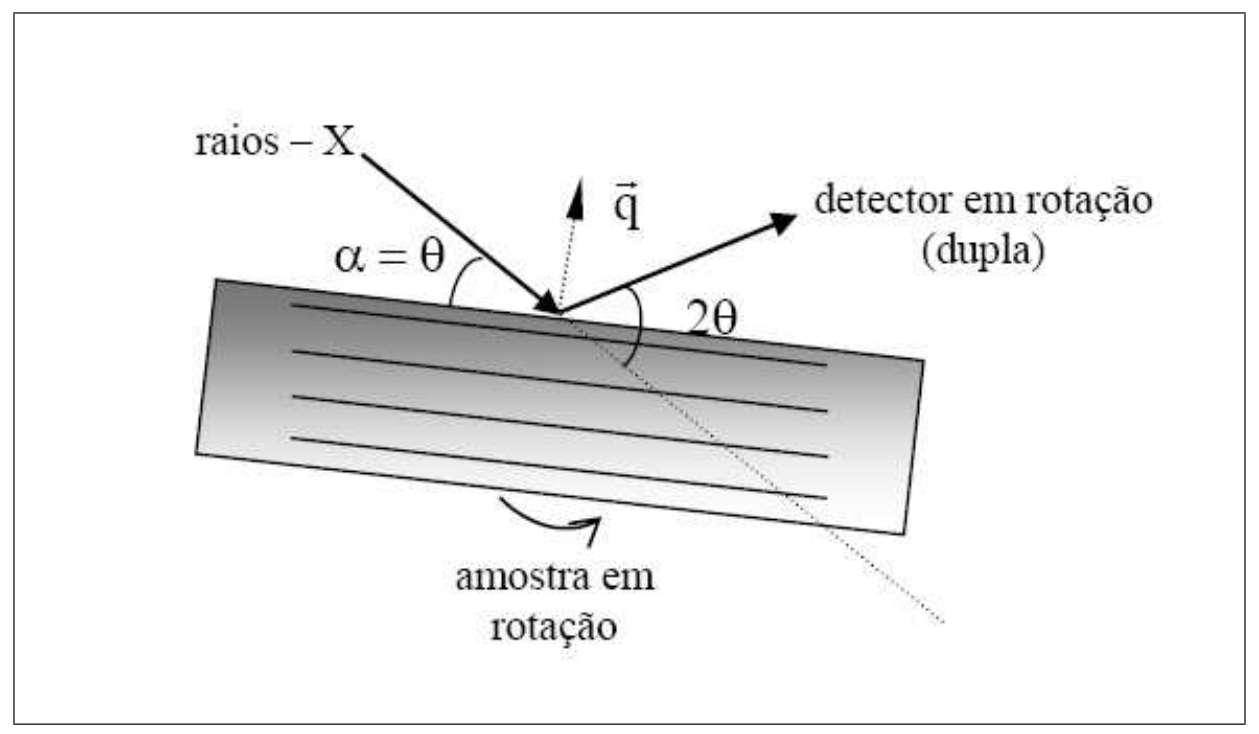

Figura 4.9: Modo $\theta-2 \theta$

O tamanho médio de cristalitos, $D_{h k l}$, dado pela equação de Scherrer [108], pode ser obtido a partir da largura a meia altura do pico de difração, descontando-se a radiação de fundo.

$$
D_{h k l}=\frac{0,9 \lambda}{\beta \cos \theta_{h k l}}
$$

onde $\beta$ é o alargamento causado pelo efeito de tamanho de grão

As medidas de difração por raios-X foram realizadas em um difratômetro Rigaku com tubo de cobre $(\lambda=1,542)$, pertencente ao Laboratório de Cristalografia do IFUSP. Todas as medidas foram realizadas no modo Bragg-Brentano $(\theta, 2 \theta)$. 


\subsubsection{Espectroscopia Raman}

A espectroscopia Raman é uma técnica de espectroscopia vibracional usada na determinação da estrutura molecular e na identificação e quantificação de materiais.

No espalhamento Raman, uma radiação no visível ou ultravioleta interage com a molécula e é espalhada com freqüência ligeiramente modificada.

Esse espalhamento inelástico da luz se dá através da interação entre a onda eletromagnética, que constitui a luz incidente, e a estrutura cristalina ou molecular. Nessa interação, um fônon pode ser criado ou aniquilado de modo que o valor da energia do fônon da rede será subtraído ou acrescentado à energia da luz espalhada. Assim, ao se obter a curva de intensidade de espalhamento em função da freqüência da luz espalhada será possível observar picos posicionados em diferentes freqüências, $\omega$ :

$$
\omega=\omega_{0} \pm \omega_{n}
$$

onde $\omega_{o}$ corresponde à freqüência da luz incidente e $\omega_{n}$ às freqüências dos modos normais de vibração da rede [109].

As análises por espalhamento Raman foram realizadas no Instituto de Física da Universidade Federal do Ceará. Foi utilizado um espectrômetro T-64000 da Jobin-Yvon, que possui detector CCD, refrigerado com nitrogênio líquido e um sistema micro-Raman, com lente, cuja distância focal é $20,5 \mathrm{~mm}$ e abertura numérica $\mathrm{NA}=0,35$. A luz incidente foi proveniente de um laser de argônio $(514,5 \mathrm{~nm})$ e a potência do laser sobre a amostra foi de $10 \mathrm{~mW}$.

\subsubsection{Microscopia de força atômica}

A microscopia de força atômica, AFM, é uma técnica que permite determinar a imagem topográfica de uma amostra.

O microscópio é composto basicamente por uma pequena ponta, que pode ser de $\mathrm{Si}$, $S i_{3} N_{4}$ ou diamante, presa a um cantilever que varre a superfície da amostra, através de uma cerâmica piezoelétrica que a movimenta. Um laser incide sobre o cantilever e é refletido para um conjunto de fotodetectores. O sinal elétrico obtido é realimentado para o computador mantendo constante a deflexão do cantilever (modo de contato) ou a amplitude de oscilação (modo contato intermitente ou não-contato). As correções na altura 
z são então gravadas juntamente com as respectivas posições x,y da amostra, gerando a imagem topográfica.

As forças de interação acontecem entre a ponta e os átomos da superfície da amostra analisada, provocando a deflexão do cantilever. Esta interação resultante pode ser atrativa ou repulsiva como é mostrado na figura 4.10.

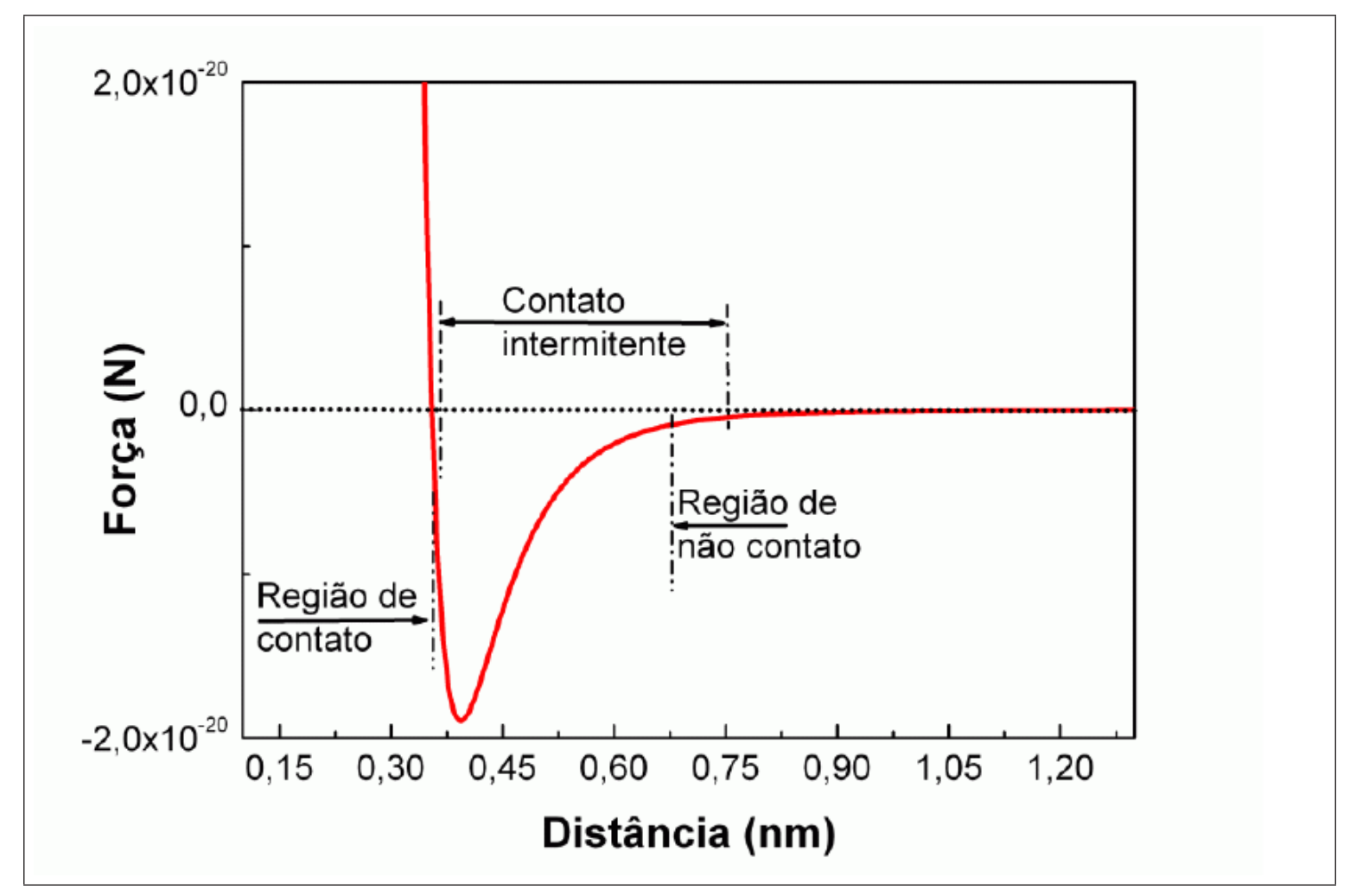

Figura 4.10: Simulação da força de interação entre um átomo da ponta e um átomo da superfície em função de sua distância obtida através do uso do potencial de LennardJones.

Uma mudança na topografia da superfície da amostra corresponde a uma mudança na deflexão do cantilever. A grandes distâncias entre a ponta e a superfície, a interação é predominantemente atrativa, devida principalmente à força de Van der Waals. À medida que a ponta e a superfície da amostra se aproximam, os orbitais eletrônicos dos átomos da ponta e da superfície da amostra começam a se repelir.

A partir da figura 4.10 é possível entender os modos de operação do microscópio de força atômica de acordo com a força de interação resultante entre a ponta e a superfície.

1. Modo contato, com forças predominantemente repulsivas, provocando a deflexão vertical para cima do cantilever; 
2. Modo tapping. O microscópio trabalha em dois regimes de forças: umas vezes atrativa, outras vezes repulsiva. A ponta oscila intermitentemente;

3. Modo não-contato, regime de força atrativo. O cantilever é mantido a grandes distâncias da superfície e vibra com uma pequena amplitude.

Para o monitoramento do sistema do microscópio estão acoplados através de um sistema de realimentação, um fotodetetor e um scanner piezoelétrico. A amostra é posicionada sobre o scanner piezoelétrico, que se estende e se contrai em função da tensão aplicada sobre ele pelo sistema de realimentação. Para a alimentação deste sistema incidese um laser sobre o cantilever que é refletido e atinge o fotodetetor. O fotodetetor é dividido em quatro partes e a análise da diferença de intensidade detectada na sua parte superior e inferior está relacionada a deflexões verticais sofridas pelo cantilever. Essas deflexões causadas pelas variações na força de interação entre a ponta e a superfície da amostra. A diferença de intensidade nos quadrantes superior e inferior do fotodetetor é mantida constante através da alteração do scanner piezoelétrico pelo circuito realimentador, que corrige o comprimento do tubo piezoelétrico de modo a manter a força de interação entre a ponta e a superfície constante e, conseqüentemente, a deflexão do cantilever constante.

Essa técnica permite determinar a rugosidade, grandeza muito importante quando se estuda a implantação iônica em filmes finos. A rugosidade RMS é obtida através da equação:

$$
\text { Rugosidade }_{R M S}=\sum_{i}\left[\frac{\left(Z_{i}-Z\right)^{2}}{n^{2}}\right]^{\frac{1}{2}}
$$

onde a altura de cada ponto na superfície é obtida a partir da imagem topográfica, sendo $Z_{i}$ o valor da altura em um dos n pontos medidos e $\mathrm{Z}$ a altura média da região.

As análises de rugosidade foram feitas em modo contato, com um microscópio de força atômica modelo Multimode equipado com um controlador Nanoscope III da Digital do Laboratório de Filmes Finos do Departamento de Física Aplicada, do IFUSP. 


\section{Capítulo 5}

\section{Resultados e discussão}

\subsection{Caracterização dos filmes de cobre puro}

Nesta seção serão apresentadas as propriedades dos filmes de cobre crescidos sobre silício e UDAC, obtidos através de bombardeamento eletrônico. Serão mostrados os resultados relativos à análise dos contaminantes incorporados durante as etapas do processamento dos filmes, à densidade, além da resistividade elétrica dos filmes. Encerrando a seção será feito um estudo da cinética de oxidação, baseando-se em análises RBS, XRD, Método de quatro pontas e Espectroscopia Raman ${ }^{1}$.

\subsubsection{Análise de contaminantes}

A determinação dos contaminantes incorporados durante o processo de deposição foi feita através de análise PIXE, com feixe de $\mathrm{He}^{+}$de energia 2.2 ou $2.4 \mathrm{MeV}$, dependendo das condições de operação no LAMFI. Foi utilizado um detector com absorvedor de Be, com espessura $50 \mu m$ e ângulo sólido $0.8 \mathrm{msr}$. O atual arranjo do LAMFI permite a obtenção simultânea dos espectros RBS e PIXE.

Nesta fase do estudo foram denominados filmes de cobre puros aqueles cujos testes para verificação de contaminantes não apresentaram contaminação acima da indicada para as lâminas de cobre pelo fabricante, descrita na seção 4.1

Como foi discutida na seção anterior, a detecção de oxigênio através dessa técnica é muito melhorada em filmes de $\mathrm{Cu} / \mathrm{C}$. Por esta razão os filmes foram depositados sobre

\footnotetext{
1 As unidades utilizadas para expressar as grandezas físicas neste capítulo são as mais freqüentemente usadas na literatura específica.
} 
UDC para tais análises. A análise RBS dos filmes virgens revelou a presença de oxigênio no filme, a principal impureza. Este elemento não é detectado nas análises PIXE, que apresenta sensibilidade para elementos com $Z \geq 10$.

No espectro RBS da Figura 5.1 estão indicadas as posições dos elementos químicos presentes no filme virgem ${ }^{2}$. Pode ser observada a presença de oxigênio na superfície do filme,(canal 150), e no substrato de carbono,(canal 110).

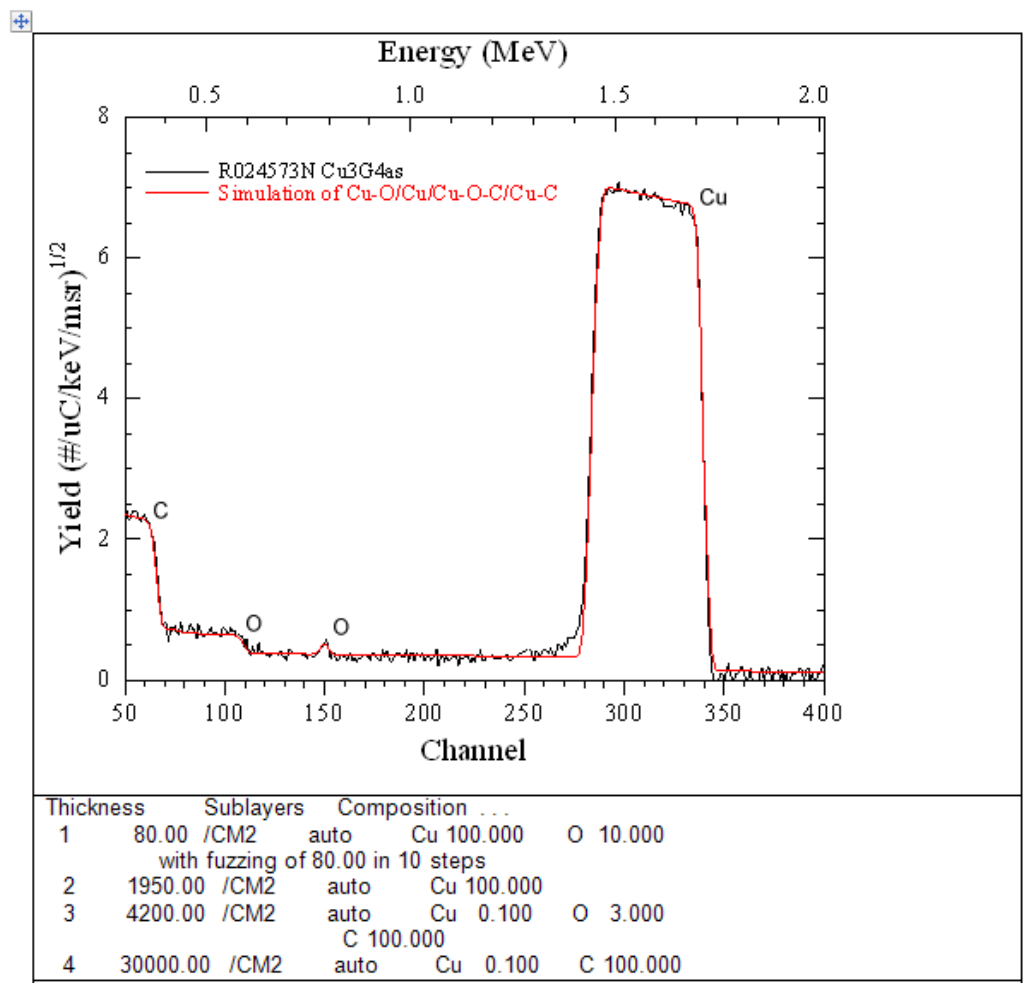

Figura 5.1: Espectro RBS do filme de $\mathrm{Cu} / \mathrm{C}$, onde são mostrados os picos referentes ao $\mathrm{O}$ (canal 150) e $\mathrm{Cu}$ (canal 340) da superfície, além do $\mathrm{O}$ (canal 110) e C(canal 70), presentes no substrato. Note a contaminação do substrato pelo oxigênio.

\subsubsection{Aderência dos filmes}

Filmes de cobre puro não apresentaram boa aderência quando o substrato utilizado foi silício. Testados com fita adesiva ${ }^{3}, 95 \%$ dos filmes se soltou do substrato de silício. No

2 O quadro abaixo da figura mostra a saída do programa de simulação RUMP. Na simulação, thickness é a espessura da camada, dada em $10^{15}$ átomos $/ \mathrm{cm}^{2}$, composition é a composição, que o programa utiliza de forma normalizada e fuzzing é um fator que representa a rugosidade da amostra e não deve ser utilizado como valor absoluto. Sua unidade é a mesma da espessura.

3 scotch test é um teste tradicional de adesão de filmes 
entanto, quando os filmes apresentaram contaminação do processo de deposição, houve uma aderência bastante significativa. Estes resultados serão descritos mais adiante.

\subsubsection{Determinação da densidade}

Na análise RBS, a partir da taxa de perda de energia por unidade de comprimento, $(\mathrm{dE} / \mathrm{dx})$, é possível determinar a espessura do material, em nm, caso seja conhecida a sua densidade.

A densidade, em unidades de $\mathrm{g} / \mathrm{cm}^{3}$, das amostras foi obtida combinando os resultados de RBS com os de perfilometria, que fornecem a espessura em unidades de comprimento.

Assim, considerando a igualdade das densidades superficiais de átomos determinadas através das duas técnicas, teremos:

$$
\rho_{\text {bulk }} \cdot t_{R B S}=\rho_{\text {filme }} \cdot t_{\text {perf }}
$$

onde $\rho_{\text {bulk }}$ é a densidade do bulk, utilizada pelo programa de simulação RUMP, $t_{R B S}$ é a espessura em nm, determinada por RBS a partir da densidade do bulk, $\rho_{\text {filme é a }}$ densidade do filme e $t_{\text {perf }}$ é a espessura do filme, determinada por perfilometria.

A tabela 5.1 mostra as densidades de vários conjuntos de amostras, calculadas a partir da equação 5.1 e a variação percentual entre a densidade do bulk e a do filme, $\Delta t(\%)$, considerando a densidade do bulk igual $8,920 \mathrm{~g} / \mathrm{cm}^{3}$.

Tabela 5.1: Densidades dos filmes de $\mathrm{Cu}$

\begin{tabular}{|c|c|c|c|}
\hline$t_{R B S}(\mathrm{~nm})$ & $t_{\text {perf }}(\mathrm{nm})$ & $\operatorname{densidade}\left(\mathrm{g} / \mathrm{cm}^{3}\right)$ & $\Delta t(\%)$ \\
\hline 65 & 78,052 & 7,4 & 17 \\
\hline 73 & 87,631 & 7,4 & 17 \\
\hline 83 & 98,941 & 7,5 & 16 \\
\hline 263 & 302,340 & 7,8 & 13 \\
\hline \multirow[t]{2}{*}{302} & 341,253 & 7,9 & 12 \\
\hline & $(7,6 \pm 0$ & $(\overline{\Delta t}=15 \pm 1) \%$ & \\
\hline
\end{tabular}

O sistema de deposição utilizado garantiu uma excelente uniformidade entre as espessuras das amostras de um mesmo grupo. As dimensões do porta-substratos e do cadinho, além da grande distância entre o porta-substratos e o material a ser depositado permi- 
tiram obter variações nas espessuras abaixo de $5 \%$. Isto possibilitou a utilização de um número viável de amostras na determinação da densidade do filme.

A densidade média dos filmes é 15\% abaixo da densidade de bulk do cobre. Como não houve preocupação com a obtenção de filmes mais densos, todos os filmes foram depositados em substratos não aquecidos. O objetivo foi determinar com precisão a densidade e as espessuras dos filmes, pois desta forma obtém-se a resistividade elétrica, um importante parâmetro na indústria microeletrônica, que aliado à resistência à eletromigração, coloca o cobre como o potencial substituto do alumínio. Além disso, esta grandeza, a densidade, é um dos parâmetros de entrada do programa TRIM, utilizado para determinar a distribuição de íons implantados no filme.

\subsubsection{Medidas da resistividade elétrica}

A resistividade elétrica foi determinada através de medidas da resistência folha pelo método das quatro pontas e da espessura do filme em nm. Esse valor foi obtido a partir da espessura dada por RBS e corrigida pela densidade média dos filmes. As medidas, feitas em temperatura de $25^{\circ} \mathrm{C}$, resultaram nos valores mostrados na tabela 5.2.

Tabela 5.2: Resistividades elétricas

\begin{tabular}{ccc}
\hline Amostras & espessuras $(\mathrm{nm})$ & resistividade $(\mu \Omega . c m)$ \\
\hline$M_{e}$ & 620 & 1,92 \\
$M_{a}$ & 435 & 2,37 \\
$M_{b}$ & 395 & 2,42 \\
$M_{c}$ & 103 & 2,63 \\
$M_{d}$ & 35 & 6,54
\end{tabular}

Observa-se pela tabela 5.2 que as resistividades elétricas dos filmes são sempre maiores que a resistividade elétrica do bulk de cobre $(1,67 \mu \Omega . \mathrm{cm})$. Esse acréscimo, $\Delta \rho$, é inversamente proporcional à espessura do filme (efeito da dimensão), conforme pode ser visto na Figura 5.2. O resultado do ajuste da curva mostra que para espessuras muito grandes, a resistividade será $1,72 \mu \Omega$.cm, valor muito próximo à resistividade do bulk. À medida que aumenta a espessura, ocorre uma redução na resistividade elétrica que pode ser atribuída à formação de uma estrutura cristalina mais regular e também a um aumento na dimensão do grão com o aumento da espessura do filme [104]. 


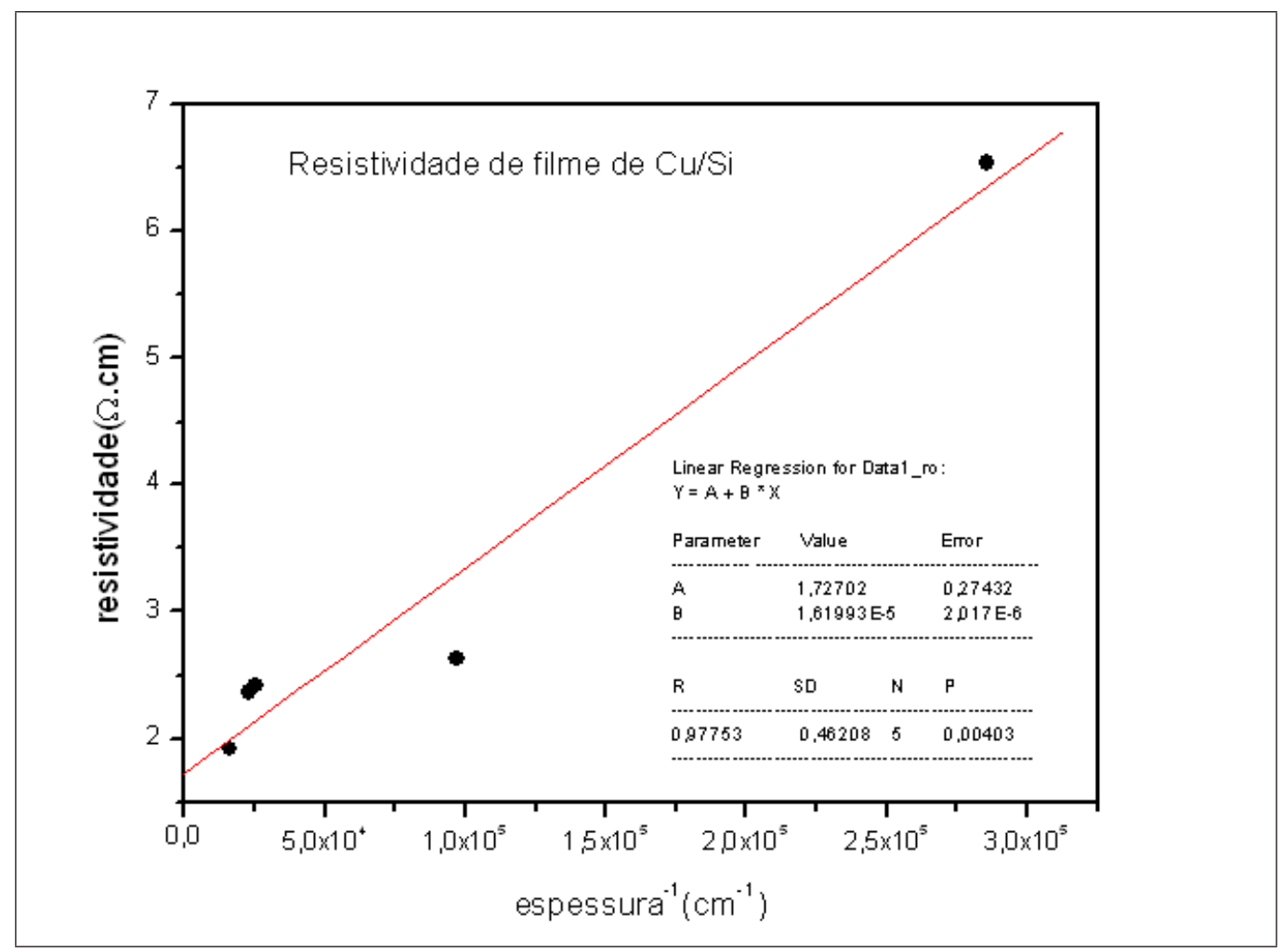

Figura 5.2: Relação entre a resistividade e a espessura do filme

A resistividade elétrica total do bulk, $\rho_{b}(T)$, é dada por: $\rho_{b}(T)=\rho_{b}(0)+\rho_{i}(T)$, onde $\rho_{b}(0)$ é a resistividade elétrica residual e $\rho_{i}(T)$ é a resistividade elétrica intrínseca( ou a parte fônon da resistividade elétrica). Filmes de cobre obtidos por bombardeamento eletrônico são policristalinos. Assim, a existência dos contornos de grãos reduz o transporte elétrico, ou em outras palavras, aumenta a resistividade elétrica do filme [110].

\subsubsection{Textura de filmes de cobre puro}

Com o aumento da possibilidade de substituição do alumínio pelo cobre, o desenvolvimento de textura $<111>$ em filmes de cobre tem sido muito investigado [111] e [112].

O desenvolvimento de textura $<110>$ tem sido preferida em aplicações cuja resistência à oxidação é importante, pois estes filmes têm taxa de oxidação mais baixa [47]. Assim, no estudo de oxidação de filmes de cobre, a textura desenvolvida deve ser considerada como um parâmetro importante.

Neste trabalho foi observado o desenvolvimento de textura $<111>,<100>$ e $<110>$ em filmes de cobre, como pode ser visto na Figura 5.3. Resultados semelhantes (exceto 


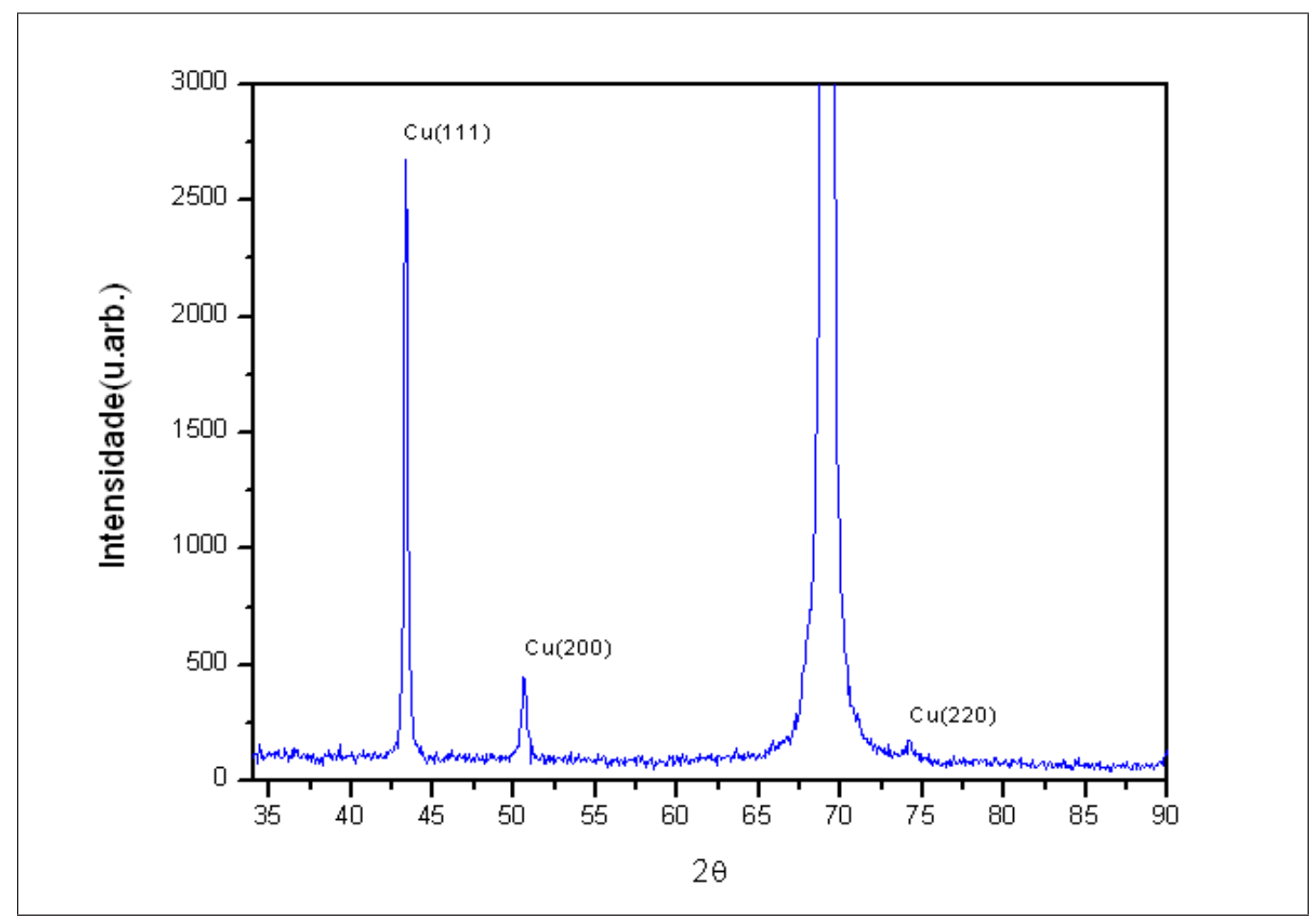

Figura 5.3: Difratograma de um filme de $\mathrm{Cu} / \mathrm{Si}$, mostrando a textura desenvolvida. O pico em $2 \theta=68,5^{0}$ pertence ao substrato de $\mathrm{Si}$.

a $<100>$ ) foram obtidos por Wei e colaboradores em filmes de cobre depositados por sputtering [113].

\subsubsection{Cinética de oxidação de filmes de cobre puro}

Para o estudo da cinética de oxidação, este trabalho foi dividido em duas partes: oxidação de filmes de cobre puro e oxidação de filmes de cobre com a aplicação de algum método de passivação.

Na primeira parte, foram testadas 8 temperaturas de oxidação e vários tempos de oxidação, mostrados na tabela 5.3. Para melhor organização, os resultados dos testes para cada temperatura foram descritos separadamente e no final, a determinação da energia de ativação para oxidação de cobre puro sintetiza os resultados obtidos para as diversas temperaturas testadas.

Na segunda parte, foram realizadas tentativas de passivação com a liga de $\mathrm{CuAl} / \mathrm{Si}$, com a cobertura de carbono $(\mathrm{C} / \mathrm{Cu} / \mathrm{C})$ e através da implantação de vários íons em filmes 
Tabela 5.3: Condições de oxidação dos filmes de $\mathrm{Cu} / \mathrm{C}$ e $\mathrm{Cu} / \mathrm{Si}$

\begin{tabular}{|c|c|c|c|}
\hline Temperaturas $\left({ }^{\circ} \mathrm{C}\right)$ & tempos $(\min )$ & Temperaturas $\left({ }^{\circ} \mathrm{C}\right)$ & tempos (min) \\
\hline \multirow[t]{2}{*}{100} & 5 & \multirow[t]{2}{*}{250} & 180 \\
\hline & 12 & & 240 \\
\hline 120 & 15 & \multirow[t]{7}{*}{300} & 2 \\
\hline 150 & 12 & & 3 \\
\hline \multirow[t]{6}{*}{180} & 10 & & 4,5 \\
\hline & 20 & & 9,5 \\
\hline & 30 & & 12 \\
\hline & 40 & & 16 \\
\hline & 60 & & 25 \\
\hline & 90 & \multirow[t]{8}{*}{350} & 2 \\
\hline \multirow[t]{4}{*}{200} & 20 & & 3 \\
\hline & 25 & & 4 \\
\hline & 30 & & 6,5 \\
\hline & 35 & & 8 \\
\hline \multirow[t]{3}{*}{250} & 18 & & 10 \\
\hline & 60 & & 14 \\
\hline & 120 & & \\
\hline
\end{tabular}

de $\mathrm{Cu} / \mathrm{C}$. Para facilitar a leitura, um quadro com as condições experimentais da segunda parte será mostrado após os resultados desta primeira parte.

\section{Oxidação de cobre a $180{ }^{\circ} \mathrm{C}$}

No estudo da oxidação de cobre a $180{ }^{\circ} \mathrm{C}$, as amostras foram exposta à atmosfera ambiente para tempos entre 10 e 90 minutos, conforme a tabela 5.3. Para determinação da estequiometria dos óxidos formados foram realizadas análises RBS. Em alguns casos, houve a necessidade de recorrer às análises por XRD e Espectroscopia Raman para a determinação da estequiometria. A união das três técnicas, aliada à monitoração dos contaminantes por PIXE possibilitou determinar com precisão os tipos de óxidos crescidos.

Em oxidação de cobre, a espessura do filme é um parâmetro muito importante, pois o processo de oxidação depende da concentração de defeito, que em se tratando de filmes 
finos, está relacionada à sua espessura. Assim, atenção especial foi dada às comparações com resultados da literatura ou resultados obtidos dentro do escopo desse estudo, discutindo as concordâncias ou divergências; tendo em mente a importância desse parâmetro.

As medidas de composição, perfis de concentração em profundidade, espessura média das monocamadas individuais e respectivas interfaces foram determinadas simulando-se os espectros experimentais RBS.

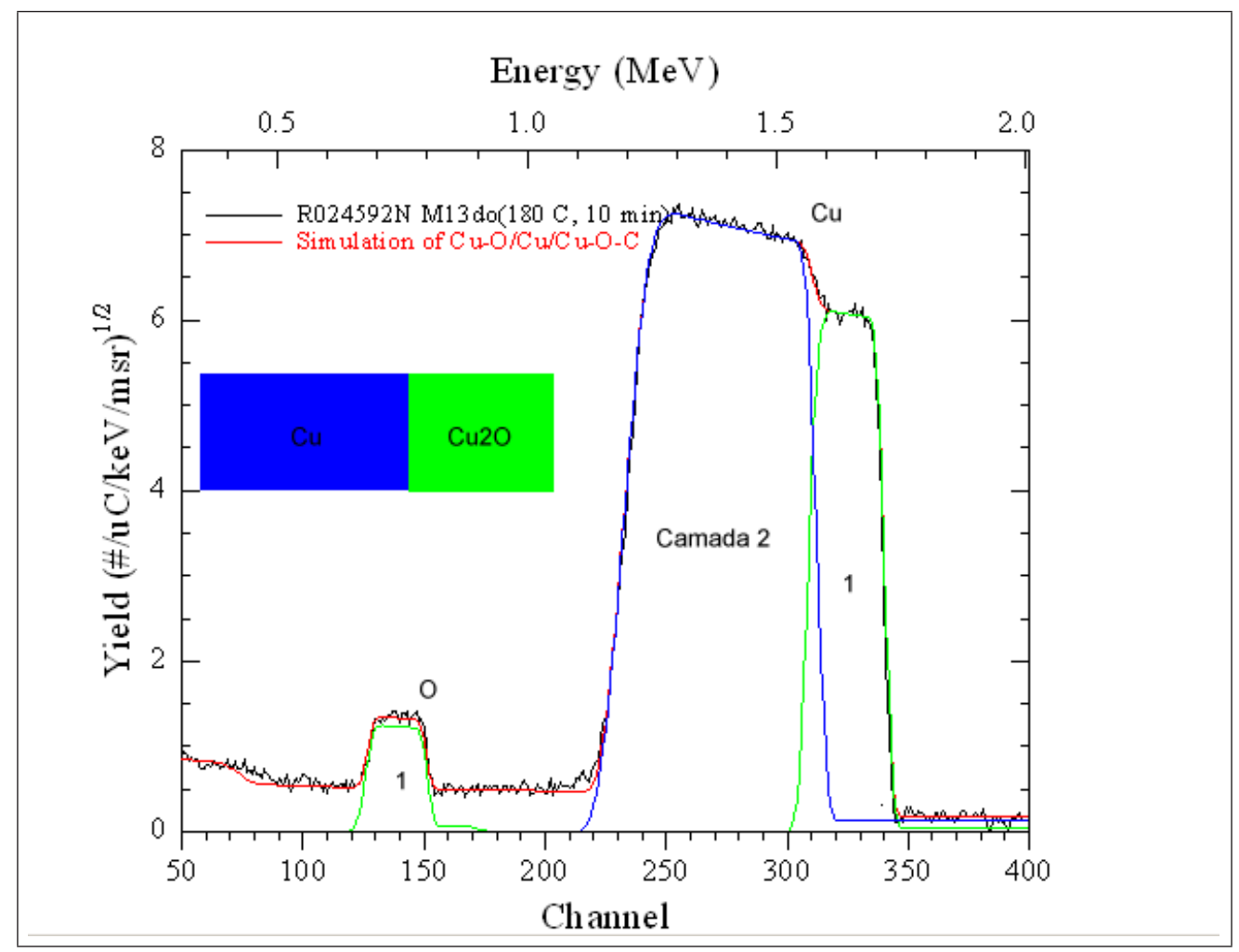

Figura 5.4: Espectro RBS de um filme de cobre após a oxidação em 10 minutos. Associada aos pontos experimentais, está a simulação, em vermelho, elaborada para o caso ideal de interfaces abruptas, mas com rugosidade presente. Também são mostradas as duas camadas da amostra. Em verde está a camada mais superficial, $\mathrm{Cu}_{2} \mathrm{O}$ e em azul o $\mathrm{Cu}$ não oxidado. Note a diferença de espessura entre o pico do cobre e o do oxigênio, indicando a não oxidação total do filme.

A Figura 5.4 mostra o espectro de RBS obtido da amostra $\mathrm{Cu} / \mathrm{C}$, oxidada por 10 minutos. Pode ser observada a presença de dois elementos: $\mathrm{Cu}$ e O, além do substrato. A linha vermelha corresponde à simulação elaborada com o programa RUMP, considerando interfaces abruptas entre a camada de $\mathrm{Cu}_{2} \mathrm{O}$ e $\mathrm{Cu}$. Devido ao bom ajuste entre o espectro experimental e o simulado, não foi necessário considerar uma zona de transição com variação gradual da composição entre as 2 camadas. Pela comparação entre as espessuras dos picos do cobre e a do oxigênio, conclui-se que este último elemento não está presente 
em todo o filme. Isso significa que não houve oxidação total do filme. Os resultados obtidos através da simulação do espectro RBS são mostrados na tabela 5.4.

Outra informação que pode ser obtida através da simulação é a rugosidade do filme. Em um espectro RBS de filmes de $\mathrm{Cu}_{2} \mathrm{O} / \mathrm{Cu} / \mathrm{C}$, a análise da extremidade direita do pico indica característica do sistema de aquisição(resolução). Já a borda esquerda é uma convolução da resolução do sistema com a rugosidade do filme. Uma inclinação maior ou menor no lado direito do pico, significa uma maior ou menor resolução. Já um aumento na inclinação do lado esquerdo do pico, dá indicação de aumento da rugosidade.

Apesar dos resultados da simulação sugerirem uma interface abrupta entre o metal e o óxido, foi necessária a inclusão de uma rugosidade no ajuste das duas camadas. Esse valor não é absoluto, mas pode ser usado como uma indicação da variação dessa grandeza.

Para oxidação a $180{ }^{\circ} \mathrm{C}$ por 90 minutos obtém-se o espectro RBS e a correspondente simulação na Figura 5.5.

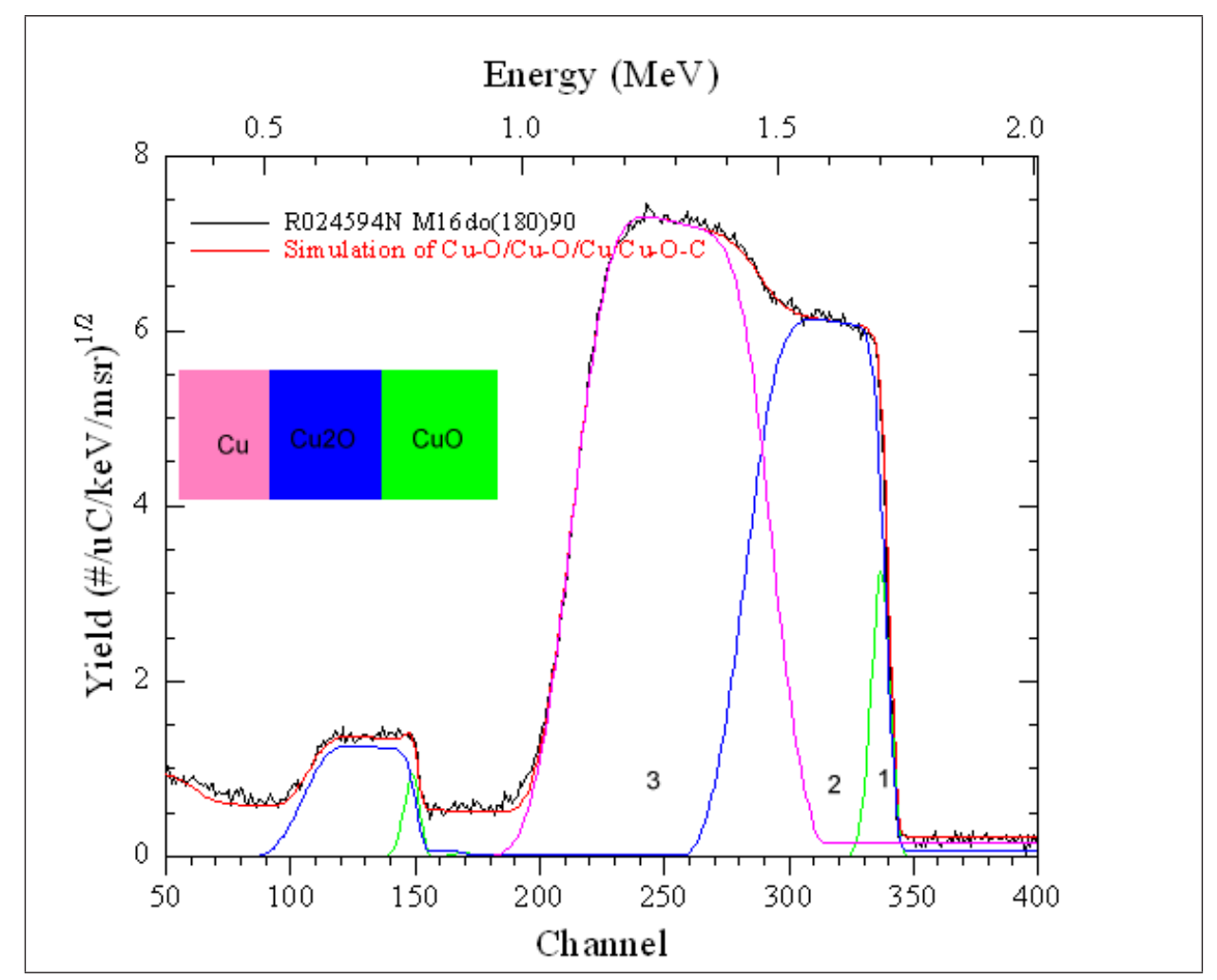

Figura 5.5: Espectro RBS de um filme de cobre após a oxidação em 90 minutos a $180{ }^{\circ} \mathrm{C}$. Associada aos pontos experimentais, está a simulação, em vermelho, elaborada para o caso ideal de interfaces abruptas, mas com rugosidade presente. Também são mostradas as três camadas da amostra. Em verde está a camada mais superficial, $\mathrm{CuO}$, em azul o $\mathrm{Cu}_{2} \mathrm{O}$ e em rosa, o $\mathrm{Cu}$ não oxidado. Note a diferença de espessura entre o pico do cobre e o do oxigênio. 
Os resultados da simulação dos espectros RBS obtidos em oxidação a $180{ }^{\circ} \mathrm{C}$ em variados tempos ( tabela 5.3) são mostrados na tabela 5.4 .

Tabela 5.4: Resultados da simulação dos espectros RBS de filmes de $\mathrm{Cu}$, oxidados em $180{ }^{\circ} \mathrm{C}$.

\begin{tabular}{cccccc}
\hline Amostra & tempo & camada 1 & camada 2 & $O_{\text {total }}\left(10^{15} \mathrm{at} / \mathrm{cm}^{2}\right)$ & rugosidade $\left(10^{15} \mathrm{at} / \mathrm{cm}^{2}\right)$ \\
\hline M13 & 10 & - & $\mathrm{Cu} u_{2} \mathrm{O}$ & 430 & 100 \\
M17 & 20 & - & $?$ & 461 & \\
M12 & 30 & - & $?$ & 660 & 550 \\
M11 & 40 & - & $\mathrm{Cu}_{2} O(?)$ & 617 & 600 \\
M15 & 60 & - & $\mathrm{Cu}_{2} O(?)$ & 863 & \\
M16 & 90 & $\mathrm{CuO}(?)$ & $\mathrm{Cu}_{2} O(?)$ & 942 &
\end{tabular}

Comparada à oxidação em 10 minutos, a sobreposição dos dois espectros mostra claramente o aumento da rugosidade e da espessura do óxido para o filme oxidado por 90 minutos, Figura 5.6.

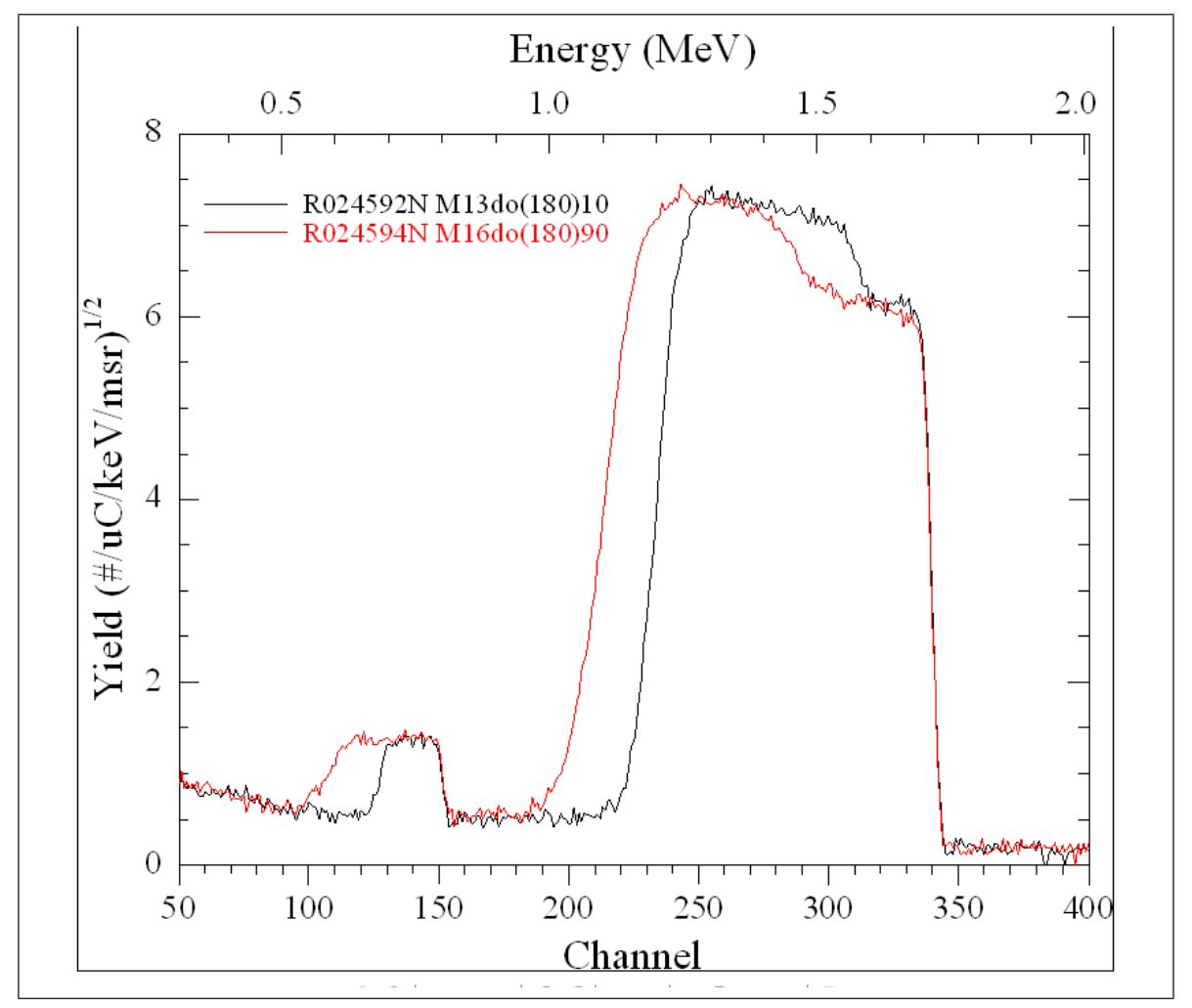

Figura 5.6: Espectro RBS de dois filmes de cobre após a oxidação em 10 e 90 minutos a 180 ${ }^{\circ} \mathrm{C}$. A linha preta refere-se ao sinal do filme oxidado por 10 minutos e a linha vermelha ao filme oxidado por 90 minutos. 
Como pode ser notado, as análises PIXE e RBS não possibilitaram a determinação da estequiometria dos óxidos em todas as condições de oxidação. Tornou-se necessária a utilização de técnicas complementares de análises. Como mencionado anteriormente, foram escolhidas a análise por XRD e Espectroscopia Raman devido à sensibilidade destas técnicas no estudo da oxidação do cobre.

A Figura 5.7 mostra a relação entre a concentração de oxigênio incorporado e o tempo de oxidação. Pode ser observado um comportamento muito próximo ao parabólico. Assim, foi atribuída à difusão o mecanismo dominante no processo de oxidação.

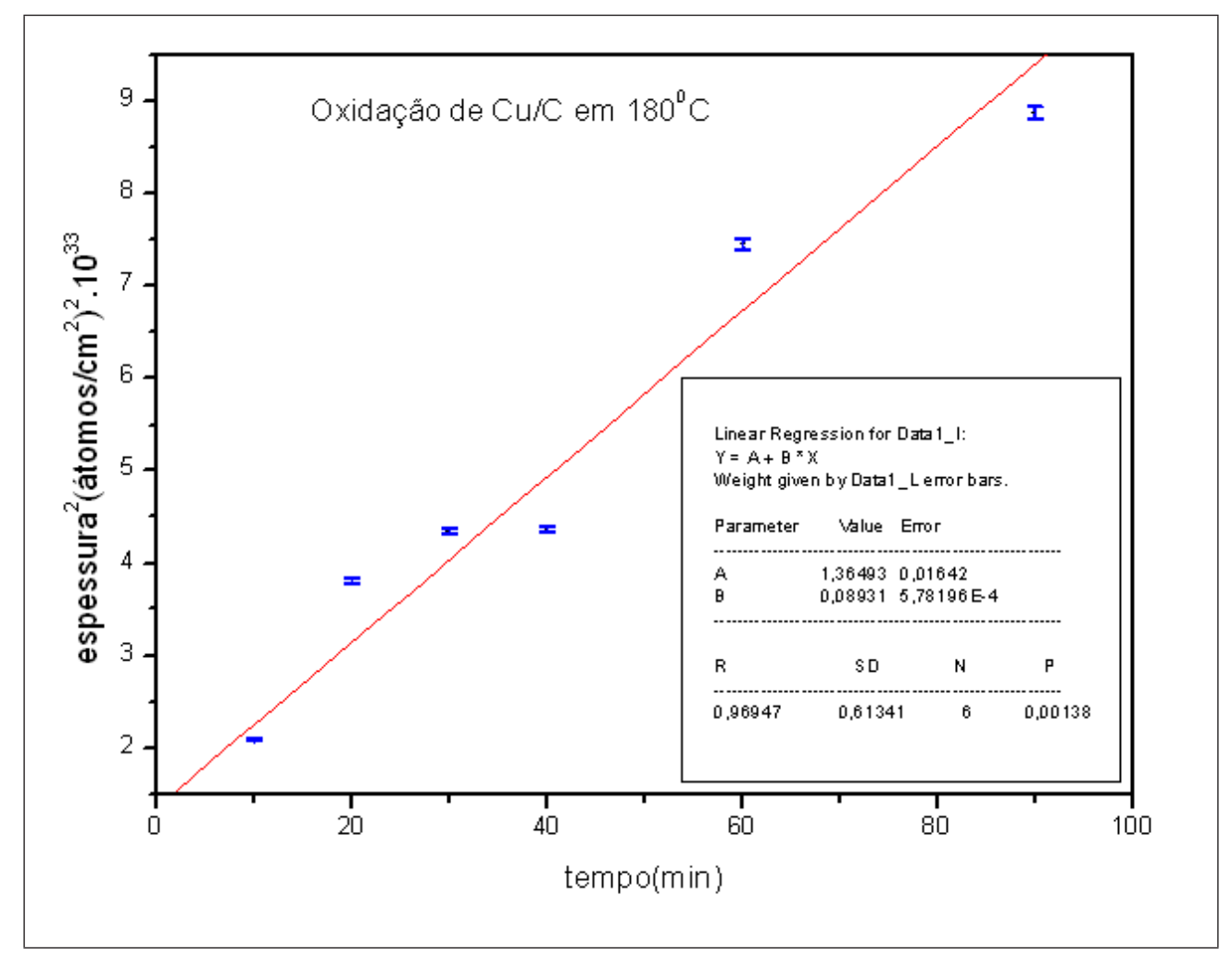

Figura 5.7: Cinética de oxidação de filmes de cobre puro a $180{ }^{\circ} \mathrm{C}$

Para tempos de 10 minutos, foi verificada a existência de apenas $C u_{2} O$, através de simulação dos espectros RBS. Assim, a oxidação de cobre a $180{ }^{\circ} \mathrm{C}$ parece mostrar como único produto o $\mathrm{Cu}_{2} \mathrm{O}$. Entretanto, para oxidação durante 20 e 30 minutos a $180{ }^{\circ} \mathrm{C}$, a simulação dos espectros tornou-se complexa, evidenciando uma estrutura com composição intermediária entre $\mathrm{Cu}_{2} \mathrm{O}$ e $\mathrm{CuO}^{4}$.

Trabalhos como o de Mayer [47] e Gao [51], que concordam com a maior parte dos estudos publicados, mostram que em baixas temperaturas, o único óxido formado é o 4 A confirmação desta hipótese será obtida até o final desta seção 
$\mathrm{Cu}_{2} \mathrm{O}$ e; outros poucos admitem a formação do $\mathrm{Cu}_{3} \mathrm{O}_{2}$ em condições especiais [114] e [15]. Assim, com o objetivo de determinar com precisão o tipo de óxido formado e concluir o estudo da cinética de oxidação do cobre em baixas temperaturas, foi realizada uma extensa investigação através de análises XRD.

\section{Análises por difração de raios-X}

Como foi mencionado, a análise RBS não foi capaz de determinar os tipos de óxidos formados, para alguns tempos de oxidação em $180{ }^{\circ} \mathrm{C}$. As amostras que necessitaram de análises por XRD para essa determinação são mostradas na tabela 5.5. A amostra M13 apesar de ter o óxido bem determinado por RBS foi analisada por XRD para servir como amostra-controle. As amostras M17 e M12, oxidadas por 20 e 30 minutos, não apresentaram resultados conclusivos nas análises por RBS. O substrato(UDAC) também foi analisado.

Tabela 5.5: Amostras oxidadas em $180{ }^{\circ} \mathrm{C}$ selecionadas para análises por XRD

\begin{tabular}{cccc}
\hline Amostra & tempo & camada 1 & camada 2 \\
\hline M13 & 10 & - & $\mathrm{Cu}_{2} \mathrm{O}$ \\
M17 & 20 & - & $?$ \\
M12 & 30 & - & $?$
\end{tabular}

As fases cristalinas foram identificadas com auxílio à biblioteca do JCPDS (Joint Committee on Power Diffraction Standards) [115], que congrega praticamente todas as estruturas cristalinas orgânicas e inorgânicas conhecidas. Os dados utilizados na análise dos difratogramas são mostrados na tabela 5.6.

\section{Resultados de Análises XRD para amostras oxidadas a $180{ }^{\circ} \mathrm{C}$, por $10 \mathrm{mi}$ - nutos}

A Figura 5.8 mostra o difratograma de raios-X do filme de $\mathrm{Cu}$ oxidado a $180{ }^{\circ} \mathrm{C}$, por 10 minutos. Foi usada radiação $C u k_{\alpha}(\lambda=1,5406 \AA ̊)$. A partir da posição angular $(2 \theta)$ do pico de cada perfil, obteve-se o espaçamento $d_{h k l}$ usando a Lei de Bragg.

A utilização do carbono amorfo ultra denso (UDAC) para este estudo através de XRD causou a superposição do pico do substrato com os picos dos elementos do filme, como 
Tabela 5.6: Valores do espaçamento interplanar e os correspondentes índices de Miller e intensidades obtidos a partir do JCPDS.

\begin{tabular}{ccccc}
\hline Composto & $2 \theta\left(^{\circ}\right)$ & $d_{h k l}(\AA)$ & hkl & Intensidade relativa \\
\hline $\mathrm{Cu}_{2} \mathrm{O}$ & 36,45 & 2,465 & 111 & 100 \\
& 42,33 & 2,135 & 200 & 37 \\
& 61,40 & 1,510 & 220 & 27 \\
$\mathrm{CuO}$ & 35,47 & 2,531 & 002 & 60 \\
& 35,57 & 2,524 & -111 & 100 \\
& 38,97 & 2,311 & 200 & 100 \\
$\mathrm{Cu} \mathrm{H}_{3} \mathrm{O}_{3}$ & 38,78 & 1,8667 & -202 & 25 \\
& 35,83 & 2,90 & 200 & 40 \\
& 36,92 & 2,50 & 202 & 100 \\
& 34,37 & 2,47 & 004 & 60 \\
& 44,18 & 2,05 & 213 & 60
\end{tabular}

pode ser visto na Figura 5.8, mas o difratograma mostra uma forma bem mais larga dos picos do UDAC, quando comparado aos picos do filme de cobre e seus óxidos.

Pode ser observada a fase cristalina do cobre, com estrutura tipo cúbica de face centrada, cujas reflexões ocorrem em $2 \theta=43,32^{\circ}, 50,56^{\circ}$ e $74,22^{\circ}$, em concordância aos resultados obtidos pela simulação de espectros RBS, que indicam a não oxidação total do filme de cobre nessas condições.

Além dessas reflexões, pode ser observada ainda o aparecimento de picos em $2 \theta=$ $36,22^{\circ}$ e $2 \theta=60,8^{\circ}$. A reflexão correspondente a $2 \theta=36,22^{\circ}$, cujo pico possui largura $w=0.94^{\circ}$ foi atribuída ao plano (111) da estrutura cúbica $C u_{2} O(J C P D S-5-667)$, com distância igual a 2,480A. Nestas condições de oxidação não foi observado nenhum pico de difração referente às fases $\mathrm{CuO}$ e $\mathrm{Cu}_{4} \mathrm{O}_{3}$, em concordância aos resultados RBS, cuja simulação dos espectros resultou somente na estrutura $\mathrm{Cu}_{2} \mathrm{O}$. A fase $\mathrm{Cu}_{4} \mathrm{O}_{3}$ é um óxido instável em temperaturas acima de $100^{\circ} \mathrm{C}$ e de difícil obtenção mesmo em condições ideais [116].

Os resultados das análises XRD para a amostra oxidada em $180{ }^{\circ} \mathrm{C}$, por 10 minutos, concordam com os obtidos por RBS. 


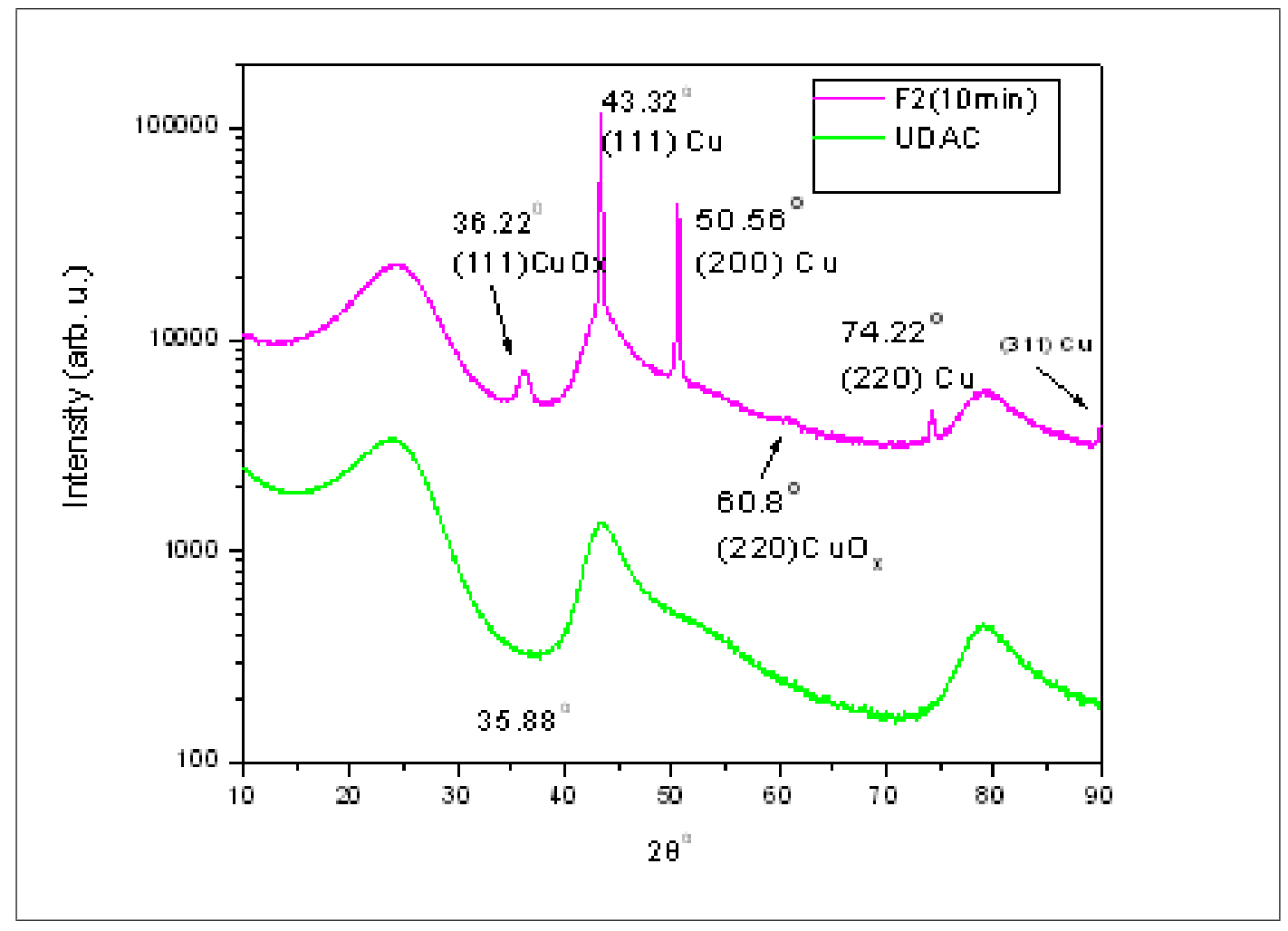

Figura 5.8: Espectro XRD do substrato de carbono e do filme de $\mathrm{Cu} / \mathrm{C}$ oxidado por 10 minutos. Os espectros foram deslocados verticalmente para facilitar a visualização

\section{Resultados de Análises XRD para amostras oxidadas a $180{ }^{\circ} \mathrm{C}$, por 20 e 30 minutos}

A Figura 5.9 mostra o espectro XRD das amostras oxidadas em 20 e 30 minutos a 180 ${ }^{\circ} \mathrm{C}$. Pode ser observada a presença da fase $\mathrm{Cu}$ nos mesmos ângulos anteriores e ainda, a presença de uma fase $C u O_{x}$ para $2 \theta=36,07^{\circ}$ e $36,08^{\circ}$, para os tempos de oxidação de 30 e 20 minutos, respectivamente. Estes picos correspondem às reflexões no plano (111) de uma estrutura cujas distâncias interplanares valem $d=2,490 \AA$ e $2,489 \AA$.

Resultados das análises RBS para filmes oxidados a $180{ }^{\circ} \mathrm{C}$ por 20 e 30 minutos não são conclusivos, mostrando a possibilidade da existência de uma estrutura de estequiometria $\mathrm{Cu}_{3} \mathrm{O}_{2}$, ou uma composição em que as concentraçoes dos óxidos $\mathrm{CuO}$ e $\mathrm{Cu}_{2} \mathrm{O}$ são idênticas.

Outro fator interessante é que os parâmetros de rede diferem ligeiramente do $\mathrm{Cu}_{2} \mathrm{O}$ e parecem mostrar uma relação com o tempo de oxidação, conforme pode ser visto na Figura 5.10. 


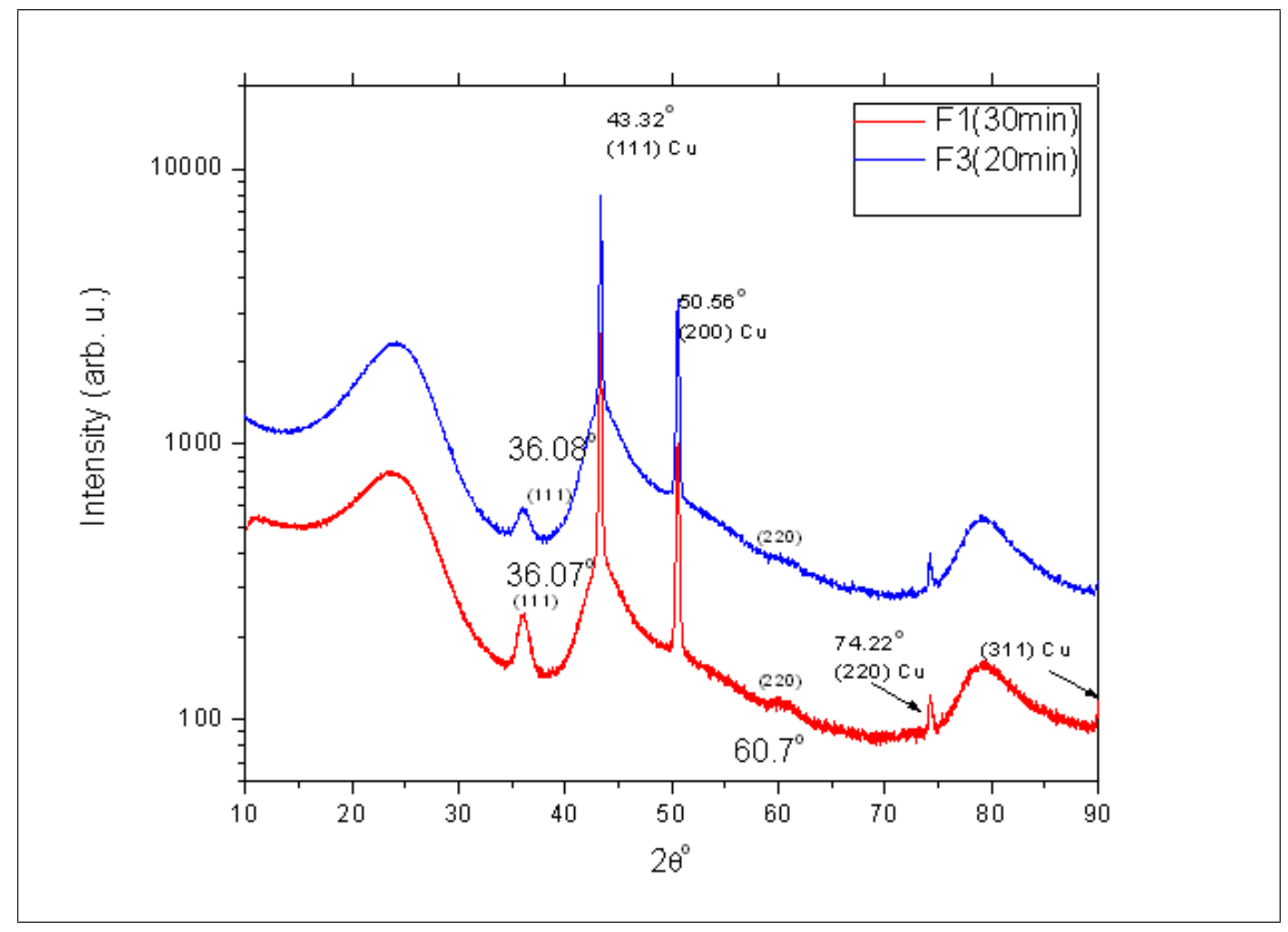

Figura 5.9: Espectro XRD dos filmes de $\mathrm{Cu} / \mathrm{C}$ oxidados durante 20 e 30 minutos

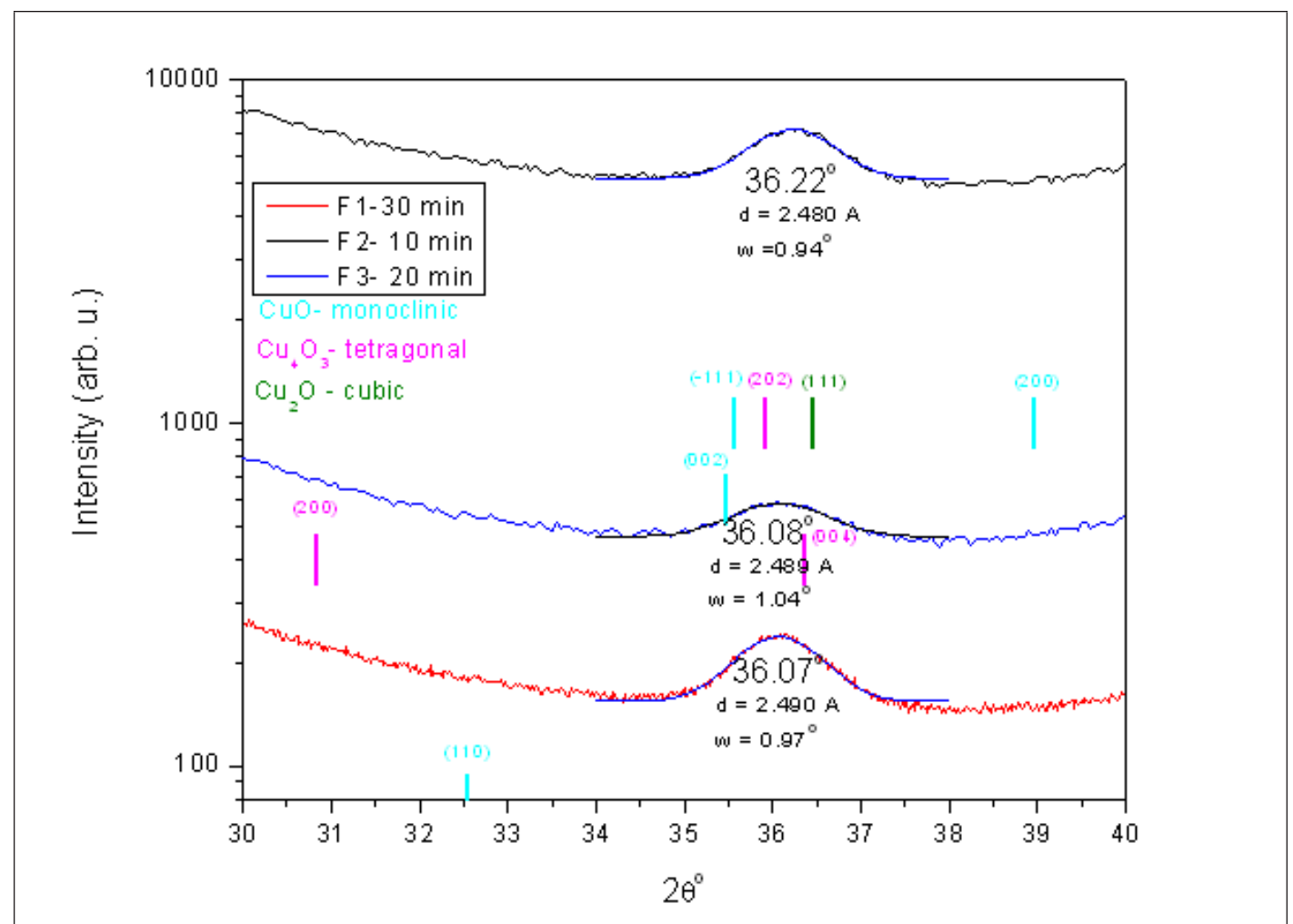

Figura 5.10: Espectro XRD dos filmes de $\mathrm{Cu} / \mathrm{C}$ oxidados durante 10, 20 e 30 minutos a 180 ${ }^{\circ} \mathrm{C}$ em torno de $2 \theta=36^{\circ}$ 
A síntese dos resultados obtidos através das análises por XRD é mostrada na tabela 5.7 e na Figura 5.11.

Tabela 5.7: Distâncias interplanares obtidas por análises por XRD e condições de oxidação

\begin{tabular}{cccc}
\hline Tempo(min $)$ & $2 \theta$ & distância interplanar $(\AA)$ & largura do $\operatorname{pico}\left({ }^{\circ}\right)$ \\
\hline 10 & 36,22 & 2,480 & 0,94 \\
20 & 36,08 & 2,489 & 1,04 \\
30 & 36,07 & 2,490 & 0,97
\end{tabular}

A Figura 5.11 mostra os difratogramas das amostras oxidadas durante 10, 20 e 30 minutos em $180^{\circ} \mathrm{C}$, e do substrato (UDAC), com $2 \theta$ variando entre 10 e $90^{\circ}$. São apresentadas todas as possíveis indexações das fases, considerando as fases descritas na biblioteca JCPDS para o cobre e seus óxidos. Verifica-se através da observação da figura que os picos correspondentes aos óxidos $\left(C u O_{x}\right)$ estão em torno de $36^{\circ}$ e $60,7^{\circ}$, este último com intensidade reduzida e largura muito grande. Deste modo, fica claro que a análise deve ser feita tomando como base o primeiro pico, cuja região está evidenciada na Figura 5.10, mostrando as possíveis reflexões referentes às estruturas $\mathrm{CuO}$ e $\mathrm{Cu}_{4} \mathrm{O}_{3}$ entre $30^{\circ}$ e $40^{\circ}$.

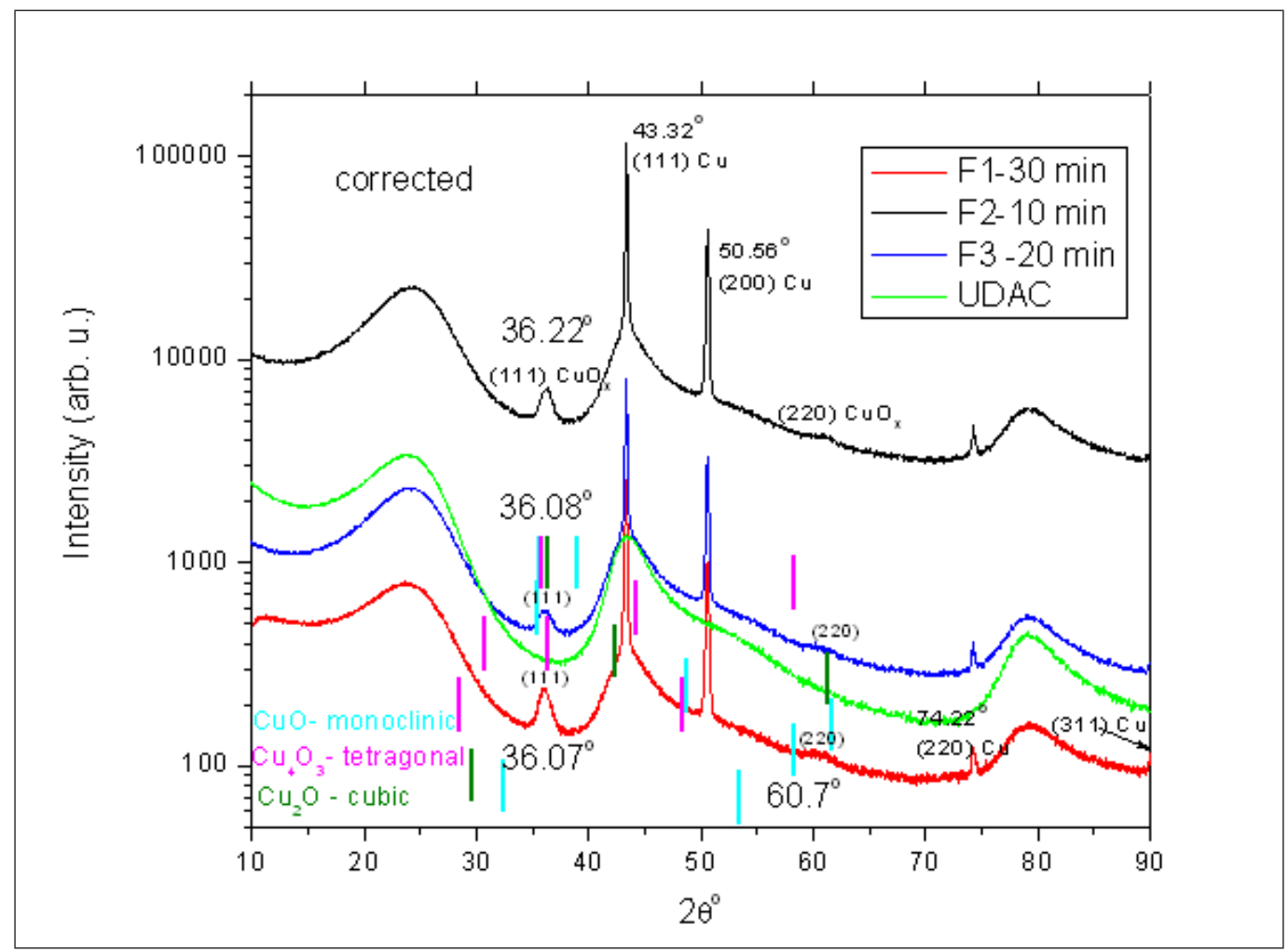

Figura 5.11: Espectro XRD dos filmes de $\mathrm{Cu} / \mathrm{C}$ oxidados durante 10, 20 e 30 minutos 
Na determinação da fase responsável pela reflexão em torno do ângulo mostrado, deve ser excluída a fase $\mathrm{CuO}$, pois caso fosse possível a sua existência nestas condições de oxidação, seria gerada outra reflexão de mesma intensidade relativa em torno de $39^{\circ}$ (JCPDS41-254). Como pode ser visto na figura, isto não ocorreu.

Quanto à fase $\mathrm{Cu}_{4} \mathrm{O}_{3}$, a sua existência garantiria uma reflexão em torno de 30,7(JCPDS3-879), o que não ocorreu nas condições trabalhadas.

Assim, conclui-se que a oxidação de filmes de cobre a $180{ }^{\circ} \mathrm{C}$ entre 10 e 60 minutos leva à formação das fases $\mathrm{Cu}_{2} \mathrm{O}$ e uma fase que não está indexada na biblioteca JCPDS, dependendo do tempo de oxidação.

As análises por RBS não foram conclusivas em relação ao tipo de óxido para o tempo de oxidação igual 20 e 30 minutos. Análises por XRD indicam a possibilidade de existência de outra fase, mas também não foi conclusiva.

Assim, a tentativa caracterização dos óxidos crescidos em tempos de 20 e 30 minutos teve o foco mudado e a caracterização da amostra oxidada em $180{ }^{\circ} \mathrm{C}$, por 90 minutos, abriu a possibilidade de determiná-los. Se forem encontrados os óxidos $\mathrm{Cu}_{3} \mathrm{O}_{2}$ ou $\mathrm{CuO}$ nessa amostra, significa que $\mathrm{Cu}_{3} \mathrm{O}_{2}$ existia quando a amostra foi oxidada por 20 e 30 minutos; pois em baixas temperaturas $\mathrm{CuO}$ resulta da conversão desse óxido. Como foi dito, a oxidação de cobre em baixas temperaturas tem como único produto $\mathrm{Cu}_{2} \mathrm{O}$. $\mathrm{O}$ aparecimento de $\mathrm{CuO}$ ocorre, em geral, a partir de $300{ }^{\circ} \mathrm{C}$. No estudo da amostra oxidada por 90 minutos, utilizou-se a Espectroscopia Raman, técnica que apresenta muita sensibilidade para detecção de cobre e seus óxidos [117] e [118].

A Figura 5.12 mostra um espectro Raman do filme de $\mathrm{Cu} / \mathrm{C}$, oxidado por 90 minutos a $180^{\circ} \mathrm{C}$. A presença dos picos em $300 / \mathrm{cm}^{-1}$ e $\left(600 / \mathrm{cm}^{-1}\right.$ mostra a existência dos compostos $\mathrm{CuO}$ e $\mathrm{Cu}_{2} \mathrm{O}$. Isso significa, que houve conversão do $\mathrm{Cu}_{3} \mathrm{O}_{2}$ presente na amostra oxidada por 20 e 30 minutos, para $\mathrm{CuO}$, concordando com resultados de estudos que mostram a possibilidade de formação do óxido $\mathrm{Cu}_{3} \mathrm{O}_{2}$ e a conversão desse para $\mathrm{CuO}$, nas condições experimentais utilizadas no nosso estudo [114] e [16], segundo a reação:

$$
\mathrm{Cu}_{3} \mathrm{O}_{2}+1 / 2 \mathrm{O}_{2} \rightarrow 3 \mathrm{CuO}
$$

É importante salientar que poucos trabalhos têm conseguido medir ainda que de forma indireta esse óxido. A maioria dos trabalhos considera somente a existência do óxido $\mathrm{Cu}_{2} \mathrm{O}$, em baixas temperaturas de oxidação e $\mathrm{CuO}$, em temperaturas mais elevadas. 


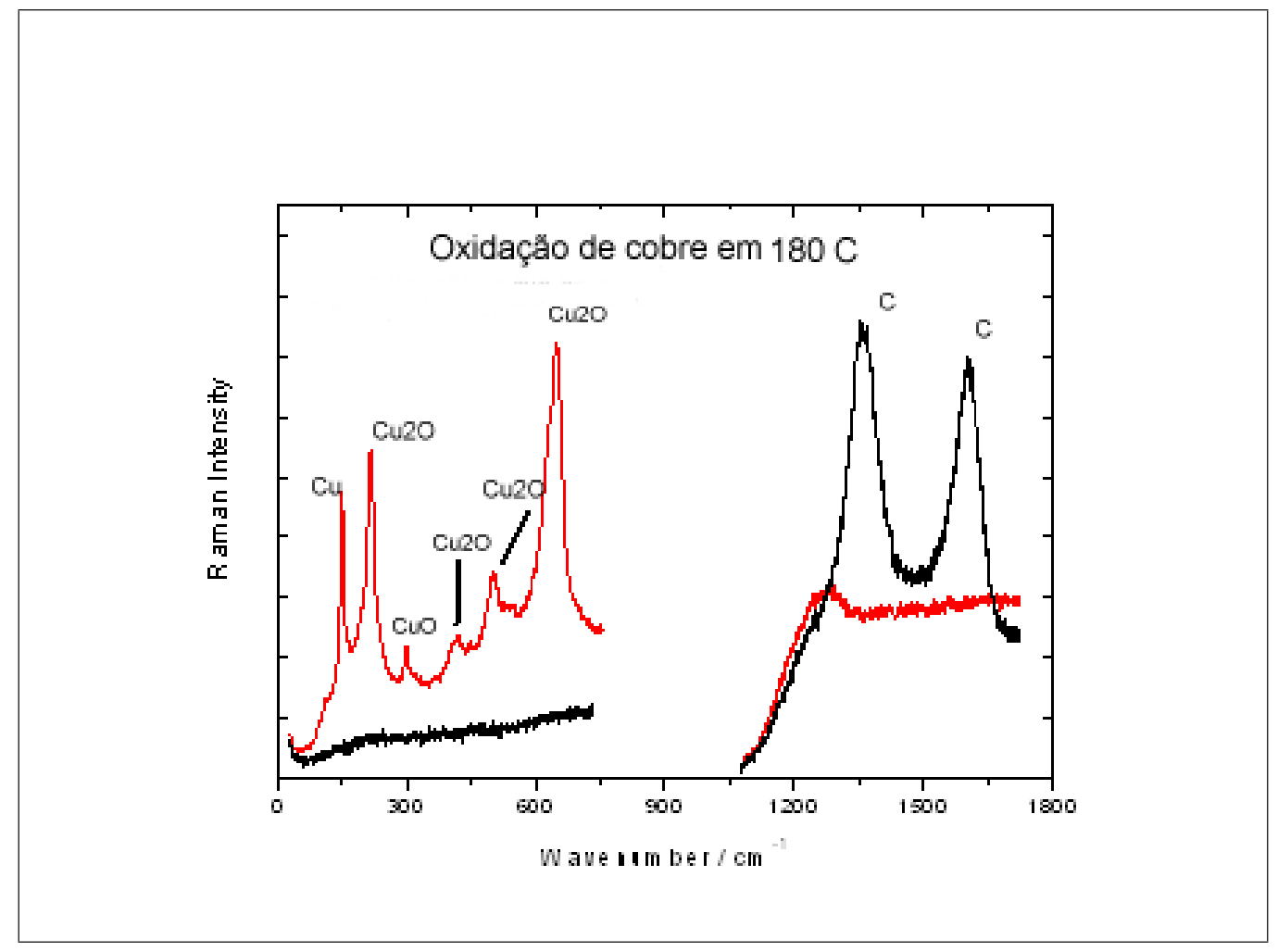

Figura 5.12: Espectro Raman do filmes de $\mathrm{Cu} / \mathrm{C}$ oxidado durante por 90 minutos $180{ }^{\circ} \mathrm{C}$, mostrando a existência do $\mathrm{CuO}$ em baixas temperaturas. As linhas vermelha e preta referem-se ao sinal do filme e ao substrato, respectivamente.

\section{Oxidação de cobre a $200^{\circ} \mathrm{C}$}

Os filmes de cobre foram submetidos à oxidação, em temperaturas de $200^{\circ} \mathrm{C}$, com variados tempos, mostrados na tabela 5.3, para verificar a possível existência de outros tipos de óxido. Como foi dito, ainda não há consenso entre quais os tipos de óxidos são crescidos em determinadas faixas de temperatura. Alguns estudos apontam para a possível existência, mas difícil determinação do $\mathrm{Cu}_{3} \mathrm{O}_{2}$, para filmes oxidados por 30 minutos em $200{ }^{\circ}$ C. Esta razão motivou a reprodução do experimento nesta condição.

Para aumentar a possibilidade de determinação, além do tempo citado, 3 outros tempos foram utilizados. Na tabela 5.8 são mostradas tais condições.

O espectro RBS obtido após a oxidação da amostra em $200{ }^{\circ} \mathrm{C}$ por 30 minutos é mostrado na Figura 5.13.

A simulação do espectro RBS resulta de modo inequívoco em uma estrutura tipo $\mathrm{Cu}_{2} \mathrm{O} / \mathrm{Cu}$, não sendo necessária nenhuma outra técnica para verificação do tipo de óxido crescido. Este resultado se repetiu para amostras oxidadas nos demais tempos. 
Tabela 5.8: Condições de obtenção do $\mathrm{Cu}_{3} \mathrm{O}_{2}$ da literatura[43]

\begin{tabular}{ccc}
\hline Amostra & Temperatura $\left({ }^{\circ} C\right)$ & tempo $(\min )$ \\
\hline M20 & 200 & 20 \\
M19 & 200 & 25 \\
M18 & 200 & 30 \\
M21 & 200 & 35
\end{tabular}

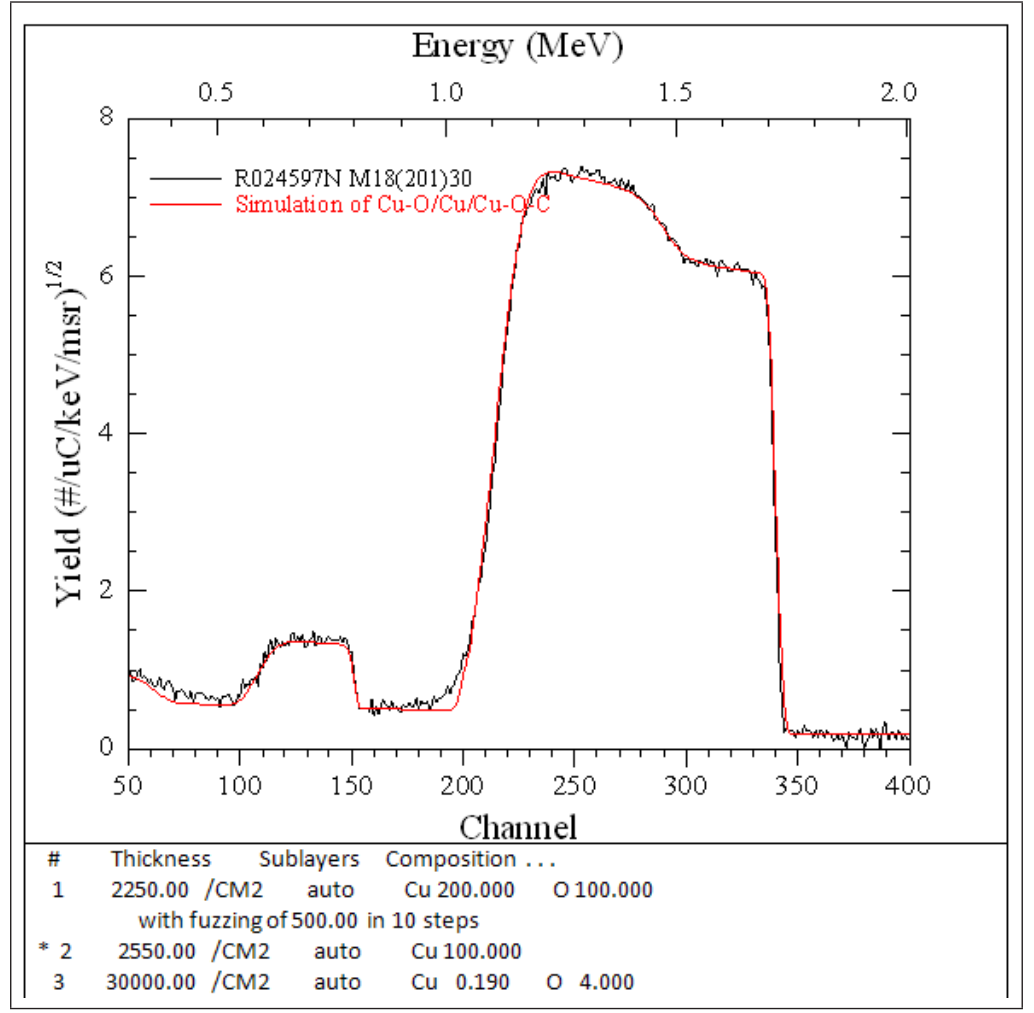

Figura 5.13: Espectro RBS dos filmes de $\mathrm{Cu} / \mathrm{C}$ oxidados durante 30 minutos em $200{ }^{\circ} \mathrm{C}$, mostrando a existência de somente um óxido crescido nessas condições.

\section{Oxidação de cobre a $250^{\circ} \mathrm{C}$}

Filmes de $\mathrm{Cu} / \mathrm{C}$ e $\mathrm{Cu} / \mathrm{Si}$, depositados a partir do procedimento descrito no capítulo anterior, foram submetidos à oxidação em atmosfera ambiente, em temperatura de 250 ${ }^{\circ} \mathrm{C}$, com tempos variando entre 18 e 240 minutos, conforme a tabela 5.3. Os espectro RBS das amostras são mostrados nas Figuras 5.14 e 5.30. As simulações dos espectros RBS mostraram que a oxidação de filmes de cobre puro em $250^{\circ} \mathrm{C}$ resulta na formação de somente um tipo de óxido, o $\mathrm{Cu}_{2} \mathrm{O}$, com cinética de oxidação parabólica, conforme pode ser visto na Figura 5.15. 


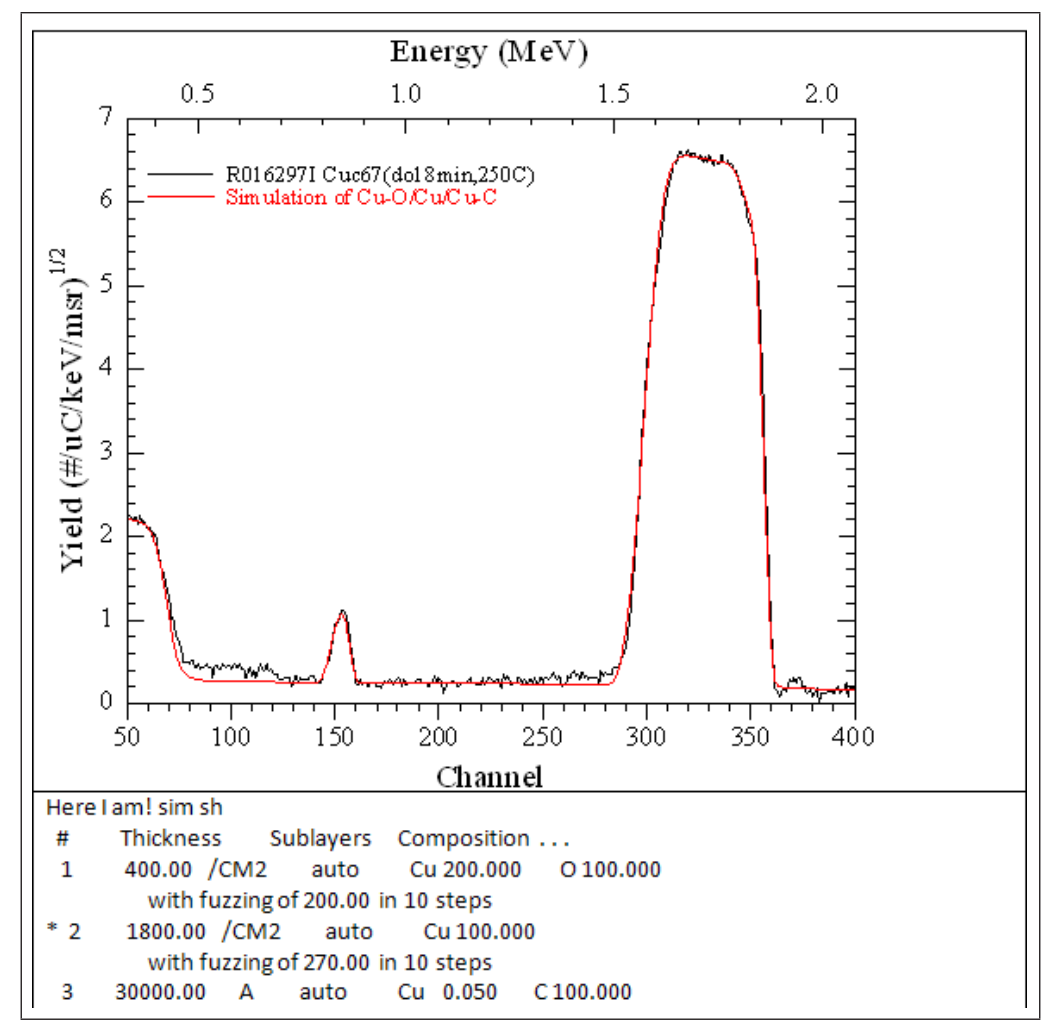

Figura 5.14: Espectro RBS de um filmes de $\mathrm{Cu}$ oxidado durante 18 minutos a $250{ }^{\circ} \mathrm{C}$. Pode ser observada a existência de somente um tipo de óxido nessas condições de oxidação.

\section{Oxidação de cobre a $300{ }^{\circ} \mathrm{C}$}

Filmes de $\mathrm{Cu} / \mathrm{C}$ foram oxidados a $300{ }^{\circ} \mathrm{C}$ por tempos entre 3,0 e 25 minutos, mostrados na tabela 5.3.

A Figura 5.16 mostra a sobreposição de dois espectros RBS, para filmes de cobre antes e depois da oxidação por 3 minutos em atmosfera ambiente.

Análises RBS mostram que tempos tão pequenos quanto 3 minutos são suficientes para oxidar totalmente filmes de 295,0 nm de espessura e que tempos de oxidação acima deste valor somente têm efeitos sobre a distribuição dos óxidos formados, alterando a concentração do oxigênio e a rugosidade do filme, como pode ser observado através da análise dos espectros RBS mostrados na Figura 5.17, cujos resultados são mostrados na tabela 5.9.

A simulação desses espectro utilizando o programa RUMP, resulta em uma estrutura composta por $\mathrm{CuO}$ na superfície externa e, mais internamente, uma mistura de dois óxidos $\mathrm{CuO}+\mathrm{Cu}_{2} \mathrm{O}$. Na camada mais interna, próxima ao substrato, a concentração de oxigênio 


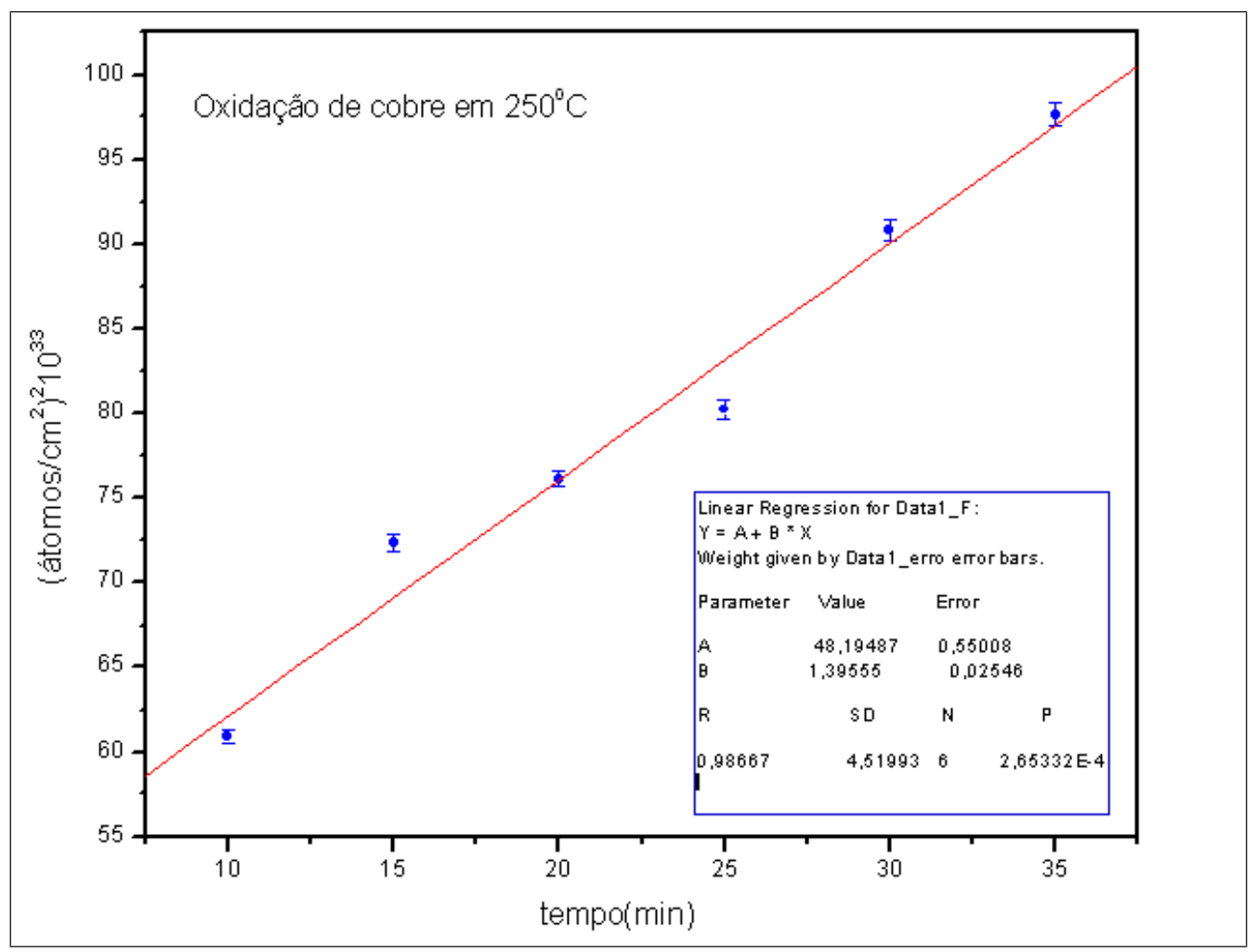

Figura 5.15: Cinética de oxidação de filmes de $\mathrm{Cu} / \mathrm{C}$, onde são mostrados variação da concentração de oxigênio incorporado no filme em função do tempo de oxidação.

Tabela 5.9: Resultados da simulação dos espectros RBS para oxidação de cobre em $300{ }^{\circ} \mathrm{C}$

\begin{tabular}{ccccc}
\hline $\begin{array}{c}\text { Tempo } \\
\text { min }\end{array}$ & $\begin{array}{c}\text { Camada 01(CuO) } \\
10^{15} \mathrm{at} / \mathrm{cm}^{2}\end{array}$ & $\begin{array}{c}\text { Camada } 02\left(\mathrm{Cu}_{2} \mathrm{O}\right) \\
10^{15} \mathrm{at} / \mathrm{cm}^{2}\end{array}$ & $\begin{array}{c}\text { Camada 03 } \\
10^{15} \mathrm{at} / \mathrm{cm}^{2}\end{array}$ & $\begin{array}{c}\text { Rugosidade } \\
10^{15} \mathrm{at} / \mathrm{cm}^{2}\end{array}$ \\
\hline 03 & 570 & 2350 & - & 400 \\
4,5 & 600 & 650 & $550\left(\mathrm{Cu}_{2} \mathrm{O}_{1,4}\right)$ & 300 \\
16 & 600 & 650 & $500\left(\mathrm{Cu}_{2} \mathrm{O}_{1,4}\right)$ & 300 \\
25 & 450 & 1000 & $300\left(\mathrm{Cu}_{2} \mathrm{O}_{1,2}\right)$ & 350
\end{tabular}

tem seu valor aumentado, indicando que o oxigênio presente na superfície do substrato, pode ter sido incorporado ao filme.

As análises RBS foram muito pouco conclusivas em relação à oxidação dos filmes em $300{ }^{\circ} \mathrm{C}$, tornando-se necessário realizar análises XRD e espectroscopia Raman para determinar com precisão o tipo do óxido crescido e a possível variação da concentração de oxigênio incorporado em função do tempo de oxidação.

A Figura 5.18 mostra o espectro XRD para um filme de $\mathrm{Cu} / \mathrm{C}$ oxidado por 16 minutos. Podem ser vistos os picos correspondentes aos óxidos $\mathrm{Cu}_{2} \mathrm{O}$ e $\mathrm{CuO}$. É possível verificar a 


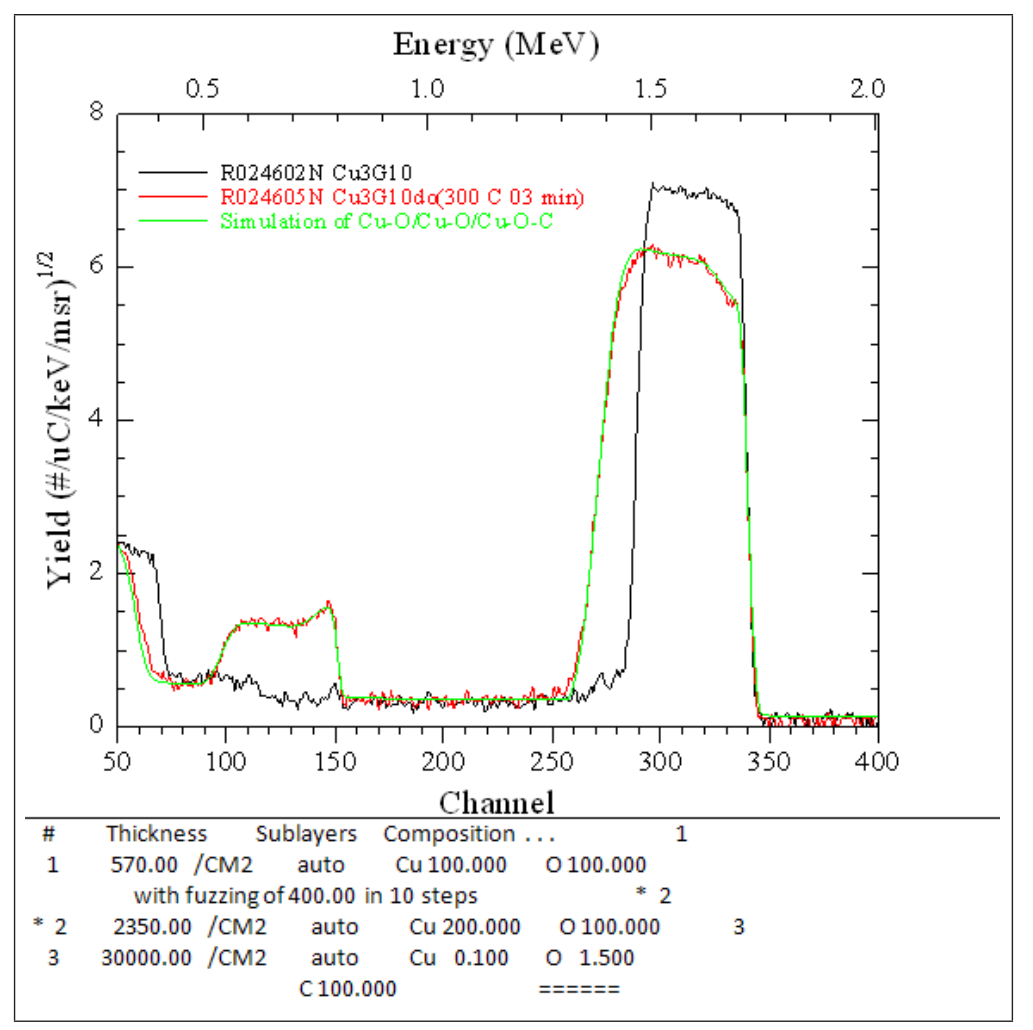

Figura 5.16: Espectro RBS de um filme de $\mathrm{Cu} / \mathrm{C}$ antes e após a oxidação por 3 minutos em $300{ }^{\circ} \mathrm{C}$ e a simulação do espectro do filme oxidado.

não existência de cobre metálico. Isto pode ter acontecido pela ausência de cobre metálico no filme devido à total oxidação do filme, mostrada nos espectros RBS; pela não existência de $\mathrm{Cu}$ na fase cristalina ou ainda pela quantidade insuficiente para ser visto. Seu pico de maior intensidade, correspondente ao plano (111), está em torno de $2 \theta=43,32^{0}$ e pode ter sido mascarado pelo sinal do UDAC.

A Figura 5.19 mostra o difratograma dos filmes de $\mathrm{Cu} / \mathrm{C}$ oxidados em 4,5, 16, e 25 minutos.

Pode ser observado pela Figura 5.20 que há uma ligeira variação nas espessuras dos óxidos.

As análises por XRD foram sensíveis à variação da concentração do tipo de óxido com o tempo, mas não conseguiram ser conclusivas em relação à existência de $\mathrm{Cu}$ metálico nestas condições. A análise por espectroscopia Raman mostrou que ainda existe cobre não oxidado na amostra, mesmo quando o processo de oxidação durou 20 minutos, como pode ser visto pela Figura 5.21.

Não foi observado o aparecimento do $\mathrm{Cu}_{4} \mathrm{O}_{3}$ nas condições experimentais trabalhadas. 


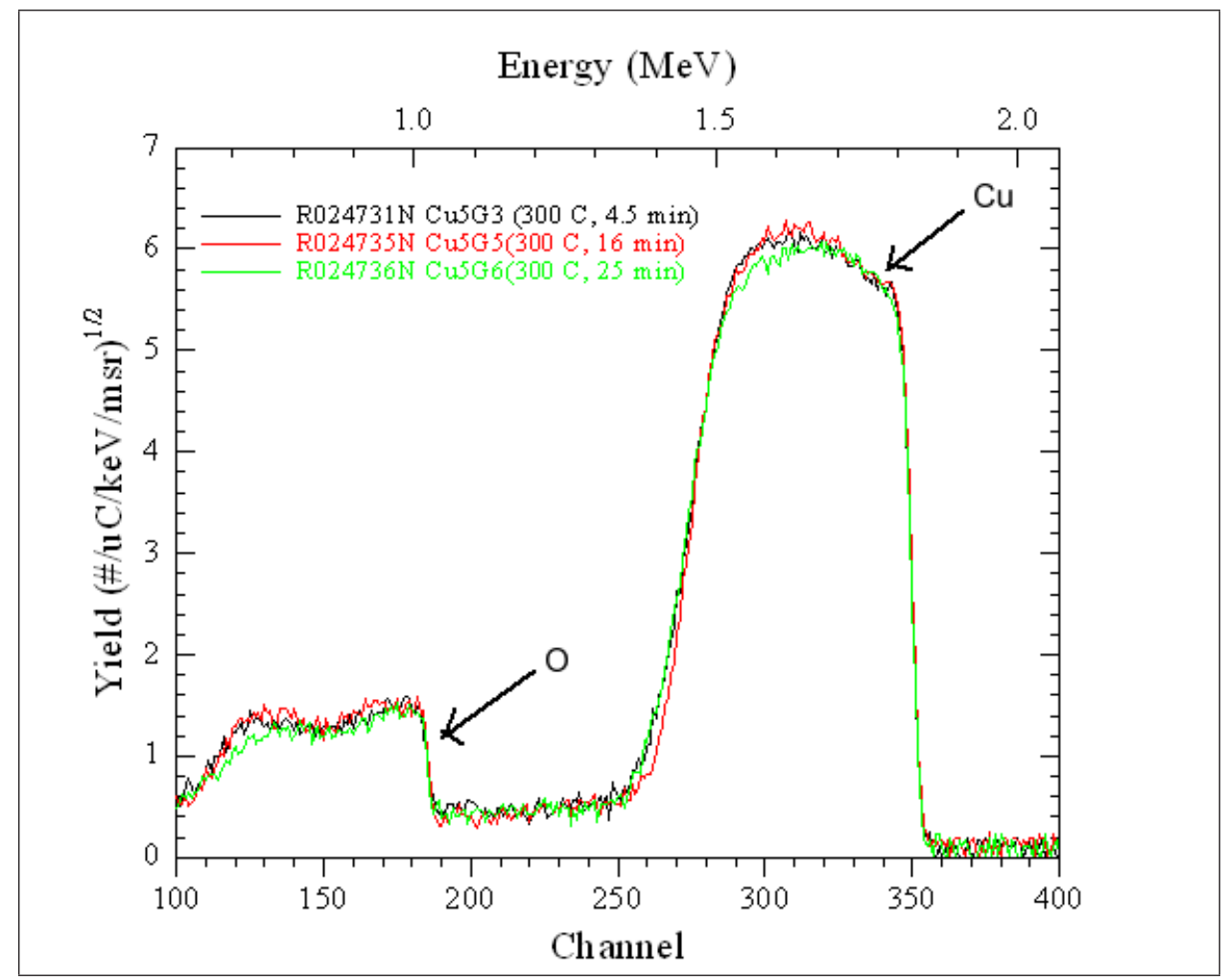

Figura 5.17: Espectro RBS de um filme de cobre após a oxidação a $300{ }^{\circ} \mathrm{C}$ durante 25,16 e 4,5 minutos.

Oxidação de cobre em $300{ }^{\circ} \mathrm{C}$ apresentou um comportamento muito diferente do esperado. À medida que o tempo aumentou, não foi observada nenhuma tendência na incorporação do oxigênio. Além disso, mesmo para tempos longos de oxidação, foi constatada a presença de cobre não oxidado.

\section{Oxidação de cobre a $350^{\circ} \mathrm{C}$}

Os filmes de cobre foram oxidados em atmosfera ambiente, em tempos variando entre 2 e 14 minutos, mostrados na tabela 5.3.

A Figura 5.22 mostra os espectros RBS de dois filmes de cobre oxidados por 2 e 14 minutos e os resultados da simulação desses espectros são mostrados na tabela 5.10.

Tabela 5.10: Resultados da simulação dos espectros RBS para oxidação de $\mathrm{Cu} / \mathrm{C}$ em $350{ }^{\circ} \mathrm{C}$, durante 2 e 14 minutos

\begin{tabular}{cccc}
\hline Tempo & Camada 01 & Camada 02( $\left.\mathrm{Cu}_{2} \mathrm{O}\right)$ & Rugosidade \\
\hline 02 & $300\left(\mathrm{Cu}_{2} \mathrm{O}_{1,4}\right)$ & 2330 & 700 \\
14 & $700(\mathrm{CuO})$ & 1950 & 500
\end{tabular}




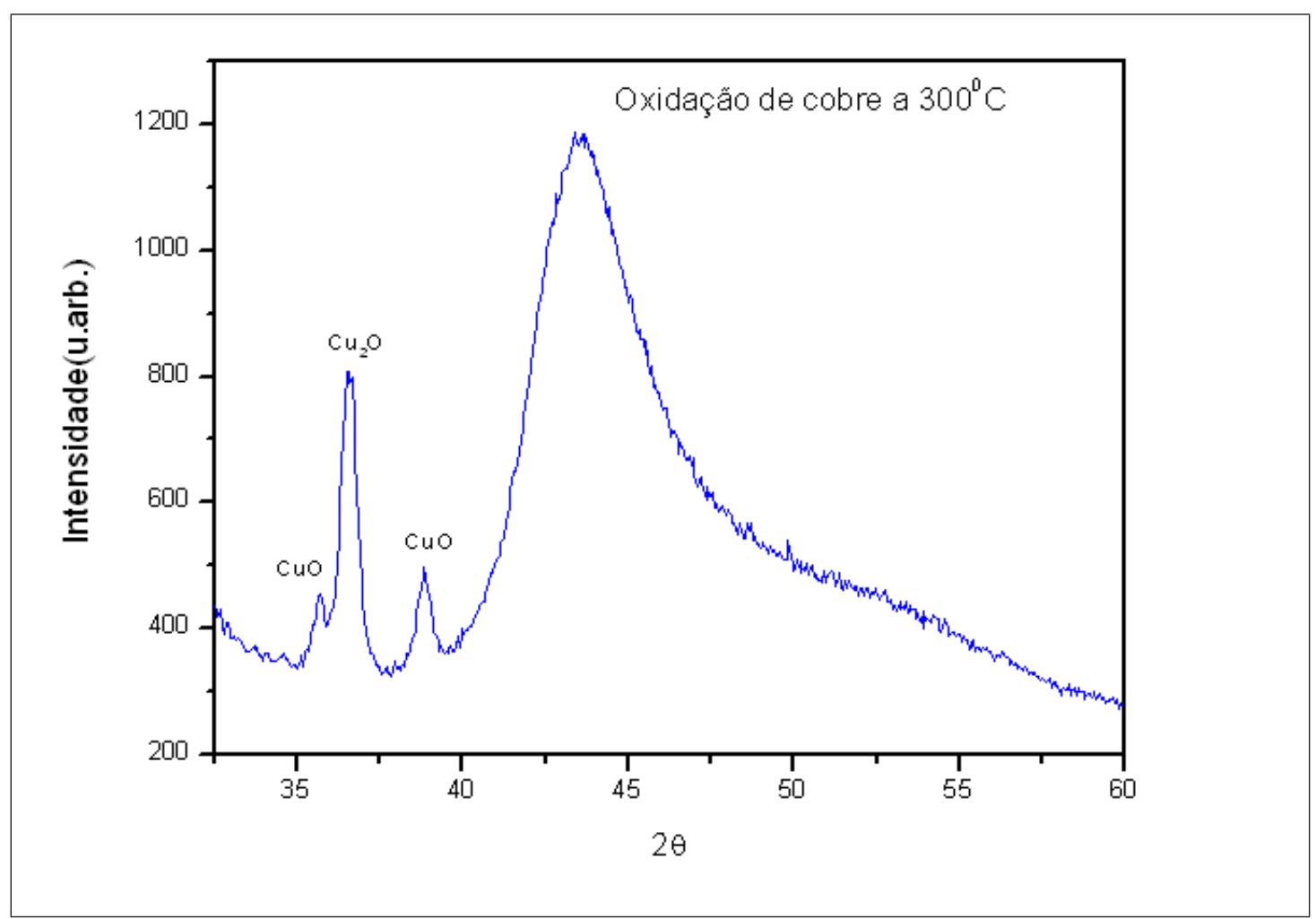

Figura 5.18: Difratogramas de um de filmes de $\mathrm{Cu} / \mathrm{C}$ oxidado a $300{ }^{\circ} \mathrm{C}$ por 16 minutos, mostrando a ausência de $\mathrm{Cu}$ metálico e a existência dos óxidos $\mathrm{Cu}_{2} \mathrm{O}$ e $\mathrm{CuO}$.

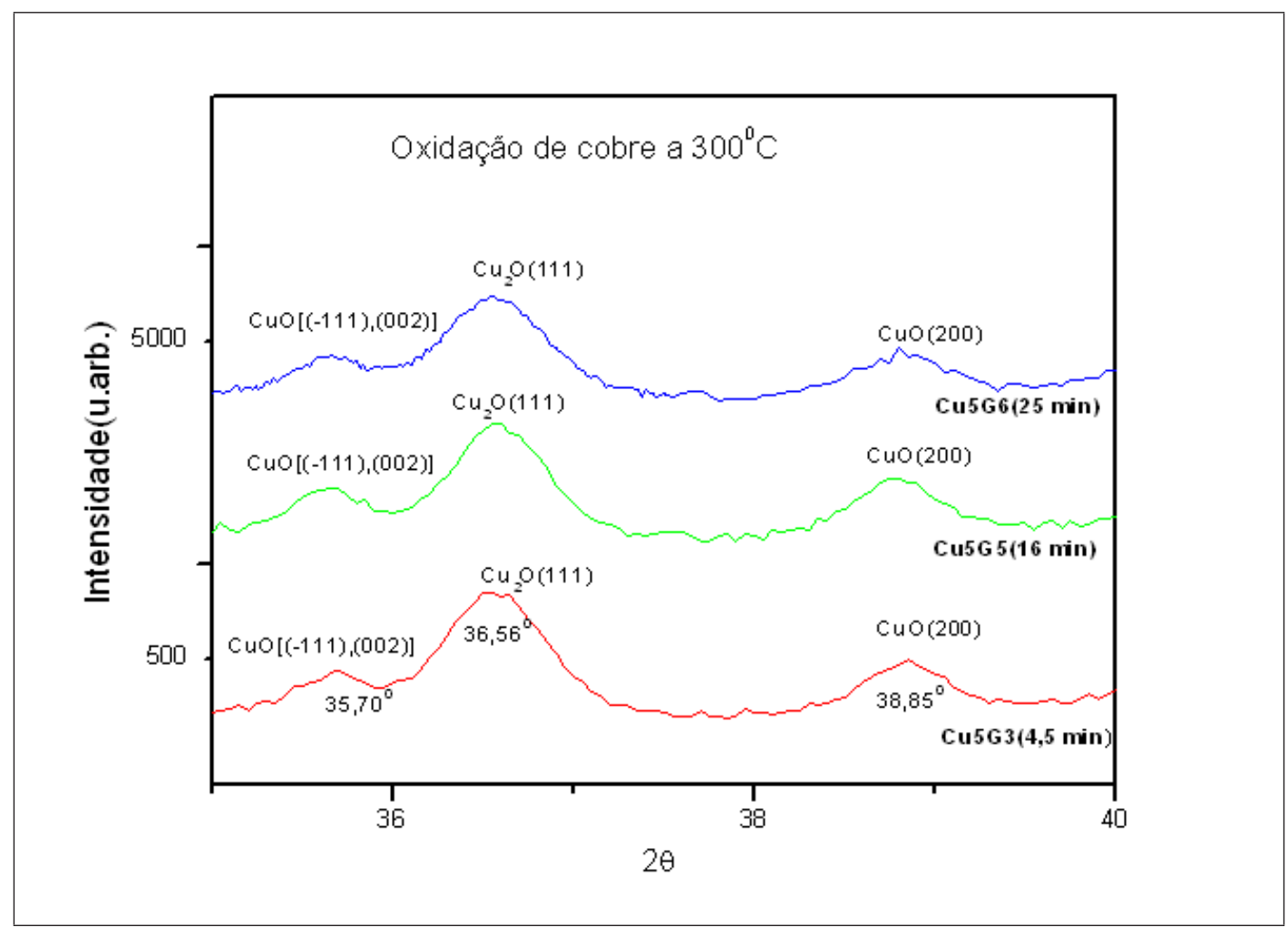

Figura 5.19: Difratogramas de filmes de cobre oxidados a $300{ }^{\circ} \mathrm{C}$ em $4,5,16$ e 25 minutos 


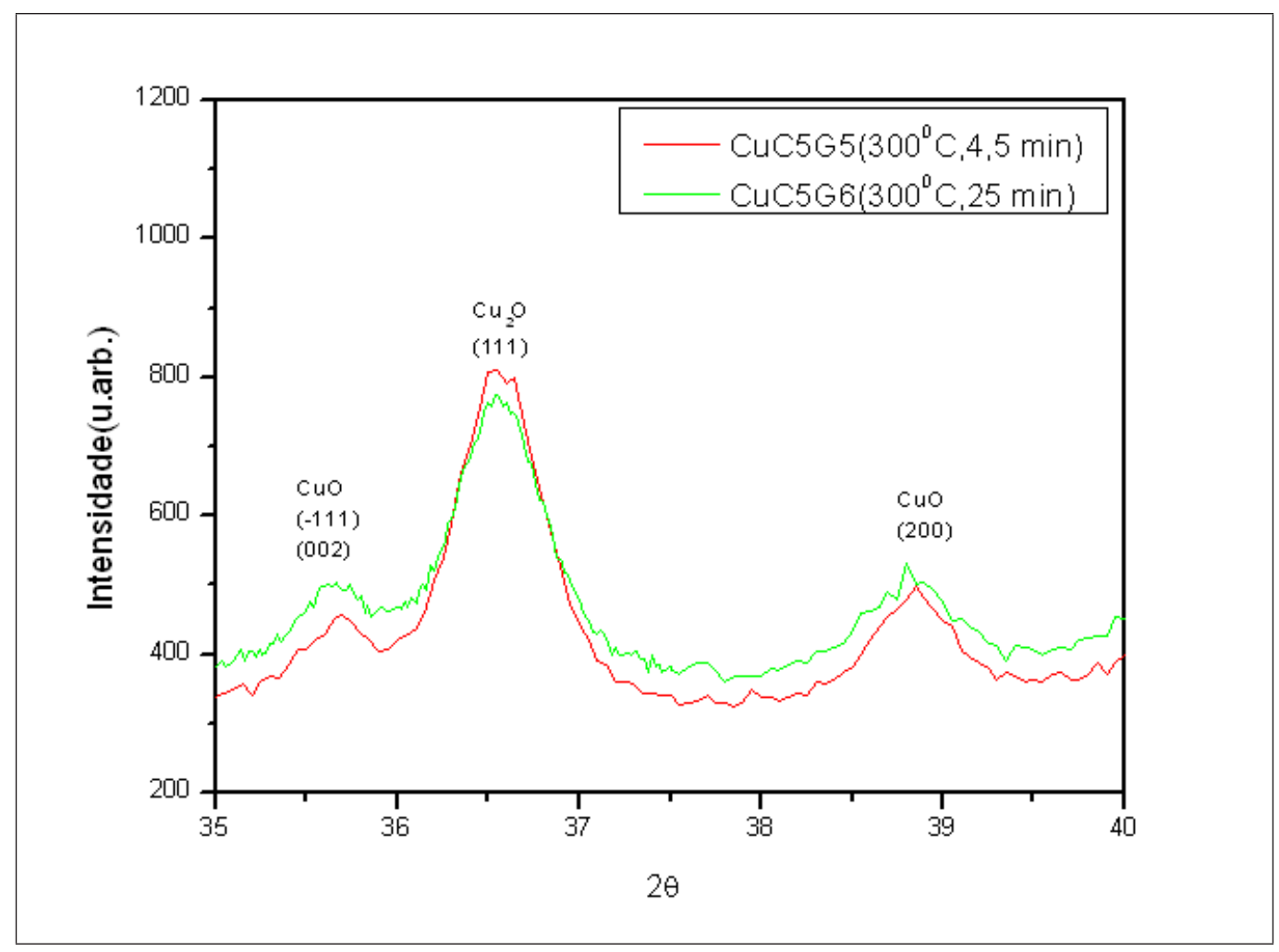

Figura 5.20: Difratogramas de filmes de cobre oxidados a $300{ }^{\circ} \mathrm{C}$ durante 4,5 , e 25 minutos, mostrando a variação das concentrações dos óxidos em função do tempo de oxidação. Note a redução de $C u_{2} O_{111}\left(2 \theta=36,5^{\circ}\right)$ quando o tempo de oxidação aumenta de 4,5 para 25 minutos e o conseqüente aumento do $\mathrm{CuO}$.

Podemos concluir que diferentemente do comportamento da oxidação em $300{ }^{\circ} \mathrm{C}$, há uma clara definição das regiões contendo os diferentes óxidos de cobre. Para tempos de oxidação reduzidos há uma pequena espessura de $\mathrm{CuO}$, mostrada na Figura 5.22. À medida que aumenta o tempo de oxidação, a concentração de $\mathrm{Cu}_{2} \mathrm{O}$ é reduzida devido à sua oxidação para $\mathrm{CuO}$, que tende a ocupar grande parte do filme de cobre. Não foi encontrado nenhum outro tipo de óxido.

Para a determinação da cinética de oxidação, foi efetuada a simulação dos espectros RBS com o programa RUMP e em seguida determinada a concentração de oxigênio incorporada, mostrada na Figura 5.23 em função do tempo de oxidação.

Assim, em $350{ }^{\circ} \mathrm{C}$, o comportamento da taxa de oxidação segue uma lei aproximadamente parabólica, mostrando que a taxa de oxidação é controlada pela difusão do cobre. 


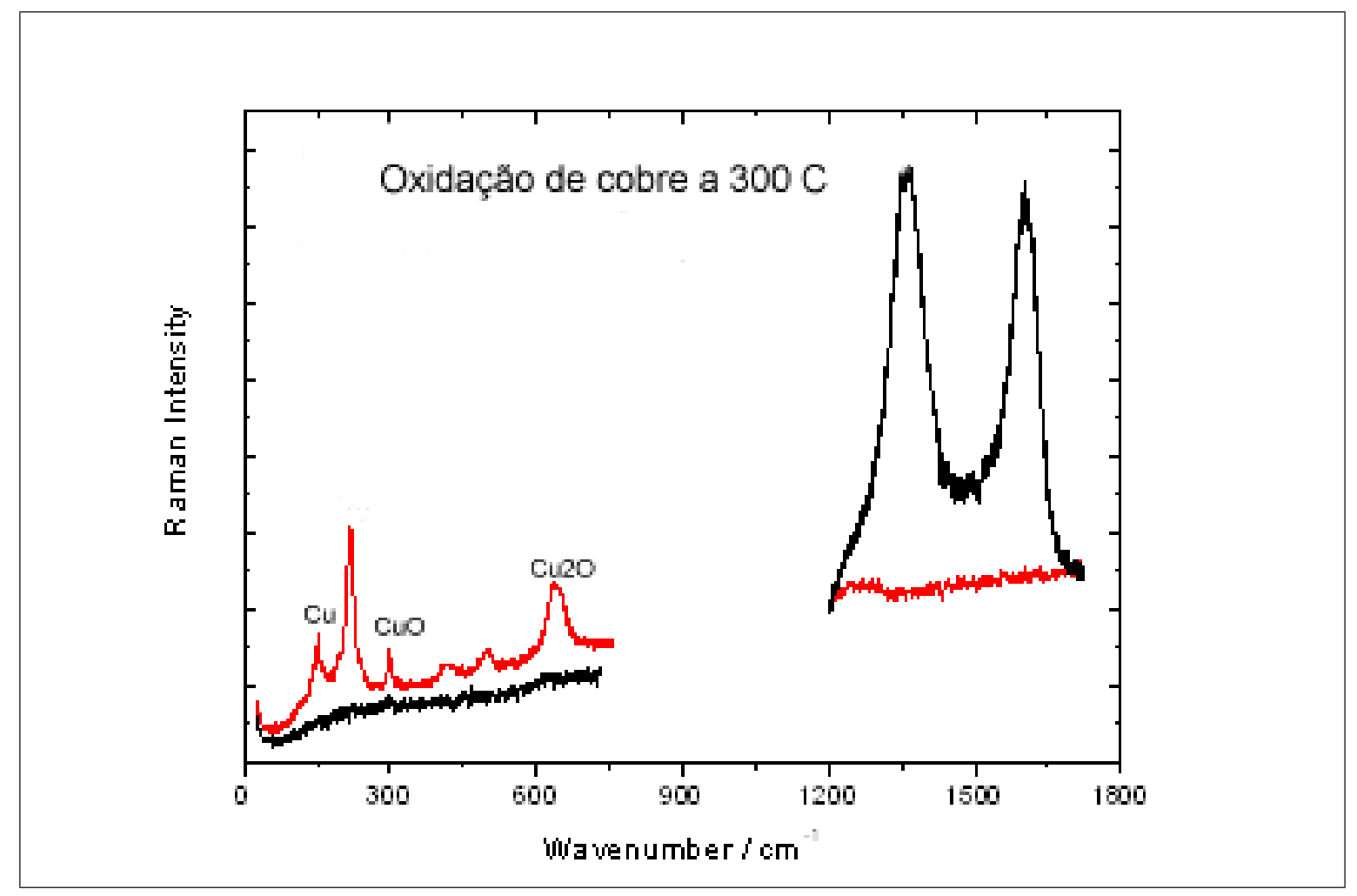

Figura 5.21: Espectro Raman de um filme de cobre após oxidação a $300{ }^{\circ} \mathrm{C}$ por 20 minutos. Podem ser vistos os picos correspondentes ao $\mathrm{Cu}$, ao $\mathrm{Cu}_{2} \mathrm{O}$ e ao $\mathrm{CuO}$.

\section{Determinação da energia de ativação para oxidação}

Dois métodos foram utilizados na determinação da energia de ativação. No primeiro, 11 amostras foram utilizadas e fez-se um ajuste multivariado. No segundo, foram selecionados três valores de temperatura para oxidação e feita a determinação da constante parabólica para cada um deles. A partir de um gráfico de Arrhenius $\left(\ln K_{p} x 1 / T\right)$, foi determinada a energia de ativação para a oxidação.

\section{Determinação através de ajuste multivariado}

Para o ajuste multivariado, foram analisados os resultados da concentração de oxigênio incorporado, obtidos através de análises RBS. Foram utilizadas 11 amostras com espessuras entre $1,5 \times 10^{18}$ a $2,1 \times 10^{18}$ átomos $/ \mathrm{cm}^{2}$ e as temperaturas variaram entre $100{ }^{\circ} \mathrm{C}$ e $350{ }^{\circ} \mathrm{C}$. Supondo parabólica a cinética de oxidação nessa região, foi feito um ajuste entre a quantidade de oxigênio incorporado, o tempo e a temperatura de oxidação, resultando em uma energia de ativação $E_{a}=(0,62 \pm 0,02) \mathrm{eV}$. 


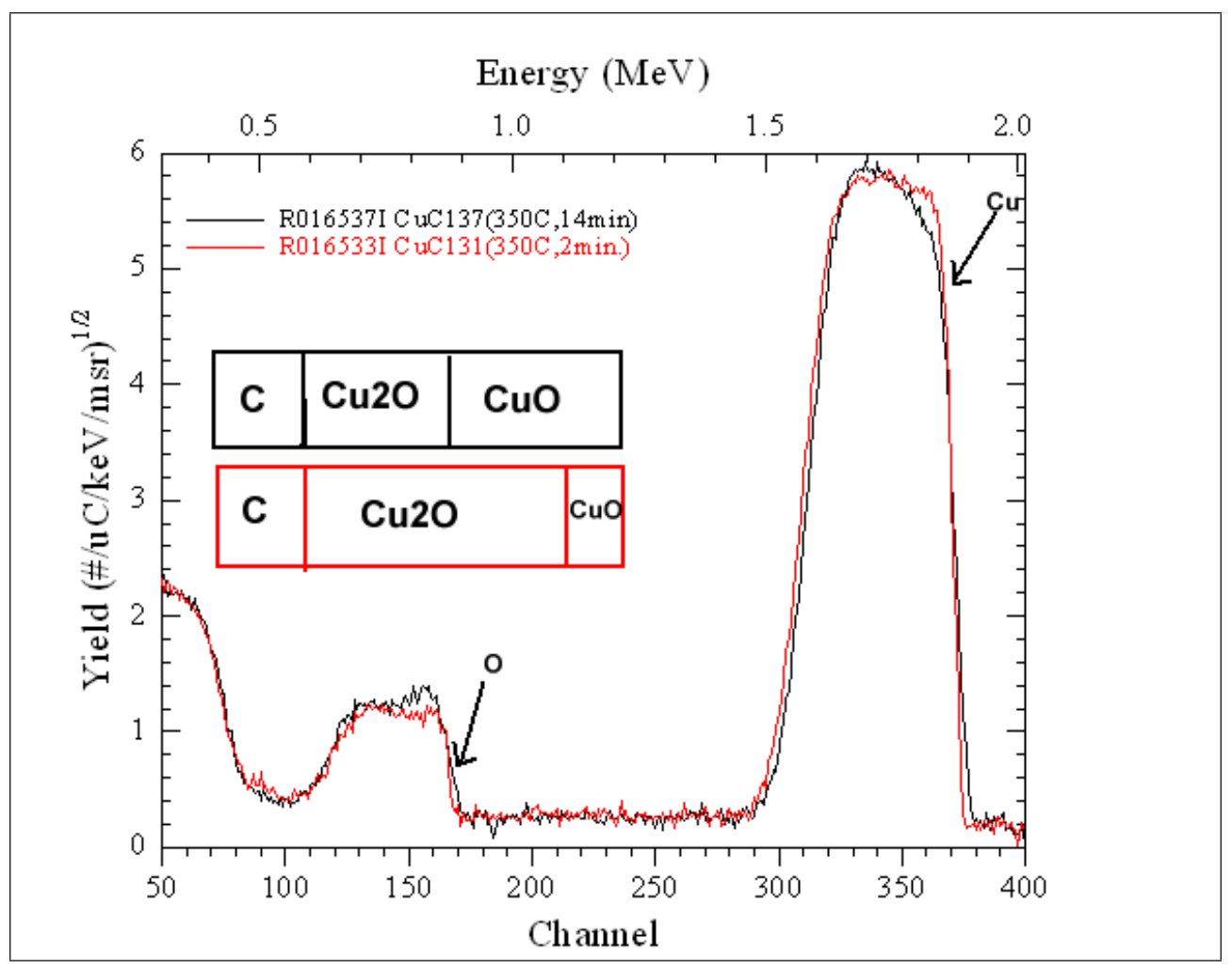

Figura 5.22: Espectro RBS de um filme de cobre após a oxidação a $350{ }^{\circ} \mathrm{C}$ durante 2 e 14 min, mostrando o aumento da espessura do $\mathrm{CuO}$ com o tempo de oxidação.

\section{Determinação através de Gráfico de Arrhenius}

A determinação da energia de ativação foi feita a partir da oxidação do cobre em 180 ${ }^{\circ} \mathrm{C}, 250{ }^{\circ} \mathrm{C}$ e $350{ }^{\circ} \mathrm{C}$, com amostras cujas espessuras variaram entre $2,7 \times 10^{18}$ a $4,0 \times 10^{18}$ átomos $/ \mathrm{cm}^{2}$. A Figura 5.24 mostra o número de átomos oxigênio $/ \mathrm{cm}^{2}$ incorporado ao filme, em diferentes temperaturas e os dados referentes aos ajustes das curvas são mostrados na tabela 5.18.

Tabela 5.11: Resultados da simulação dos espectros RBS para oxidação de cobre em $180{ }^{\circ} \mathrm{C}$, $250{ }^{\circ} \mathrm{C}$ e $350{ }^{\circ} \mathrm{C}$

\begin{tabular}{cccc}
\hline Temperatura $\left({ }^{\circ} \mathrm{C}\right)$ & coeficiente angular & Coeficiente linear & coef. de correlação \\
\hline 180 & $(0,0900 \pm 0,0005)$ & $(1,36 \pm 0,02)$ & 0,97 \\
250 & $(1,39 \pm 0,02$ & $(48,19 \pm 0,55)$ & 0,99 \\
350 & $(42,97 \pm 0,56)$ & $(491,8 \pm 3,5)$ & 0,95
\end{tabular}




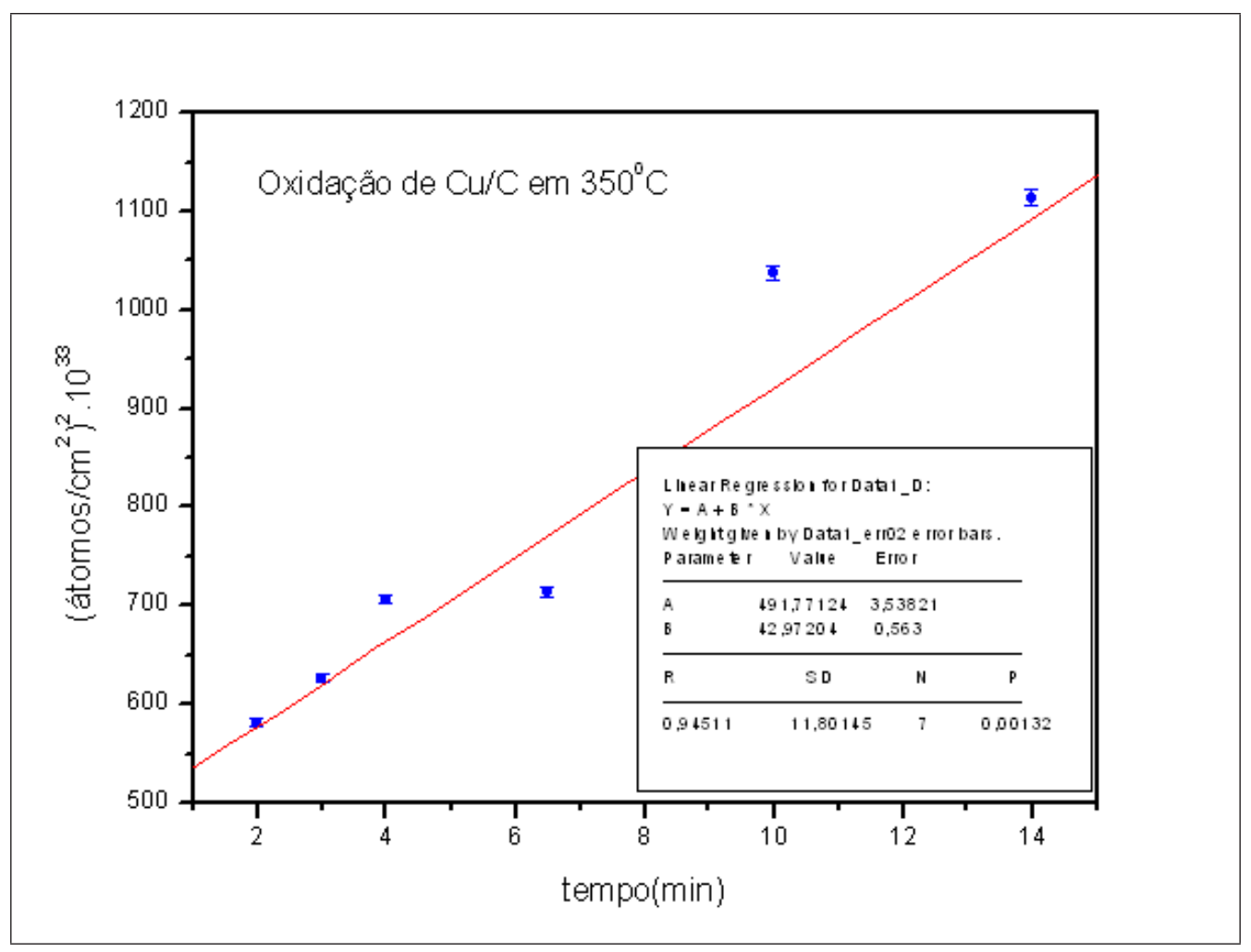

Figura 5.23: Cinética de oxidação de filmes de cobre a $350{ }^{\circ} \mathrm{C}$, para tempos de oxidação entre 2 e 14 minutos.A inclinação da reta permite a determinação da constante parabólica de oxidação.

Assumindo o comportamento parabólico para a cinética de oxidação do cobre, a espessura $x$, será dada por:

$$
x^{2}=\frac{1}{2} k_{p} t
$$

onde $k_{p}$ e $t$ são as constantes da taxa parabólica e $t$ o tempo de oxidação, respectivamente. A constante $k_{p}$ é dependente da temperatura de acordo com a seguinte equação:

$$
k_{p}=A e^{\frac{-E_{a}}{R T}}
$$

onde $A$ é uma constante e $E_{a}$ e $T$ são a energia de ativação e a temperatura, respectivamente.

A Figura 5.25 mostra um gráfico de Arrhenius para a oxidação do filme de cobre em função da temperatura. A partir da inclinação desta curva, determinou-se o valor da energia de ativação, resultando em $(0,79 \pm 0,01) \mathrm{eV}$.

Após esse estudo, conclui-se que filmes de cobre oxidados em temperaturas entre 180 e $350{ }^{\circ} \mathrm{C}$ apresentam uma cinética de oxidação com comportamento parabólico. Os filmes 


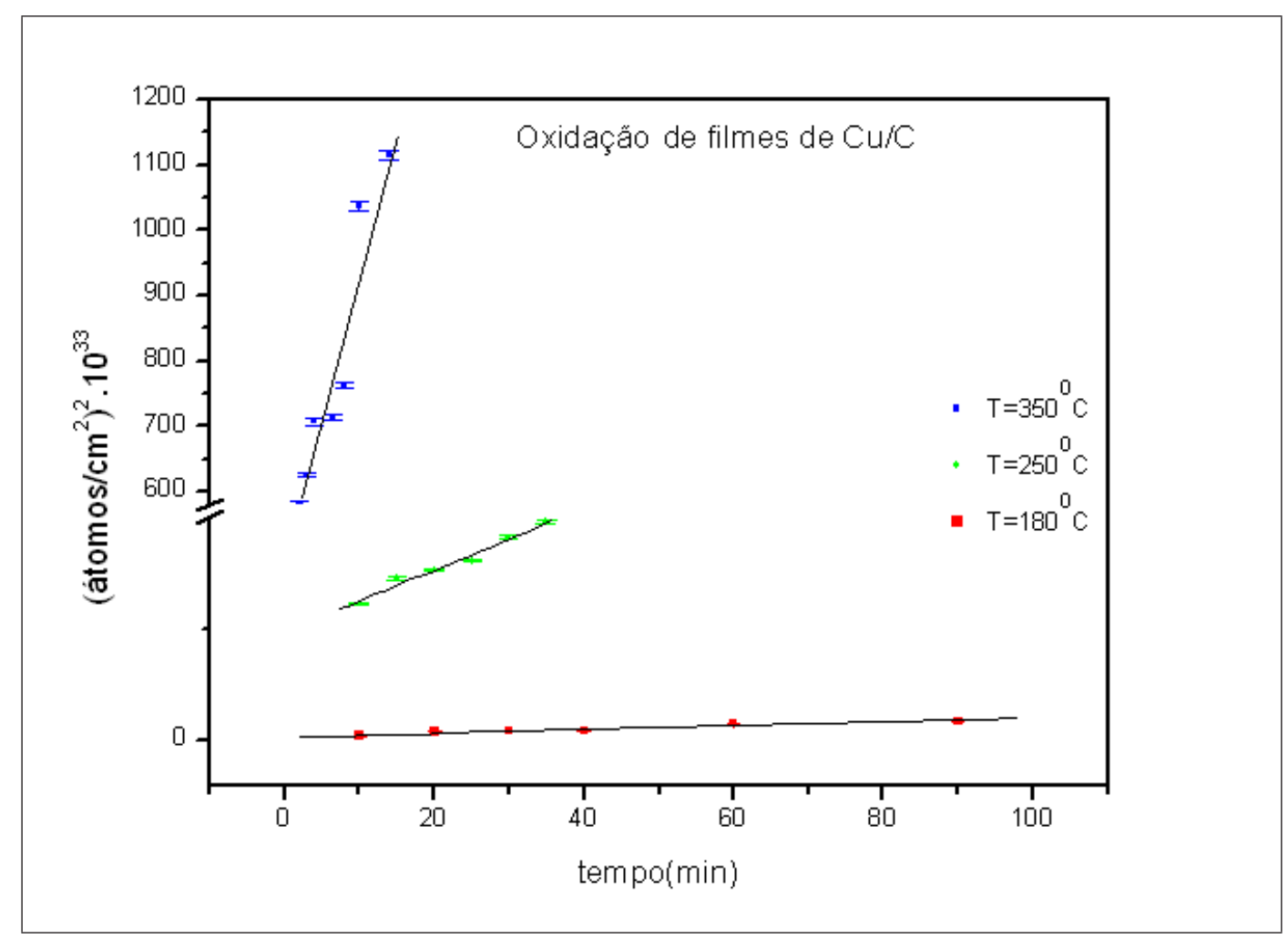

Figura 5.24: Comportamento da concentração de oxigênio incorporado em filmes de cobre em $180{ }^{\circ} \mathrm{C}, 250{ }^{\circ} \mathrm{C}$ e $350{ }^{\circ} \mathrm{C}$ em função do tempo do tratamento térmico.

possuíam a mesma textura, característica muito importante, considerando que a taxa de oxidação é dependente da orientação cristalográfica.

Depois que uma camada de óxido é formada entre o filme de cobre e o oxigênio, o crescimento do óxido é controlado pelo transporte dos íons de cobre até a interface óxido/oxigênio através do gradiente de concentração. Esta difusão geralmente se dá através de dois mecanismos: difusão através da rede(vacâncias e interstícios) e difusão relacionada a defeitos, como difusão através dos contornos de grão, que é um mecanismo rápido de difusão. Como os mecanismos são diferentes, eles requerem diferentes valores para a energia de ativação. O valor da energia de ativação obtida neste trabalho, $0,79 \mathrm{eV}$, indica que o mecanismo de difusão nestes filmes não ocorre através de vacâncias, que é mais comum em monocristais, onde a energia de ativação é aproximadamente a energia de ligação do íon cobre(acima de 2,0 eV). Assim é razoável assumir que o processo de oxidação é controlado por difusão (taxa parabólica) e que a difusão se dá através dos contornos de grãos. 


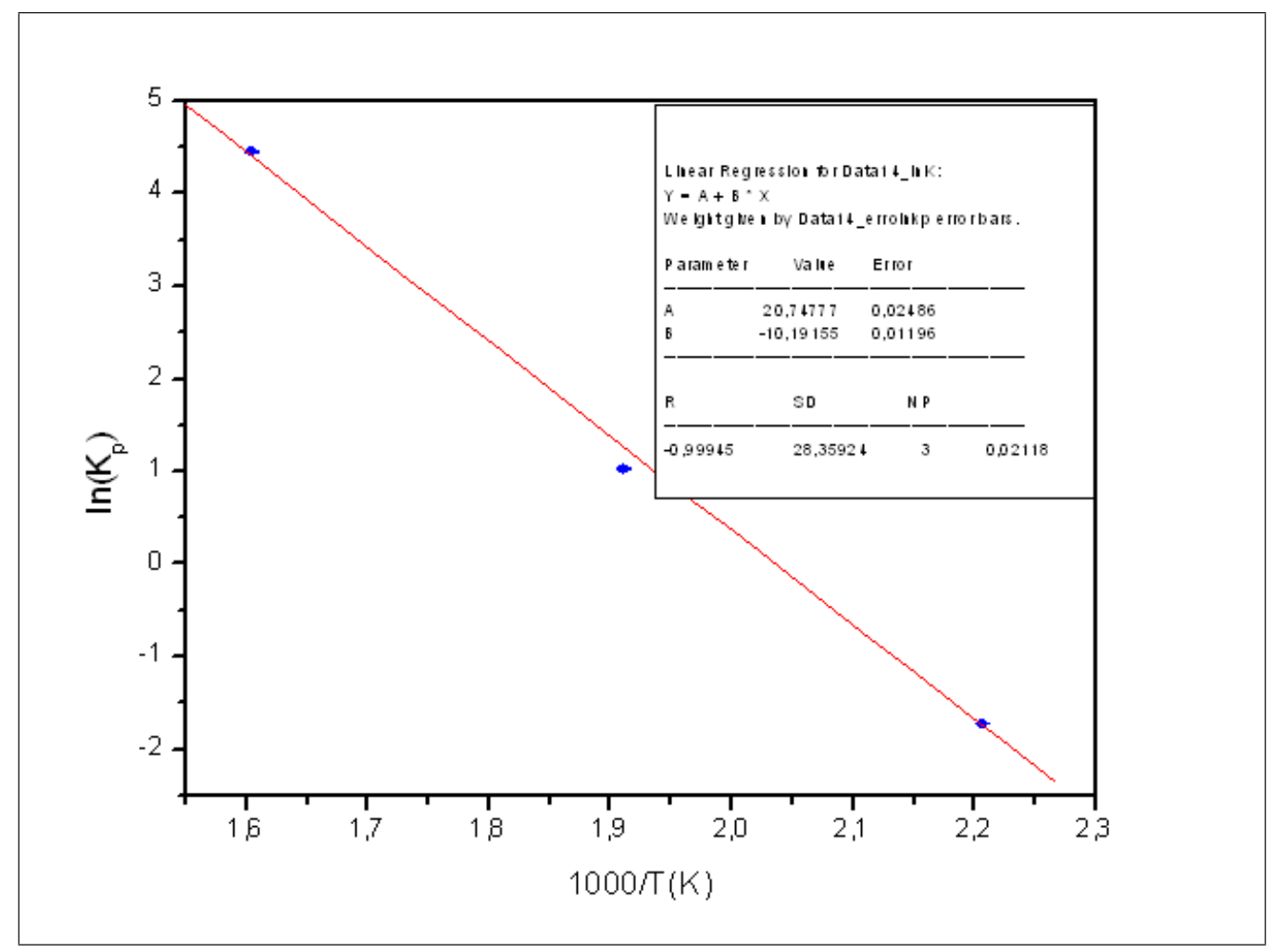

Figura 5.25: Gráfico de Arrhenius para a oxidação do cobre, mostrando a variação da constante parabólica com a temperatura

O valor da energia de ativação obtida é baixo comparada ao obtido por M.O'Reilly (0,88 eV)para bulk [119] e por Feng(1,05 eV) para pó [120]. Estes valores sugerem diferentes mecanismos para a oxidação de bulk e pó de cobre.

Ao mesmo tempo, o valor da energia de ativação obtida para oxidação de cobre neste trabalho é mais elevado que o obtido por Zhong $(0,57 \mathrm{eV})$ para filmes [20] e mais elevado que o obtido anteriormente em nossos estudos $(0,62 \mathrm{eV})$, através de ajuste multivariado, utilizando 11 amostras, com espessura máxima de 2,1x10 ${ }^{18}$ átomos $/ \mathrm{cm}^{2}$.

Em se tratando de filmes finos, quanto mais fino o filme maior a densidade de defeitos existentes. Assim, a difusão determinada pelos contornos dos grãos deve ocorrer mais facilmente, levando a uma energia de ativação mais baixa. Nesta fase do trabalho, os vários grupos de filmes finos (não tão finos) estudados possuíam espessura de até $3,7 \times 10^{18}$ átomos $/ \mathrm{cm}^{2}$, cerca de $510 \mathrm{~nm}$. Além disto, a obtenção das amostras foi feita em um sistema que possui uma refrigeração suficiente para evitar superaquecimento da evaporadora. Isto permitiu manter muito baixa a taxa de deposição, $100 \mu \mathrm{g} / \mathrm{s}$, monitorada através de um cristal oscilador, medidor de espessura. Todos estes fatores contribuíram 
para a obtenção de filmes com menor densidade de defeitos e, conseqüentemente, maior energia de ativação para oxidação.

Em temperatura de $180{ }^{\circ} \mathrm{C}$ e $200{ }^{\circ} \mathrm{C}$ para alguns tempos de oxidação somente $\mathrm{Cu}_{2} \mathrm{O}$ foi crescido.

Para temperaturas de $180^{\circ} \mathrm{C}$ e tempos de 20 e 30 minutos os resultados sugerem o aparecimento de uma estrutura diferente do $\mathrm{Cu}_{2} \mathrm{O}$. A análise RBS, sensível somente à estequiometria, permite concluir que há uma mistura dos dois tipos de óxidos. Análises por XRD mostram que nestas condições( 20 e 30 minutos) não existe a fase $\mathrm{CuO}$. Mostram também que nesta estrutura há uma expansão do parâmetro de rede(a=0,4311 nm e 0,4313 nm) comparado ao parâmetro de rede do $\mathrm{Cu}_{2} \mathrm{O}(0,4295 \mathrm{~nm})$, concordando com resultados da literatura [45].

Assim, o resultado para oxidação de cobre a $180{ }^{\circ} \mathrm{C}$ por 20 e 30 minutos envolve um processo de conversão de $\mathrm{Cu}$ para $\mathrm{Cu}_{3} \mathrm{O}_{2}$. Apesar das análises RBS não terem detectado com precisão a existência do $\mathrm{Cu}_{3} \mathrm{O}_{2}$ em 40 e 60 minutos de oxidação, a presença de $\mathrm{CuO}$ em filme oxidado a $90^{\circ} \mathrm{C}$ permite concluir que $\mathrm{Cu}_{3} \mathrm{O}_{2}$ estava presentes em amostras oxidadas em 40 e 60 minutos. A presença desse óxido nessas condições experimentais é relatada em um número muito reduzido de trabalhos, dentre eles o elaborado por Lefez e colaboradores[15]. É bem estabelecido que em temperaturas abaixo de $250{ }^{\circ} \mathrm{C}$ só é observada a presença de $\mathrm{Cu}_{2} \mathrm{O}$. Conclui-se então, que embora não tenha sido observado nas análises RBS para filmes oxidados por 40 e 60 minutos, há $\mathrm{CuO}$ quando a amostra é oxidada por 90 minutos, resultando na conversão de parte do $\mathrm{Cu}_{3} \mathrm{O}_{2}$. Desta maneira, a tabela 5.12 pode ser completada com os resultados obtidos, aliando as técnicas de análise.

Tabela 5.12: Resultados obtidos aliando RBS à XRD e à espectroscopia Raman para filmes de $\mathrm{Cu} / \mathrm{C}$, oxidados em $180^{\circ} \mathrm{C}$.

\begin{tabular}{cccccc}
\hline Amostra & tempo & camada 1 & camada 2 & $O_{\text {total }}\left(10^{15} \mathrm{at} / \mathrm{cm}^{2}\right)$ & rugosidade $\left(10^{15} \mathrm{at} / \mathrm{cm}^{2}\right)$ \\
\hline M13 & 10 & - & $\mathrm{Cu} u_{2} \mathrm{O}$ & 430 & 100 \\
M17 & 20 & $\mathrm{Cu}_{3} \mathrm{O}_{2}$ & $\mathrm{C} u_{2} \mathrm{O}$ & 461 & 400 \\
M12 & 30 & $\mathrm{Cu}_{3} \mathrm{O}_{2}$ & $\mathrm{C} u_{2} \mathrm{O}$ & 660 & 800 \\
M11 & 40 & $\mathrm{Cu}_{3} \mathrm{O}_{2}$ & $\mathrm{Cu}_{2} \mathrm{O}(?)$ & 617 & 550 \\
M15 & 60 & $\mathrm{Cu}_{3} \mathrm{O}_{2}$ & $\mathrm{Cu}_{2} \mathrm{O}(?)$ & 863 & 600 \\
M16 & 90 & $\mathrm{CuO}$ & $\mathrm{Cu} \mathrm{O}_{1.7}$ & 942 & 900
\end{tabular}


Em $200{ }^{\circ} \mathrm{C}$ não foi observada a formação do $\mathrm{Cu}_{3} \mathrm{O}_{2}$. Para $250{ }^{\circ} \mathrm{C}$, o único óxido formado foi o $\mathrm{Cu}_{2} \mathrm{O}$, concordando com alguns trabalhos que mostram que em baixas temperaturas de oxidação há somente esse óxido. [20].

Já em temperaturas mais altas $\left(>250^{\circ} \mathrm{C}\right)$ aparecem os dois óxidos, com predominância do óxido cúprico para tempos longos de oxidação.

Em temperatura de $300{ }^{\circ} \mathrm{C}$ e $350{ }^{\circ} \mathrm{C}$ foi observado o aparecimento do $\mathrm{CuO}$ na superfície externa do filme, além do $\mathrm{Cu}_{2} \mathrm{O}$ na interna.

Em $300{ }^{\circ} C$, após 4,5 minutos de oxidação, houve uma pequena variação da concentração dos óxidos em função do tempo, mas os resultados obtidos por análises RBS e XRD não indicam nenhuma tendência nesta variação. A reduzida incorporação de oxigênio pode ser creditada à formação de um óxido não poroso, já que resultados das análises PIXE descartam a possibilidade destes filmes apresentarem um grau de contaminação por impurezas, o que poderia reduzir a mobilidade dos íons de cobre e oxigênio no filme. Apesar das análises RBS indicarem a oxidação total do filme, a análise por Espectroscopia Raman mostrou a presença do sinal do cobre não oxidado. Isso mostra que as técnicas RBS e espectroscopia Raman são complementares no estudo da oxidação de filme de cobre.

Para oxidação em temperatura de $350{ }^{\circ} \mathrm{C}$ é observado um claro aumento da concentração de oxigênio incorporado com o tempo, mudando com isto, os tipos de óxidos formados. Inicialmente, há uma reduzida camada de $\mathrm{CuO}$ na superfície externa. Para tempos mais longos de oxidação, análises RBS mostram que a camada interna de $\mathrm{Cu}_{2} \mathrm{O}$ vai sendo transformada em $\mathrm{CuO}$. A predominância de um ou outro óxido foi totalmente dependente do tempo de oxidação.

O fato do $\mathrm{Cu}_{3} \mathrm{O}_{2}$ e $\mathrm{CuO}$ estarem presentes em oxidação a $180{ }^{\circ} \mathrm{C}$ e não aparecerem em $200{ }^{\circ} \mathrm{C}$ e $250{ }^{\circ} \mathrm{C}$, sugerem uma dependência da cinética da oxidação com outros parâmetros além da temperatura, como o histórico da amostra.

Assim, conclui-se que em uma investigação mais criteriosa do processo de oxidação do cobre atenção especial deve ser dada à uniformidade da espessura do filme, pois como foi visto, a energia de ativação é totalmente dependente deste parâmetro.

RBS é uma poderosa técnica de análise no estudo de oxidação, especialmente quando se utiliza substrato de carbono, mas os resultados deste trabalho, leva-nos à conclusão de que essa técnica deve ser sempre aliada às outras técnicas de análises como XRD e Espectroscopia Raman. 
Um importante parâmetro no estudo da oxidação é a energia de ativação, mas muito cuidado deve ser tomado ao fazer comparações quando diferentes intervalos de temperaturas forem utilizados, ou mesmo quando os filmes forem depositados por métodos diferentes ou até mesmo parâmetros diferentes de deposição. As comparações devem ser feitas somente para melhor entendimento das diferenças obtidas.

\subsection{Passivação superficial de filmes de $\mathrm{Cu} / \mathrm{Al} / \mathrm{Si}$}

Nesta seção será estudado o mecanismo responsável pela passivação de filmes de cobre em estruturas $\mathrm{Cu} / \mathrm{Al} / \mathrm{Si}$. Será abordada a influência da temperatura do tratamento térmico no grau de passivação e na variação da resistividade elétrica.

As amostras foram depositadas através de evaporação seqüencial, sem quebra de vácuo, de alumínio e cobre por bombardeamento eletrônico, resultando em uma estrutura $\mathrm{Cu}\left(2,140 \times 10^{18} a t / \mathrm{cm}^{2}\right) / \operatorname{Al}\left(1,233 \times 10^{16} \mathrm{at} / \mathrm{cm}^{2}\right) /$ Si . Foram utilizadas diferença de potencial de $3,2 \mathrm{kV}$ entre o filamento e o cadinho e corrente de $30 \mathrm{~mA}$ no filamento. A pressão base na evaporadora foi $2 \times 10^{-7}$ mbar, chegando a $2 \times 10^{-6}$ mbar durante a evaporação do alumínio e a $2 \times 10^{-5}$ mbar, quando o cobre foi evaporado. A evaporadora utilizada não permitiu o controle da espessura. Este foi feito através da medida da massa utilizada, que como foi dito, não apresenta reprodutibilidade.

A aderência dos filmes ao substrato de silício foi testada utilizando uma fita durex, marca $3 \mathrm{M}$.

As amostras foram submetidas a tratamento térmico, em uma pressão de $4 \times 10^{-6}$ mbar, em temperaturas de $400{ }^{\circ} \mathrm{C}$ e $500{ }^{\circ} \mathrm{C}$, com duração de 30 minutos. Foram estudados tempos de tratamento térmico entre 30 e 90 minutos. A escolha do tempo mais adequado tomou como base o que provocou a maior redução da rugosidade e, ao mesmo tempo, possibilitou obter uma reduzida taxa de oxidação e baixa resistividade para a liga, comparada ao filme de cobre puro.

O grau de passivação dos filmes foi determinado pelo aquecimento das amostras em atmosfera ambiente, a temperatura de $250^{\circ} \mathrm{C}$, em tempos variados. A resistividade das amostras foi obtida pelo método de quatro pontas. 


\subsubsection{Resultados}

A tabela 5.13 mostra os resultados dos testes para a densidade dos filmes.

Tabela 5.13: Resultados do teste de densidade.

\begin{tabular}{ccc}
\hline espessura $(\mathrm{Al}) 10^{15} \mathrm{at} / \mathrm{cm}^{2}$ & espessura $(\mathrm{Cu}) 10^{15} \mathrm{at} / \mathrm{cm}^{2}$ & densidade $\left(\mathrm{g} / \mathrm{cm}^{3}\right.$ \\
\hline 150 & 2000 & 7,6 \\
150 & 1600 & 7,3 \\
110 & 1650 & 7,5 \\
100 & 1550 & 7,5 \\
150 & 2000 & 7,6 \\
120 & 2050 & 7,7 \\
150 & 2000 & 7,6 \\
120 & 2050 & 7,6 \\
\hline
\end{tabular}

A densidade dos filmes obtidos não apresentou variação devido à incorporação da camada de alumínio.

Quanto ao teste de aderência, as amostras apresentaram resultados idênticos antes e depois do tratamento térmico. Teste de aderência antes do tratamento térmico mostrou que todos os filmes apresentaram aderência ao silício, que se manteve quando as amostras foram submetidas a tratamento térmico em temperaturas entre $50^{\circ} \mathrm{C}$ e $500{ }^{\circ} \mathrm{C}$.

Quanto à resistividade, esta grandeza apresentou o comportamento mostrado na Figura 5.26 , com o valor antes do tratamento térmico igual a $\rho_{0}=2,52 \mu \Omega . \mathrm{cm}$

Observa-se que a resistividade elétrica apresenta um comportamento variável. Este comportamento pode ser atribuído a dois efeitos que competem ora aumentando, ora reduzindo a resistividade. À medida que a temperatura do tratamento térmico aumenta, há uma redução da resistividade devido à remoção dos defeitos nos filmes depositados e, conseqüentemente, o aumento do transporte elétrico; ao mesmo tempo, mais átomos de alumínio chegam à superfície do filme de cobre, aumentando a sua resistividade elétrica. A migração dos átomos de alumínio pode ser observada na Figura 5.27, onde são mostrados espectros RBS de um filme de $\mathrm{Cu} / \mathrm{Al} / \mathrm{Si}$, antes e após o tratamento térmico. O sinal correspondente aos átomos de $\mathrm{Al}$ depositado entre o substrato e o $\mathrm{Cu}$ está indicado por 


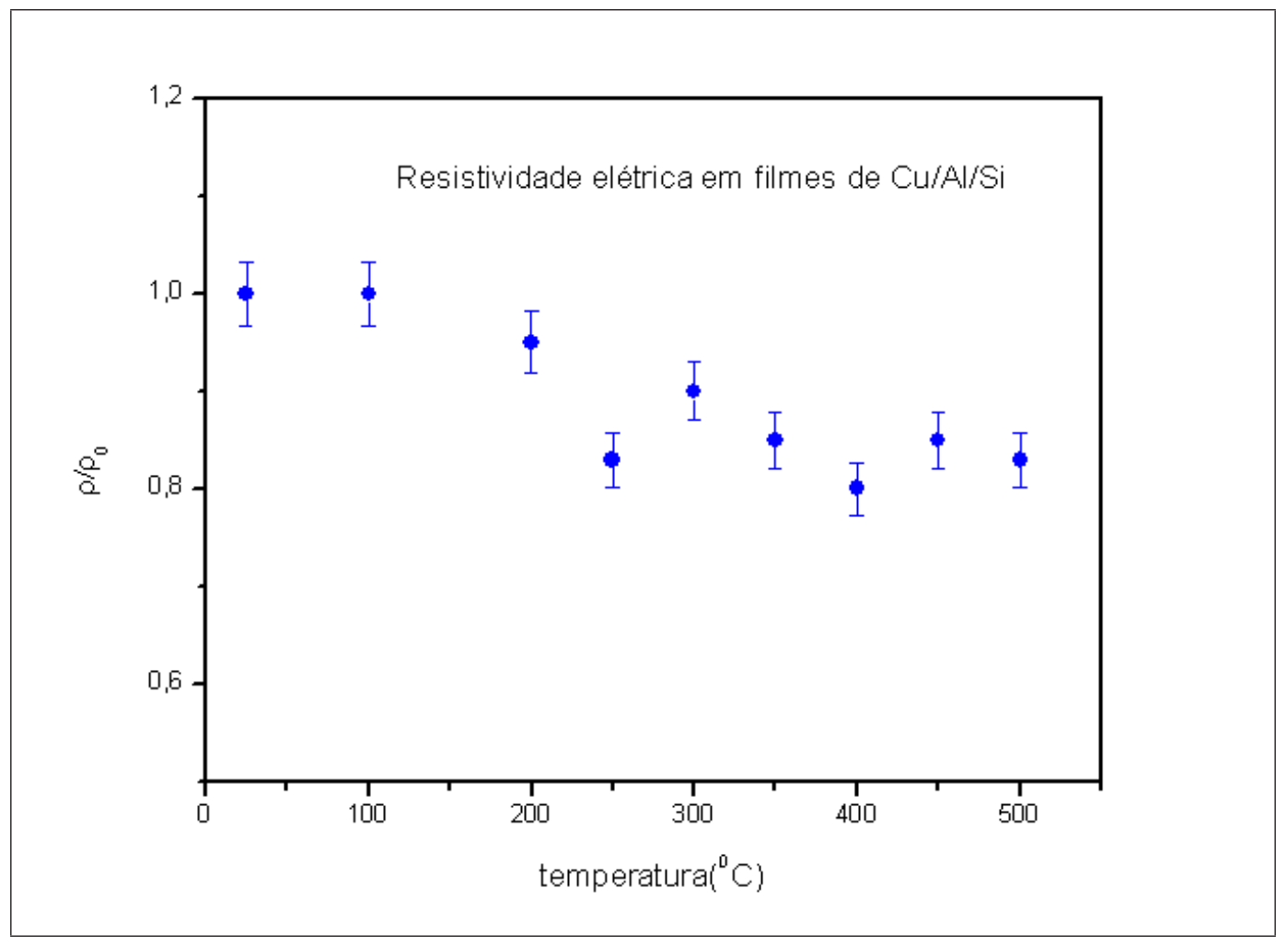

Figura 5.26: Variação da resistividade elétrica dos filmes de $\mathrm{Cu}(\mathrm{Al}) / \mathrm{Si}$, submetidos a tratamento térmico para temperaturas entre $50^{\circ} \mathrm{C}$ e $500{ }^{\circ} \mathrm{C}$ por 30 minutos.

Al no espectro RBS e o correspondente aos átomos de Al presentes na superfície da amostra está designado por $\mathrm{Al}(260)$.

Filmes de cobre puro, com a mesma espessura dos filmes de $\mathrm{CuAl}$ possuem resistividade igual a 2,25 $\mu \Omega$.cm, calculada através dos parâmetros do ajuste da curva da Figura 5.2. Com o tratamento térmico em $500^{\circ} \mathrm{C}$ a resistividade dos filmes $\mathrm{CuAl}$ cai para 2,00 $\mu \Omega$.cm.

\subsubsection{Passivação superficial}

Os testes para medir a resistência à oxidação foram realizados em atmosfera ambiente, a $250{ }^{\circ} \mathrm{C}$, entre 1 e 4 horas. As simulações do espectro oxidado por uma hora, a partir de um modelo de multicamadas é mostrada na Figura 5.28. A composição da amostra obtida através da simulação é mostrada na tabela 5.14. São mostrados somente os resultados da simulação das camadas pertencentes ao filme.

Para comparação são mostrados nas Figuras 5.29 e 5.30os espectros RBS de filmes de cobre puro oxidados nas mesmas condições. 


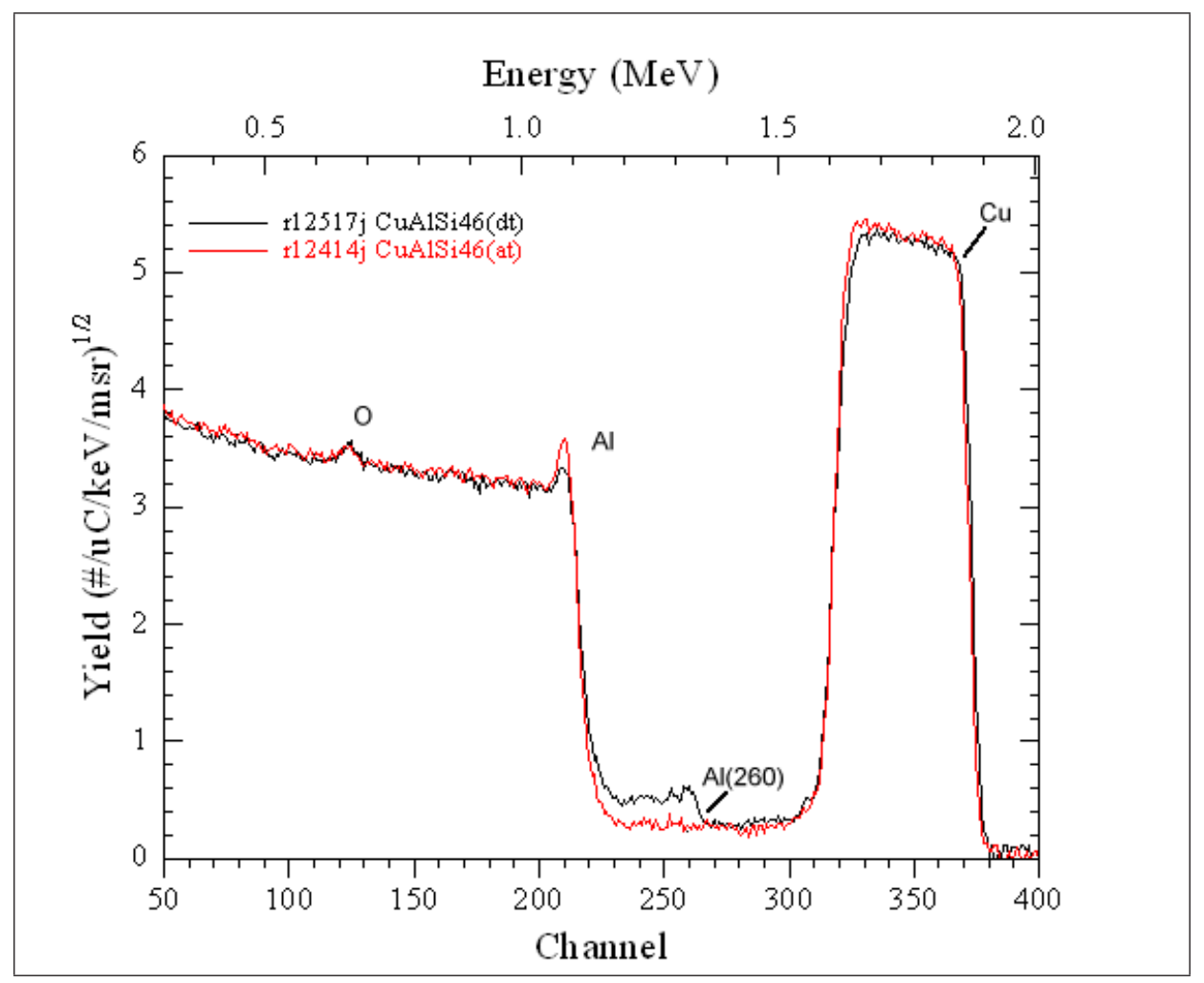

Figura 5.27: Espectro RBS de filmes de $\mathrm{CuAl} / \mathrm{Si}$ antes(at), em vermelho e após(dt), em preto o tratamento térmico em $500{ }^{\circ} \mathrm{C}$. Pode ser observado o sinal correspondente aos átomos de $\mathrm{Al}$ presentes na superfície da amostra.

A comparação entre as Figuras 5.29 e 5.30 mostra a passivação superficial obtida com a deposição e posterior migração do alumínio no cobre. A Figura 5.31 mostra os resultados para 3 filmes: cobre puro, $\mathrm{Cu}(\mathrm{Al}) / \mathrm{Si}$ submetido a tratamento térmico em temperatura igual a $400{ }^{\circ} \mathrm{C}$ e $\mathrm{CuAl} / \mathrm{Si}$, submetido a tratamento térmico em temperatura igual a 500 ${ }^{\circ} \mathrm{C}$.

Os resultados para filmes tratados termicamente a $400{ }^{\circ} \mathrm{C}$ mostram que os filmes oxidam-se muito mais lentamente do que filmes de cobre puro, mas o crescimento do óxido ainda é proporcional à raiz quadrada do tempo de oxidação, como pode ser visto na figura 5.31. O filme tratado termicamente a $500{ }^{\circ} \mathrm{C}$ foi muito passivado, indicando a eficiência da técnica.

A figura 5.29 permite ainda a observação da difusão do alumínio no cobre. Isso é compatível com o estudo do diagrama de fases do sistema cobre-alumínio, que mostra claramente a existência de uma liga $\mathrm{Cu}-\mathrm{Al}$, mesmo em temperaturas abaixo das utilizadas nesse trabalho. 


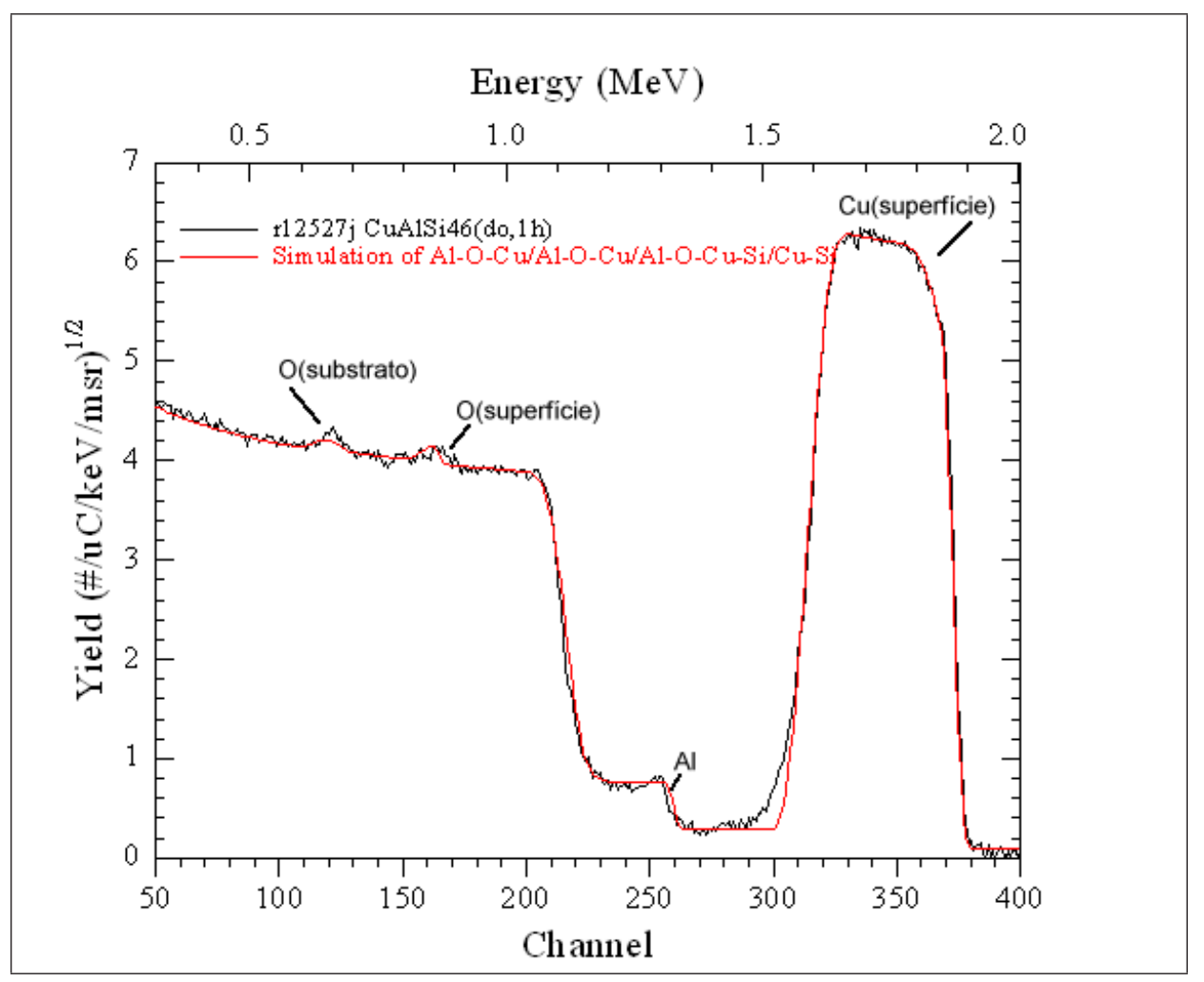

Figura 5.28: Espectro RBS de filmes de $\mathrm{CuAl} / \mathrm{Si}$ após a oxidação em $250{ }^{\circ} \mathrm{C}$ por uma hora. Foi usado um modelo multicamadas que prevê a variação da concentração dos elementos ao longo da amostra

A análise e a simulação dos espectros $\mathrm{RBS}$ mostraram que a liga $\mathrm{Cu}(\mathrm{Al})$ quando oxidada a $250{ }^{\circ} \mathrm{C}$ formou o $\mathrm{CuO}$, diferentemente dos filmes de cobre puro, que formam $\mathrm{Cu}_{2} \mathrm{O}$ nesta temperatura.

A simulação dos espectros RBS mostrou também que o alumínio está presente em quase todo o filme, devido à sua intensa migração, quando o tratamento térmico foi feito em $500{ }^{\circ} \mathrm{C}$ por 70 minutos. Apesar da não utilização do carbono como substrato, e, conseqüentemente a maior dificuldade em se medir o oxigênio e o alumínio, cujos picos se sobrepõem ao do silício, a viabilidade desta análise foi devida à reduzida corrente do feixe, $3 \mathrm{nA}$, e das condições de grande estabilidade do feixe. Isto elevou o tempo de aquisição de cada espectro RBS para 2 horas, mas permitiu observar o processo de difusão do alumínio em uma concentração tão baixa quanto a utilizada neste trabalho.

A liga de $\mathrm{Cu}(\mathrm{Al})$ formada pelo tratamento térmico da estrutura $\mathrm{Cu} / \mathrm{Al} / \mathrm{SiO}_{2}$ apresentou algumas propriedades diferentes do filme de cobre puro. Além da grande aderência ao $\mathrm{SiO}_{2}$ ela apresentou menor rugosidade após o tratamento térmico(0,9 nm contra 1,8 
Tabela 5.14: Resultados da simulação dos espectros RBS de $\mathrm{Cu}(\mathrm{Al}) / \mathrm{Si}$, oxidados por uma hora

\begin{tabular}{llcc}
\hline tempo(h) & Composição & espessura $\left(10^{15} a t / \mathrm{cm}^{2}\right)$ & rugosidade \\
\hline 1 & $\mathrm{Cu}(100) \mathrm{O}(100) \mathrm{Al}(5)$ & 250 & 450 \\
& $\mathrm{Cu}(100) \mathrm{O}(40) \mathrm{Al}(20)$ & 250 & \\
& $\mathrm{Cu}(100) \mathrm{Al}(5)$ & 1750 & 600 \\
\hline 2 & $\mathrm{Cu}(100) \mathrm{O}(100) \mathrm{Al}(10)$ & 200 & \\
& $\mathrm{Cu}(200) \mathrm{O}(100) \mathrm{Al}(7)$ & 300 & 400 \\
& $\mathrm{Cu}(100) \mathrm{O}(010) \mathrm{Al}(7)$ & 300 & 600 \\
\hline \multirow{2}{*}{4} & $\mathrm{Cu}(100) \mathrm{O}(100) \mathrm{Al}(10)$ & 350 & \\
& $\mathrm{Cu}(100) \mathrm{O}(5) \mathrm{Al}(6)$ & 1900 & \\
& $\mathrm{Cu}(100) \mathrm{O}(100) \mathrm{Al}(4)$ & 400 & \\
& $\mathrm{Cu}(200) \mathrm{O}(100) \mathrm{Al}(7)$ & 300 & \\
& $\mathrm{Cu}(100) \mathrm{O}(10) \mathrm{Al}(7)$ & 300 & \\
& $\mathrm{Cu}(100) \mathrm{Al}(8)$ & 1500 & \\
\hline
\end{tabular}

$\mathrm{nm})$, determinada pela simulação dos espectros RBS e confirmada através de medidas por AFM.

O efeito da temperatura do tratamento na passivação dos filmes é mostrado na Figura 5.31, cujos os dados dos ajustes estão na tabela 5.15. Os mais baixos valores para o coeficiente angular, que reflete em uma menor constante parabólica, mostra que filmes tratados em $500{ }^{\circ} \mathrm{C}$ apresentam um grau de passivação maior quando comparados aos tratados em $400{ }^{\circ} \mathrm{C}$, que por sua vez, tem menor taxa de oxidação que filmes de cobre puro. Esse efeito pode ser explicado pela maior migração dos átomos de alumínio até a superfície do cobre em temperaturas maiores, preenchendo as vacâncias óxido formado.

Tabela 5.15: Resultados dos ajustes das curvas referentes ao estudo da cinética de filmes de $\mathrm{CuAl} / \mathrm{Si}$

\begin{tabular}{cccc}
\hline Temperatura $\left({ }^{\circ} \mathrm{C}\right)$ & coeficiente angular & coeficiente linear. & coef. correlação \\
\hline 500 & $(0,030 \pm 0,003)$ & $(0,78 \pm 0,49)$ & 0,99 \\
400 & $(0,21 \pm 0,04)$ & $(43,1 \pm 7,2)$ & 0,96 \\
$C u_{\text {puro }}$ & $(4,30 \pm 0,87)$ & $(-105,44 \pm 143,93)$ & 0,96
\end{tabular}




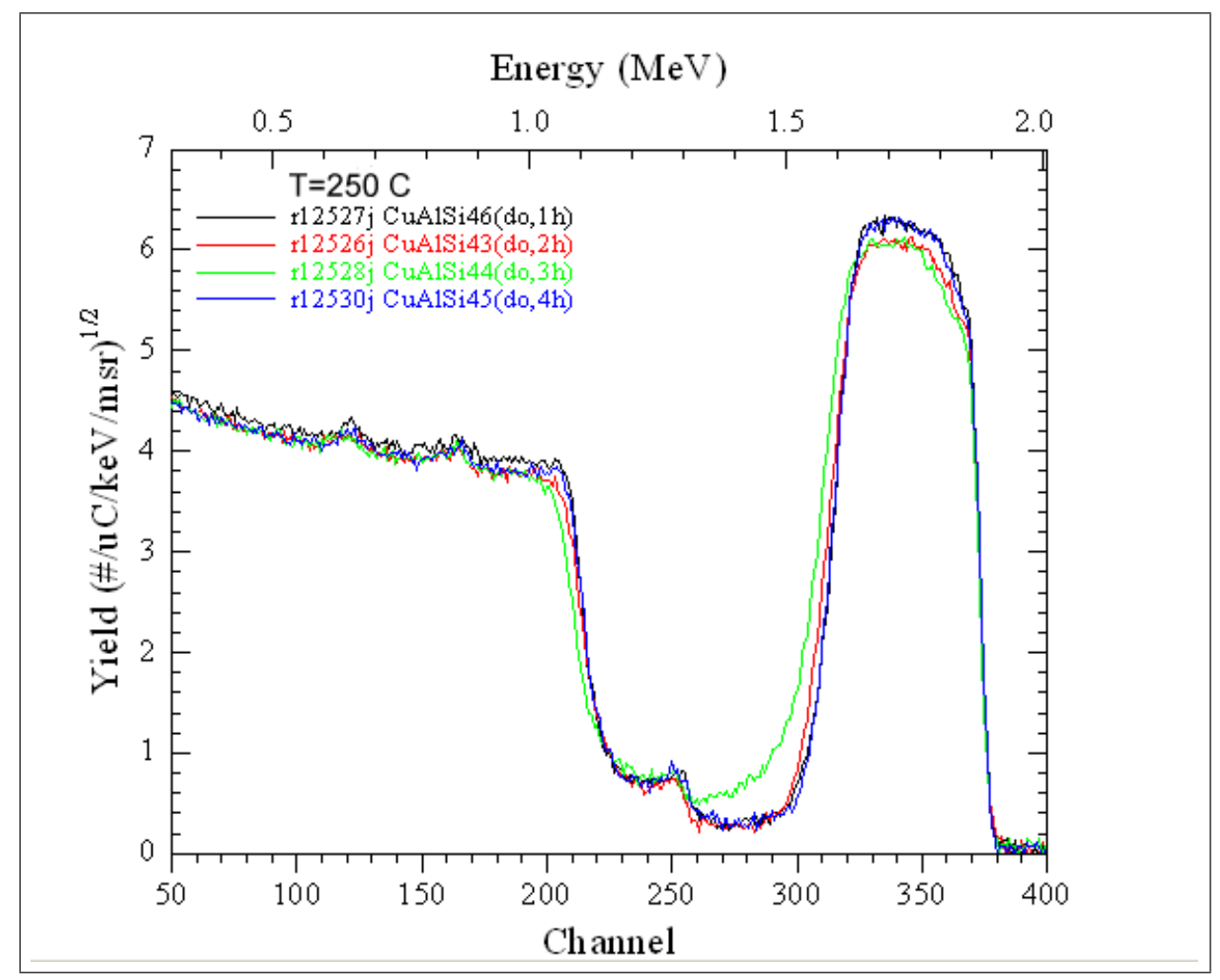

Figura 5.29: Espectro RBS de filmes de $\mathrm{CuAl} / \mathrm{Si}$ após a oxidação a $250{ }^{\circ} \mathrm{C}$ entre 1 e $4 \mathrm{~h}$

Assim, o mecanismo de passivação deve ser atribuído à redução da mobilidade dos íons de cobre causada pela pequena concentração do alumínio presente em todo o filme. Há um estudo que atribui o mecanismo de passivação à formação de um óxido denso na superfície, $\mathrm{Al}_{2} \mathrm{O}_{3}$, que serviria como barreira contra a oxidação [26]. No presente trabalho não foi identificado o óxido $\mathrm{Al}_{2} \mathrm{O}_{3}$ na superfície do cobre. Dessa maneira, a passivação do filme de $\mathrm{Cu}(\mathrm{Al})$ deve ser atribuída a outro mecanismo. Óxido de cobre cresce através do transporte de $\mathrm{Cu}^{+}$da interface $\mathrm{Cu}_{2} \mathrm{O} / \mathrm{Cu}$ até a superfície do filme, onde ele é oxidado. O tratamento térmico da estrutura $C u / A l / S i$ promove a difusão do alumínio e, com isto possilibita o preenchimento das vacâncias, reduzindo o transporte do íon $C u^{+}$. A redução deste transporte faz com que a difusão de oxigênio no óxido $\mathrm{Cu}_{2} \mathrm{O}$ seja o mecanismo dominante e resulte na formação de uma camada de $\mathrm{CuO}$, diferentemente do que acontece com filmes de cobre puro, oxidado em mesma temperatura. Assim, a passivação superficial deve ser atribuída à formação de um óxido mais denso, $\mathrm{CuO}$, que bloqueia o transporte de $C u^{+}$.

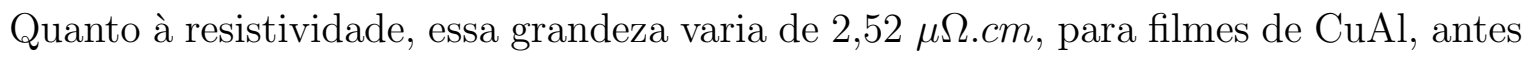
do tratamento térmico a 2,00 $\mu \Omega$.cm para filmes tratados a $500{ }^{\circ} \mathrm{C}$. Comparado a filmes de cobre puro 


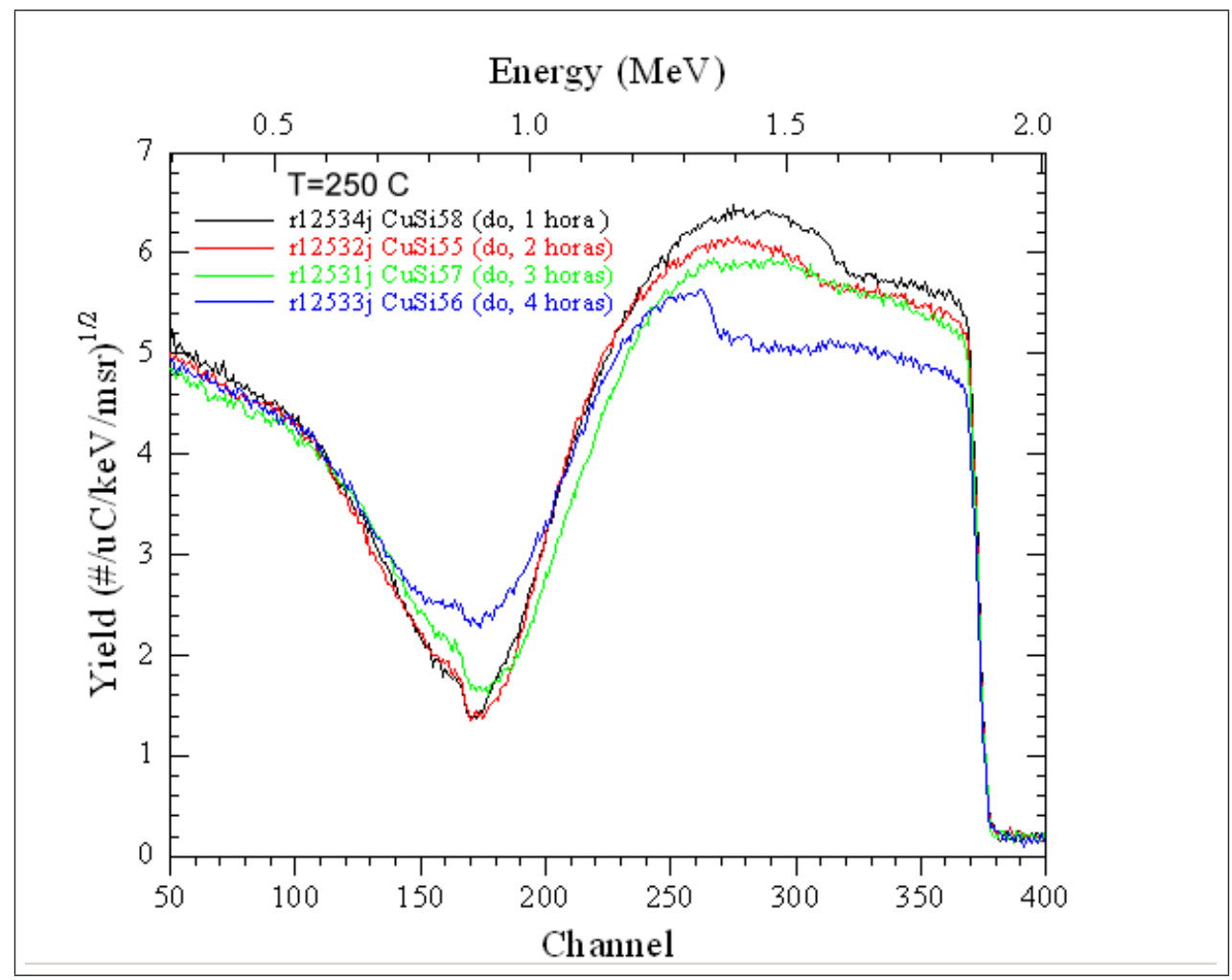

Figura 5.30: Espectro RBS de filmes de $\mathrm{Cu} / \mathrm{Si}$ após a oxidação a $250{ }^{\circ} \mathrm{C}$ por tempos entre $1 \mathrm{e}$ 4 horas

\subsection{Passivação de filmes de cobre através de cober- tura de carbono}

Apesar do mecanismo de passivação através de camada protetora ser conhecido, foi elaborada uma experiência para auxiliar no entendimento do mecanismo de passivação proposto por Kellock e colaboradores [95]. Nesse trabalho os autores mostraram que no processo de passivação superficial do cobre através da implantação iônica, o mecanismo de passivação consiste na fixação do carbono presente no ambiente através de irradiação do filme de cobre com feixe de hélio. A camada de carbono, na forma de $C_{x} O_{y}$, formaria uma barreira contra a difusão de cobre.

Nesta seção foi verificada a possibilidade de passivação de filmes de cobre através de cobertura de carbono.

Filmes de $\mathrm{C} / \mathrm{Cu} / \mathrm{C}$ com espessura de $4,0 \times 10^{16}$ átomos $/ \mathrm{cm}^{2}$ de carbono foram depositados por bombardeamento eletrônico, seqüencialmente sobre filmes de cobre. Neste processo, a taxa de oxidação foi verificada através de aquecimento em atmosfera ambiente no sistema descrito nos ítens anteriores. 


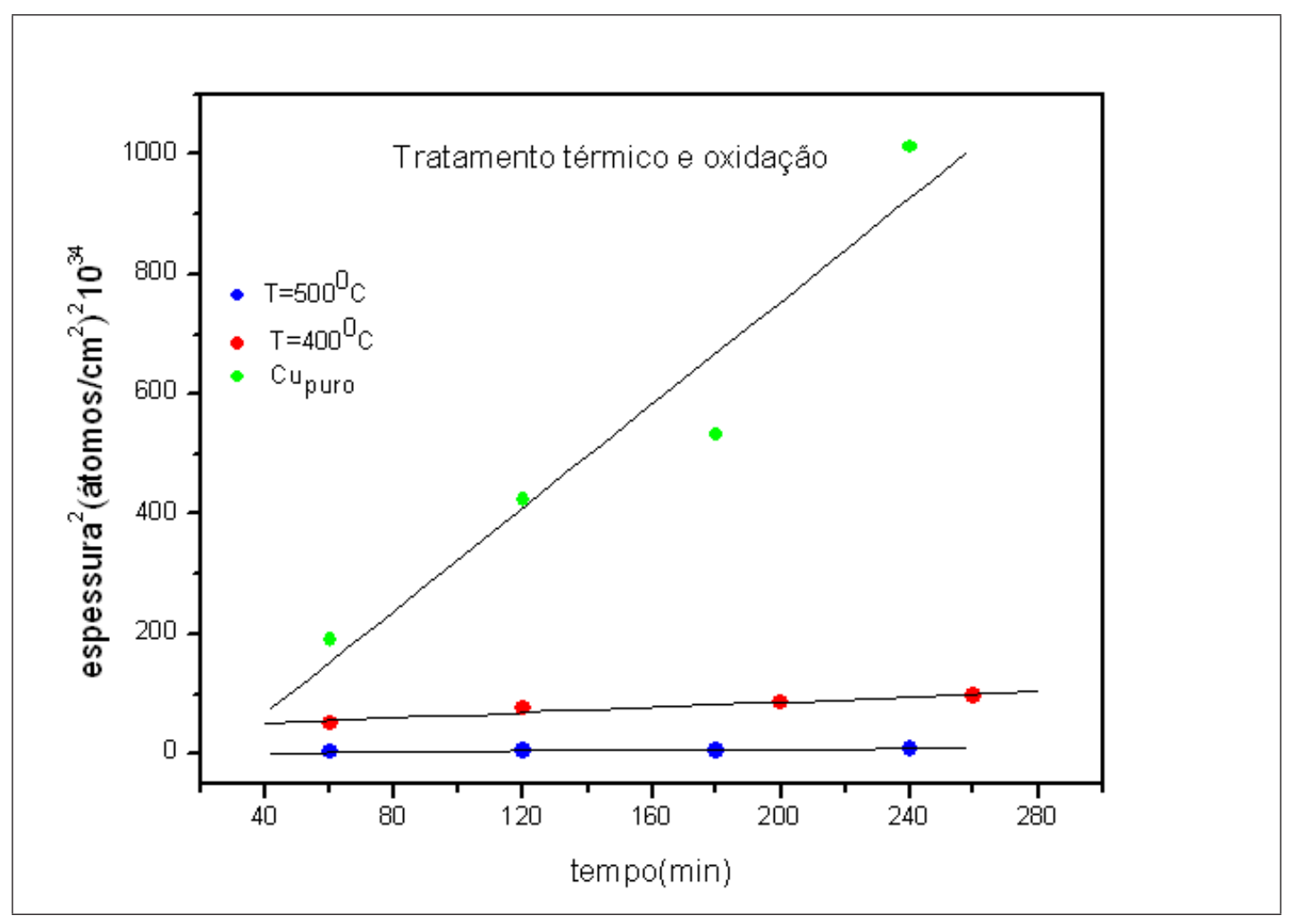

Figura 5.31: Cinética de oxidação de filmes de $\mathrm{Cu}$ puro e filmes de $\mathrm{Cu}(\mathrm{Al}) / \mathrm{Si}$ tratados termicamente em vácuo, em $400{ }^{\circ} \mathrm{C}$ e $500{ }^{\circ} \mathrm{C}$. As amostras foram oxidadas em atmosfera ambiente, em $250{ }^{\circ} \mathrm{C}$ em tempos variando entre 1 e 4 horas

A Figura 5.32 mostra uma comparação entre a oxidação de filme de $\mathrm{Cu} / \mathrm{C}$ e filme de $\mathrm{C} / \mathrm{Cu} / \mathrm{C}$ a partir dos espectros RBS dos filmes antes e após a oxidação. Nas Figuras 5.33 e 5.34 são mostrados os espectros e suas respectivas simulações.

A Figura 5.35 mostra os espectros XRD de filmes de $\mathrm{C} / \mathrm{Cu} / \mathrm{C}$, oxidados em $350{ }^{\circ} \mathrm{C}$ por 8 minutos.

Simulação dos espectros RBS e análise do difratograma da Figura mostram que, diferentemente dos filmes de $\mathrm{Cu} / \mathrm{C}$, que para oxidação em $350{ }^{\circ} \mathrm{C}$, formam-se dois óxidos $\left(\mathrm{Cu}_{2} \mathrm{O}\right.$ e $\mathrm{CuO}$ ), a oxidação de filmes de $\mathrm{C} / \mathrm{Cu} / \mathrm{C}$, em $350{ }^{\circ} \mathrm{C}$ leva à formação de $\mathrm{Cu} \mathrm{O}_{2} \mathrm{O}$ como o único óxido existente até 8 minutos de oxidação.

Em 10 minutos de oxidação, verifica-se que o processo de conversão do $\mathrm{Cu}_{2} \mathrm{O}$ para $\mathrm{CuO}$ inicia-se na interface gás-óxido. À medida que aumenta o tempo de oxidação, mais $\mathrm{CuO}$ é encontrado no filme.

Neste trabalho, conclui-se que coberturas de filmes de carbono puro não reduzem a taxa de oxidação de filmes de cobre, não sendo eficientes para passivar a superfície. Ela somente inibe a formação de $\mathrm{CuO}$, reduzindo o transporte do oxigênio, mas não impede 


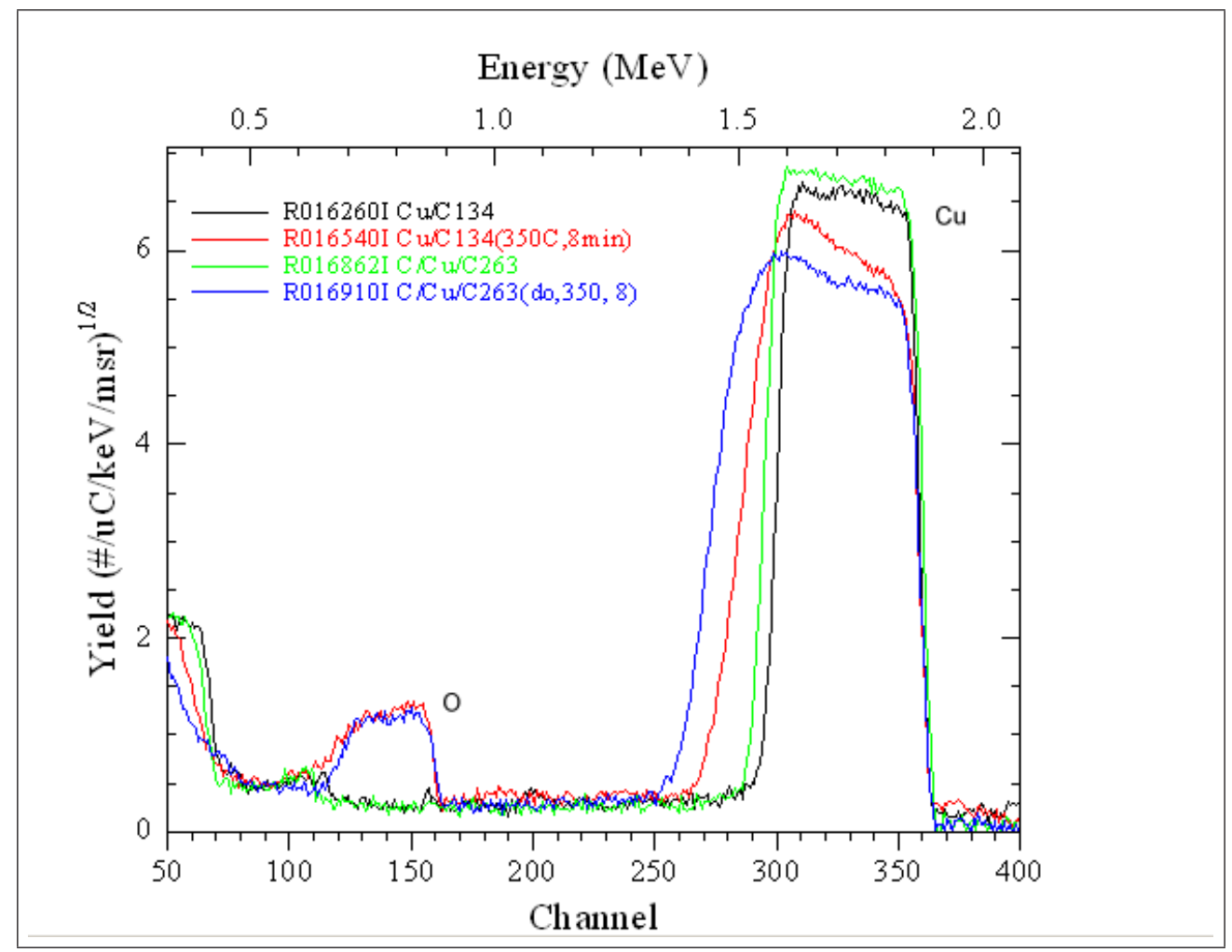

Figura 5.32: Espectro RBS de filmes de $\mathrm{Cu} / \mathrm{C}$ e C/Cu/C, antes e após a oxidação em $350{ }^{\circ} \mathrm{C}$ em 8 minutos. Em preto e verde, estão respectivamente, os sinais dos filmes $\mathrm{Cu} / \mathrm{C}$ e $\mathrm{C} / \mathrm{Cu} / \mathrm{C}$, antes da oxidação. Em vemelho e azul estão os sinais dos filmes $\mathrm{Cu} / \mathrm{C}$ e $\mathrm{C} / \mathrm{Cu} / \mathrm{C}$ após a oxidação.

Tabela 5.16: Resultados das simulações dos espectros RBS para filmes de $\mathrm{Cu} / \mathrm{C}$ e $\mathrm{C} / \mathrm{Cu} / \mathrm{C}$, oxidados por 8 minutos, em $350{ }^{\circ} \mathrm{C}$. A espessura e a rugosidade são dadas em $10^{15} \mathrm{at} / \mathrm{cm}^{2}$

\begin{tabular}{|c|c|c|c|}
\hline camadas & Composição & espessura & Rugosidade \\
\hline & Amostra - $\mathrm{Cu} / \mathrm{C}$ & & \\
\hline 1 & $\mathrm{Cu}(100) \mathrm{O}(100)$ & 400 & 700 \\
\hline 2 & $\mathrm{Cu}(200 \mathrm{O}(100)$ & 800 & \\
\hline 3 & $\mathrm{Cu}(100) \mathrm{O}(30)$ & 1000 & \\
\hline 4 & $\mathrm{Cu}(100) \mathrm{O}(5)$ & 900 & \\
\hline \multirow[t]{2}{*}{5} & $\mathrm{Cu}(0.1) \mathrm{O}(2) \mathrm{C}(100)$ & 3600 & \\
\hline & Amostra - C/Cu/C & & \\
\hline 1 & $\mathrm{Cu}(200) \mathrm{O}(100) \mathrm{C}(2)$ & 800 & 600 \\
\hline 2 & $\mathrm{Cu}(200) \mathrm{O}(90) \mathrm{C}(2)$ & 1200 & \\
\hline 3 & $\mathrm{Cu}(200) \mathrm{O}(1) \mathrm{C}(5)$ & 1700 & \\
\hline
\end{tabular}



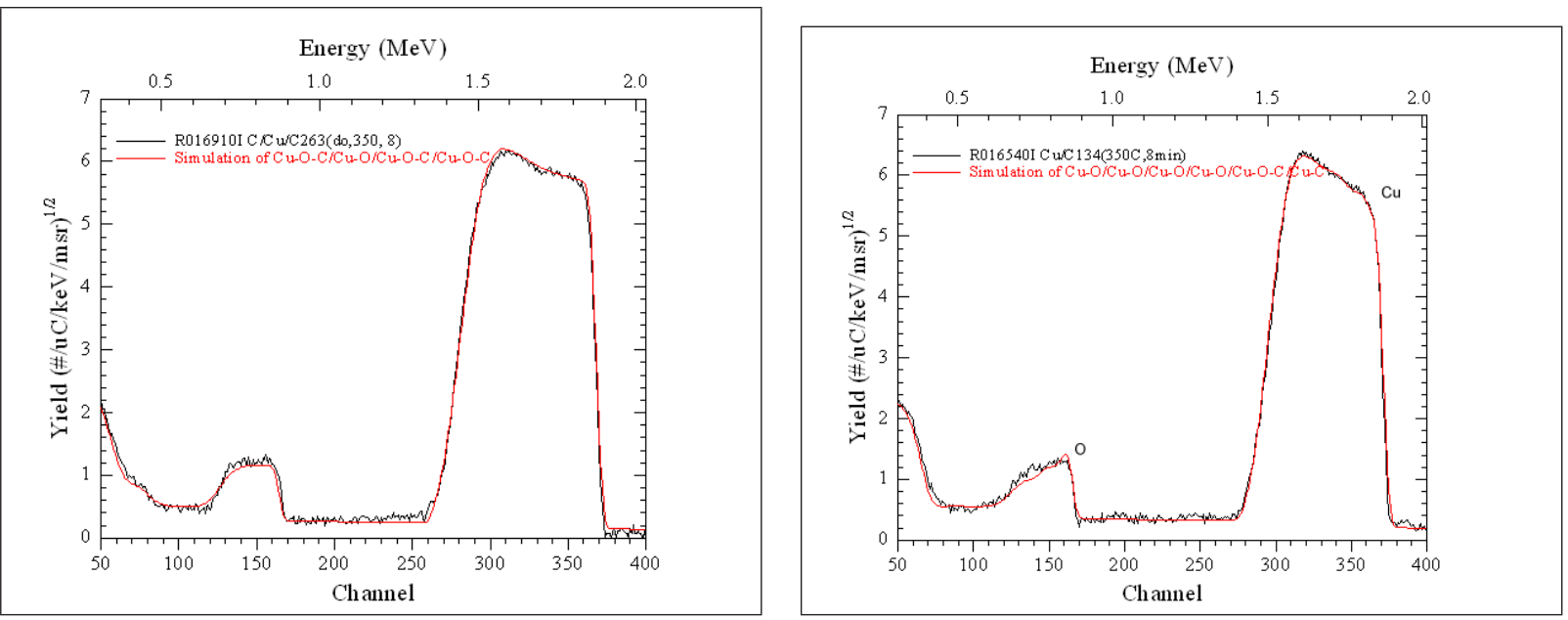

Figura 5.33: Simulação do espectro RBS de Figura 5.34: Simulação do espectro RBS de filmes de $\mathrm{C} / \mathrm{Cu} / \mathrm{C}$, após a oxidação em $350{ }^{\circ} \mathrm{C}$ filmes de $\mathrm{Cu} / \mathrm{C}$, após a oxidação em $350{ }^{\circ} \mathrm{C}$ em 8 minutos em 8 minutos

a difusão do cobre. ${ }^{5}$ Quando tempos mais longos de oxidação são utilizados, há oxidação total dos filmes.

\subsection{Estudo da passivação de filmes de cobre dopados com cloro}

No presente trabalho, o efeito da adição de um elemento halogênio em filmes de cobre foi estudado através de contaminação dos filmes por cloro.

Como mencionado, a remoção do óxido das placas de cobre utilizadas para a evaporação é feita através da limpeza com uma solução de tricloroacético. Presume-se que esta tenha sido a origem da contaminação das amostras. Como foi dito, após cada etapa do processamento, efetua-se uma análise PIXE. Descoberta a contaminação de $3 \%$ de cloro nos filmes de $\mathrm{Cu} / \mathrm{C}$ e tendo conhecimento do efeito halogênio, para ligas de TiAl, optou-se por fazer um estudo da oxidação desses filmes.

A passivação de filmes através da adição de um elemento halogênio, denominada efeito halogênio, têm sido investigada para ligas de TiAl [121] e [122].

Neste trabalho amostras de cobre contaminadas com cloro foram estudadas.

\footnotetext{
$\overline{5}$ A diferença na incorporação de oxigênio para filmes oxidados por 8 minutos foi $7 \%$. Para $\mathrm{Cu} / \mathrm{C}-(8,00$ x $10^{17}$ átomos $/ \mathrm{cm}^{2}$ e para C $/ \mathrm{Cu} / \mathrm{C}-7,46 \times 10^{17}$ átomos $/ \mathrm{cm}^{2}$
} 


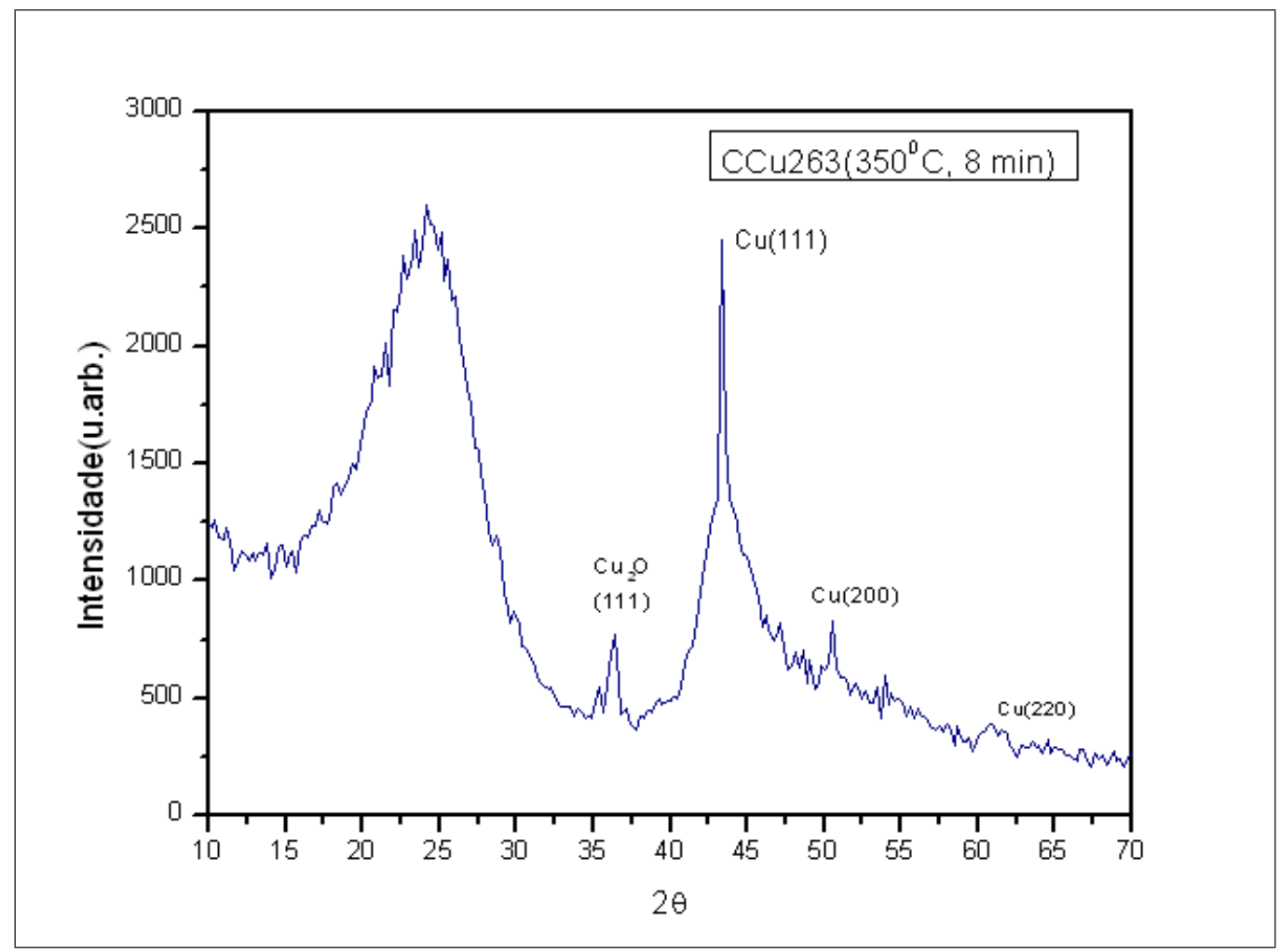

Figura 5.35: Espectro XRD de um filme de $\mathrm{C} / \mathrm{Cu} / \mathrm{C}$, após oxidação em $\mathrm{T}=350{ }^{\circ} \mathrm{C}$ por 8 minutos, mostrando a existência de somente um tipo de óxido nessas condições de oxidação.

A Figura 5.36 mostra o espectro PIXE de uma amostra de $\mathrm{Cu}(\mathrm{Cl})$ deste grupo.

Análise conjunta por PIXE e RBS resultaram em um filme de $C u\left(C l_{3 \%}\right)$. Esses filmes foram oxidados em $180{ }^{\circ} \mathrm{C}$ por tempos variando entre 4 e 36 minutos.

A Figura 5.37 mostra o comportamento da oxidação em 9 e 36 minutos. Para comparação, espectros de filmes de cobre puro obtidos em condições semelhantes são mostrados na figura 5.38.

A comparação dos espectros RBS das amostras oxidadas em $180{ }^{\circ} \mathrm{C}$ em vários tempos mostra que há uma ligeira variação da espessura do óxido em função da tempo, conforme pode ser visto na Figura 5.37. Mesmo para tempos tão longos quanto 36 minutos, a quantidade de oxigênio incorporado ao filme é muito baixa.

A Figura 5.39 mostra um difratograma de filmes oxidados em 9, 16 e 25 minutos. A análise desta figura indica que não há nenhuma fase cristalina de óxido de cobre, mas a simulação dos espectros RBS, mostrada na Figura 5.40, cujos resultados estão na tabela 5.17, indica o crescimento de $\mathrm{Cu}_{2} \mathrm{O}$. 


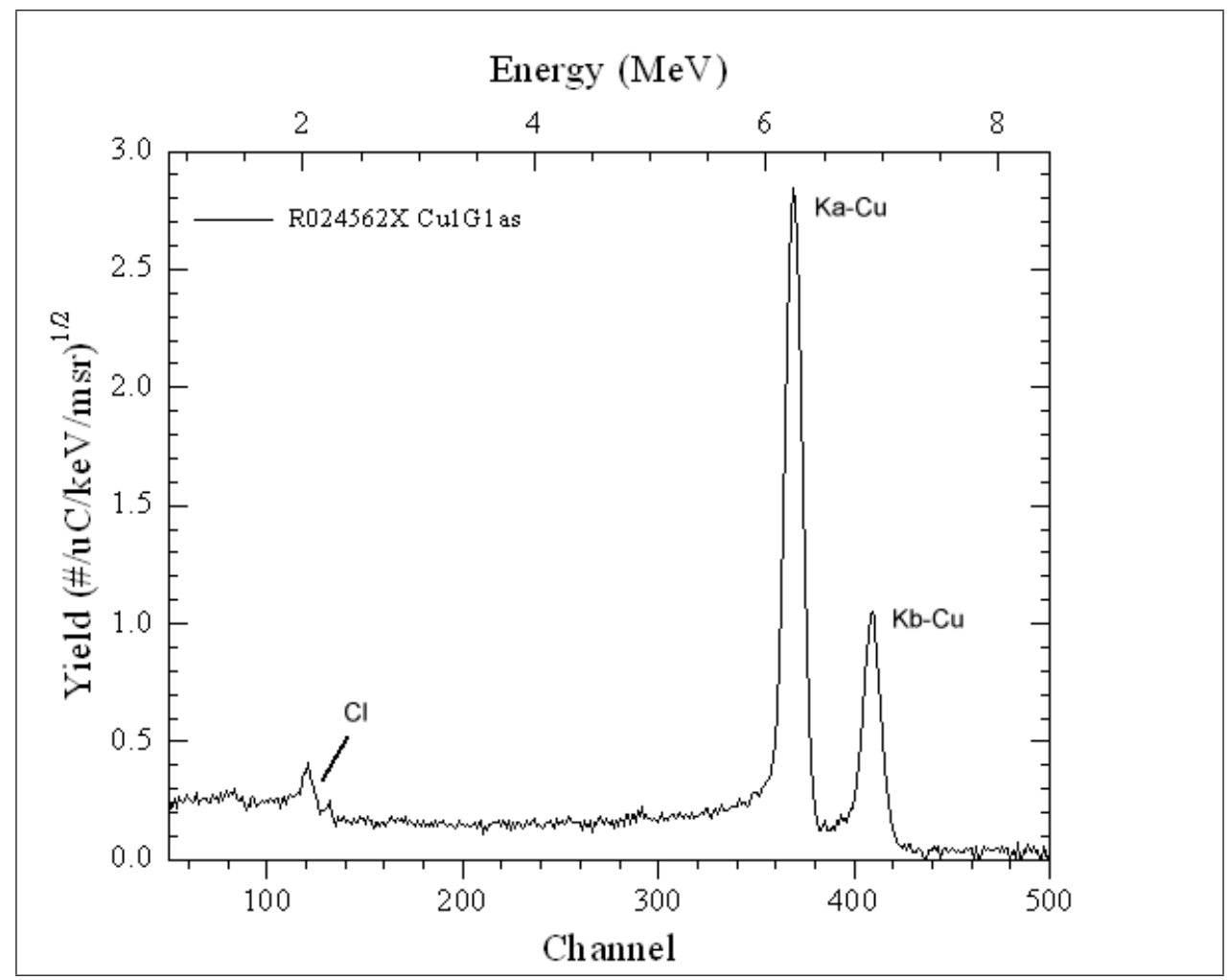

Figura 5.36: Espectro PIXE de uma amostra contaminada com cloro

Os resultados do teste para oxidação em outros tempos utilizados são graficados na Figura 5.41. ${ }^{6}$

Tabela 5.17: Resultados da simulações do espectro RBS para um filme de $\mathrm{CuCl} / \mathrm{C}$, oxidado por 4 minutos, em $180{ }^{\circ} \mathrm{C}$. A espessura e a rugosidade são dadas em $10^{15} \mathrm{at} / \mathrm{cm}^{2}$

\begin{tabular}{llcc}
\hline camadas & Composição & espessura & Rugosidade \\
\hline 1 & $\mathrm{Cu}(200) \mathrm{O}(100) \mathrm{Cl}(3)$ & 50 & 50 \\
2 & $\mathrm{Cu}(100) \mathrm{Cl}(1,5)$ & 1550 & 100
\end{tabular}

Filmes de cobre dopados com cloro foram oxidados em temperatura de $180{ }^{\circ} \mathrm{C}$, em variados tempos. Análises por XRD mostraram não haver nenhuma camada de óxido na superfície, indicando alta capacidade de passivação. O pequeno pico de oxigênio, presente nos espectros RBS, sugere a formação de uma reduzida camada de óxido, mas que não apresentou concentração ou cristalinidade suficiente para ser detectada por XRD.

O comportamento da cinética de oxidação, observado na Figura 5.42 e na tabela 5.18, mostra o efeito passivador da adição de cloro.

$\overline{6}$ Dados do ajuste $\mathrm{Y}=\mathrm{A}+\mathrm{BX}, \operatorname{com~} \mathrm{A}=(0,013 \pm 0,001)$ e $\mathrm{B}=\left(0,001 \pm 9 \mathrm{x} 10^{-5}\right)$ 

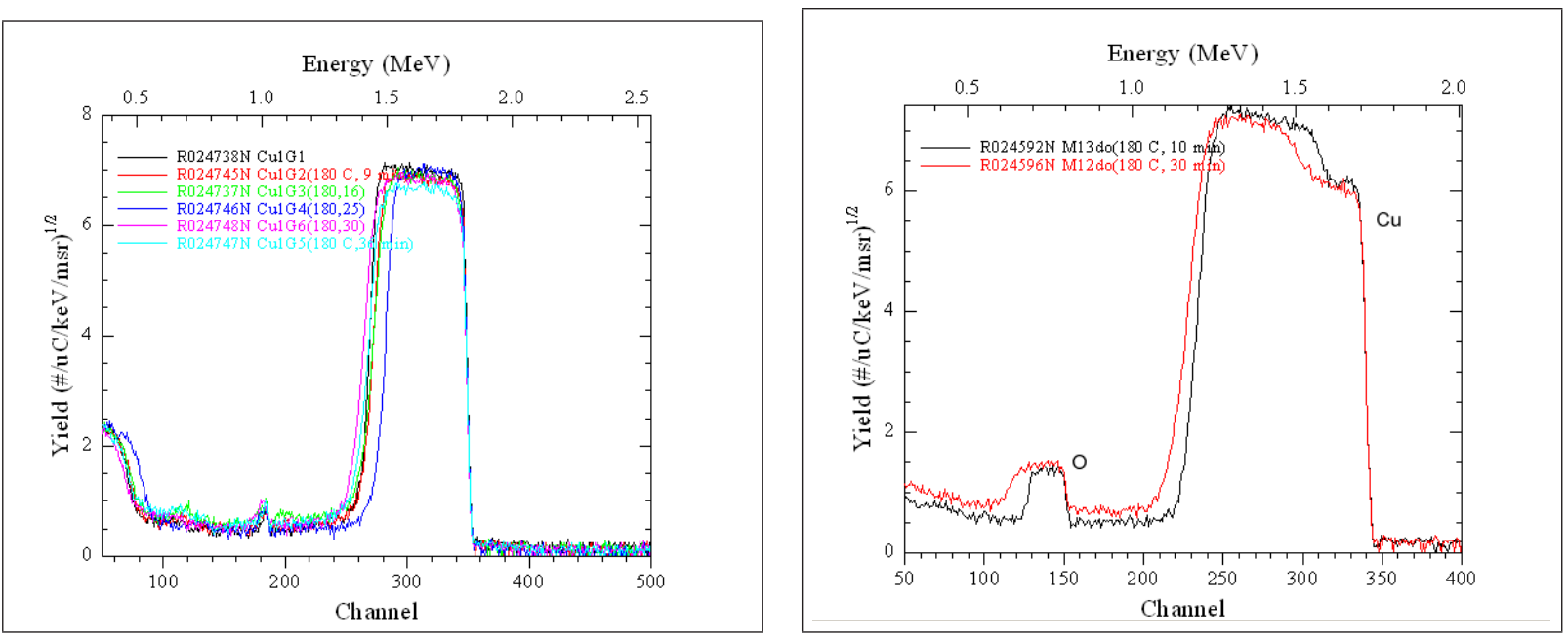

Figura 5.37: Filmes de $\mathrm{Cu}(\mathrm{Cl})$ oxidados em Figura 5.38: Filmes de $\mathrm{Cu}$ oxidados em 180 $180{ }^{\circ} \mathrm{C}$ ${ }^{\circ} \mathrm{C}$

Tabela 5.18: Comparação entre a cinética de oxidação de filmes de $\mathrm{Cu} / \mathrm{C}$ e $\mathrm{CuCl} / \mathrm{C}$, em temperatura de $180{ }^{\circ} \mathrm{C}$.

\begin{tabular}{ccccc}
\hline Filme & Temperatura $\left({ }^{\circ} C\right)$ & coeficiente angular & Coeficiente linear & coef. de correlação \\
\hline $\mathrm{Cu} / \mathrm{C}$ & 180 & $(0,0900 \pm 0,0005)$ & $(1,36 \pm 0,02)$ & 0,97 \\
$\mathrm{CuCl} / \mathrm{C}$ & 180 & $(0,00100 \pm 0,00009$ & $(0,01 \pm 0,001)$ & 0,97
\end{tabular}

\subsection{Passivação de filmes de cobre através de implan- tação iônica}

No estudo da passivação de filmes de cobre foram os íons: $B^{+}, P d^{+}$e $A r^{+}$. A seguir será descrito o efeito da implantação de cada um destes íons na taxa de oxidação de filmes de cobre.

\subsubsection{Implantação de $B^{+}$}

As implantações foram feitas com energia de $50 \mathrm{keV}$ e doses de $1 \times 10^{13}$ a $5 \times 10^{14}$ átomos $/ \mathrm{cm}^{2}$.

A profundidade determinada pelo programa de simulação SRIM 2003 foi 90,2 nm. O interesse em implantar íons de boro reside no fato do processo de implantação deste íons ser uma das etapas do processamento dos dispositivos semicondutores. As doses tão 


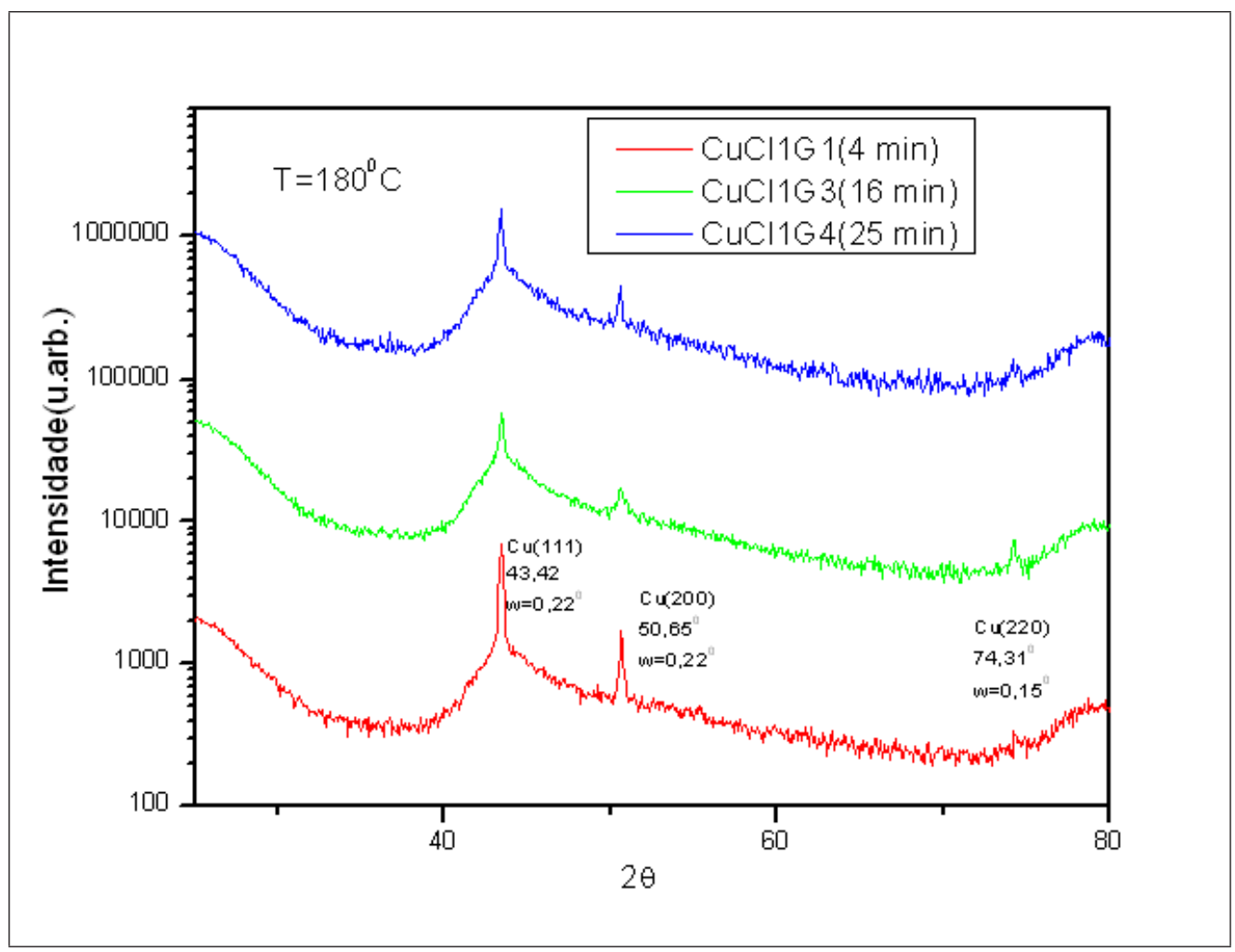

Figura 5.39: Espectro XRD de uma amostra contaminada com cloro

baixas são justificadas pelo fato de causarem menor variação na resistividade elétrica do metal. Os testes para oxidação foram feitos em atmosfera ambiente, com temperatura de $250{ }^{\circ} \mathrm{C}$ em tempos variando entre 10 e 150 minutos.

A implantação de boro não aumentou a aderência dos filmes de cobre ao silício.

Análises RBS mostraram uma ligeira redução na taxa de oxidação com as doses utilizadas. O tipo e a espessura do óxido formado nestas condições foram diferentes do formado para filmes de cobre puro. Diferentemente dos filmes de cobre puro, para os filmes implantados com boro houve crescimento de $\mathrm{CuO}$, além de $\mathrm{Cu}_{2} \mathrm{O}$. Isso pode ser visto na Figura 5.43, que mostra o espectro RBS de um filme oxidado e sua simulação. ${ }^{7}$ À medida que o tempo de oxidação aumenta o filme de óxido formado tem a sua rugosidade aumentada, como pode ser observado na Figura 5.44.

A Figura 5.46 mostra as diferenças entre dois filmes de cobre; um puro e o outro com $1 \times 10^{13} \mathrm{~B}^{+} / \mathrm{cm}^{2}$ implantados. Pode ser claramente observada a redução da rugosidade e da concentração de oxigênio incorporado no filme de cobre implantado com boro, embora não tenha ocorrido passivação total do filme. A redução da concentração de oxigênio 7 Composição $\mathrm{CuO}(300) / \mathrm{Cu}_{2} \mathrm{O}(2500) / \mathrm{C} u_{2} \mathrm{O}_{0,8}(1800)$ - Rugosidade:650.As grandezas estão em unidade de $10^{15}$ átomos $/ \mathrm{cm}^{2}$ 


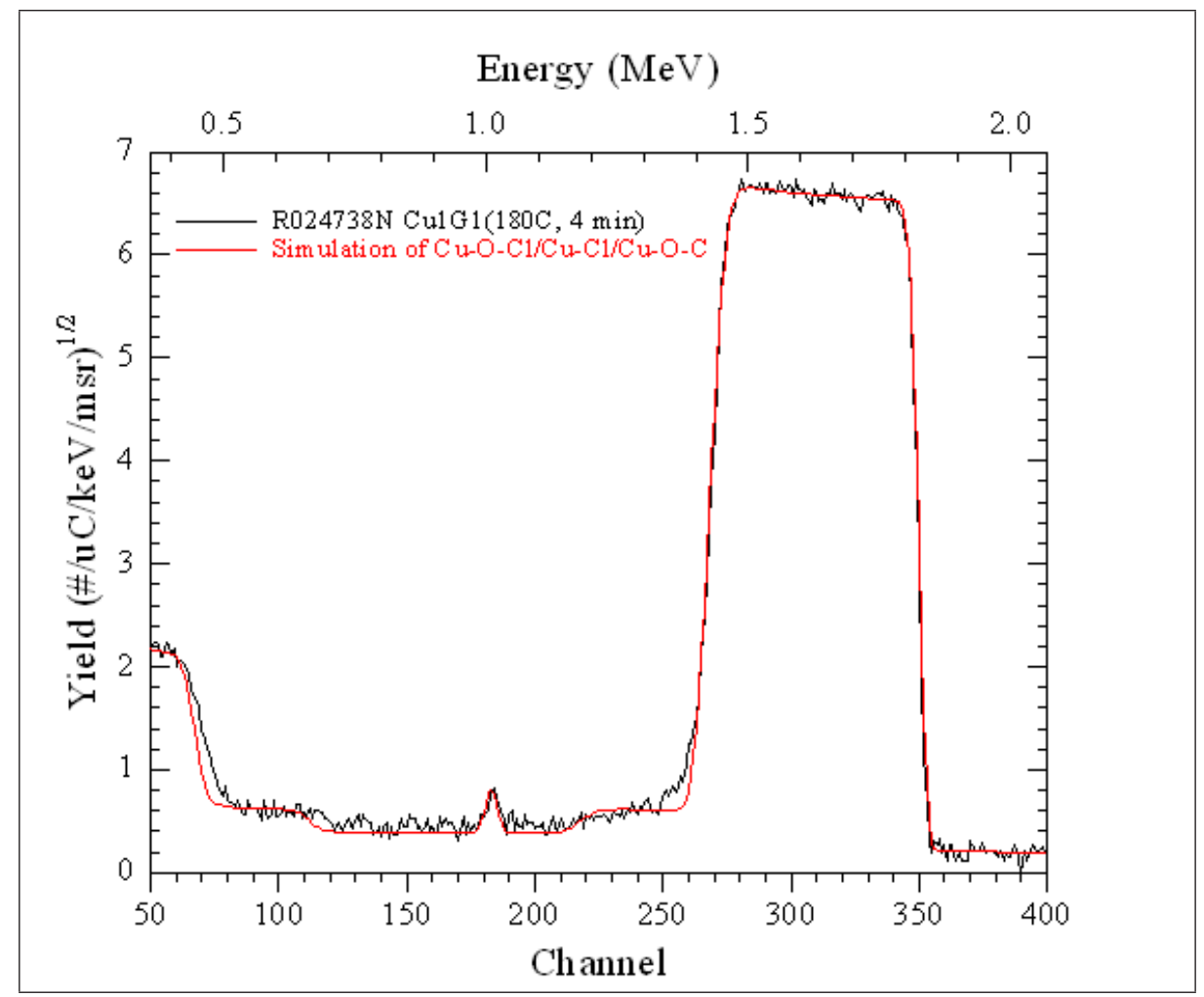

Figura 5.40: Espectro RBS de uma amostra contaminada com cloro, oxidada por 4 minutos, em $180{ }^{\circ} \mathrm{C}$.

incorporado pode ser melhor observada através da análise da Figura 5.45, na qual é exibida a variação da concentração de oxigênio incorporado em função do tempo de oxidação.

A variação da passivação com a dose implantada foi estudada para $1 \times 10^{14} \mathrm{~B}^{+} / \mathrm{cm}^{2} \mathrm{e}$ $5 \times 10^{14} \mathrm{~B}^{+} / \mathrm{cm}^{2}$. As Figuras 5.47 e a tabela 5.19permitem a determinação da variação da concentração de oxigênio incorporado com a dose de implantação.

Tabela 5.19: Cinética de oxidação de filmes de cobre oxidados em $250{ }^{\circ} \mathrm{C}$

\begin{tabular}{ccccc}
\hline Amostra & Temperatura $\left({ }^{\circ} C\right)$ & Coef. angular & Coef. linear & Coef. de correlação \\
\hline $\mathrm{Cu}_{\text {puro }}{ }^{8}$ & 250 & $(1,39 \pm 0,02)$ & $(48,19 \pm 0,55)$ & 0,99 \\
$\mathrm{Cu}\left(1 \times 10^{13} B^{+}\right)$ & 250 & $(1,53 \pm 0,07)$ & $(1,6 \pm 1,2)$ & 0,99 \\
$\mathrm{Cu}\left(1 \times 10^{14} B^{+}\right)$ & 250 & $(0,53 \pm 0,08)$ & $(40,9 \pm 6,3)$ & 0,97 \\
$\mathrm{Cu}\left(5 \times 10^{14} B^{+}\right)$ & 250 & $(0,53 \pm 0,05)$ & $(44,4 \pm 2,4)$ & 0,97
\end{tabular}




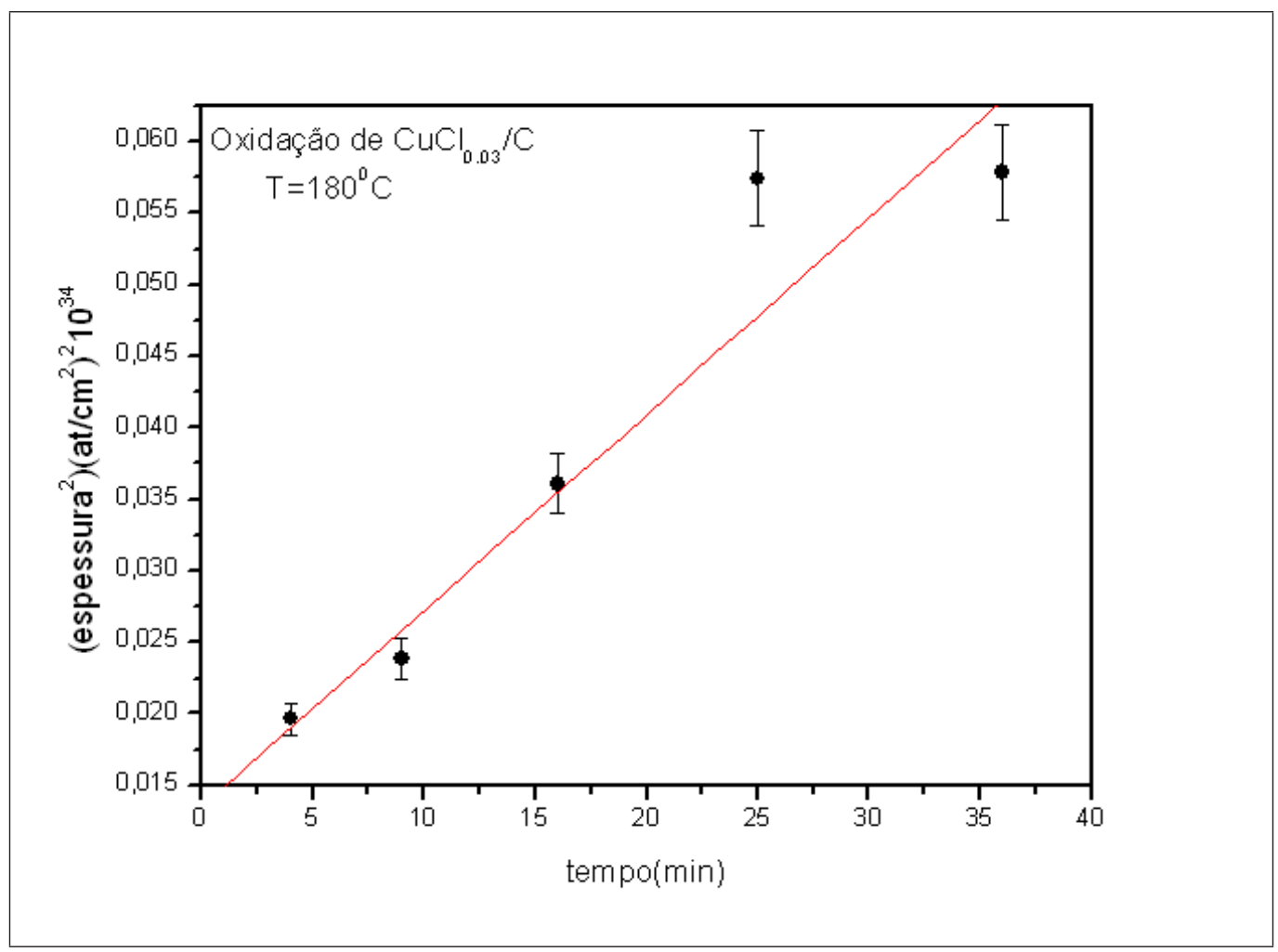

Figura 5.41: Cinética de oxidação em filmes de $C u C l_{0,03}$, em $180{ }^{\circ} \mathrm{C}$.

Quando comparadas as várias doses implantadas foi verificado que os óxidos formados a partir de filmes implantados com doses mais altas tinham menor rugosidade ${ }^{9}$. Além disso, foi observada variação da taxa de oxidação com a dose implantada, como pode ser visto na tabela 5.19 .

Não houve formação de qualquer composto que pudesse servir como passivador. Desta forma, o mecanismo de passivação de filmes de cobre por $B^{+}$pode ser descrito através da redução da difusão de íons $\mathrm{Cu}^{+}$, devido ao preenchimento das vacâncias no óxido $\mathrm{Cu}_{2} \mathrm{O}$ inicialmente formado. Sabemos que o processo de oxidação do cobre é governado pelo movimento dos íons $\mathrm{Cu}^{+}$no sentido metal-óxido. A implantação de boro preenche as vacâncias, reduzindo com isto, o transporte de cobre até a superfície.

Estudo realizado por Ding e colaboradores mostra uma efetiva passivação para doses acima de $2,5 \times 10^{15} \mathrm{~B}^{+} / \mathrm{cm}^{2}$ [8] e [94], mas não foi estudada a variação da taxa de oxidação para doses tão baixas quanto às utilizadas aqui.

9 Para tempos entre 10 e 150 minutos, o fator fuzzing da simulação variou entre 550 a 1000 , para a menor dose e para as doses de 1 e $5 \times 10^{14} B^{+} / \mathrm{cm}^{2}$ foi 550 e 500 , respectivamente, em unidades de $10^{15}$ átomos $/ \mathrm{cm}^{2}$ 


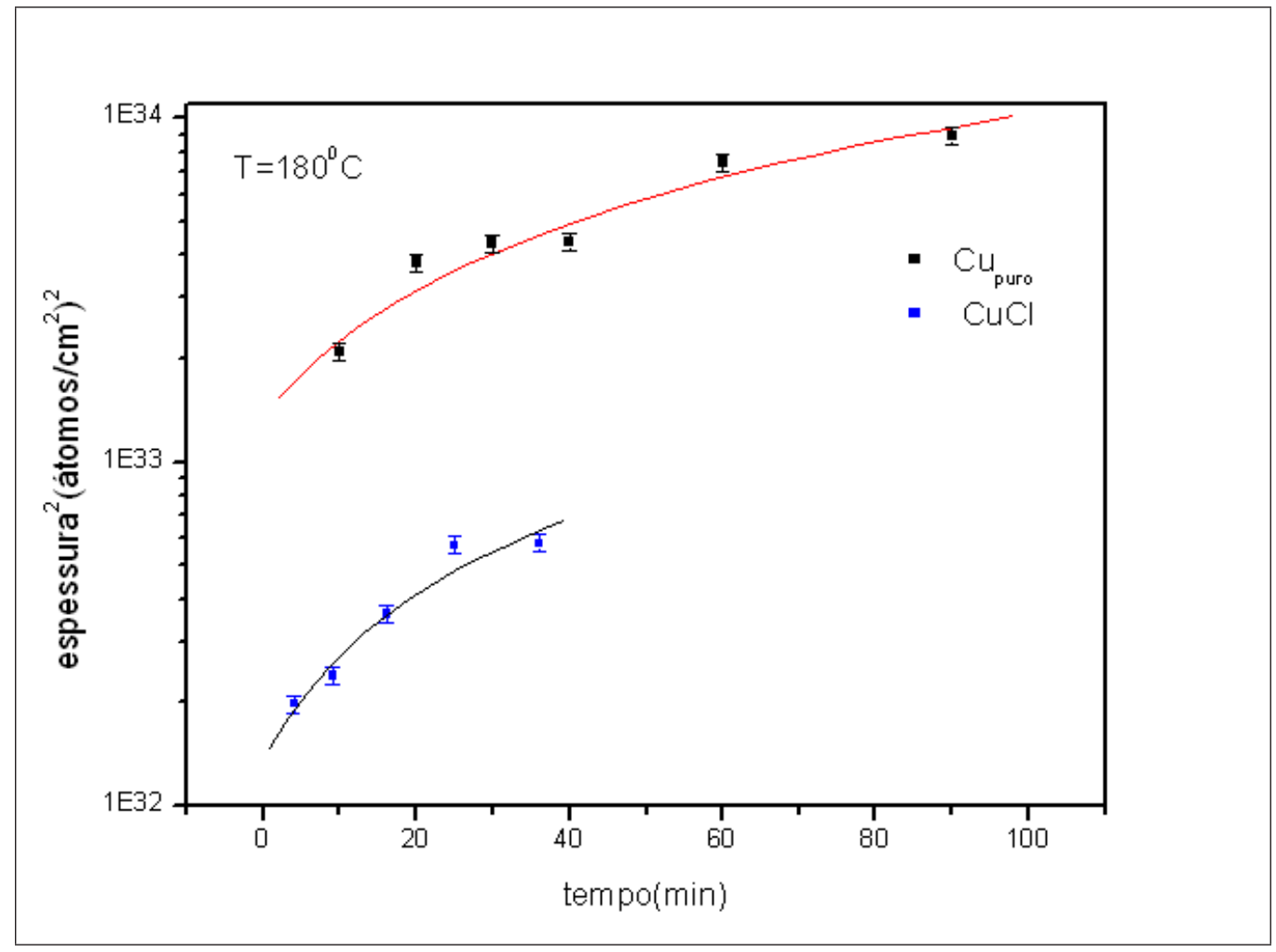

Figura 5.42: Cinética de oxidação em filmes de $C u C l_{0,03} / C$ e $\mathrm{Cu} / \mathrm{C}$ em $180{ }^{\circ} C$.

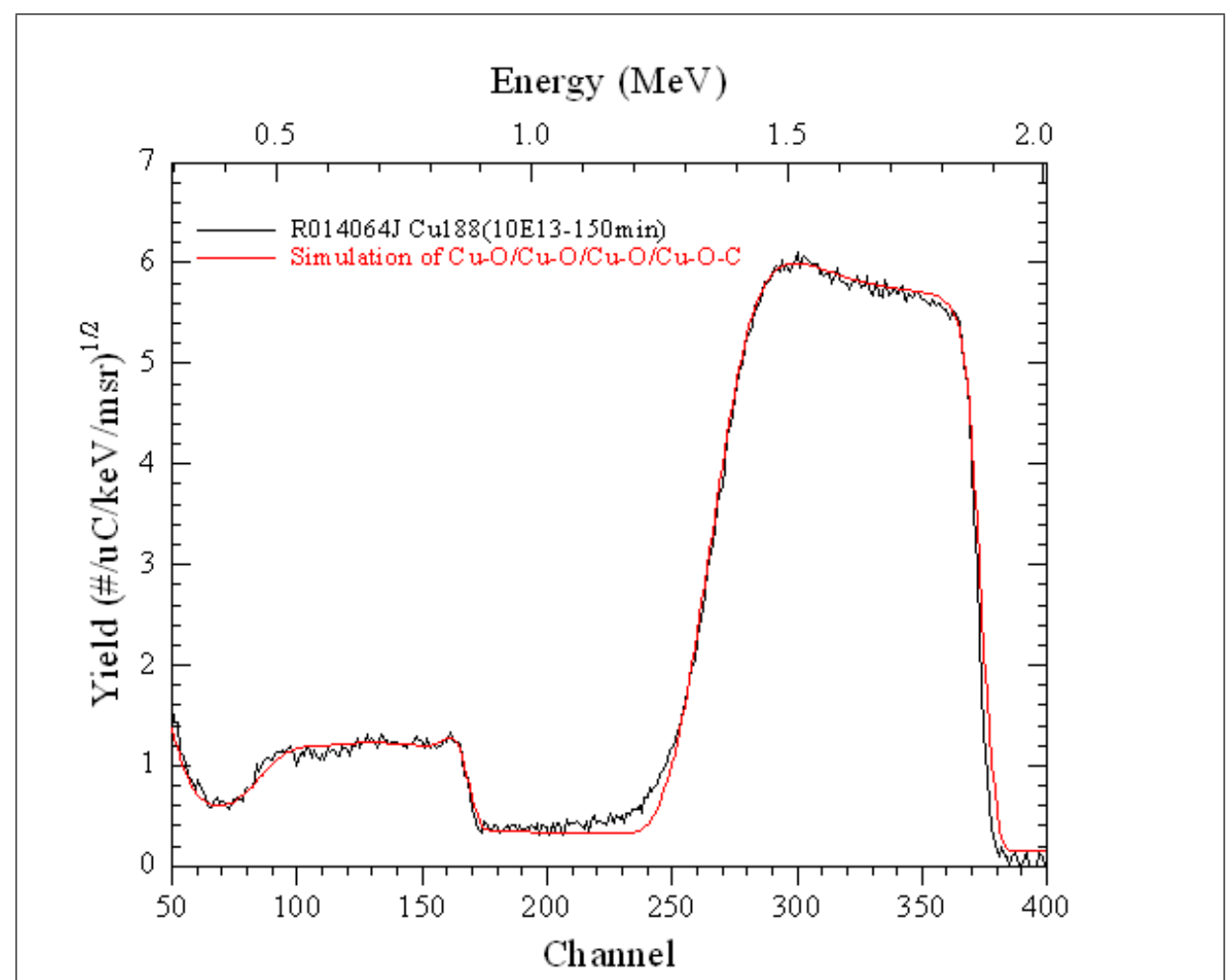

Figura 5.43: Espectro RBS de filmes implantados com $1 \times 10^{13} \mathrm{~B}^{+} / \mathrm{cm}^{2}$ e oxidados em $\mathrm{T}=250^{\circ} \mathrm{C}$, mostrando os dois tipos de óxidos formados. 


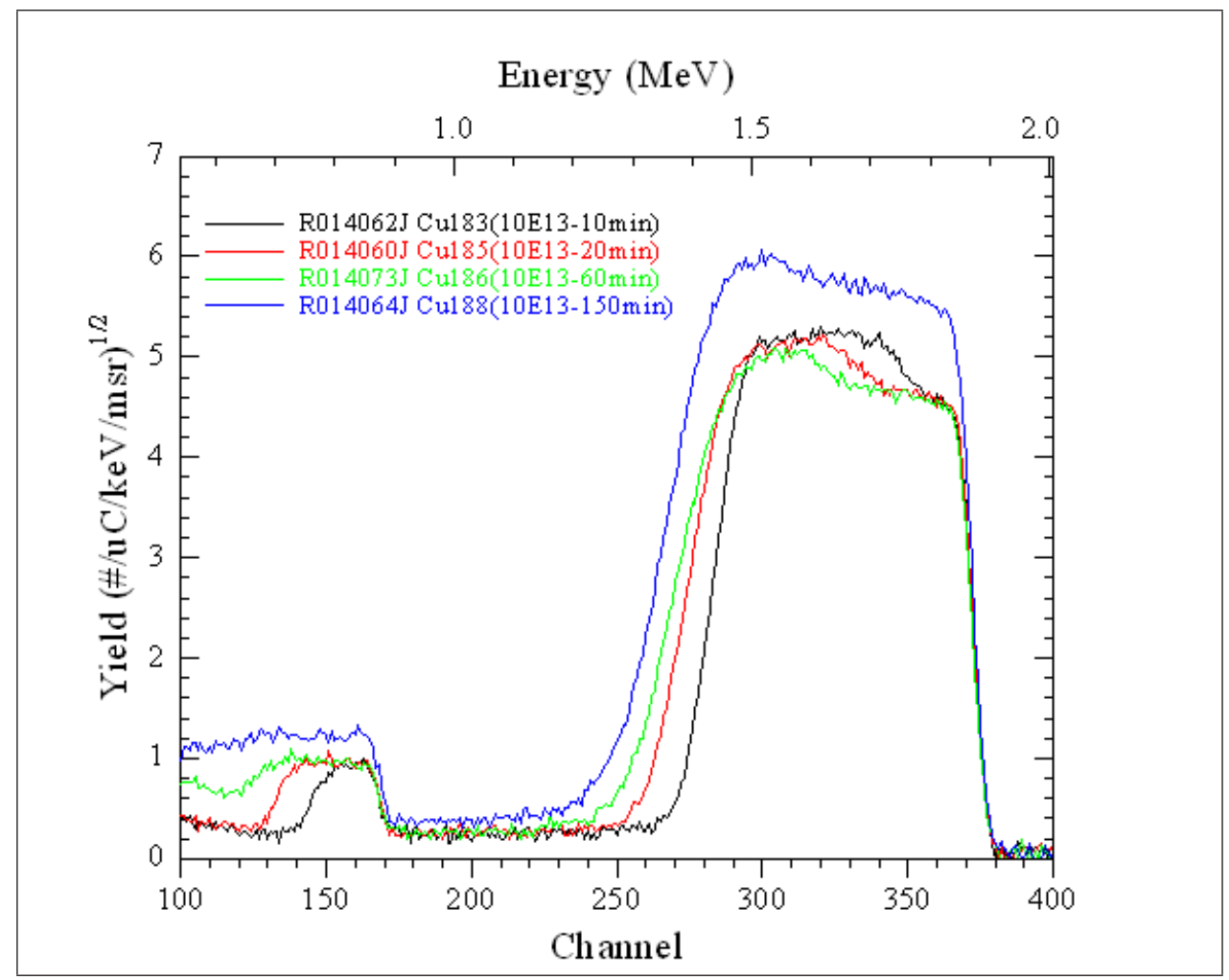

Figura 5.44: Espectro RBS de um filme implantados com $1 \times 10^{13} \mathrm{~B}^{+} / \mathrm{cm}^{2}$ e oxidado em $\mathrm{T}=250^{\circ} \mathrm{C}$, mostrando o aumento da espessura do óxido e da rugosidade com o tempo de oxidação.

\subsubsection{Implantação de $P d^{+}$}

As implantações de $P d^{+}$foram feitas com energia de $100 \mathrm{keV}$ e dose de $5 \times 10^{15}$ átomos $/ \mathrm{cm}^{2}$ em filmes de cobre de espessura $5,5 \times 10^{17}$ átomos $/ \mathrm{cm}^{2}$. A profundidade implantada, determinada pelo programa de simulação SRIM2003, foi 23,5 nm e a determinada pela simulação do espectro RBS foi 23,7 nm. A aderência dos filmes de $\mathrm{Cu} / \mathrm{Si}$ não foi modificada pela implantação, pois a penetração dos íons não alcança a interface Si-Cu. Os teste para oxidação foram feitos em atmosfera ambiente, em temperatura de $350{ }^{\circ} \mathrm{C}$ e tempos variando entre 2 e 20 minutos.

A Figura 5.48 mostra o espectro RBS do filme de cobre antes e após a implantação de $P d^{+}$. Também é mostrado o espectro do filme implantado e oxidado por 2 minutos. Pode ser observado o aumento da rugosidade quando o filme é transformado em óxido de cobre. Utilizando o parâmetro fuzzing da simulação do espectro RBS, verifica-se que o aumento relativo é de $300 /(150)$. 


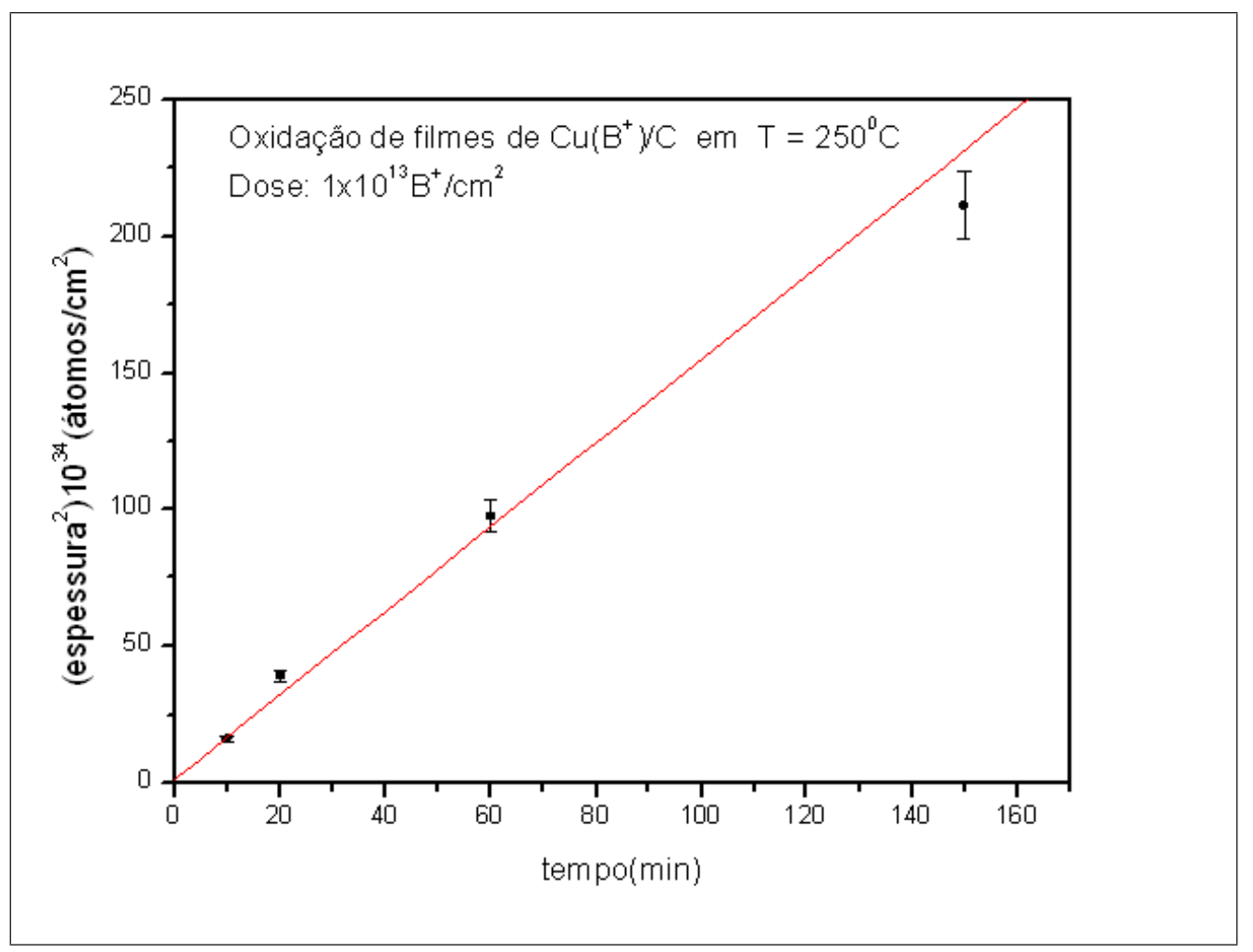

Figura 5.45: Cinética de oxidação de filmes implantados com $1 \times 10^{13} \mathrm{~B}^{+} / \mathrm{cm}^{2}$ e oxidados em $\mathrm{T}=250{ }^{\circ} \mathrm{C}$

Pode ser observado pela Figura 5.48 que com tempo tão reduzido quanto 2 minutos o filme de cobre é totalmente oxidado.

Simulações do espectro RBS mostram que existem dois tipos de óxidos crescidos, $\mathrm{CuO}$ e $\mathrm{Cu}_{2} \mathrm{O}$.

Não foi observada nenhuma relação entre a variação da rugosidade do óxido com o tempo de oxidação.

Assim, conclui-se que a implantação de íons de $\mathrm{Pd}$ com dose de $5 \times 10^{15}$ átomos $/ \mathrm{cm}^{2}$ não é capaz de passivar a superfície de cobre. Apenas 2 minutos é capaz de oxidar um filme com cerca de $6,00 \times 10^{17}$ átomos $/ \mathrm{cm}^{2}$ de espessura. Pela observação do espectro RBS observa-se que a difusão dos íons de Pd ocorre da superfície para dentro do filme. Resultados da simulação mostram que há penetração $2,00 \times 10^{17}$ átomos $/ \mathrm{cm}^{2}$ no substrato de carbono durante a oxidação.

Resultados da literatura mostram que ligas de $\mathrm{Cu}(\mathrm{Pd})$ possuem uma maior resistência à oxidação do que filmes de cobre puro e que quanto maior a concentração de Pd na liga, maior a resistência à oxidação [47]. Formando composto com o $\mathrm{Cu}$, o $\mathrm{Pd}$ reduz o movimento desses átomos e diminui a taxa de oxidação. No presente trabalho, foi 


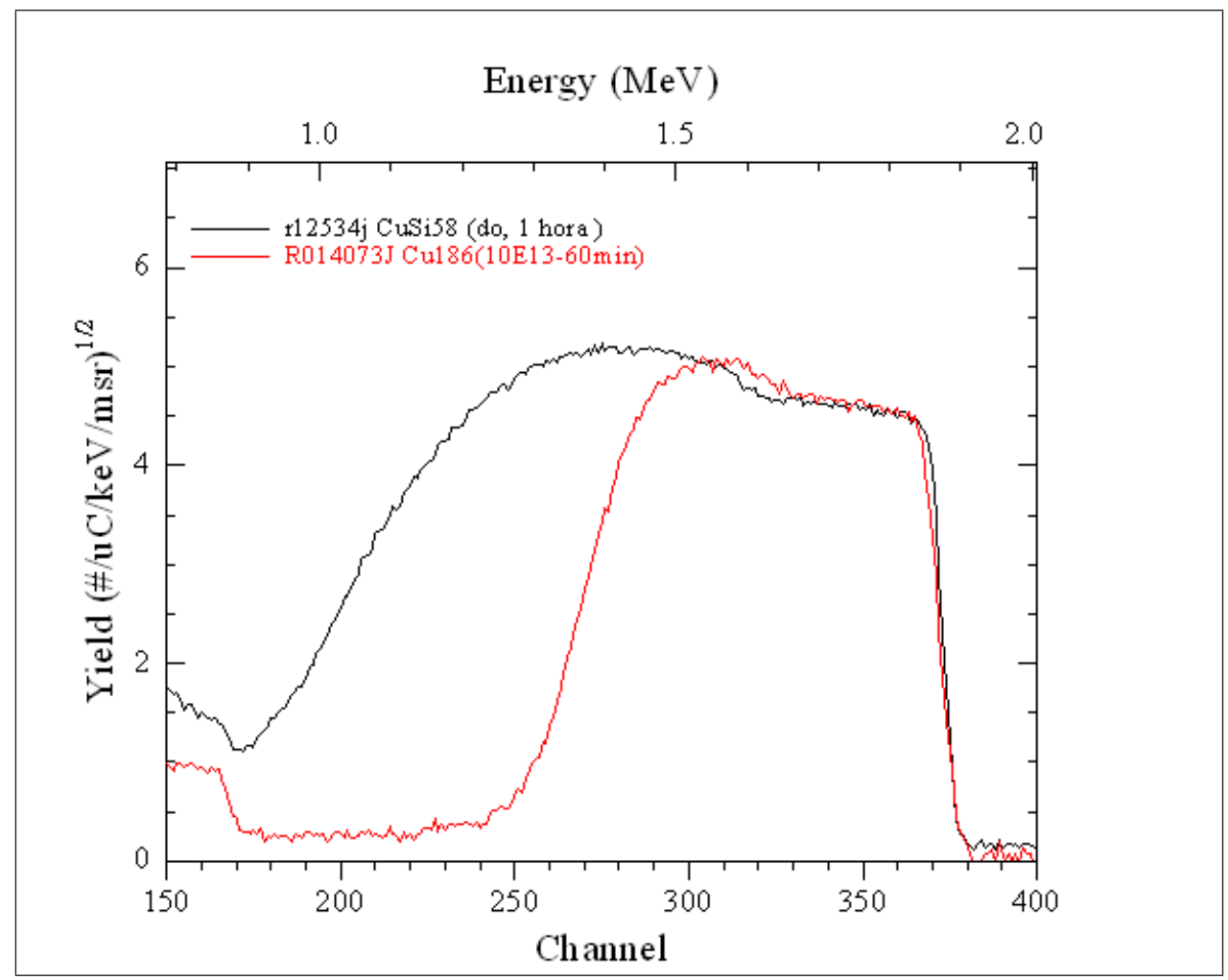

Figura 5.46: Espectro RBS de um filme de cobre puro e outro implantado com $1 \times 10^{13} \mathrm{~B}^{+} / \mathrm{cm}^{2}$, ambos oxidados em $\mathrm{T}=250^{\circ} \mathrm{C}$, por uma hora, mostrando a diferença na incorporação de oxigênio entre os dois filmes e a diferença entre a rugosidade dos óxidos formados nos dois filmes.

verificado que a implantação desses íons não constitui em uma alternativa à formação de compostos, pois o átomo de Pd difunde no cobre e diminui a concentração na superfície, deixando o filme de $\mathrm{Cu}$ livre de $\mathrm{Pd}$ na superfície, e oxidando-se, como pode ser visto na Figura 5.48.

\subsubsection{Implantação de $A r^{+}$}

A passivação superficial que ocorre quando um íon inerte é implantado não pode ser explicada por formação de ligas ou de compostos passivadores.

Nesta fase do trabalho íons de argônio foram implantados em cobre em diferentes doses e energias.

Foram utilizadas energias de implantação variando entre 10 e $90 \mathrm{keV}$, com doses entre $1 \times 10^{15}$ e $1 \times 10^{17}$ átomos $/ \mathrm{cm}^{2}$. As profundidades determinadas pelo programa de simulação SRIM 2003 foram 6,8 nm(10 keV), 16,5 nm(30 keV) e 45,2 nm(90keV). 

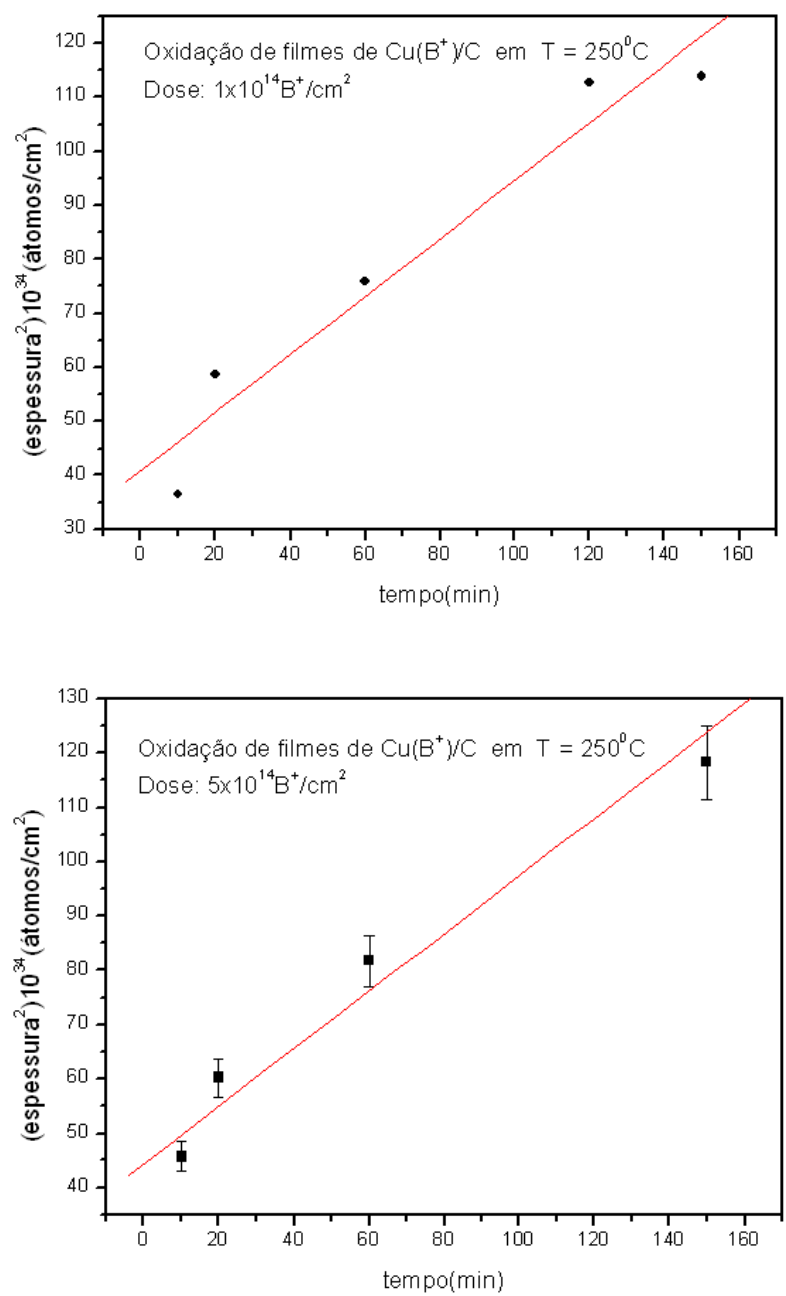

Figura 5.47: Cinética de oxidação de filme de $\mathrm{Cu}$ implantados com $1 \times 10^{14} \mathrm{~B}^{+} / \mathrm{cm}^{2}$ e $5 \times 10^{14} \mathrm{~B}^{+} / \mathrm{cm}^{2}$

\section{Rugosidade}

O efeito da implantação na microestrutura foi determinado através de análises por AFM, com scan $2 \mu m \times 2 \mu m$. Os resultados das medidas são mostrados nas Figuras 5.49 a 5.52 e na tabela 5.20. A amostra Cu124 não foi submetida à implantação iônica.

Nas figuras 5.51 e 5.52 são mostrados dois filmes implantados com a mesma energia e doses diferentes. Os resulta das análises são mostrados na tabela 5.20.

A análise por AFM não foi conclusiva em relação ao comportamento da rugosidade com a implantação iônica. Analisando a tabela 5.20 não é possível estabelecer nenhuma relação entre dose, energia e rugosidade. Optou-se então, por utilizar o parâmetro fuzzing 


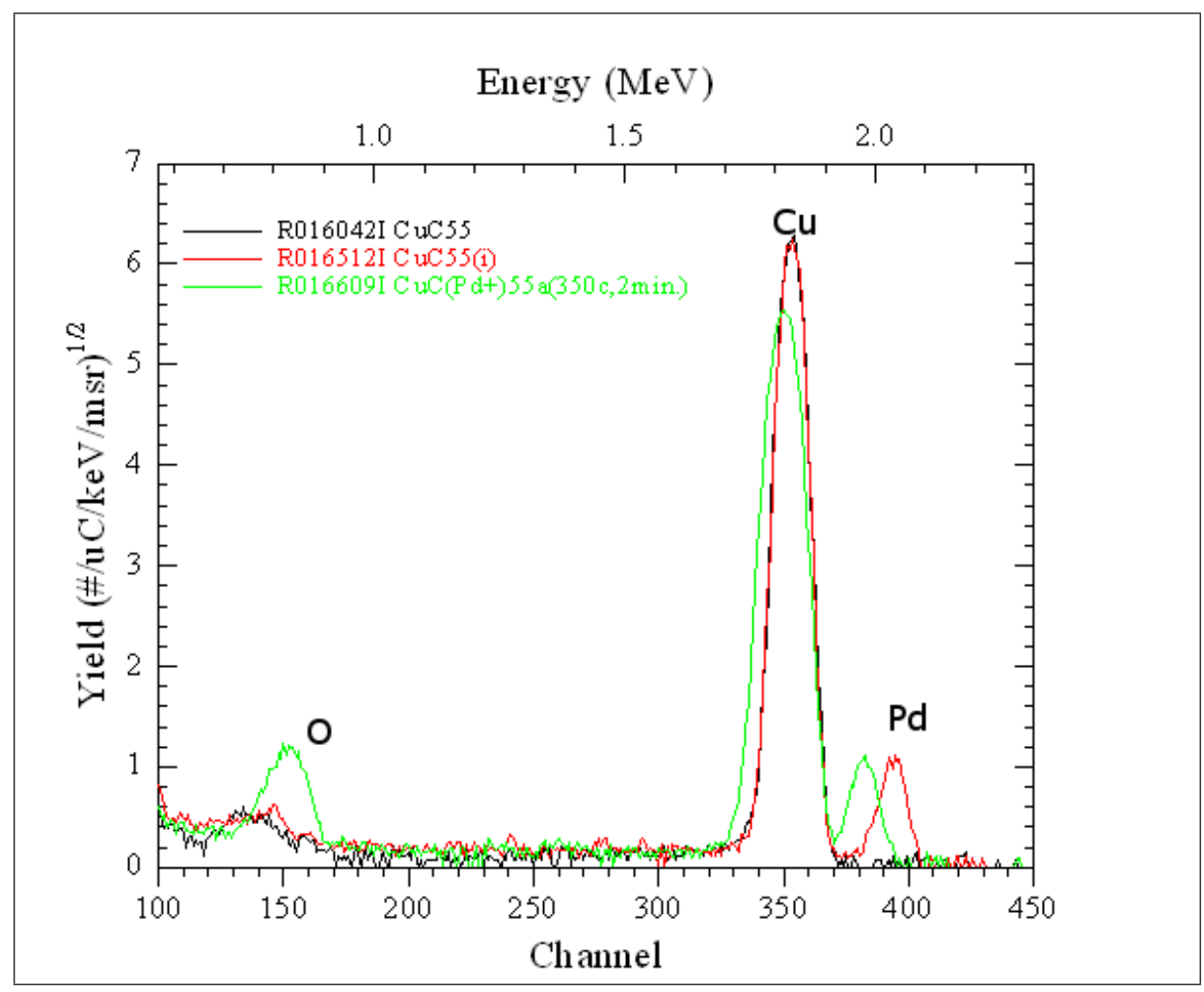

Figura 5.48: Espectro RBS de um filme de cobre antes e após a implantação com $P d^{+}$. Também é mostrado o espectro após a oxidação em $\mathrm{T}=350{ }^{\circ} \mathrm{C}$ por 2 minutos, com a difusão desses íons da superfície para dentro do filme.

do programa de simulação RUMP, que possibilita comparar variações de rugosidades para os filmes. Os resultados são mostrados na tabela 5.21.

Estudos têm mostrado variação da rugosidade de filmes de $\mathrm{Cu}$, dependendo da dose e do íon implantado e ainda do substrato utilizado [123] e [124]. No presente trabalho, tanto os resultados obtidos por AFM quanto os valores obtidos através da utilização do parâmetro fuzzing do RUMP não indicam nenhuma tendência de variação da rugosidade com a dose de implantação do $A r^{+}$.

\section{Resistividade elétrica}

No estudo do comportamento da resistividade com a implantação iônica foram feitas medidas pelo método das 4 pontas antes e após a implantação iônica e após o tratamento térmico, que foi feito em vácuo, a $550^{\circ} \mathrm{C}$, por 30 minutos. Os resultados são mostrados na tabela 5.22, cuja simbologia adotada foi a seguinte: $\rho_{a i}$ é a resistividade elétrica antes da implantação iônica; $\rho_{d t}$, a resistividade elétrica após o tratamento térmico; $\Delta \rho_{d i}$ a variação percentual da resistividade elétrica em função da implantação iônica e $\Delta \rho_{d t}$ a variação 


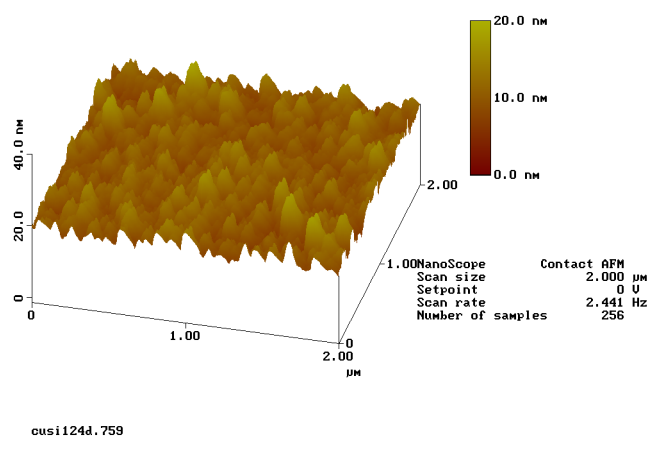

\begin{tabular}{|c|c|}
\hline $\begin{array}{l}\text { Img. Mean } \\
\text { Img. Rms (Rq) } \\
\text { Img. Ra } \\
\text { Img. Rmax } \\
\text { Img. Srf. area } \\
\text { Img. Srf. area diff }\end{array}$ & $\begin{array}{l}-0.000000 \mathrm{~nm} \\
1.714 \mathrm{~nm} \\
1.314 \mathrm{~nm} \\
14.510 \mathrm{~nm}\end{array}$ \\
\hline \multicolumn{2}{|c|}{ Box Statistics } \\
\hline $\begin{array}{l}\text { RMs (Rq) } \\
\text { Mean roughness (Ra) } \\
\text { Max height (Rmax) } \\
\text { Surface area } \\
\text { Surface area diff } \\
\text { Box } x \text { dimension } \\
\text { Box y dimension }\end{array}$ & \\
\hline
\end{tabular}

Figura 5.49: Imagem obtida por AFM de filme de cobre antes da implantação

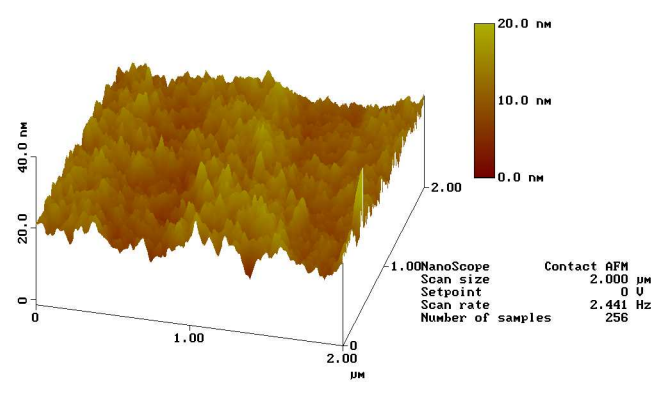

cuc115d. 773

\begin{tabular}{|c|c|}
\hline $\begin{array}{l}\text { Img. Mean } \\
\text { Img. Rms (Rq) } \\
\text { Img. Ra } \\
\text { Img. Rmax } \\
\text { Img. Srf. area } \\
\text { Img. Srf. area diff }\end{array}$ & $\begin{array}{l}-0.000002 \mathrm{~nm} \\
2.002 \mathrm{~nm} \\
1.609 \mathrm{~nm} \\
23.792 \mathrm{~nm}\end{array}$ \\
\hline \multicolumn{2}{|c|}{ Box Statistics } \\
\hline $\begin{array}{l}\text { RMs (Rq) } \\
\text { Mean roughness (Ra) } \\
\text { Max height (Rmax) } \\
\text { Surface area } \\
\text { Surface area diff } \\
\text { Box } x \text { dimension } \\
\text { Box } y \text { dimension }\end{array}$ & \\
\hline
\end{tabular}

Figura 5.50: Imagem obtida por AFM de filme de cobre implantado com $1 \times 10^{16} \mathrm{Ar}^{+} / \mathrm{cm}^{2}$, com energia de $90 \mathrm{keV}$.

da resistividade elétrica em função do tratamento térmico, considerada a partir do valor obtido após a implantação iônica.

Analisando a tabela 5.22, verifica-se o aumento da resistividade elétrica com a dose de íons. Em alguns estudos, pesquisadores têm tentado determinar a dose mínima necessária para causar uma completa amorfização de um cristal [125] e [126].

É sabido que a implantação iônica reduz o tamanho dos grãos. Assim, esse aumento do número de defeitos reduz o transporte elétrico, aumentando assim, a resistividade elétrica.

Com o tratamento térmico, a ordem cristalina é novamente estabelecida e ocorre o aumento da condutividade elétrica, mostrado na última coluna da tabela. 


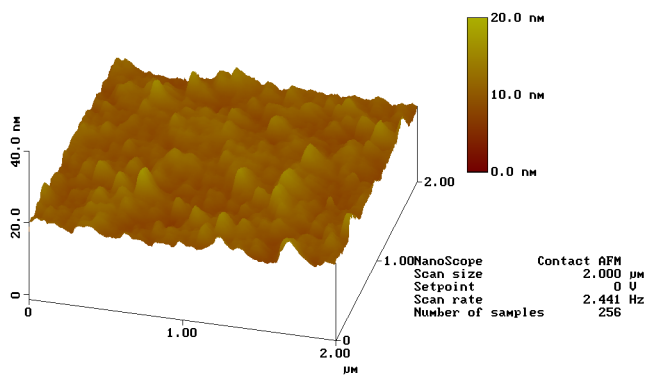

cusi $122 \mathrm{~d} .732$

\begin{tabular}{|c|c|}
\hline $\begin{array}{l}\text { Img. Mean } \\
\text { Img. Rms (Rq) } \\
\text { Img. Ra } \\
\text { Img. Rmax } \\
\text { Img. Srf. area } \\
\text { Img. Srf, area diff }\end{array}$ & $\begin{array}{l}0.000000 \mathrm{~nm} \\
1.297 \mathrm{~nm} \\
0.992 \mathrm{~nm} \\
11.586 \mathrm{~nm}\end{array}$ \\
\hline \multicolumn{2}{|c|}{ Box Statistics } \\
\hline $\begin{array}{l}\text { Rms (Rq) } \\
\text { Mean roughness (Ra) } \\
\text { Max height (Rmax) } \\
\text { Surface area } \\
\text { Surface area diff } \\
\text { Box } x \text { dimension } \\
\text { Box } y \text { dimension }\end{array}$ & \\
\hline
\end{tabular}

Figura 5.51: Imagem obtida por AFM de filme de cobre implantado com $1 \times 10^{15} \mathrm{Ar}^{+} / \mathrm{cm}^{2}$, com energia de $90 \mathrm{keV}$.

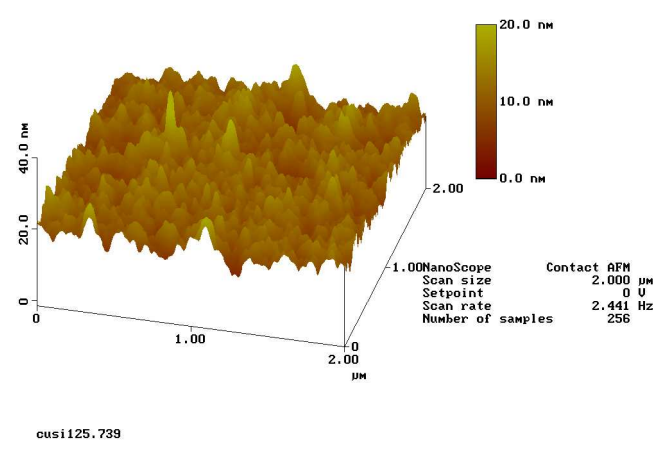

\begin{tabular}{|c|c|}
\hline \multicolumn{2}{|c|}{ Image Statistics } \\
\hline $\begin{array}{l}\text { Img. Mean } \\
\text { Img. Rms (Rq) } \\
\text { Img. Ra } \\
\text { Img. Rmax } \\
\text { Img. Srf. area } \\
\text { Img. Srf. area diff }\end{array}$ & $\begin{array}{l}0.000000 \mathrm{~nm} \\
1.989 \mathrm{~nm} \\
1.545 \mathrm{~nm} \\
22.986 \mathrm{~nm}\end{array}$ \\
\hline \multicolumn{2}{|c|}{ Box Statistics } \\
\hline $\begin{array}{l}\text { Rms (Rq) } \\
\text { Mean roughness (Ra) } \\
\text { Max height (Rmax) } \\
\text { Surface area } \\
\text { Surface area diff } \\
\text { Box } x \text { dimension } \\
\text { Box y dimension }\end{array}$ & \\
\hline
\end{tabular}

Figura 5.52: Imagem obtida por AFM de filme de cobre implantado com $1 \times 10^{16} \mathrm{Ar}^{+} / \mathrm{cm}^{2}$, com energia de $90 \mathrm{keV}$.

\section{Resistência à oxidação}

A resistência à oxidação foi testada para temperaturas de $180{ }^{\circ} \mathrm{C}, 200{ }^{\circ} \mathrm{C}$ e $300{ }^{\circ} \mathrm{C}$, em tempos variando entre 5 e 30 minutos, com e sem tratamento térmico em $550{ }^{\circ} \mathrm{C}$, em 30 minutos, em vácuo de $10^{-5}$ Torr. O sistema utilizado para tratamento térmico nessa fase do trabalho, consistia de um forno Kokusai, com uma rampa que permitia que o centro atingisse a temperatura utilizada em 30 minutos. A rampa de descida, 8 horas, foi reduzida para 2 horas através do uso de um ventilador industrial.

\section{Influência do tratamento térmico}

Para maior controle das condições experimentais, foi utilizada uma máscara, permitindo que as amostras tivessem somente uma parte implantada. Assim, na mesma 
Tabela 5.20: Rugosidade das amostras implantadas com argônio

\begin{tabular}{cccc}
\hline Amostra & dose & energia $(\mathrm{keV})$ & $\mathrm{RMS}(\AA)$ \\
\hline Cu107 & $1 \times 10^{15}$ & 30 & 18 \\
$\mathrm{Cu} 109$ & $1 \times 10^{15}$ & 90 & 16 \\
$\mathrm{Cu} 113$ & $1 \times 10^{16}$ & 30 & 16 \\
$\mathrm{Cu} 115$ & $1 \times 10^{16}$ & 90 & 20 \\
$\mathrm{Cu} 122$ & $1 \times 10^{15}$ & 90 & 13 \\
$\mathrm{Cu} 123$ & $1 \times 10^{16}$ & 30 & 19 \\
$\mathrm{Cu} 124$ & - & - & 17 \\
$\mathrm{Cu} 125$ & $1 \times 10^{16}$ & 90 & 20
\end{tabular}

Tabela 5.21: Rugosidade das amostras implantadas com argônio, obtidas por simulação dos espectros RBS

\begin{tabular}{cccc}
\hline Amostra & dose & energia $(\mathrm{keV})$ & Rugosidade $\left(10^{15}\right.$ átomos $\left./ \mathrm{cm}^{2}\right)$ \\
\hline Cu107 & $1 \times 10^{15}$ & 30 & 200 \\
Cu109 & $1 \times 10^{15}$ & 90 & 150 \\
Cu113 & $1 \times 10^{16}$ & 30 & 180 \\
Cu115 & $1 \times 10^{16}$ & 90 & 100 \\
Cu122 & $1 \times 10^{15}$ & 90 & 100 \\
Cu123 & $1 \times 10^{16}$ & 30 & 100 \\
Cu124 & - & - & 100 \\
Cu125 & $1 \times 10^{16}$ & 90 & 120
\end{tabular}

Tabela 5.22: Comportamento da resistividade elétrica dos filmes com a implantação iônica.

\begin{tabular}{cccccc}
\hline Amostra & dose $\left(10^{16}\right)$ & $\rho_{a i}(\mu \Omega . c m)$ & $\Delta \rho_{d i} \%$ & $\rho_{d t}(\mu \Omega . c m)$ & $\Delta \rho_{d t} \%$ \\
\hline G2 & 5 & 3,2 & +25 & 2,0 & -50 \\
G7 & 1 & 3,2 & +12 & 1,9 & -47 \\
G8 & 5 & 2,1 & +28 & 1,9 & -30 \\
G9 & 10 & 2,3 & +52 & 2,0 & -43
\end{tabular}

amostra, havia uma parte implantada e uma não implantada. Este procedimento foi utilizado sempre que as dimensões das amostras eram compatíveis com a precisão requerida. 


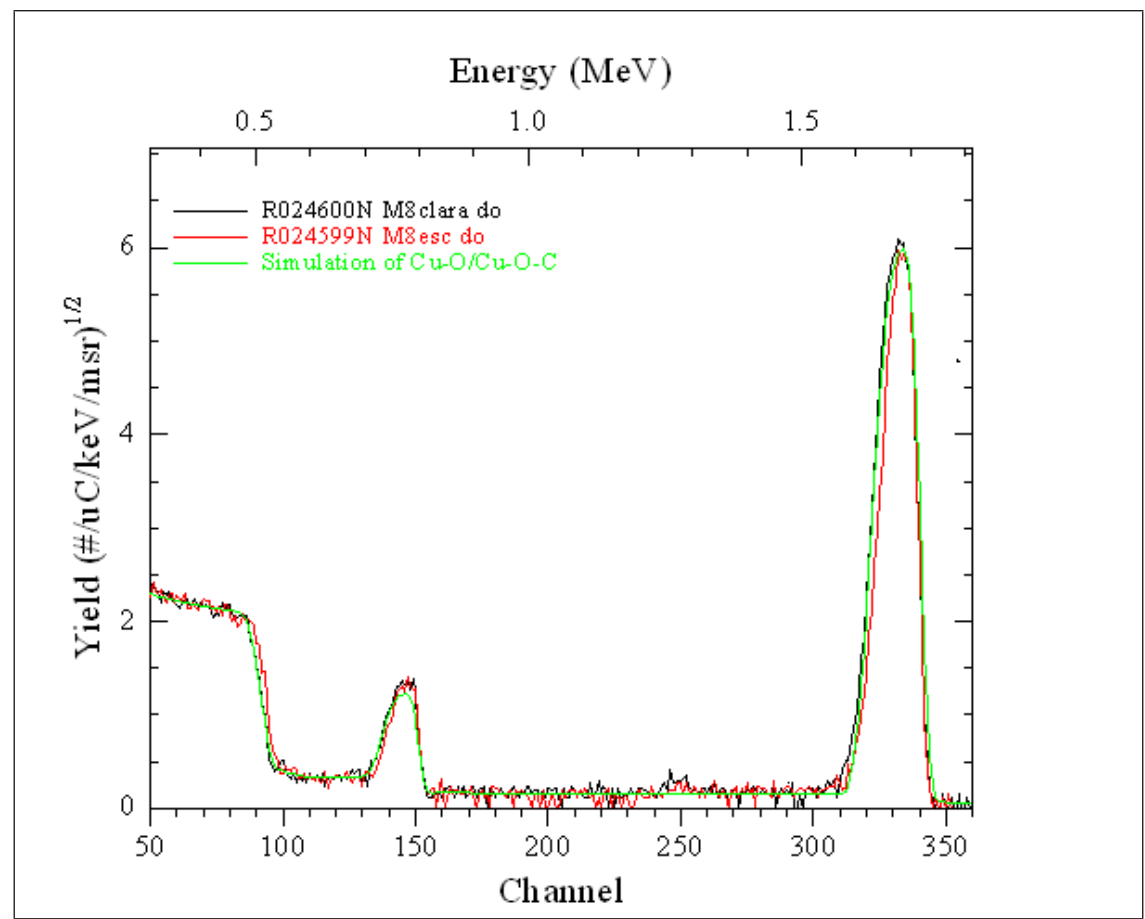

Figura 5.53: Espectros RBS de filme de cobre após a oxidação. A amostra designada por M8clara foi implantada com $1 \times 10^{17} \mathrm{Ar}^{+} / \mathrm{cm}^{2}$, com energia de $10 \mathrm{keV}$ e oxidada em $\mathrm{T}=200{ }^{\circ} \mathrm{C}$, por 30 minutos; a designada por esc é a parte não implantada do filme.

Para determinar o grau de passivação devido à implantação de $A r^{+}$em filmes não tratados termicamente, uma amostra foi parcialmente implantada com $1 \times 10^{17} \mathrm{Ar}^{+} / \mathrm{cm}^{2} \mathrm{e}$, em seguida, oxidada por 30 minutos, em temperatura de $200{ }^{\circ} \mathrm{C}$.

A Figura 5.53 mostra os espectros RBS após a oxidação e a tabela 5.23 os resultados da simulação.

Tabela 5.23: Resultados da simulação do espectro RBS da figura 5.54

\begin{tabular}{cccc}
\hline Camada & Composição & espessura & rugosidade \\
\hline 1 & $\mathrm{Cu}(200) \mathrm{O}(100)$ & 650 & 230 \\
2 & $\mathrm{Cu}(0,02) \mathrm{O}(1) \mathrm{C}(100)$ & substrato & -
\end{tabular}

Nota-se total coincidência entre as duas figuras, concluindo que não há eficiência na passivação com íons de argônio para amostras não tratadas termicamente. Para verificação do tipo de óxido crescido a amostra foi analisada por espectroscopia Raman.

A Figura 5.54 mostra o espectro Raman de um filme de cobre implantado com $\mathrm{Ar}^{+}$ após ser submetido à oxidação. Pode ser observada uma banda em $300 \mathrm{~cm}^{-1}$ e $600 \mathrm{~cm}^{-1}$, correspondente à vibração do $C u_{2} O$, e uma em $150 \mathrm{~cm}^{-1}$, corresponde ao $\mathrm{Cu}$. As duas 


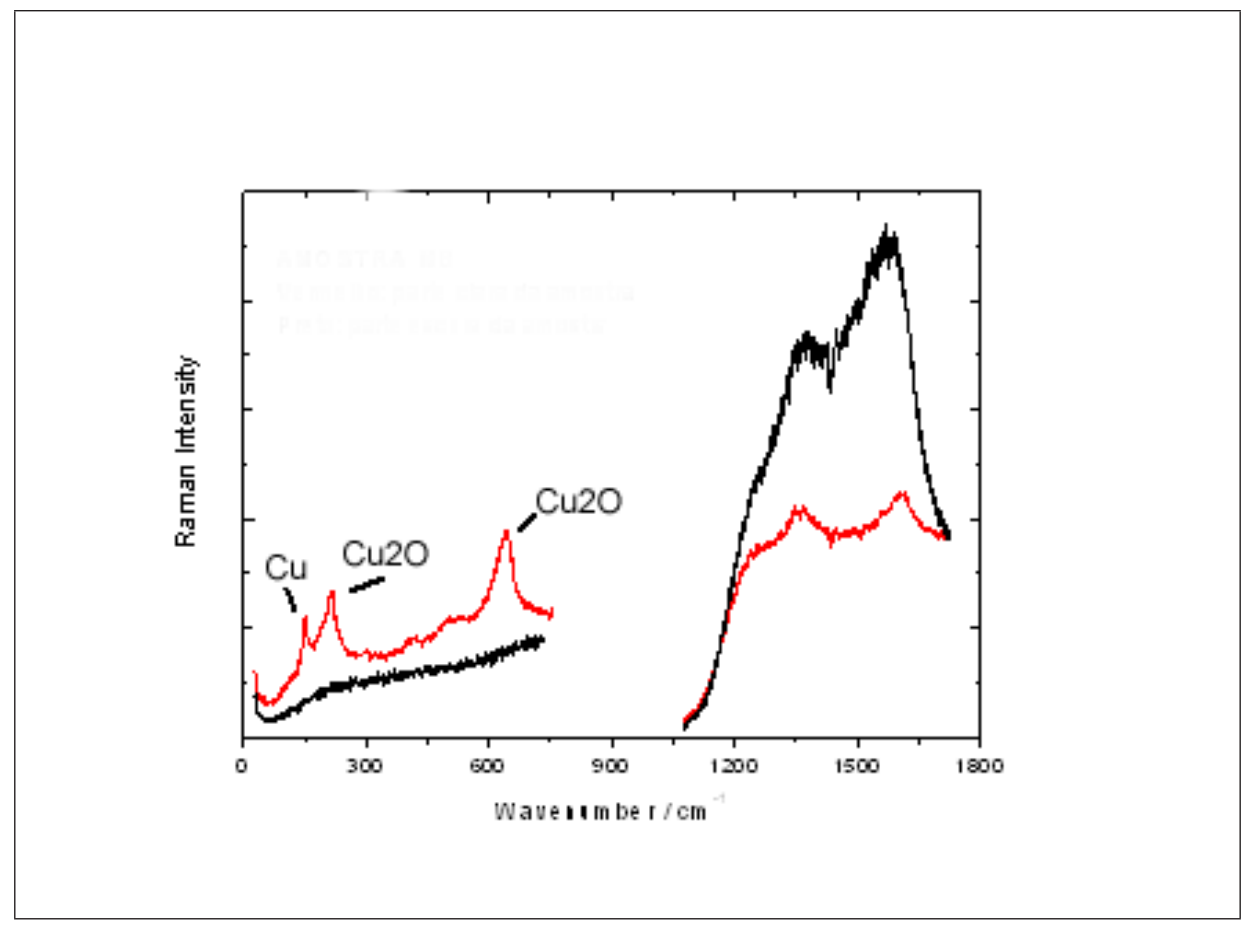

Figura 5.54: Espectro Raman de uma amostra implantada com $1 \times 10^{17} \mathrm{Ar}^{+} / \mathrm{cm}^{2}$, com energia de $10 \mathrm{keV}$ e oxidada em $\mathrm{T}=200^{\circ} \mathrm{C}$, por 30 minutos.

bandas intensas entre 1200 e $1650 \mathrm{~cm}^{-1}$ devem-se aos estiramentos do carbono. Esses resultado concorda com as análises RBS em relação ao tipo de óxido formado, mas difere em relação à oxidação total do filme de $\mathrm{Cu}$. Esses diferentes resultados entre as duas técnicas parece indicar a existência de núcleos oxidados e não oxidados no filme e não uma camada uniforme.

Assim, conclui-se que a implantação de $A r^{+}$nas condições de dose e energia utilizadas neste trabalho, não exerce nenhuma influência na cinética de oxidação para filmes não submetidos a tratamento térmico após a implantação.

\section{Oxidação em amostras submetidas a tratamento térmico}

As amostras de $\mathrm{Cu} / \mathrm{C}$ foram implantadas com $\mathrm{Ar}^{+}$, com doses de $1 \times 10^{16} / \mathrm{cm}^{2}, 5 \times 10^{16}$ $/ \mathrm{cm}^{2}$ e $1 \times 10^{17} / \mathrm{cm}^{2}$ e energia de $10 \mathrm{keV}$. Os testes para oxidação foram feitos em temperaturas de $180{ }^{\circ} \mathrm{C}$ e $300{ }^{\circ} \mathrm{C}$.

A Figura 5.55 mostra os espectros RBS de um filme cuja a metade foi implantada com $5 \times 10^{16} \mathrm{Ar}^{+} / \mathrm{cm}^{2}$. 


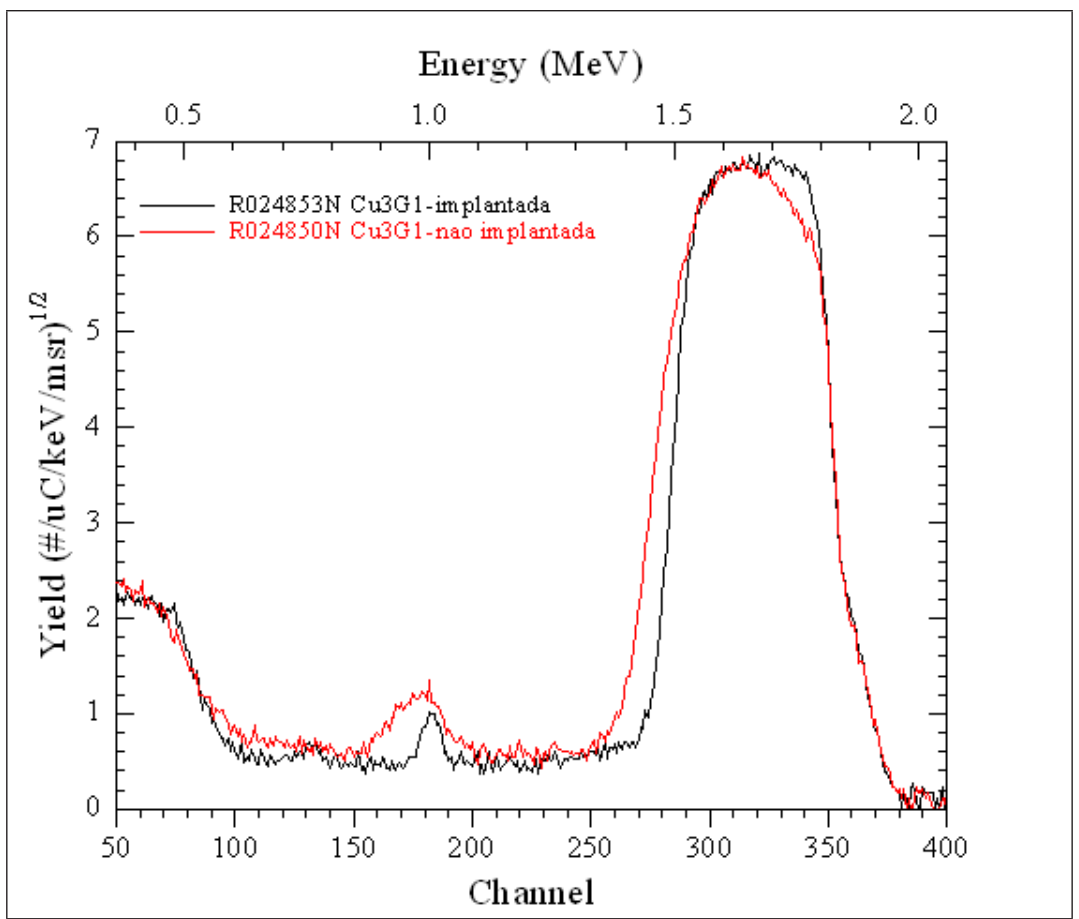

Figura 5.55: Espectros RBS de uma amostra cuja metade foi implantada com $1 \times 10^{17} \mathrm{Ar}^{+} / \mathrm{cm}^{2}$, com energia de $10 \mathrm{keV}$ e oxidada em $\mathrm{T}=180{ }^{\circ} \mathrm{C}$, por 20 minutos.

A comparação entre as duas figuras mostra uma menor incorporação de oxigênio na parte implantada do filme. A simulação dos espectros resulta em estruturas mostradas na tabela 5.24 .

Tabela 5.24: Resultados da simulação do espectro RBS da figura 5.55

\begin{tabular}{cccc}
\hline Camada & Composição & espessura & rugosidade \\
\hline \multicolumn{5}{c}{ implantada } & $10^{15} \mathrm{at} / \mathrm{cm}^{2}$ & $10^{15} \mathrm{at} / \mathrm{cm}^{2}$ \\
\hline 1 & $\mathrm{Cu}(300) \mathrm{O}(200) \operatorname{Ar}(40)$ & 300 & 250 \\
2 & $\mathrm{Cu}(100) \operatorname{Ar}(2))$ & 1300 \\
\hline 1 & não implantada & \\
\hline & $\mathrm{Cu}(300) \mathrm{O}(200)$ & 420 & 250 \\
& $\mathrm{Cu}(100) 0(5))$ & 1050 & 200
\end{tabular}

Através da análise da Figura 5.55 e dos resultados mostrados na tabela 5.24, conclui-se que a implantação de $A r^{+}$modifica a concentração de oxigênio incorporado no filme de cobre. Os resultados obtidos através das simulações dos espectros, sugerem que o óxido formado tem a estequiometria $\mathrm{Cu}_{3} \mathrm{O}_{2}$, mostrando novamente a possibilidade de existência desse óxido nessas condições experimentais, que como foi visto é de difícil comprovação. 


\section{Dependência com a dose de implantação}

A dependência da oxidação com a dose de íons implantados foi testada para três doses de $A r^{+}: 1 \times 10^{16} / \mathrm{cm}^{2}, 5 \times 10^{16} / \mathrm{cm}^{2}$ e $1 \times 10^{17} / \mathrm{cm}^{2}$.

A Figura 5.56 mostra os espectros RBS de filmes oxidados, em $180{ }^{\circ} \mathrm{C}$, por $20 \mathrm{mi}$ nutos, para as doses utilizadas e a tabela 5.25 mostra os resultados da simulação desses espectros. $^{10}$

Apesar das análises RBS indicarem a presença de argônio nos filmes, mesmo após o tratamento térmico e oxidação dos filmes, foram feitas análises PIXE para essa confirmação e na simulação dos espectros RBS esse elemento foi incluído.

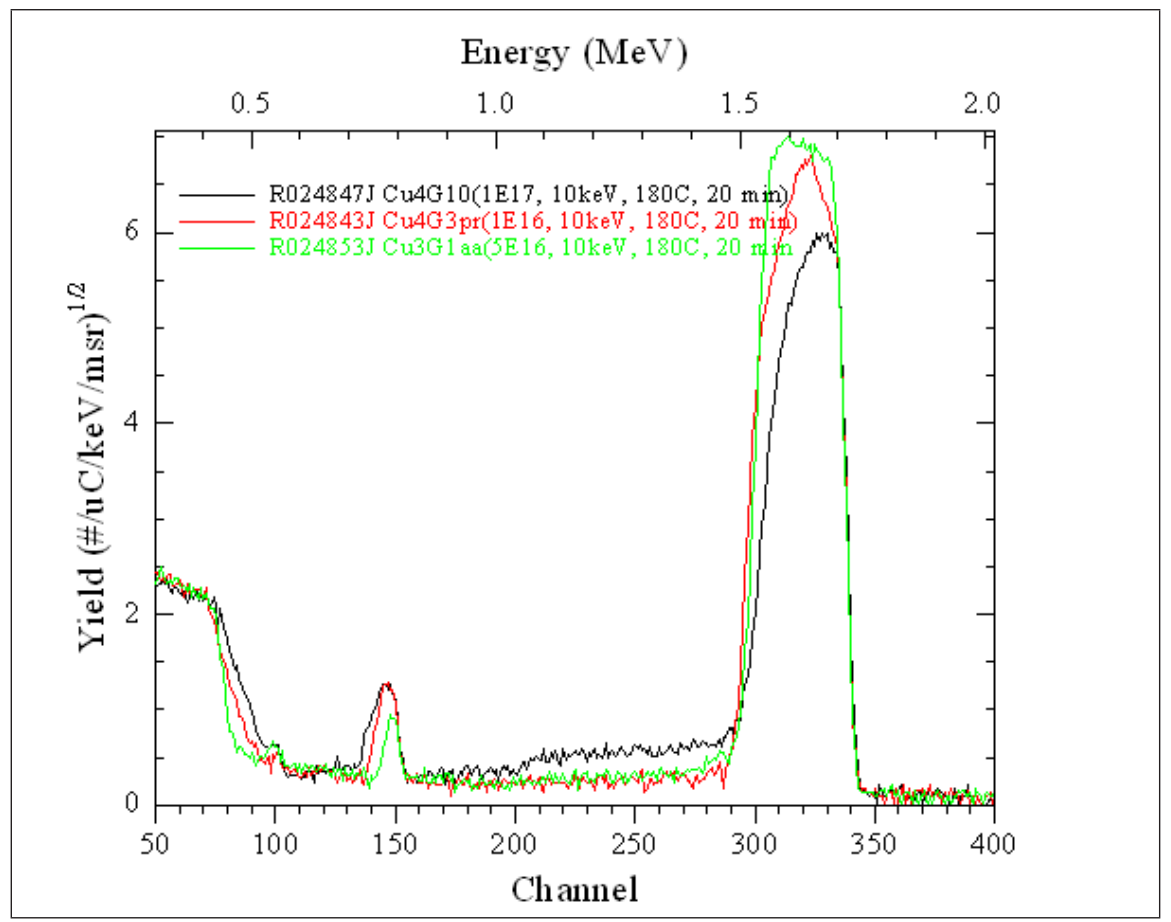

Figura 5.56: Espectros RBS de amostras implantadas com $1 \times 10^{16} / \mathrm{cm}^{2}, 5 \times 10^{16} / \mathrm{cm}^{2}$ e $1 \times 10^{17} / \mathrm{cm}^{2}$, com energia de $10 \mathrm{keV}$. As amostras foram oxidadas em $\mathrm{T}=180{ }^{\circ} \mathrm{C}$ por $20 \mathrm{mi}-$ nutos, mostrando a dependência da oxidação com a dose implantada.

Conclui-se que a implantação de $A r^{+}$reduz a oxidação de filmes de $\mathrm{Cu}$ puro e a proteção superficial varia em função da dose implantada. Para os valores de dose utilizados neste trabalho, houve redução da oxidação, mas a maior proteção superficial ocorreu para $5 \times 10^{16} / \mathrm{cm}^{2}$ íons implantados.

A passivação através da implantação de íons de $A r^{+}$foi testada para $\mathrm{T}=300{ }^{\circ} \mathrm{C}$. A Figura 5.57 mostra a comparação entre dois espectros RBS da mesma amostra, parcial- 
Tabela 5.25: Resultados da simulação do espectro RBS da figura 5.56

\begin{tabular}{|c|c|c|c|c|}
\hline Camada & Composição & espessura & rugosidade & Oxigênio total \\
\hline & Dose $1 \times 10^{16} / \mathrm{cm}^{2}$ & & & 140 \\
\hline 1 & $\mathrm{Cu}(200) \mathrm{O}(100) \operatorname{Ar}(20)$ & 400 & 200 & \\
\hline \multirow[t]{2}{*}{2} & $\mathrm{Cu}(100)$ & 800 & 300 & \\
\hline & Dose $5 \times 10^{16} / \mathrm{cm}^{2}$ & & & 107 \\
\hline 1 & $\mathrm{Cu}(300) \mathrm{O}(200)$ & 300 & 250 & \\
\hline \multirow[t]{2}{*}{2} & $\mathrm{Cu}(100) \operatorname{Ar}(2)$ & 1300 & & \\
\hline & Dose $1 \times 10^{17} / \mathrm{cm}^{2}$ & & & 166 \\
\hline 1 & $\mathrm{Cu}(300) \mathrm{O}(200) \operatorname{Ar}(10)$ & 500 & 500 & \\
\hline 2 & $\mathrm{Cu}(300) \mathrm{O}(50) \operatorname{Ar}(50))$ & 200 & & \\
\hline 3 & $\mathrm{Cu}(300) \mathrm{O}(15)$ & 350 & & \\
\hline
\end{tabular}

mente implantada, oxidada em $\mathrm{T}=300{ }^{\circ} \mathrm{C}$, por 5 minutos. Os resultados da simulação são mostrados na tabela 5.26 .

Tabela 5.26: Resultados da simulação do espectro RBS da figura 5.57

\begin{tabular}{ccccc}
\hline Camada & Composição & espessura & rugosidade & Oxigênio \\
\hline \multicolumn{5}{c}{ implantada } \\
1 & $\mathrm{Cu}(300) \mathrm{O}(100)$ & 300 & 250 & 807 \\
2 & $\mathrm{Cu}(200) \mathrm{O}(100)$ & 1500 & & \\
\hline 3 & $\mathrm{Cu}(200) \mathrm{O}(40)$ & 400 & - & \\
4 & $\mathrm{Cu}(200) \mathrm{O}(20)$ & 300 & & 102 \\
\hline 1 & $\mathrm{não} \mathrm{implantada}$ & & & \\
2 & $\mathrm{Cu}(100) \mathrm{O}(100)$ & 400 & 400 &
\end{tabular}

A dependência da passivação superficial com a dose implantada foi feita também para oxidação em $\mathrm{T}=300{ }^{\circ} \mathrm{C}$, por 5 minutos. A Figura 5.58 mostra os espectros RBS dessas amostras.

A simulação desses espectros foi realizada utilizando um modelo de multicamadas e os resultados mostraram a possível formação de dois óxidos, $\mathrm{Cu}_{2} \mathrm{O}$ e $\mathrm{CuO}$, com uma variação de oxigênio ao longo do filme de óxido formado. A comparação com os resultados obtidos 


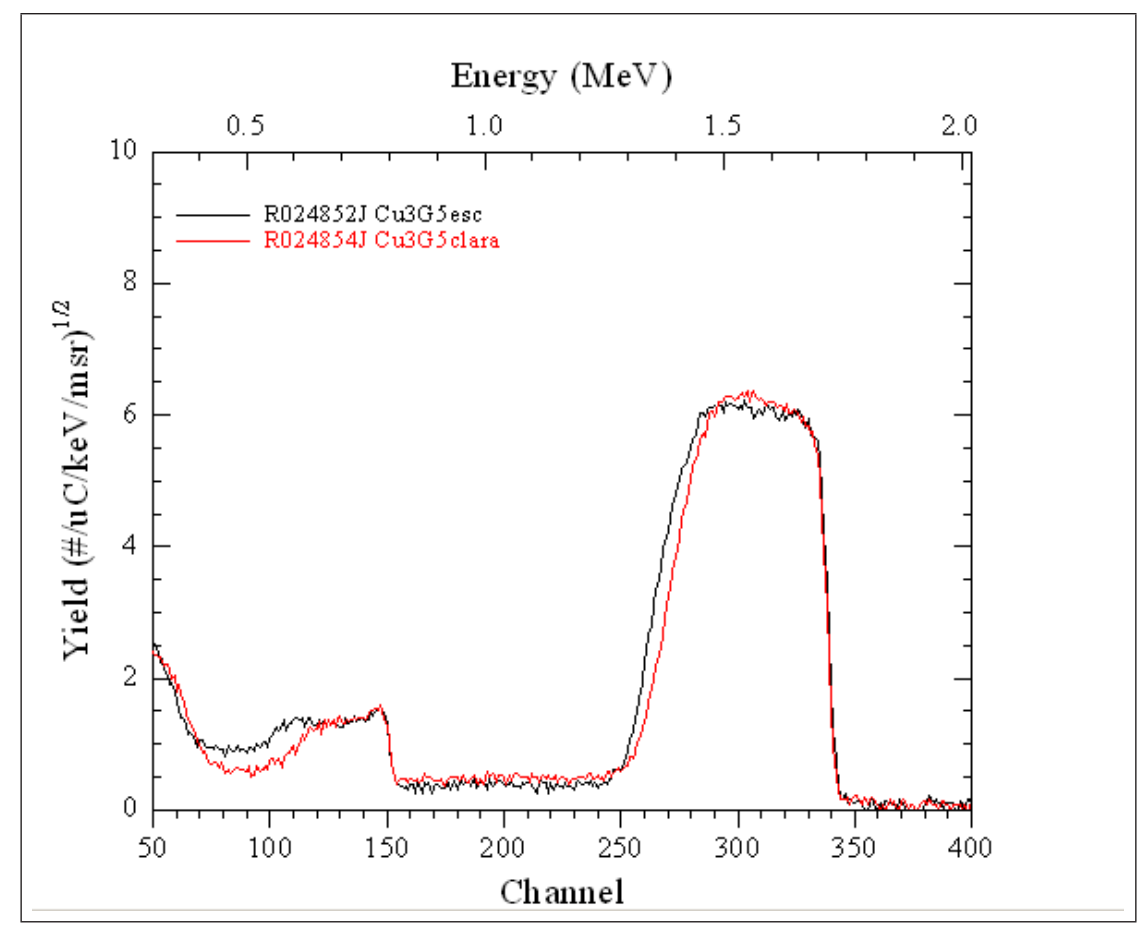

Figura 5.57: Espectros RBS de uma amostra parcialmente implantada com $5 \times 10^{16} / \mathrm{cm}^{2}$, com energia de $10 \mathrm{keV}$ e oxidadas em $\mathrm{T}=300{ }^{\circ} \mathrm{C}$, por 5 minutos

para a parte não implantada da amostra mostra que com a implantação há redução da quantidade de oxigênio incorporado, mas essa redução foi semelhante para todos os valores de dose utilizado nesse trabalho.

A passivação de cobre por implantação de $A r^{+}$de baixa energia não envolve os mesmos mecanismos que a implantação de outros elementos, pelas características desse elemento químico. Uma das hipóteses que pode ser usada para explicar o fato de um gás nobre implantado em um metal reduzir a taxa de oxidação é supor que os átomos desse gás formam uma barreira difusão do metal, reduzindo a taxa de oxidação, pois mesmo após o tratamento térmico, em $550{ }^{\circ} \mathrm{C}$, por 30 minutos, esse elemento é encontrado no filme, funcionando como uma barreira de difusão dos átomos de cobre e diminuindo a sua mobilidade, com conseqüente redução da oxidação. Esse efeito não pôde ser observado quando os filmes não foram tratados termicamente, sugerindo uma competição entre a redução da oxidação causada pela presença do argônio e o aumento da oxidação devido ao aumento do número de defeitos no filme. 


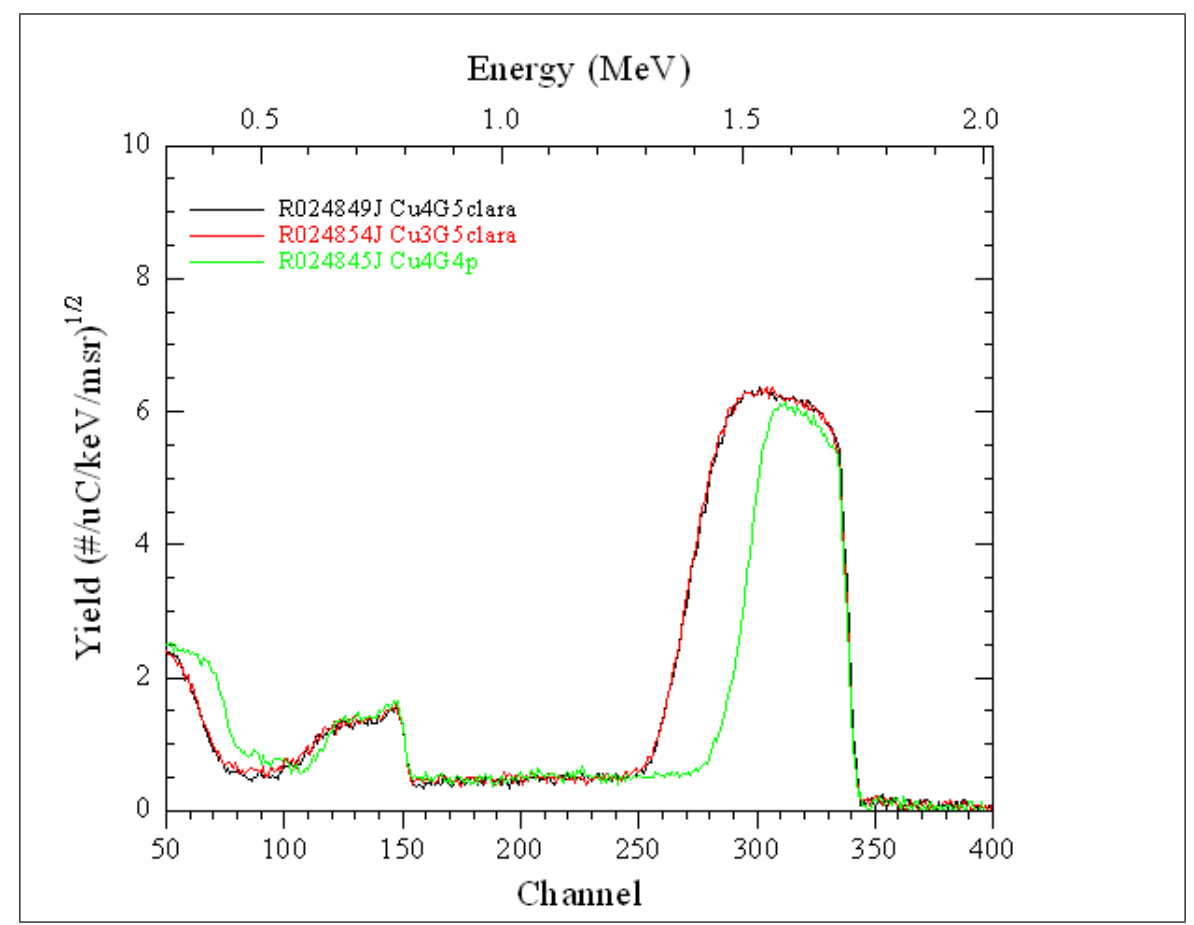

Figura 5.58: Espectros RBS de amostras implantadas com $1 \times 10^{16} / \mathrm{cm}^{2}, 5 \times 10^{16} / \mathrm{cm}^{2}$ e $1 \times 10^{17} / \mathrm{cm}^{2}$, com energia de $10 \mathrm{keV}$ e oxidadas em $\mathrm{T}=300{ }^{\circ} \mathrm{C}$, por 5 minutos 


\section{Capítulo 6}

\section{Conclusões}

Filmes de cobre puro oxidados em temperaturas entre 180 e $350^{\circ} \mathrm{C}$ apresentam uma cinética de oxidação com comportamento parabólico.

A energia de ativação obtida, $(0,79 \pm 0,01) \mathrm{eV}$, indica que o mecanismo de difusão nestes filmes não ocorre através de vacâncias e o processo de oxidação é determinado pela difusão através dos contornos de grãos. Utilizando amostras com espessuras menores, obteve-se uma energia de ativação de $(0,62 \pm 0,2) \mathrm{eV}$, indicando haver uma dependência com a faixa de temperatura utilizada para a sua determinação.

A energia de ativação obtida é diferente dos valores encontrados na Literatura, que também apresentam grandes variações, e mostrou ser totalmente dependente da espessura dos filmes analisados. Isso indica que atenção especial deve ser dada à uniformidade da espessura e à faixa de temperatura utilizada para o estudo da cinética de oxidação.

A $180{ }^{\circ} \mathrm{C}$, os resultados mostram o aparecimento da estrutura diferente do $\mathrm{Cu}_{2} \mathrm{O}$, concordando com um reduzido número de trabalhos publicados. Isso pôde ser confirmado aliando as várias técnicas de análises utilizadas neste trabalho.

Para filmes de cobre puro, oxidados a $200{ }^{\circ} \mathrm{C}$ e $250{ }^{\circ} \mathrm{C}$ somente um tipo de óxido foi crescido: o $\mathrm{Cu}_{2} \mathrm{O}$, independente do tempo de oxidação.

Em temperaturas mais altas $\left(>250{ }^{\circ} \mathrm{C}\right)$ aparecem os dois óxidos, com predominância do óxido cúprico para tempos longos de oxidação, confirmando os resultados da Literatura.

A utilização de substrato de carbono revelou-se um instrumento muito importante na determinação do oxigênio, mas em alguns casos não permitiu obter conclusões precisas em relação à estequiometria dos óxidos, devido à estrutura multicamada que se forma durante a oxidação do cobre. Assim, a análise por espalhamento Raman mostrou-se muito sensível 
para detectar cobre e os óxidos, mesmo em amostras cujos resultados obtidos por RBS mostram não haver cobre metálico.

A adição de alumínio nos filmes aumenta a aderência ao óxido de silício, reduz a rugosidade do filme e ainda tem efeito passivador. Após tratamento térmico, há um aumento da condutividade elétrica, parâmetro muito importante para a indústria microeletrônica. O mecanismo da passivação está ligado a ocupação de vacâncias pela migração dos átomos de alumínio. A adição de cloro também reduz a oxidação de cobre. Já a cobertura de carbono reduz a oxidação superficial somente em tempos reduzidos de oxidação.

A implantação de boro reduz a oxidação de filmes de cobre, mesmo em baixas doses de implantação, tendo o mesmo efeito da adição de alumínio.

Para implantação de argônio verifica-se o aumento da resistividade elétrica com a dose de íons. Após o tratamento térmico há uma redução da resistividade elétrica abaixo do valor inicial. A passivação de cobre por implantação de $A r^{+}$de baixa energia não envolve os mesmos mecanismos que a implantação de outros elementos, pelas características desse elemento químico. A explicação para a passivação proposta neste trabalho supõe a formação uma barreira de difusão formada pelos átomos desse gás, reduzindo a oxidação. Após o tratamento térmico, em $550{ }^{\circ} \mathrm{C}$, por 30 minutos, esse elemento ainda é encontrado no filme, reduzindo a mobilidade do cobre, com conseqüente redução da oxidação. Esse efeito não pôde ser observado quando os filmes não foram tratados termicamente, sugerindo uma competição entre a redução da oxidação causada pela presença do argônio e o aumento da oxidação devido ao aumento do número de defeitos no filme. 


\section{Referências Bibliográficas}

[1] Hayato Takasago, Kohei Adachi, and Mitsuyuki Takada. A copper/polyimide metalbase packaging technology. Journal of Electronic Materials, 18(2):319-326, 1989.

[2] Y.F.Zhu, H.M.Lu, Q.Jiang, K.Mimura, and M.Isshiki. Effect of alloying Mg on corrosion resistance of $\mathrm{Cu}$ at high temperature. Journal of The Electrochemical Society, 154(3):C153-C158, 2007.

[3] Shoso Shingubara, Yasushi Nakasaki, and Hisashi Kaneko. Electromigration in a single crystalline submicron width aluminum interconnection. Applied Physics Letters, 58(1):42-44, 1991.

[4] S.P.Murarka. Multilevel interconnections for ulsi and gsi. Materials Science and Engineering: R: Reports, 19(3):87-151, 1997.

[5] G.Schneider, G.Denbeaux, E.Anderson, W.Bates, F.Salmassi, P.Nachimuthu, A.Pearson, D.Richardson, D.Hambach, N.Hoffmann, W.Hasse, and K.Hoffmann. Electromigration in integrated circuit interconnects studied by x-ray microscopy. NIM B, 199:469-474, 2003.

[6] G. Schneider, D. Hambach, B. Niemann, B. Kaulich, N. Hoffmann J. Susini, and W. Hasse. In situ x-ray microscopic observation of the electromigration in passivated Cu interconnects. Applied Physics Letters, 78(13):1936-1938, 2001.

[7] Y.Schacham-diamand, A.Dedhia, D.Hoffstetter, and W.G.Oldham. Copper transport in thermal $\mathrm{SiO}_{2}$. Journal of the Electrochemical Society, 140(8):2427-, 1993.

[8] S.P.Murarka, R.J.Gutmann, A.E.Kaloyeros, and W.A.Lanford. Advanced multilayer metallization schemes with copper as interconnection metal. Thin Solid Films, 236:257-266, 1993. 
[9] S.Joseph, M.Eizenberg, C.Marcadal, and L.Chen. TiSiN films produced by chemical vapor deposition as diffusion barriers for $\mathrm{Cu}$ metalization. Journal Vacuum Science and Tecgnology B, 20(4):1471-1475, 2002.

[10] M.T.Wang, Y.C.Lin, and M.C.Chen. Barrier properties of very thin Ta and TaN layers against copper diffusion. Journal of the Electrochemical Society, 145(7):2538$2545,1998$.

[11] M.Haneda, J.Iijima, and J.Koike. Growth behavior of self-formed barrier at $\mathrm{Cu}-\mathrm{Mn} / \mathrm{SiO}_{2}$ interface at 250-450 degrees c. Applied Physics Letters, $90(25): 252107,2007$.

[12] J.Koike and M.Wada. Self-forming diffusion barrier layer in CuMn alloy metallization. Applied Physics Letters, 85(4):041911, 2005.

[13] Takamasa Usui, Hayato Nasu, Shingo Takahashi, Noriyoshi Shimizu, T. Nishikawa, Masaki Yoshimaru, Hideki Shibata, Makoto Wada, and Junichi Koike. Highly reliable copper dual-damascene:interconnects with self-formed $\mathrm{MnSi}_{x} \mathrm{O}_{y}$ barrier layer. IEEE Transaction on electron Devices, 53(10):2492-2499, 2006.

[14] Z.E.Horvath, G.Paszti, E.Zsoldos, E.Szilagyi, G.BAttistig, T.Lohner, G.L.Molnar, and J.Gyulai. Enhancemete of oxidation resistance in $\mathrm{Cu}$ and $\mathrm{Cu}(\mathrm{Al})$ thin layers. NIMB, 148:868-871, 1999.

[15] B. Lefez, K. Kartouni nd M. Lenglet, D. Ronnow, and C. G. Ribbing. Application of reflectance spectrophotometry to the study of copper (i) oxides $\left(\mathrm{Cu}_{2} \mathrm{O}\right.$ and $\left.\mathrm{Cu}_{3} \mathrm{O}_{2}\right)$ on metallic substrate. Surface and Interface Analysis, 22:451-455, 1994.

[16] D.L.Cocke, R.Schennach, M.A.Hossain, D.E.Mencer, H.McWhinney, J.R.Parga, M.Kesmez, J.A.G.Gomes, and M.Y.A.Mollah. The low-temperature thermal oxidation of copper, $\mathrm{Cu}_{3} \mathrm{O}_{2}$, and its influence on past and future studies. Vacuum, $79(1-2): 71-83,2005$.

[17] Yao Zhi Hu, Rahul Sharangpani, and Sing-Pin Tay. Kinetic investigation of copper film oxidation by spectroscopic ellipsometry and reflectometry. Journal Vaccum Science and Technology A, 18(5):2527-2531, 2000. 
[18] Elizabeth Apen, B. R. Rogers, and James A. Sellers. X-ray photoeletctron spectroscopy characterization of the oxidation electroplated and sputerr deposited copper surfaces. Journal of Vaccum Science and technoloy A, 16:1227-1232, 1998.

[19] Ho Yeung H. Chan, Christos G. Takoudis, and Michael J. Weaver. Electrochemical control of gas-phase oxidation and reduction of copper as probed by surfaceenhanced raman spectroscopy. Electrochemical of State Solid Letters, 2(4):189-191, 1999.

[20] C.Zhong, Y.M.Jiang, Y.F.Luo, B.Deng, L.Zhang, and J.Li. Kinetics characterization of the oxidation of $\mathrm{Cu}$ thin films at low temperature by using sheet resistance measurements. Applied Physics A, 90:263-266, 2008.

[21] G.Papadimitropoulos, N.Vourdas, V.Em Vamvakas, and D.Davazoglou. Deposition and characterization of copper oxide thin films. Journal of Physics: Conference Series 10, pages 182-185, 2005.

[22] Shau-Lin Shue. Self-passivation procedure for a copper damascene structure. United States Patent http://www.freepatentsonline.com/6281127.html, 6281127, 2001.

[23] Anthony M. Piano. Bismuth coating protection for copper. United States Patent http://www.patentstorm.us/patents/6090493-description.html, 6090493, 2000.

[24] X.Q.Zhao, Y.F.Hanand, and B.X.Liu. Modification of oxidation resistance of copper films by shallow implantation. Journal of Applied Physics, 90(3):1638-1641, 2001.

[25] L.V.Poperenko, Essam Ramadan Shaaban, N.Q. Khánh, V.S. Stashchuk, M.V.Vinnichenko, I.V.Yurgelevich, D.V.Nosach, and T.Lohner. Effect of ion irradiation on the optical properties and room temperature oxidation of copper surface. Thin Solid Films, pages 453-456, 2004.

[26] P.J.Ding, A.Lanford, S.Hymes, and S.P.Murarka. Thermal annealing of buried Al barrier layers to passivate the surface of copper films. Applied Physics Letters, 65(4):1778-1780, 1994.

[27] Mayumi Takeyama, Takaaki Ichikawa, and Atsushi Noya. Oxidation behavior of AlW alloy films deposited on $\mathrm{Cu}$ as a passivation layer. Thin Solid Films, 272:18-20, 1996. 
[28] Bing Liu and Lin Liu. Improvement of corrosion resistance of $\mathrm{Cu}$-based bulk metallic glasses by the microalloying of Mo. Intermetallics, 15:679-682, 2007.

[29] Zhen-Cheng Wu and Yu-Lin Liu NS Mao-Chieh Chen. Passivation of copper filmes with magnesium doping using recoil ion implantation. Thin Solid Films, 358:180$186,2000$.

[30] H.Bubert, E.Grallath, A.Quentmeier, M.Wielunski, and L.Borucki. Comparative investigation on copper oxides by depth profiling using XPS, RBS and GDOES. Fresenius' Journal of Analytical Chemistry, 353(3-4):456-463, 1995.

[31] A.Bouquillona, J.C. Dran, A.G.Lagardeb, P.Martinettoa, F.Mathisa, B.Moignarda, J.Salomona, and Ph.Waltera. In situ dynamic analysis of solids or aqueous solutions undergoing chemical reactions by RBS or PIXE with external beams. NIM B, 188(14):1569-161, 2002.

[32] Andreas Gupper Robert Schennach. Copper oxidation studied by in sity raman spectroscopy.

[33] Cheonho Yoon and David L. Cocke. Evidence for electron transfer control of oxygen incorporation into bulk copper. Journal of the Electrochemical Society, 134(3):643$644,1987$.

[34] H. Derin and K. Kantarli. Optical characterization of thin thermal oxide films on copper by ellipsometry. Applied Physics A, 75:3914-395, 2002.

[35] N.Cabrera e N.F.Mott. Theory of the oxidation of metals. Reports on Progress in Physics, 12:163-184, 1949.

[36] J.C.Yang, B.Kolasa, J.M.Gibson, and M.Yeadon. Oxygen surface diffusion in threedimensional $\mathrm{Cu}_{2} \mathrm{O}$ growth on $\mathrm{Cu}(001)$ thin films. Applied Physics Letters, 70:3522$3524,1997$.

[37] Kenneth R.Lawless. Oxidation of metals. Reports on Progress in Physics, 37:231316, 1973.

[38] S.Aggarwal, A.P.Monga, S.R.Perusse, R.Ramesh, V.Ballarotto, E.D.Williams, BR.Chalamala, Y.Wei, and R.H.Reuss. Spontaneous ordering of oxide nanostructures. Science, 287-5461:2235-2237, 2000. 
[39] S.Aggarwal, S.B.Ogale, C.S.Ganpule, S.R.Shinde, V.A.Novikov, A.P.Monga, M.R. Burr, R.Ramesh, V.Ballarotto, and E.D.Williams. Applied Physics Letters, 78:14421444, 2001.

[40] J.C.Yang, B.Kolasa, J.M.Gibson, and M.Yeadon. Self-limiting oxidation of copper. Applied Physics Letters, 73:2841-2843, 1998.

[41] S.R.Shinde, S.Abhijit, S.B.Ogale, S.Aggarwal, V.Novikov andE.D.Williams, and R.Ramesh. Self-organized pattern formation in the oxidation of supported iron thin films. an experimental study. Physics Review Letters B, 64:35408, 2001.

[42] Guangwen Zhou and Judith C.Yang. Inicial oxidation kinetics of copper (110) film investigated by in situ UHV-TEM. Surface Science, 531:359-367, 2003.

[43] Harold Wieder and A.W.Czanderna. The oxidation of copper films to $\mathrm{CuO}_{0.67}$. Journal of Physical Chemistry, 66(5):816-821, 1962.

[44] W.Jaenicke H.Neumeister. Studies on kinetics of $C u_{1.50}$ formation by simultaneous measurement of changes in weigth and susceptibility during oxidation of $\mathrm{Cu}$ to $\mathrm{Cu}_{2} \mathrm{O}$. Zeitschrift fur Physikalische Chemie-Frankfurt, 108(2):217-234, 1977.

[45] M. Lenglet, K. Kartouni, J. Machefert, J. M. Claude, P. Steinmetz, E. Beauprez, J. Heinrich, and N. Celati. Low temperature oxidation of copper: The formation of CuO. Materials Research Bulletin, 30(4):393-403, 1995.

[46] D.L. Cocke, G.K. Chuah, N. Kruse, and J.H. Block. Copper oxidation and surface copper oxide stability investigated by pulsed field desorption mass spectrometry. Applied Surface Science, 84:153-161, 1995.

[47] Jian Li, J.W. Mayer, and E.G. Colgan. Oxidation and protection in copper and copper alloy thin films. Journal Applied Physics, 70(5):2820-2827, 1991.

[48] Yong Fu Zhu, Kouji Mimura, Jae-Won Lim, Minouru Isshiki, and Qing Jiang. Brief review of oxidation kinetics of copper at $350^{\circ} \mathrm{C}$ to $1050^{\circ} \mathrm{C}$. Metallurgical and Materials Transactions A, 37:1231, 2006.

[49] Y. Zhu, K.Mimura, and M.Isshiki. Influence of small amounts of impurities on copper oxidation at $600{ }^{\circ} \mathrm{C}$ e $1050{ }^{\circ} \mathrm{C}$. Oxidation of Metals, 59(5-6):575-590, 2003. 
[50] G.L.Ang, L.C.Goh, K.W.Heng, and S.K.Lahiri. Oxidation of copper leadframe. Physical and Failure Analysis of Integrated Circuits, pages 218-220, 1995.

[51] W.Gao, H.Gong, and J.He. Oxidation behaviour of $\mathrm{Cu}$ thin films on Si wafer at $175-400^{\circ} \mathrm{C}$. Materials Letters, 51:78-84, 2001.

[52] D. Weiss, O.Kraft, and E.Arzt. Grain-boundary voiding in self passivated $C u A l_{0.01}$ alloy films on Si substrates. Journal Materials Research, 17(6):1363-1370, 2002.

[53] P.J.Ding, W.A.Lanford, S.Hymes, and S.P.Murarka. Effects of the addition of small amounts of $\mathrm{Al}$ to copper: corrosion, resistivity, adhesion, morphology, and diffusion. Journal of Applied Physics, 75(7):3627-3631, 1994.

[54] T.Kravchuk and A.Hoffman. Enhanced reactivity and selectivity in oxidation of $\mathrm{Cu}(100)$ and $\alpha-C u-A l(5 \%)(100)$ surfaces studied by electron and ion spectroscopies. Surface Science, 600:1252-1259, 2006.

[55] F.H.Kaatz, V.G.Harris, L.Kurihara, D.R.Rolison, and A.S.Edelstein. Slowing the oxidation of $\mathrm{Cu}$ in $\mathrm{Cu}$-Co nanocrystals by Co surface passivation. Applied Physics Letters, 67(25):3807-3809, 1995.

[56] V.V.Belousov. Mechanisms of accelerated oxidation of copper in the presence of molten oxides. Oxidation of Metals, 67(5-6):235-250, 2007.

[57] P.J.Ding, W.A.Lanford, S.Hymes, and S.P.Murarka. Oxidation resistant high conductivity copper films. Applied Physics Letters, 64(21):2899, 1994.

[58] P.J.Ding, W.A.Lanford, Wei Wang, S.Hymes, and S.P.Murarka. Alloying of copper for use in microelectronic metallization. Materials Chemistru and Physics, 41:192198, 1995.

[59] J.F.Moore, M.P.Mccann, M.J.Pellin, and A.Zinovevand J.N.Hryn. Ultrathin copper aluminum and nickel aluminide protective oxidation studied with an x-ray photoelectron spectrometer. Journal Vacuum Science and Technology A, 21(5):1631-1634, 2003.

[60] L.Ogbuji and D.L.Humphrey. Comparison of the oxidation rates of some new copper alloys. Oxidation of Metals, 60(3/4):271-291, 2003. 
[61] Y.Zhu, K.Mimura, and M.Issiki. Inluence of small amounts of impurities on copper oxidation at 600-1050 ${ }^{\circ} \mathrm{C}$. Oxidation of Metals, 59(5-6):575-589, 2003.

[62] T.A.Utigard G.Plascencia. High temperature oxidation mechanism of dilute copper aluminium alloys. Corrosion Science, 47:1149-1163, 2005.

[63] T.Marin G.Plascencia, T.A. Utigard. The oxidation resistance of copper-aluminium alloys at temperature up to $1000^{\circ} \mathrm{C}$. JOM, page 80, 2005 .

[64] M.Takeyama, A.Noya, M.Taguchi, and T.Ichikwa. Oxidation behavior of Ta thin film as a passivation layer deposited on Cu. Japanese Journal Applied Physics, 35:1844-1845, 1996.

[65] J.C.Chuang and M.C.Chen. Passivation of $\mathrm{Cu}$ by sputterdeposited $\mathrm{Ta}$ and reactively sputter-deposited Ta-nitride layers. Journal Electrochemical Society, 145(9):3170-3177, 1998.

[66] M.Takeyama, A.Noya, M.Taguchi, and T.Ichikwa. Oxidation characteristics of AlTa thin alloy film as a passivation layer on $\mathrm{Cu}$. Japanese Journal Applied Physics, 35:704-708, 1996.

[67] Cheng Li Chuang and J.N.Aoh. Thermosonic bonding of gold wire onto copper pad with titanium thin film deposition. Journal of Electronic Materials, 33(4):290-299, 2004 .

[68] J.C.Chuang and M.C.Chen. Effects of thermal $N_{2}$ annealing on passivation capability of sputtered $\mathrm{Ta}(\mathrm{N})$ layers against $\mathrm{Cu}$ oxidation. Journal Electrochemical Society, 145(11):4029-4035, 1998.

[69] J.F.Rohan, G.O'riordan, and J.Boardman. Selective electroless nickel deposition on copper pad as a final barrier/bonding layer material for microelectronics applications. Applied Surface Science, 185:289-297, 2002.

[70] J.G.Strand, S.Popelar, and C.Jauerning. Interconnecting to aluminum- and copperbased semiconductors (electroless-nickel/gold for solder bumping and wire bondings. Microelectronic Reability, 42:265-283, 2002. 
[71] R.Galloni, Y.S.Tsuo, D.W.Baker, and F.Zignani. Boron doping and hydrogenation by ion-implantation of a-Si-H. Jornal of Non-Crystalline solids, 114:271-273, 1989.

[72] H.D.Wanzenboeck, C.Ostermaier, A.Gruen, B.Eichinger, M.Karner, and E.Bertagnolli. Dot-array implantation for patterned doping of semiconductors. NIM B, 242(1-2):257-260, 2006.

[73] L.Eriksson, G. fladda, and K.Bjorkqvi. Influence of n-type dopants on lattice location of implanted p-type dopants in Si and Ge. Applied Physics Letters, 14(6):195, 1969.

[74] Sy.Shiryaev, An.Larsen, and N.Safronov. Rapid thermal annealing of highconcentration mixed as/in-implanted and $\mathrm{p} /$ in-implanted silicon single-crystals. Journal of Applied Physics, 68(8):3953-3960, 1990.

[75] K.Sawano, A.Fukumoto, and Y.Hoshi. Strained Si n-channel metal-oxidesemiconductor field-effect transistors formed on very thin SiGe relaxed layer fabricated by ion implantation technique. Applied Physics Letters, 90(20):202101, 2007.

[76] K.Endo, M.Masahara, Y.X. Liu, T.Matsukawa, K.Ishii, E.Sugimata, H.Takashima, H.Yamauchi, and E.Suzuki. Investigation of n-channel triple-gate metal-oxidesemiconductor field-effect transistors on (100) silicon on insulator substrate. Japanese Journal Of Applied Physics Part 1, 45(4B):3097-3100, 2006.

[77] M.H.Juang, C.I.Ou-Yang, and S.L.Jang. A design consideration of channel doping profile for sub-0.12 mum partially depleted SOI n-mosfet's. Solid-State Electronics, 46(8):1117-1121, 2002.

[78] G.Dearnaley. Ion beam modification of metals. Nuclear Instruments and Methods in Physics Research B, 50:358-367, 1990.

[79] A.H.Dietzel W.H.Bruenger and H.Loeschner. Ion projection surface structuring with noble gas ions at $75 \mathrm{keV}$. Surface and Coatings Technology, 201:8437-8441, 2007.

[80] R.Arkush, M.H.Mintz, and N.Shamir. Passivation of uranium towads air corrosion by $N_{2}^{+}$e $C^{+}$. Journal of Nuclear Materials, 281:182-190, 2000. 
[81] Han-Cheol Choe. Effects of nitrogen ion implantation on the surface characteristics of iron aluminides. Surface and Coatings Technology, 148:77-87, 2001.

[82] Y.Hara, T.Yamanishi, K.Azuma, H.Uchida, and M.Yatsuzuka. Microestructure of Al-alloy surface implanted with high-dose nitrogen. Surface and Coatings Technology, 156:166-169, 2002.

[83] Seunghee Han Kang-Jin Kim Ju Hi Hong, Yeonhee Lee. Improvement of adhesion properties for $\mathrm{Cu}$ films on the polyimide by plasma source ion implantation. Surface and Coating Technology, 201:197-202, 2006.

[84] H.Pelletier, D.Müller, P.Mille, A.Cornet, and J.J.Grob. Dose effect on mechanical properties of high-energy nitrogen implanted 316L stainless stell. Surface and Coatings Technology, 151-152:377-382, 2002.

[85] B.Gosh, P.Chakraborty, S.Mohapatra, C.Vijayan P.Ann Kurian, P.C.Deshmukh, and P.Mazzoldi. Linear and nonlinear optical absorption in copper nanoclusterglass composites. Materials Letters, 61(23-24):4512-4515, 2007.

[86] E.C.Rangel. Implantação Iônica de Flmes Finos Depositados por PECVD. PhD thesis, Universidade de Campinas, Instituto de Física, 1999.

[87] Lian-Peng Tian, Yu Zuo, Xu hui Zhao, and Jin ping Xiong. The improvement corrosion resistance of anodic films on aluminum by nickel ions implantation. Surface and Coatings Technology, 201:3246-3252, 2006.

[88] H.-E.Zschauand M.Schütze, H.Baumann, and K.Bethge. Application of ion beam analysis for the control of the improvement of the oxidation resistance of TiAl at $900{ }^{\circ} \mathrm{C}$ in air by fluorine ion implantation and Hf-treatment. NIM B, 240:137-141, 2005.

[89] Zhen-Cheng Wu, Yu-Lin Liu, and Mao-Chieh Chen. Effects of BF2+ implantation on the oxidation resistance of copper films. Thin Solid Films, 346(1-2):186-190, 1999.

[90] H.M.Naguib, R.J.Kriegler, J.A.Davies, and J.B.Mitchell. Effect of B, C, N, and Ne ion implantation on the oxidation of polycrystalline $\mathrm{Cu}^{*}$. Journal of Vacuum Science and Technology, 13(1):396-400, 1976. 
[91] R.A.Collins P.J.Ratcliffe. The influence of ion-implantation on the thermaloxidation of copper. Physica Status Solidi A-Applied Research, 78(2):547-553, 1983.

[92] R.A.Collins P.J.Ratcliffe. Thermal oxidation of ion-implanted copper. Physica Status Solidi A-Applied Research, 108(2):537-543, 1988.

[93] G.Dearnaley J.R.Morris. Influence of ion-implantation on thermal-oxidation of copper. Journal of Physics F-Metal Physics, 8(6):1333-1342, 1978.

[94] W.A.Lanford S.Hymes S.P.Murarka P.J.Ding, W.Wang. Investigation of the mechanism responsible for the corrosion resistance of B implanted copper. Nuclear Instruments and Methods in Physics Research B, 85:260-263, 1994.

[95] A.J.Kellock, M.H.Tabacniks, J.E.Baglin, N.S. Somcio, T. Bardin, and D.C.Miller. Mechanism for ion beam passivation of copper surfaces. Nuclear Instruments and Methods in Physics Research B, 85(127-128):742-746, 1997.

[96] A.R. Perkins e H.G. Meier. Journal of Metals, 8:17, 1989.

[97] M.Takeyama, A.Noya, M.Taguchi, and T.Ichikawa. Characteristics of Al-Ta thin alloy film as a passivation layer on Cu. Japanese Journal Applied Physics, 35:704708, 1996.

[98] J.Bardeen, W.H. Brattain, and W.Shockley. Investigation of oxidation of copper by use of radioactive $\mathrm{Cu}$ tracer. Journal of Chemical Physics, 14:714-721, 1946.

[99] HNB Pilling e RE Bedworth. The oxidation of metals at high temperatures. Journal Institute of Metals, 29:529-583, 1923.

[100] T.B.Grimley and B.M.W.Trapnell. The gas/oxide interface and the oxidation of metals. Proceedings of the Royal Society of London, 234(1198):405-4118, 1956.

[101] H.Schmidt-Bocking. Penetration of heavy ions through matter. In Experimental Methods in Heavy Ion Physics, volume 83, 1978.

[102] M.H.Tabacniks. Tese de livre docência. Instituto de Física da USP, 2004.

[103] The Stopping and Range of Ions in Matter. www.srim.org, 2003. 
[104] Milton Ohring. The Materials Science of Thin Films. Academic Press, New York, First edition, 1992.

[105] Wei-Kan Chu, J.W.Mayer, and M.-A.Nicolet. Backscattering Spectrometry. Academic Press, New York, First edition, 1978.

[106] Manfredo Harri Tabacniks. Calibração do sistema pixe-sp de análise elementar. Master's thesis, Instituto de Física da USP, 1983.

[107] T.B Johansson S.A.E.Johansson. Analytical application of particle induced x-ray emission. Nuclear Instruments and Methods, 137:473-516, 1976.

[108] Z.H.Gan, G.Q.Yu, B.K.Tay, C.M.Tan, Z.W.zhao, and Y.Q.Fu. Preparation and characterization of copper oxide thin films deposited by filteres cathodic vacuum arc. Journal of Physics D, 37:81-85, 2004.

[109] E.B.Barros. Propriedades de Espumas Grafíticas e de Nanotubos de Carbono. PhD thesis, Universidade Federal do Ceará, Departamento de Física, 2006.

[110] W.L. Prater, E.L. Allen, Wen-Y.Lee, M.F.Toney, J.Daniels, and J.A.Hedstrom. Reduction of resistivity in $\mathrm{Cu}$ thin films by partial oxidation: Microstructural mechanisms. Applied Physics Letters, 84(14):2518-2520, 2004.

[111] Anil U.Mane and S.A.Shivashankar. Growth of (llll)-textured copper thin films by atomic layer deposition. Journal of Crystal Growth.

[112] J.-Y.Cho, K.Mirpuri, D.N.Lee J.-K.An, and J.A.Szpunar1. Texture investigation of copper interconnects with a different line width. Journal Journal of Electronic Materials, 34(1):53-61, 2005.

[113] H.L>Wei, H.Huang, C.H.Woo, R.K.Zheng, G.H.Wen, and X.X.Zhang. Development of $<110>$ texture in copper thin films. Applied Physics Letters, 80(136):2290-2292, 2002.

[114] D.L.Cocke, R.Schennach, M.A.Hossain, D.E.Mencer, H.McWhinney, J.R.Parga, M.Kesmez, J.A.G.Gomes, T.Gradyc, and T.L.Barre. On the surface analysis of copper oxides: the difficulty in detecting $\mathrm{Cu}_{3} \mathrm{O}_{2}$. Vacuum, 77(1):27-35, 2004. 
[115] Power diffraction file search manual. International Centre For Difraction Data, Pennsylvania, U.S.A., 1981.

[116] P.E.D.Morgan, D.E.Partin, B.L.Chamberland, and M.O.Keeffe. Synthesis of paramelaconite:Cu $\mathrm{O}_{3}$. Journal of Solid State Chemistry, 121:33-37, 1996.

[117] Y.L.Gong, C.Lee, and C.K.Yang. Atomic force microscopy and raman spectroscopy studies on the oxidation of $\mathrm{Cu}$ thins films. Journal of Applied Physics, 77(10):54225425, 1995.

[118] X.F.Zhang, X.L.Dong, H.Huang, D.K.Wang, B.Lv, and J.P. Lei. High permittivity from defective carbon-coated cu nanocapsules. Nanotechnology, 18:8437-8441, 2007.

[119] M.O'Reilly, X.Jiang, J.T.Beechinor, S.Lynch, C.N.I.heasuna, J.C.Patterson, and G.M.Crean. Investigation of the oxidation behaviour of thin film and bulk copper. Applied Surface Science, 91:152-156, 1995.

[120] Z.Feng, C.R.Marks, and A.Barkatt. Oxidation-rate excursions during the oxidation of copper in gaseous environments at moderate temperatures. Oxidation of Metals, 60(5/6):393-408, 2003.

[121] M.Schütze, G.Schumacher, F.Dettenwanger, U.Hornauer, E.Richter, E.Wieser, and W.Möller. The halogen effect in the oxidation of intermetallic titanium aluminides. Corrosion Science, 44(2):303-318, 2002.

[122] R.A.Yankov, N.Shevchenko, A.Rogozin, M.F.Maitz, E.Richter, W.Möller, A.Donchev, and M.Schütze. Reactive plasma immersion ion implantation for surface passivation. Surface and Coatings Technology, 201:6752-6758, 2007.

[123] J.H.Hong, Y.Lee, S.Han, and K.J.Kim. Improvemente of adhesion properties for Cu films on the polyimide by plasma source ion implantation. Surface And Coatings Technology, 201:197-202, 2006.

[124] G.J.Wan, M.F.Maitz, H.Sun, P.P.Li, and N.Huang. Corrosion properties of oxygen plasma immersion ion implantation treated magnesium. Surface And Coatings Technology, 201:8267-8272, 2007. 
[125] A.I.Gerasimov, E.I.Zorin, P.V.Pavlov, and D.I.Tetelbaum. On the peculiarities of silicon amorphization at ion bombardment. Physica Status Solidi A, 12(2):679-685, 1972.

[126] V.F.Reutov and A.S.Sokhatskii. Helium ion bombardment induced amorphization of silicon crystals. Technical Physics Letters, 28(7):615-617, 2002. 